\title{
Kleine Zinkfinger-Proteine in Haloferax volcanii
}

\author{
Dissertation \\ Zur Erlangung des Doktorgrades \\ der Naturwissenschaften
}

\begin{abstract}
vorgelegt beim Fachbereich Biowissenschaften
der Johann Wolfgang Goethe-Universität

in Frankfurt am Main
\end{abstract}

von

Sebastian Zahn

aus Lichtenfels

Frankfurt am Main 2021

(D 30) 
vom Fachbereich Biowissenschaften (15) der

Johann Wolfgang Goethe-Universität als Dissertation angenommen.

Dekan: $\quad$ Prof. Dr. Sven Klimpel

Gutachter: Prof. Dr. Jörg Soppa

Prof. Dr. Eckhard Boles

Datum der Disputation: 24.06.2021 


\section{Inhaltsverzeichnis}

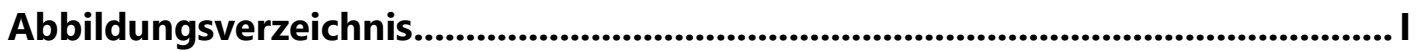

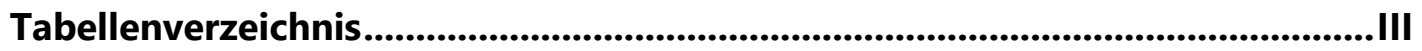

Abkürzungsverzeichnis.................................................................................................... V

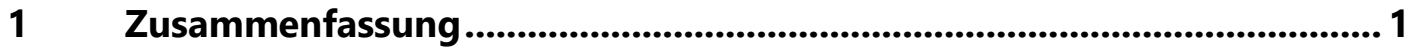

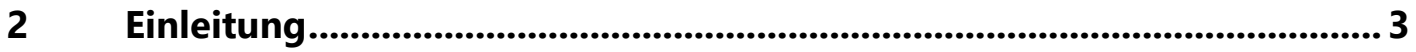

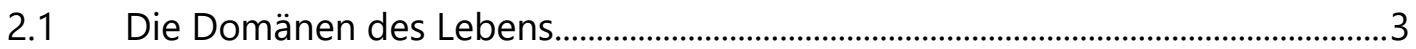

2.2 Der haloarchaeale Modellorganismus Haloferax volcanii ........................................5

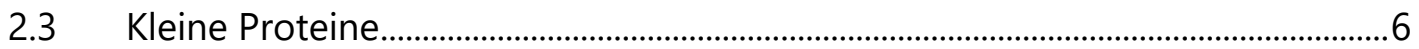

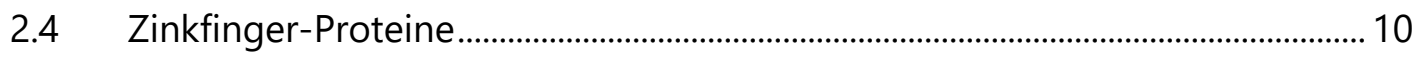

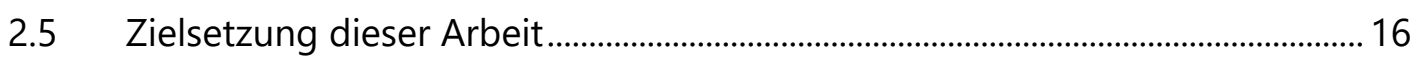

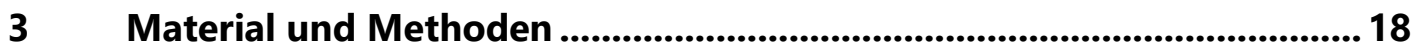

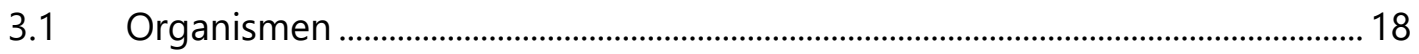

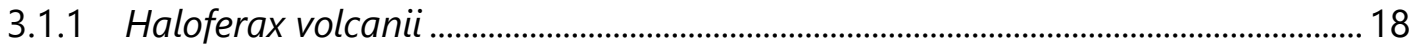

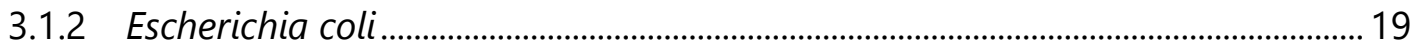

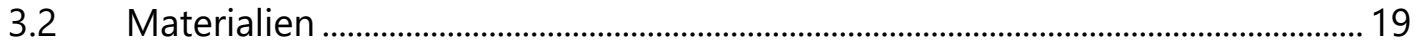

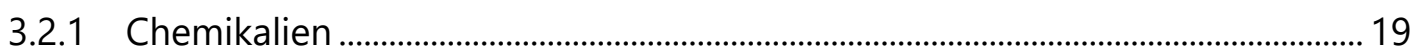

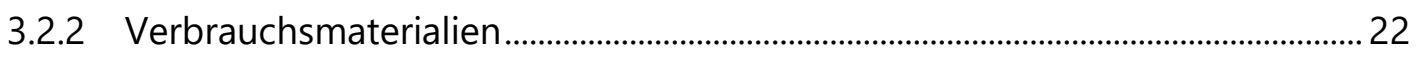

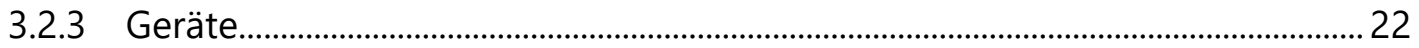

3.2.4 Molekularbiologische und biochemische Kit-Systeme ....................................... 24

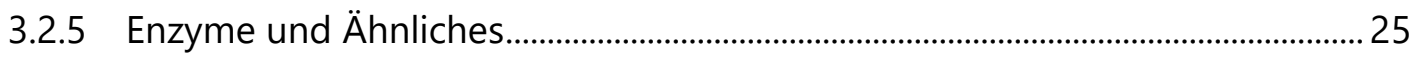

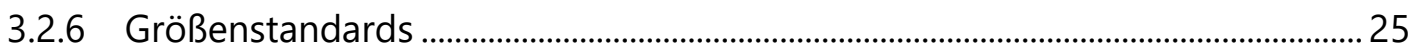

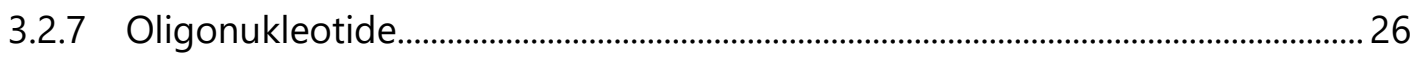

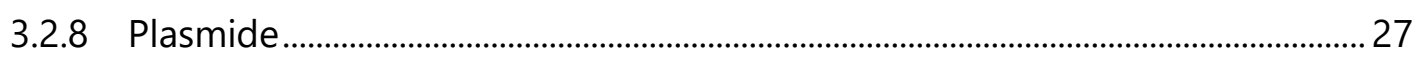

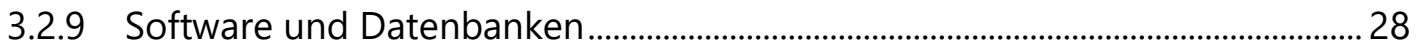

3.3 Mikrobiologische Methoden................................................................................... 29

3.3.1 Medien und Kultivierung von Haloferax volcanii ................................................... 29

3.3.2 Medien und Kultivierung von Escherichia coli ....................................................... 31

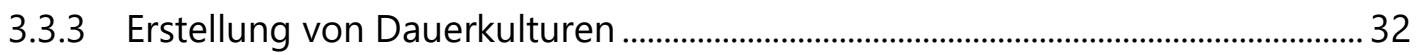

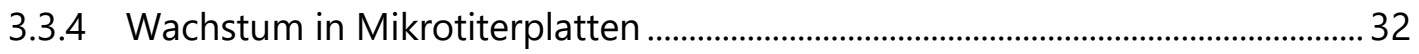

3.3.5 Zelldichtebestimmung............................................................................................ 33

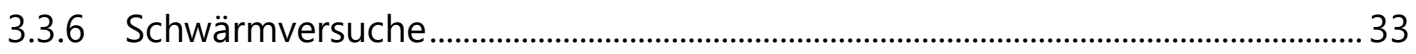

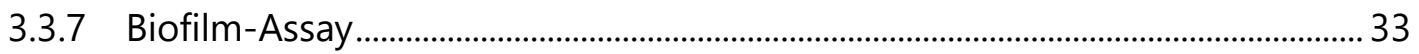

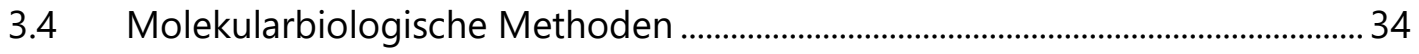

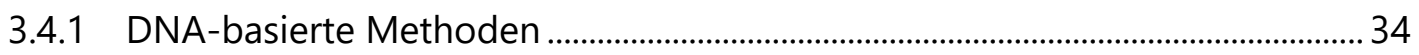

3.4.1.1 Isolierung plasmidischer DNA aus E. coli............................................................. 34 


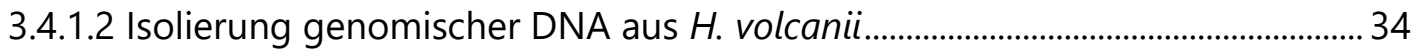

3.4.1.3 Photometrische Konzentrationsbestimmung von DNA........................................35

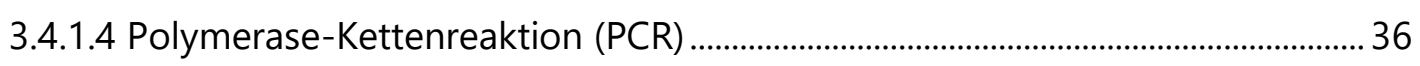

3.4.1.5 Gelelektrophoretische Auftrennung von DNA …………...................................... 42

3.4.1.6 Spaltung von DNA mittels Restriktionsenzymen...................................................... 43

3.4.1.7 Ligation von DNA-Fragmenten ............................................................................. 43

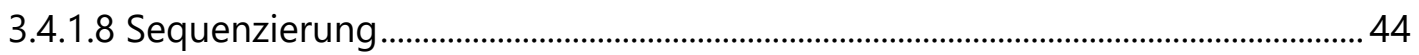

3.4.2 Transformationen von Mikroorganismen ................................................................ 44

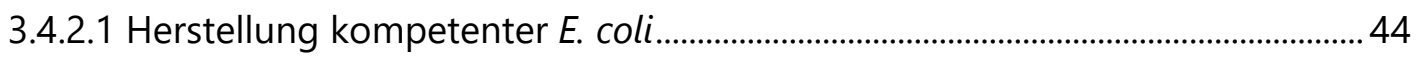

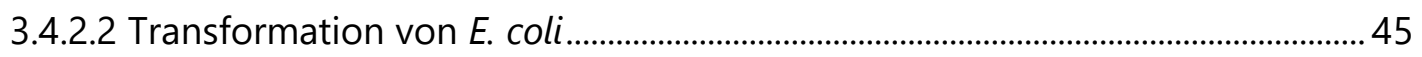

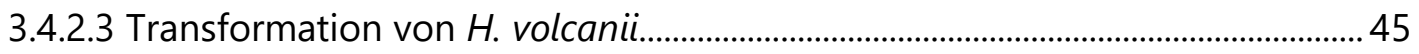

3.4.3 Erzeugung von Deletionsmutanten mittels Pop-In/Pop-Out-Methode.......... 47

3.4.4 RNA-basierte Methoden........................................................................................... 48

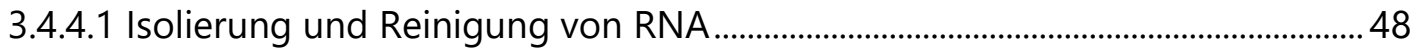

3.4.4.2 Photometrische Konzentrationsbestimmung von RNA ........................................ 50

3.4.4.3 Gelelektrophoretische Auftrennung von RNA....................................................... 51

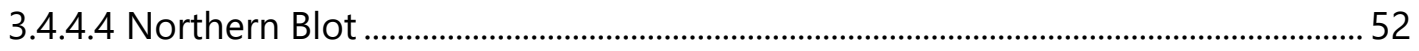

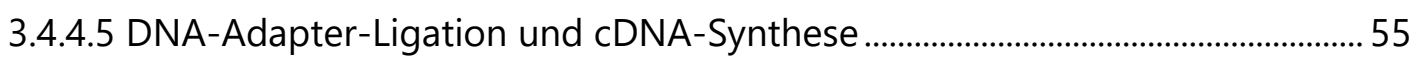

3.4.5 Protein-basierte Methoden ......................................................................................... 58

3.4.5.1 Gelelektrophoretische Auftrennung von Proteinen ............................................... 58

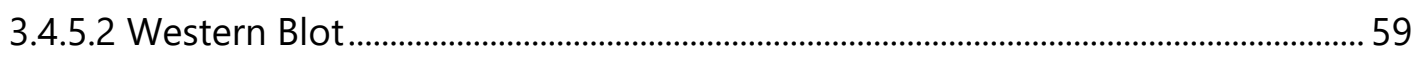

3.4.5.3 Produktion spezifischer polyklonaler Antikörper .................................................. 60

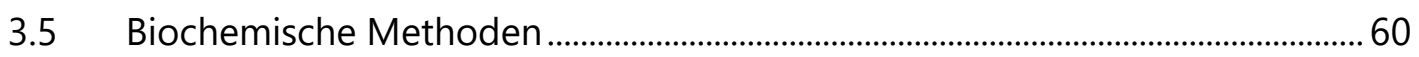

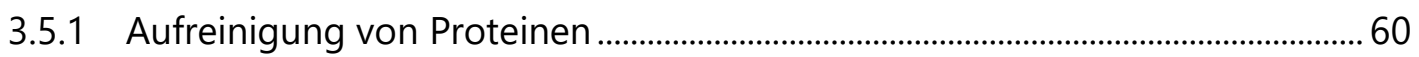

3.5.1.1 Homologe Überproduktion von HVO_2753 ......................................................... 60

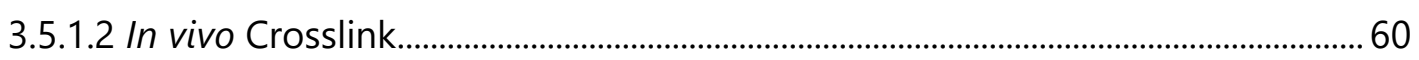

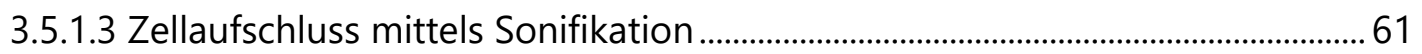

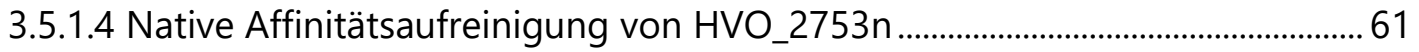

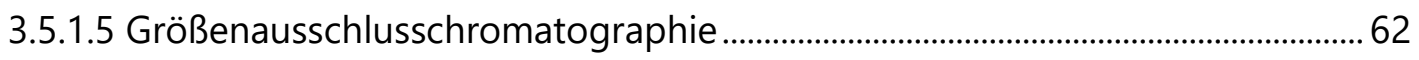

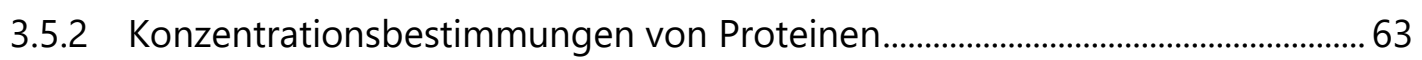

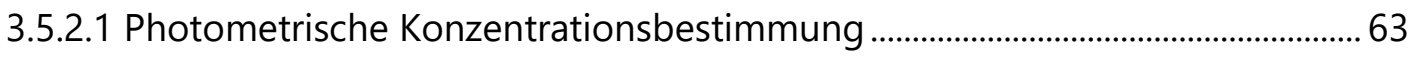

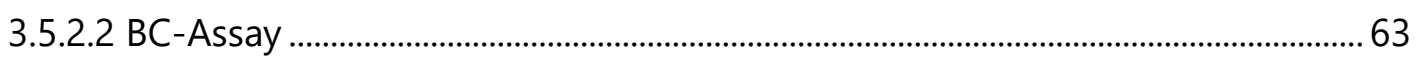

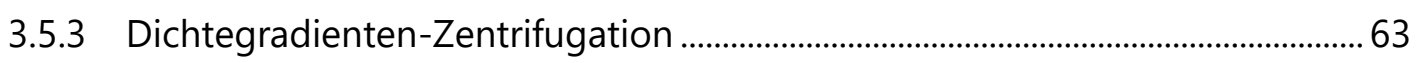

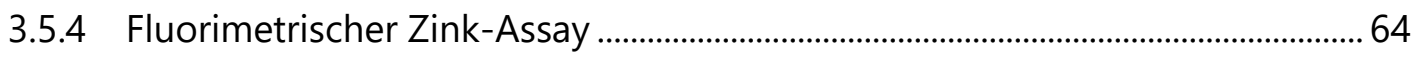

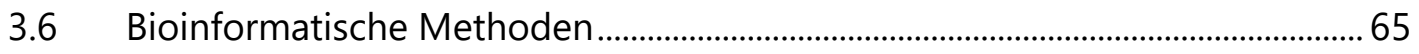

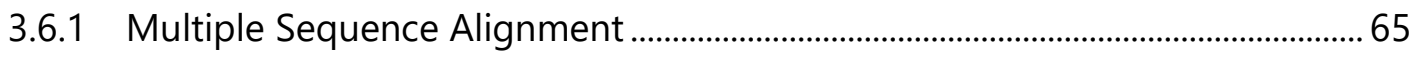

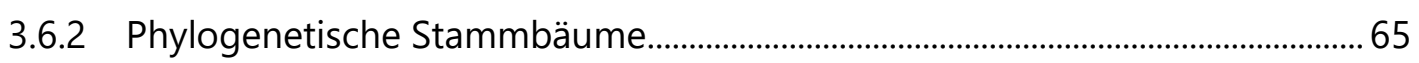

3.6.3 RNA und dRNA-Sequenzvergleiche ......................................................................... 66

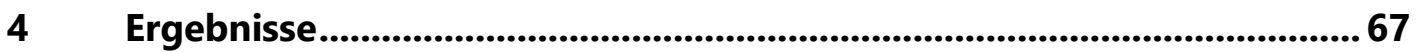




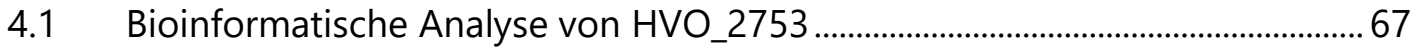

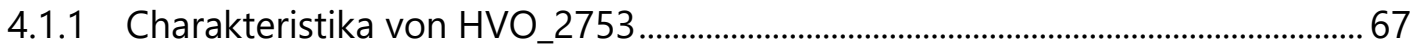

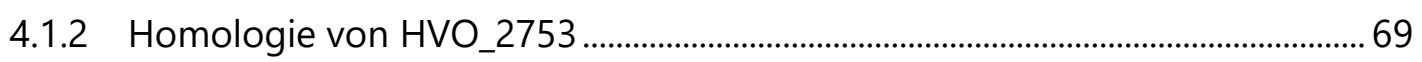

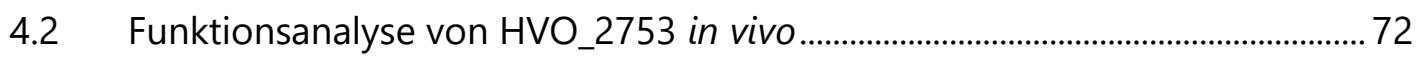

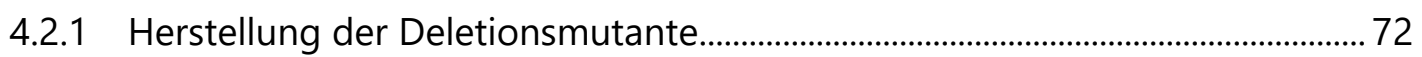

4.2.2 Phänotypische Charakterisierung der Deletionsmutante..................................... 72

4.2.2.1 Wachstum unter verschiedenen Bedingungen ....................................................... 72

4.2.2.2 Biofilmbildung und Schwärmverhalten ................................................................... 73

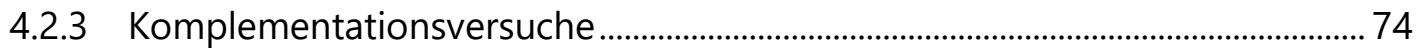

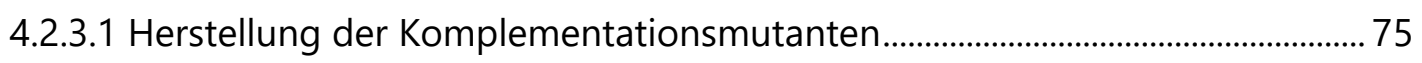

4.2.3.2 Phänotypische Charakterisierung................................................................................. 76

4.2.3.3 Herstellung und Untersuchung von Punktmutanten ............................................. 80

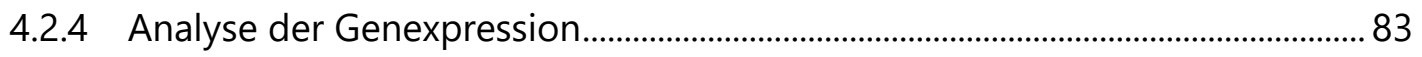

4.2.5 Ribosomenprofil durch Dichtegradientenzentrifugation ...................................... 84

4.2.6 Die homologe Überproduktion von HVO_2753 zur Erzeugung von

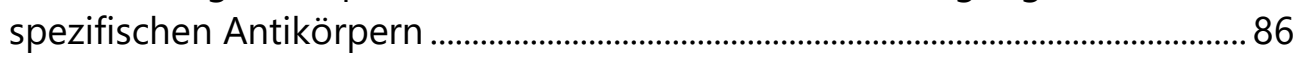

4.3 Struktur- und Funktionsanalyse von HVO_2753 in vitro......................................... 87

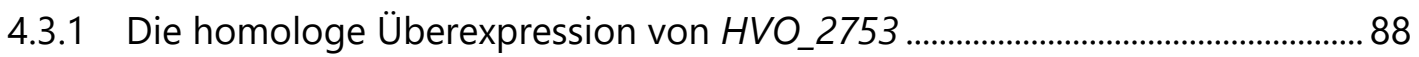

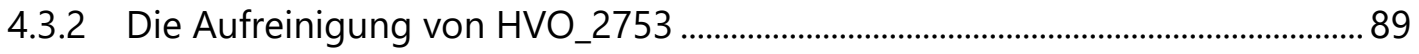

4.3.2.1 Affinitätsaufreinigung mittels Nickel-Chelat-Sepharose ...................................... 89

4.3.2.2 Aufreinigung mittels Größenausschlusschromatographie................................... 90

4.3.3 Massenspektrometrische Analyse von HVO_2753 .................................................. 91

4.3.4 Quantitative Analyse von gebundenem Zink ......................................................... 91

4.3.5 Bindepartnersuche mittels Co-Affinitätsaufreinigung .......................................... 93

4.3.5.1 Suche nach potenziellen RNA-Bindepartnern ...................................................... 93

4.3.5.2 Suche nach potenziellen Protein-Bindepartnern................................................... 96

4.4 Transkriptomanalyse mittels RNA-Sequenzierung ................................................... 99

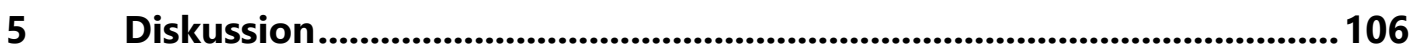

5.1 Die Strukturelemente des Eindomänen-Zinkfinger-Proteins HVO_2753 .....107

5.2 Interaktionen von HVO_2753 mit RNA und Proteinen........................................112

5.3 Das Zinkfinger- $\mu$-Protein HVO_2753 als Regulator für Schwärmen, Adhäsion

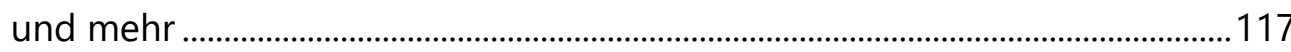

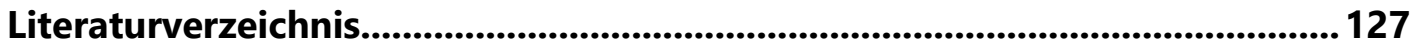

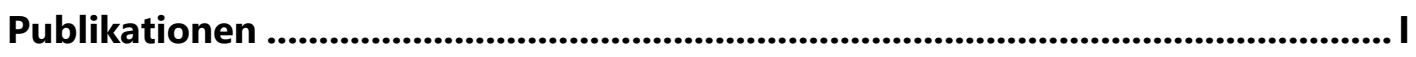

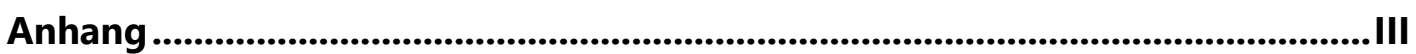





\section{Abbildungsverzeichnis}

Abbildung 1: Phylogenetischer Stammbaum .......................................................................

Abbildung 2: Übersicht und Klassifizierung der Funktionen der in

Halobacterium salinarum identifizierten kleinen Proteine.............................. 10

Abbildung 3: Schematische Darstellung der Pop-In/Pop-Out-Methode....................... 48

Abbildung 4: Aminosäuresequenz von HVO_2753 ............................................................. 68

Abbildung 5: Übersicht über den genomischen Bereich von HVO_2753.......................69

Abbildung 6: Multiple Sequence Alignment von HVO_2753 und 20 weiteren

Orthologen ausgewählter halophiler und methanogener Gattungen und

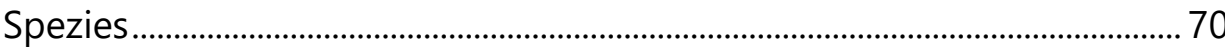

Abbildung 7: Phylogenetische Stammbäume von HVO_2753 und seinen

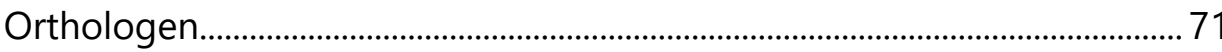

Abbildung 8: Wachstumskurven des Wildtyps H26 und der Deletionsmutante

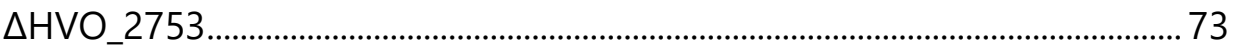

Abbildung 9: Biofilm-Assay des Wildtyps H26 und der Deletionsmutante

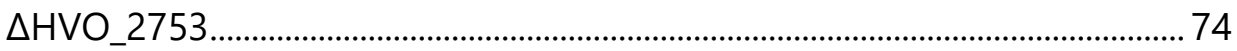

Abbildung 10: Wachstumskurven der Komplementationsmutanten und der

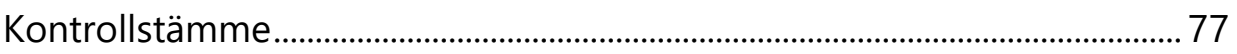

Abbildung 11: Schwärmverhalten der Komplementationsmutanten und der

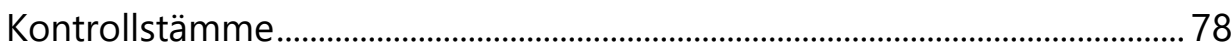

Abbildung 12: Schwärmplatte der Komplementationsmutanten und der

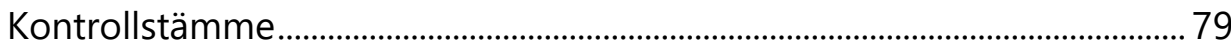

Abbildung 13: Biofilm-Assay der Komplementationsmutanten und der Kontrollstämme.

Abbildung 14: Aminosäuresequenz von HVO_2753 mit eingeführten Punktmutationen

Abbildung 15: Schwärmplatte der Punktmutanten ................................................................. 82

Abbildung 16: Genexpressionsanalyse mittels Northern Blot .......................................... 84

Abbildung 17: Ribosomenprofil nach der Dichtegradientenzentrifugation.................. 85

Abbildung 18: Denaturierende RNA-Gelelektrophorese ausgewählter Fraktionen nach der Dichtegradientenzentrifugation ......................................................... 86

Abbildung 19: Western Blot-Analyse zur Spezifität des Antikörpers $\alpha H$ VO_2753n. 87

Abbildung 20: Tricin-SDS-PAGE ausgewählter Fraktionen der beiden

Aufreinigungsschritte von HVO_2753n............................................................. 90

Abbildung 21: Chromatogramm der Größenausschlusschromatographie von HVO_2753n.

Abbildung 22: Quantifizierung von Zink-Ionen mittels fluorimetrischem Zink-Assay

Abbildung 23: Chromatogramme der Größenausschlusschromatographie von

HVO_2753n mit und ohne in vivo Crosslink........................................................ 97

Abbildung 24: 3D-Struktur von HVO_2753.......................................................................... 110 
Abbildung 25: Regulatorische Funktionen des kleinen Zinkfinger- $\mu$-Proteins HVO_2753... 


\section{Tabellenverzeichnis}

Tabelle 1: Übersicht über alle verwendeten $H$. volcanii Stämme..................................... 18

Tabelle 2: Chemikalienliste............................................................................................................. 19

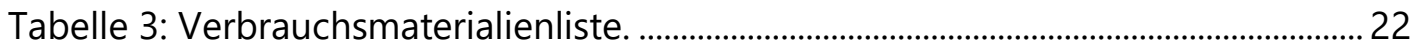

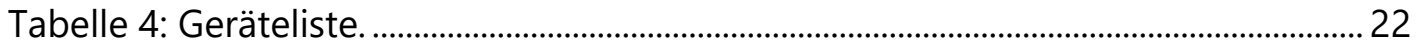

Tabelle 5: Liste molekularbiologischer und biochemischer Kit-Systeme...................... 24

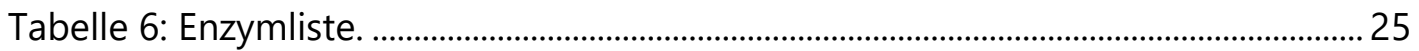

Tabelle 7: Liste der Größenstandards............................................................................. 25

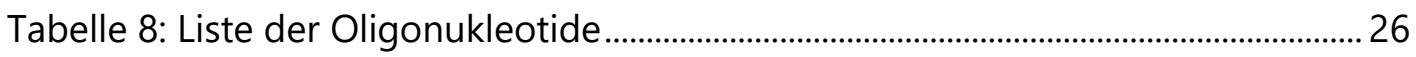

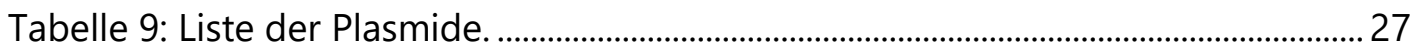

Tabelle 10: Tabelle der Software und der Datenbanken......................................................28

Tabelle 11: Zusammensetzung der Bestandteile des Komplexmediums für

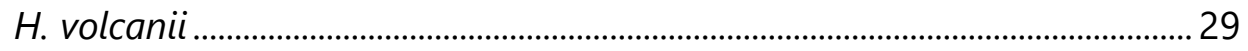

Tabelle 12: Zusammensetzung des synthetischen Mediums für $H$. volcanii................ 31

Tabelle 13: Zusammensetzung des SOB Mediums für E. coli ........................................... 32

Tabelle 14: Zusammensetzung der Lösungen für die Isolierung genomischer DNA

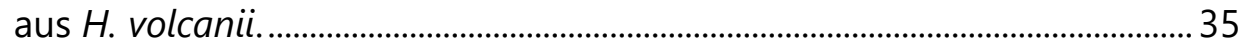

Tabelle 15: Zusammensetzung des Taq-Polymerase-Puffers und des Standard-

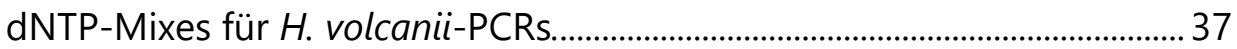

Tabelle 16: Zusammensetzung eines Standard-PCR-Ansatzes ......................................... 37

Tabelle 17: PCR Cycler-Programm für eine Standard-PCR. ............................................. 38

Tabelle 18: PCR Cycler-Programm für eine Zweischritt-Fusions-PCR............................. 39

Tabelle 19: PCR Cycler-Programm für eine dsDNA-Sonden-PCR ................................... 40

Tabelle 20: PCR Cycler-Programm für eine ssDNA-Sonden-PCR .................................... 40

Tabelle 21: Zusammensetzung eines PCR-Ansatzes für die Ortsspezifische

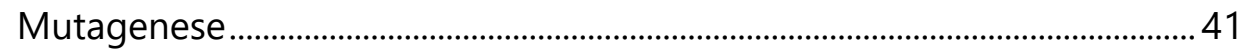

Tabelle 22: PCR Cycler-Programm für die Ortsspezifische Mutagenese. ....................... 42

Tabelle 23: Zusammensetzungen der Puffer für die DNA-Gelelektrophorese............ 43

Tabelle 24: Zusammensetzung eines Ansatzes einer Blunt-end-Ligation in Anwesenheit des entsprechenden Restriktionsenzyms

Tabelle 25: Zusammensetzung des TB-Puffers für die Herstellung kompetenter E. coli.

Tabelle 26: Zusammensetzung aller benötigten Lösungen für die Transformation von $H$. volcanii.

Tabelle 27: Zusammensetzung der Aufschlusslösung für die RNA-Isolierung aus H. volcanii. 50

Tabelle 28: Zusammensetzungen der für die RNA-Gelelektrophorese benötigten Puffer...

Tabelle 29: Zusammensetzung der benötigten Lösungen und Puffer für den Northern-Blot 
Tabelle 30: Zusammensetzung der benötigten Lösungen und Puffer für die Hybridisierung beim Northern-Blot.

Tabelle 31: Schritte der Entwicklung während dem Chemolumineszenz-Nachweis beim Northern-Blot.

Tabelle 32: Zusammensetzung der Puffer und Lösungen für den

Chemolumineszenz-Nachweis beim Southern-Blot.

Tabelle 33: Ablauf der DNA-Adapter-Ligation und cDNA-Synthese zur Identifikation von RNA-Bindepartern. Die Protokollnummern beziehen sich auf die jeweiligen Pipettierschemata in Tabelle 34.

Tabelle 34: Pipettierschemata der verschiedenen Reaktionsansätze während der DNA-Adapter-Ligation und cDNA-Synthese. .56

Tabelle 35: Zusammensetzung der Lösungen für die Visualisierung von Tricin-SDS-

Gelen. 59

Tabelle 36: Lösungen und Puffer für die Affinitätsaufreinigung von HVO_2753n.... 62

Tabelle 37: Zusammensetzung der Gradientenpuffers für die Dichtegradienten-

Zentrifugation. 64

Tabelle 38: Zusammensetzungen der Lösungen und Puffer für den Zink-Assay...... 65

Tabelle 39: Aminosäurezusammensetzung von HVO_2753 im Vergleich zum H. volcanii Proteom. 68

Tabelle 40: Ergebnisse der RNA-Bindepartner-Suche von HVO_2753. .95

Tabelle 41: Auswahl an Genen, die in Abwesenheit von HVO_2753 herunterreguliert vorliegen 102

Tabelle 42: Auswahl an Genen, die für Transportproteine codieren und in Abwesenheit von HVO_2753 reguliert vorliegen .103 


\section{Abkürzungsverzeichnis}

AA

$A B C$

$\mathrm{ad}$

ATP

bp

BR

BSA

CHM

$\mathrm{CHP}$

$\mathrm{CHY}$

CIM

COM

$\mathrm{CP}$

CPSF

DEPC- $\mathrm{H}_{2} \mathrm{O}$

DNA

dNTP

DPANN

dRNA-Seq

EM

evc

FC

gDNA

GEN

GFP

$\mathrm{H}_{2} \mathrm{O}$

$\mathrm{H}_{2} \mathrm{O}_{\text {bidest }}$

Htrs

HY

kbp

LIP

M

Mbp

MCP
Aminosäuremetabolismus

ATP-bindende Kassette

auffüllen auf

Adenosintriphosphat

Basenpaar(e)

Biologisches Replikat

Kälber-Serumalbumin

Kohlenhydratmetabolismus

Chaperone

Konserviertes hypothetisches Protein

Zentraler intermediärer Metabolismus

Koenzymmetabolismus

Zelluläre Prozesse

Cleavage and polyadenylation specificity factor

DEPC-behandeltes, RNase-freies Wasser

Desoxyribonukleinsäure

Desoxynukleotidtriphosphat

Superphylum der Archaea

benannt nach seinen ersten fünf Stämmen Diapherotriten, Parvarchaeota, Aenigmarchaeota, Nanoarchaeota und Nanohaloarchaeota

differenzielle RNA-Sequenzierung

Energiemetabolismus

Leervektorkontrolle (empty vector control)

Funktionsklasse

genomische DNA

Generelle enzymatische Funktion

grün-fluoreszierendes Protein

Wasser

bidestilliertes Wasser

halobakterielle Transducer für Sensor-Rhodopsin

Hypothetisches Protein

Kilobasenpaare

Lipidmetabolismus

Molar

Megabasenpaare

Methyl-akzeptierende Chemotaxis Proteine 


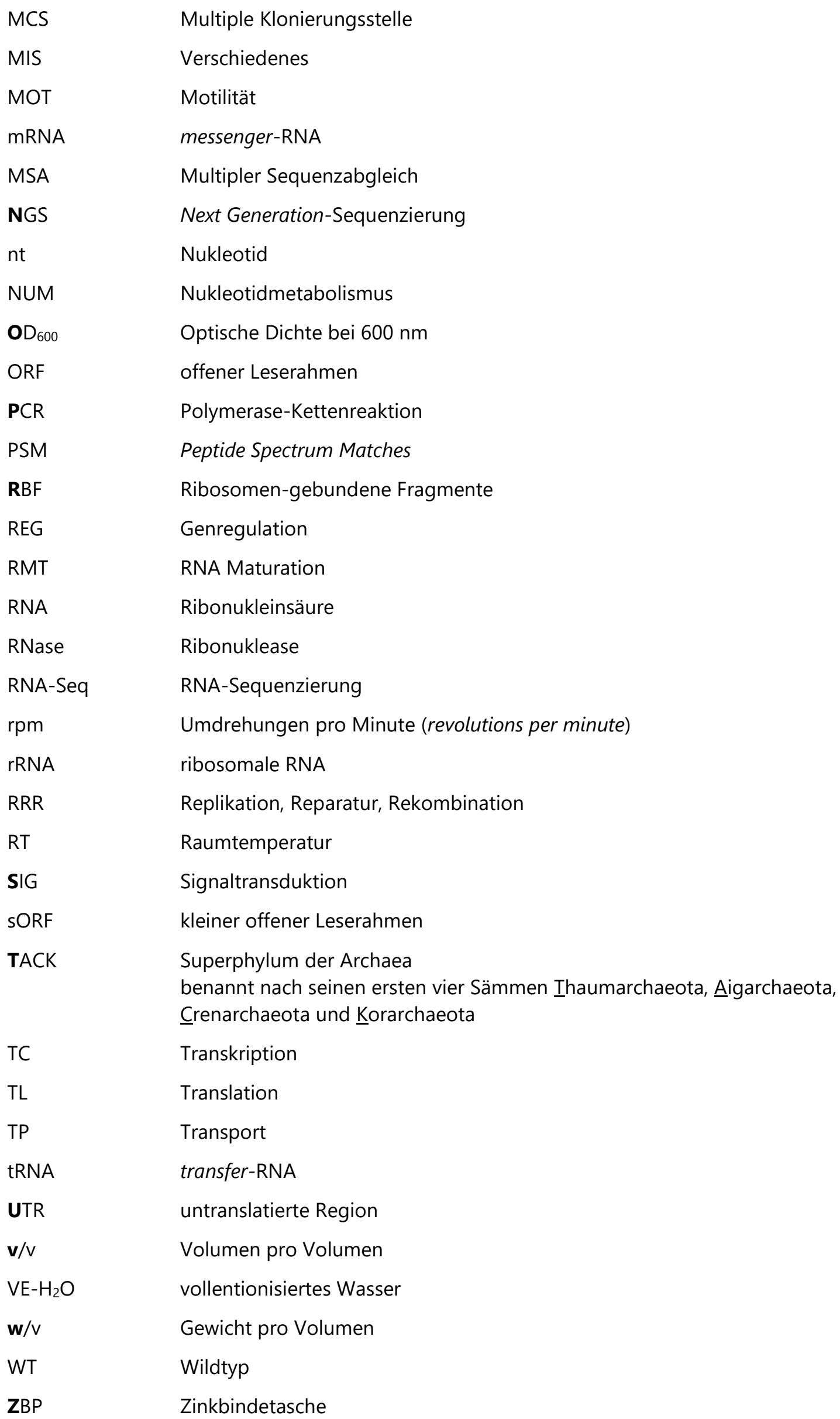




\section{Zusammenfassung}

In der vorliegenden Arbeit wurde das Zinkfinger- $\mu$-Protein HVO_2753 des halophilen Archaeons Haloferax volcanii hinsichtlich seiner biologischen Funktion und seiner Struktur charakterisiert.

Zinkfinger- $\mu$-Proteine wurden bisher nur sehr wenig untersucht, während ihnen jedoch in den letzten Jahren steigendes Interessse entgegengebracht wird. Im Genom von $H$. volcanii sind mehr als 40 solcher Zinkfinger- $\mu$-Proteine codiert. Von diesen besitzt mit HVO_2753 lediglich eines nicht nur zwei, sondern vier der charakteristischen C(P)XCG-Muster, was für die Anwesenheit von zwei ZinkfingerMotiven spricht. Während Homologe von HVO_2753 in vielen Euryachaeota vorkommen und manche davon als Zink-Ribbon RNA-Bindeproteine annotiert sind, ist über ihre Funktion jedoch nichts bekannt. Zur Charakterisierung des Proteins wurde zunächst eine in frame-Deletionsmutante seines Gens erstellt und diese einer phänotypischen Charakterisierung unterzogen. Die Mutante wies, verglichen mit dem Wildtyp, keine Unterschiede im Wachstum in Komplexmedium oder in synthetischem Medium mit Glukose als Kohlenstoffquelle auf. Ein schweres Defizit konnte jedoch sowohl bei der Adhäsion und Biofilmbildung als auch der Schwärmfähigkeit der Deletionsmutante festgestellt werden. Während die Schwärmfähigkeit des Wildtyps durch plasmidische Expression von HVO_2753 in der Deletionsmutante teilweise wiederhergestellt werden konnte, war eine solche Komplementation bei der Biofilmbildung nicht möglich. Die Analyse der Relevanz ausgewählter Aminosäuren, wie beispielsweise das jeweils erste Cystein in jedem C(P)XCG-Muster zeigte, dass die Substitution jeder einzelnen der getesteten Aminosäuren einen Funktionsverlust des Proteins nach sich zieht. Die Untersuchung des HVO_2753-Transkripts mittels Northern Blot-Analyse bestätigte erste Hinweise aus vorangegangenen dRNA- und RNA-Seq-Studien, die eine Co-Transkription von HVO_2753 mit dem Nachbargen HVO_2752, das für den Translations-Elongationsfaktor aEF-1 beta codiert, aufzeigten. Daraufhin erfolgte eine Untersuchung des Ribosomenprofils, bei der keine Unterschiede zwischen der Deletionsmutante und der Überexpressionsmutante von HVO_2753 festgestellt werden konnten.

Eine Variante von HVO_2753 mit N-terminalem Hexahistidin-Tag wurde homolog überproduziert und aufgereinigt. Die Überproduktion und Aufreinigung wurden 
im Zuge dieser Arbeit weiter, speziell für HVO_2753, optimiert. So konnten große Mengen von HVO_2753n überproduziert und bei nativen Salzbedingungen mittels Nickel-Affinitätschromatographie und anschließender Größenausschlusschromatographie aufgereinigt werden. Eine massenspektrometrische Analyse bestätigte sowohl das Molekulargewicht als auch die Abwesenheit posttranslationaler Modifikationen. Die Untersuchung der Menge an gebundenem Zink im Protein erfolgte beim Zink-Assay mit Hilfe des hochsensitiven und hochspezifischen Fluorophors ZnAF-2F. Dabei konnte gezeigt werden, dass überraschenderweise lediglich ein Zink-Ion in HVO_2753 gebunden vorliegt.

Zur weiteren Funktionsaufklärung erfolgte eine Interaktionspartnersuche. Hierfür wurde HVO_2753 überproduziert, ein in vivo-Crosslink und anschließend eine native Aufreinung durchgeführt. Die massenspektrometrische Analyse ausgewählter Fraktionen nach der Größenausschlusschromatographie ergaben eine Vielzahl an möglichen Bindepartnern. Besonders häufig wurde hier die GalE family Epimerase/Dehydratase gefunden. Eine weitere Methode zur Suche nach Interaktionspartnern richtete sich auf RNAs. Hier konnten mittels eines eigens entwickelten Protokolls neben RNAs des Translationsapparates auch mehrfach die tRNA(Glu) gefunden werden.

Zusätzlich sollte die Transkriptomanalyse mittels RNA-Sequenzierung Unterschiede zwischen Wildtyp, Deletionsmutante und Komplementationsmutante aufzeigen. Hier wurden weitreichende Auswirkungen der Deletion von HVO_2753 gefunden. Zahlreiche Gene in mehreren Operons zur Motilität und Chemotaxis lagen in der Deletionsmutante stark herunterreguliert vor, während die Gene einiger Metallionen-Transporter und der Eisen(III)-Siderophor-Biosynthese hochreguliert vorlagen. In der Komplementationsmutante konnten nur von den letzteren Genen Transkriptlevel vergleichbar mit denen des Wildtyps wiedergefunden werden.

In dieser Arbeit konnte gezeigt werden, dass das kleine Zinkfinger-Protein HVO_2753 eine essenzielle Rolle in der positiven Regulation der Motilität, Chemotaxis und der Adhäsion bzw. Biofilmbildung spielt. Gleichzeitig übt HVO_2753 eine negative Regulation auf den Metallionen-Transport und die Biosynthese des Eisen(III)-Siderophors aus. 


\section{Einleitung}

\subsection{Die Domänen des Lebens}

Erste Einteilungen allen zellulären Lebens in Evolutionslinien basierten auf dem Reich der "Monera", dem prokaryotische Zellen angehörten, dem Reich der "Protista" mit eukaryotischen Einzellern und weiteren Reichen, die multizelluläre Eukaryoten abbildeten (Whittaker, 1969). Hier waren Archaea und Bacteria noch in derselben Gruppe dargestellt, da die Einteilung hauptsächlich auf der Morphologie der Zellen basierte. Erst die Entwicklung von Nukleinsäure-basierten, vergleichenden und phylogenetischen Analysen und die Pionierarbeit von Carl Woese führte zu Einblicken in das evolutionäre Verwandtschaftsverhältnis von Mikroorganismen (Woese et al., 1975). Diese Analysen führten zunächst zur Einteilung in die drei Domänen Eukarya, Eubacteria und Archaebacteria, die, nach späterem Umbenennen, die noch heute bekannten Domänen Eukarya, Bacteria und Archaea darstellen (Woese \& Fox, 1977; Woese et al., 1978). Auch in den folgenden Jahren erhärtete sich die Meinung, dass die prokaryotischen Archaea mit den Eukarya näher verwandt sind als mit den Bacteria (Doolittle \& Logsdon, 1998). So besitzen die meisten Archaea, wie alle Eukarya, Histone, die die Rolle der Organisation der DNA übernehmen (Henneman et al., 2018). Außerdem ist die RNAPolymerase der Archaea, eine Schlüsselkompenente allen zellulären Lebens, nah verwandt mit der der Eukarya (Huet et al., 1983; Zillig et al., 1989). Die Weiterentwicklung wissenschaftlicher Methoden zur DNA-Sequenzierung und die Entwicklung neuer Herangehensweisen in der Informationstechnologie trieben nachfolgend den Fortschritt in der Evolutionsbiologie voran. So führten neue Erkenntnisse im letzten Jahrzehnt zu der aktuellen Ansicht, dass Bacteria und Archaea jeweils monophyletisch sind und einen gemeinsamen Vorfahren besitzen, während Eukarya einen Teil des archaealen Zweigs darstellen (Cox et al., 2008; Williams et al., 2013; Adam et al., 2017; Eme et al., 2017; Baker et al., 2020). Somit konnten nicht nur bekannte Organismen besser eingeordnet, sondern mittels metagenomischer Herangehensweisen auch viele neue Organismen identifiziert und zugeordnet werden. Nach aktuellem Stand der Wissenschaft sind innerhalb der Archaea drei sogenannte Superphyla bekannt: Asgard, DPANN (Diapherotriten, $\underline{\text { Parvarchaeota, }}$ Aenigmarchaeota, Nanoarchaeota und Nanohaloarchaeota) 
und TACK (Thaumarchaeota, Aigarchaeota, Crenarchaeota und Korarchaeota). Die Euryachaeota hingegen sind ein eigenständiges Phylum innerhalb der Archaea und nicht in eines der aktuell anerkannten Superphyla gegliedert. Die Entdeckungen der Lokiarchaeota und nachfolgenden, zu Phyla zusammengefassten und nah verwandten Archaea, zunächst meist aus Meeressedimenten isoliert, konnten im Superphylum der Asgard-Archaea zusammengefasst werden. Neueste Untersuchungen deuten an, dass ein Vorfahr dieser Asgard-Archaea den Wirt für die endosymbiontische Interaktion mit einem Proteobakterium dargestellt hat. Dieses Ereignis führte später zur Entwicklung von Mitochondrien und der Entstehung erster Eukarya (Baker et al., 2020). Eine schematische Übersicht über den phylogenetischen Stammbaum zeigt Abbildung 1.

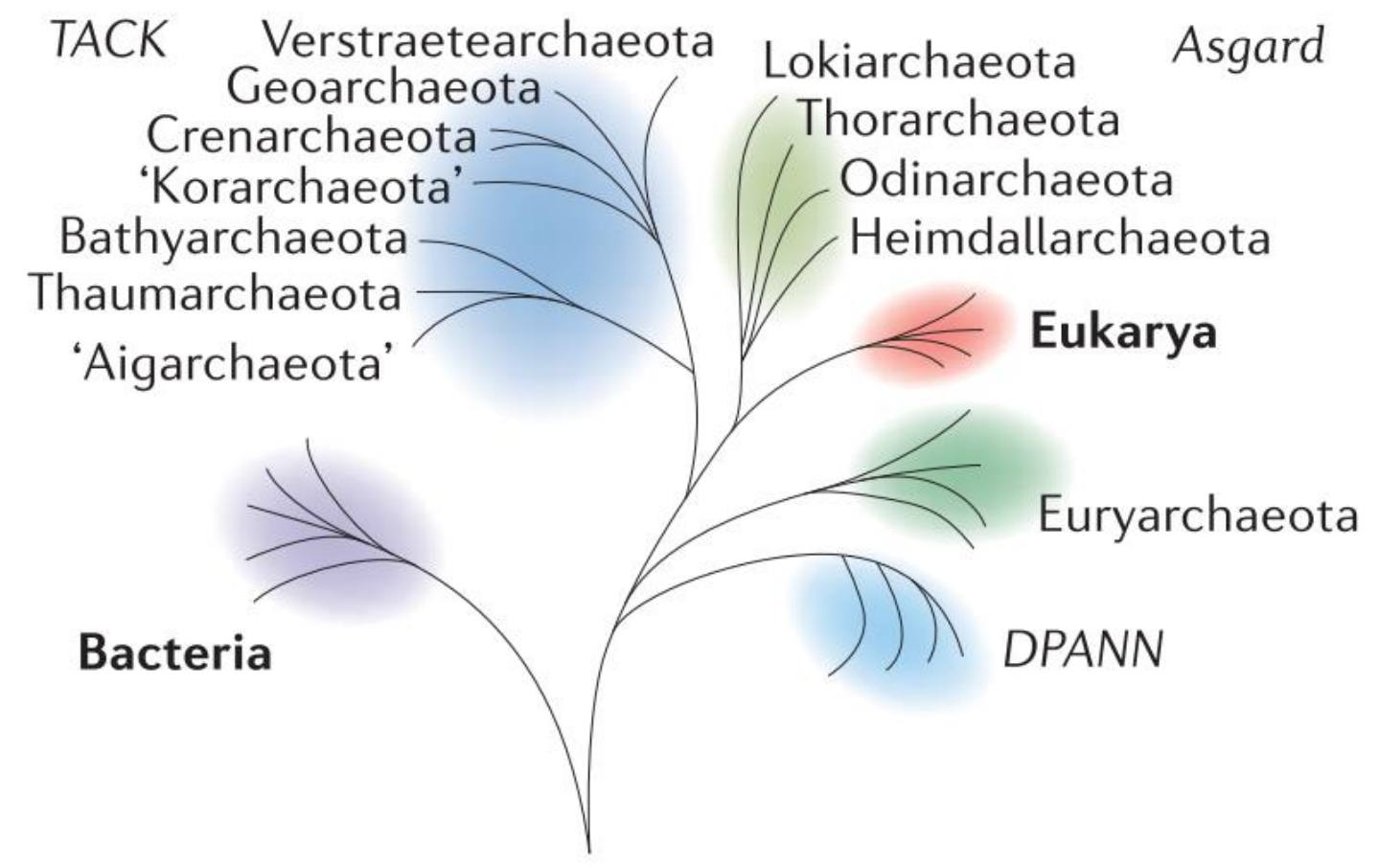

Abbildung 1: Phylogenetischer Stammbaum. Gezeigt ist eine schematische Darstellung der Verwandtschaft der Domänen des Lebens. Bacteria sind in violett, Eukarya in rot dargestellt. Letztere besitzen nach aktuellem Stand zusammen mit den Asgard Archaea einen gemeinsamen Vorfahren. Archaeale Phyla und Superphyla sind in grün und blau dargestellt. Abbildung entnommen und modifiziert aus Eme et al., 2017.

Während Archaea ursprünglich als Extremophile galten, da sie aus vielen Nischen extremer Lebensbedingungen isoliert werden konnten, hat sich diese Ansicht inden letzten Jahren geändert. Waren zunächst viele halophile, acidophile, alkaliphile, psychrophile und thermophile Vertreter bekannt, sind durch die Vielzahl 
an neu entdeckten Archaea auch viele Mesophile entdeckt worden. Sie bilden somit eine vielfältige und sehr weit verbreitete Gruppe von Mikroorganismen (Baker et al., 2020) und stellen 20 \% aller planktonischen Zellen in den Weltmeeren dar (DeLong \& Pace, 2001; Karner et al., 2001). Des Weiteren scheinen sie einen noch größeren Anteil im marinen Sediment auszumachen (Lipp et al., 2008). Archaea wurden außerdem in Böden, Pflanzen, Wiederkäuern und im Menschen gefunden (Conway de Macario \& Macario, 2009; Frey et al., 2010; Chroňáková et al., 2012; Taffner et al., 2018). Dem aktuellen Wissensstand nach lässt sich zusammenfassen, dass Archaea vielfältige und ubiquitär vorkommende Mikroorganismen sind, die aktive Komponenten zahlreicher Mikrobiome darstellen und einen wesentlichen Einfluss auf ihren Wirt oder auf andere Mitglieder des Mikrobioms ausüben (Borrel et al., 2020).

\subsection{Der haloarchaeale Modellorganismus Haloferax volcanii}

Der in der vorliegenden Arbeit verwendete Modellorganismus wurde erstmals im Jahre 1975 aus dem Toten Meer isoliert und nach dem Entdecker extrem halophiler Mikroorganismen Benjamin E. Volcani zunächst Halobacterium volcanii genannt (Mullakhanbhai \& Larsen, 1975). Neue Erkenntnisse in der systematischen Mikrobiologie führten später zur Umbenennung in Haloferax volcanii (Torreblanca et al., 1986). Es ist ein halophiles Archaeon der Abteilung Euryarchaeota. Das Genom des Stammes DS2 ist seit dem Jahre 2010 vollständig sequenziert (Hartman et al., 2010) und setzt sich aus fünf zirkulären genetischen Elementen zusammen: dem Hauptchromosom (2,8 Mb), drei kleineren Chromosomen (dem 636 kb pHV4, dem 438 kb pHV3 und dem 85,1 kb pHV1) sowie einem Plasmid (dem 6,35 kb pHV2). Der durchschnittliche GC-Gehalt liegt bei 65 \%. Die Anpassung an die optimale Salzkonzentration von 1,7-2,5 M Natriumchlorid erfolgt durch die intrazelluläre Anreicherung von Kaliumchlorid (Pérez-Fillol \& Rodríguez-Valera, 1986; Mojica et al., 1997). Dies führt zu vielen Besonderheiten in der Zelle. So sind halophile Proteine durch eine hochfunktionalisierte Aminosäurekomposition gekennzeichnet. Es kommen Asparaginsäure, Glutaminsäure, Valin und Threonin signifikant häufiger vor, während Lysin, Methionin, Leucin, Isoleucin und Cystein seltener in halophilen als in nicht-halophilen Proteinen vorkommen (Paul et al., 2008). 
$H$. volcanii eignet sich aufgrund der moderaten Bedingungen für seine Kultivierung, seiner geringen Generationszeit, seines extrem flexiblen Metabolismus und seiner genetischen Zugänglichkeit ideal als ein Modellorganismus für halophile Archaea. So sind seine optimalen Wachstumsbedingungen $2,1 \mathrm{M} \mathrm{NaCl}$ und $42{ }^{\circ} \mathrm{C}$ und führen in Vollmedium zu einer Generationszeit von lediglich $3 \mathrm{~h}$. H. volcanii kann eine Vielzahl von möglichen Kohlenstoffquellen verstoffwechseln und sowohl aerob als auch anaerob wachsen. Es existieren molekularbiologische Methoden zur effizienten Transformation und zur Deletion und Repression von Genen (Soppa, 2006, 2011; Hammelmann \& Soppa, 2008; Stachler et al., 2020). $H$. volcanii kann außerdem für ein hochparallelisiertes Phänotypen-Screening in Mikrotiterplatten kultiviert werden (Jantzer et al., 2011).

Der $\mathrm{H}$. volcanii-Stamm H26 wurde in der vorliegenden Arbeit als Wildtyp verwendet und auf ihm basieren ebenso alle weiteren verwendeten Stämme. H26 selbst ist eine Uracil-auxotrophe Variante des DS70 Stamms. Letzterer stellt einen optimierten Laborstamm von DS2 dar, dem das Plasmid pHV2 fehlt, während pHV4 ins Hauptchromosom integriert vorliegt (Wendoloski et al., 2001; Hawkins et al., 2013). Zur Erzeugung eines Selektionsmarkers wurde in diesem Stamm wiederum das Orotat-Phosphoribosyltransferase-Gen (pyrE2) deletiert, was in dem Stamm H26 resultierte (Allers et al., 2004).

\subsection{Kleine Proteine}

Während in den letzten Jahrzehnten hunderttausende von Proteinen im Detail untersucht, dabei deren Strukturen aufgeklärt und deren Aktivitäten analysiert wurden, fielen kleine Proteine in vielen wissenschaftlichen Bereichen durch das Raster und innen kam keine Aufmerksam zuteil. Hier gilt es zu beachten, dass der Begriff "kleine Proteine" noch keiner einheitlichen Definition unterliegt. So werden in der Literatur für "kleine Proteine" auch Begriffe wie Peptide, sORF-codierte Peptide (small open reading frame, kleiner offener Leserahmen), sORF-codierte Proteine, Mikropeptide, Mikroproteine oder $\mu$-Proteine verwendet. Dabei kommen teilweise gleiche, aber auch verschiedene Definitionen zum Einsatz. So muss hierfür ein Protein manchmal von einem SORF codiert und ribosomal translatiert sein, kann es jedoch auch Ribosom-unabhängig synthetisiert sein oder durch proteolytische Prozesse aus einem größeren Precursor-Protein erzeugt werden. Dar- 
über hinaus ist auch die Größe eines "kleinen Proteins" noch nicht einheitlich definiert. So kamen historisch bedingt häufig 100 Codons als Grenze für ORFs zum Einsatz, die gesetzt wurde, um bei der Annotation neuer Genome falsch-positive Annotationen und einen damit einhergehenden hohen Hintergrund zu vermeiden. Im Zuge des Aufkommens größeren Interesses an kleinen Proteinen wurden diese dann so definiert, dass sie zuvor gesetzte Grenzen nicht berücksichtigt wurden. Zusätzlich zum beschriebenen bioinformatischen Problem bei der Annotation kleiner ORFs, bereiten kleine Proteine in nahezu allen Bereichen experimenteller Arbeit Schwierigkeiten, da die verwendeten Methoden ursprünglich für mittlere und große Proteine entwickelt und optimiert wurden. So sind beispielsweise klassische Polyacrylamid-Gelelektrophoresen zur Detektion kleiner Proteine ungeeignet, da diese während der Auftrennung oder der Färbung verloren gehen.

Jedoch gibt es seit wenigen Jahren ein steigendes Interesse an kleinen Proteinen. Dies liegt daran, dass erkannt wurde, dass ihre Existenz in der Zelle nicht etwa eine Ausnahme, sondern die Regel darstellt. Es existiert eine Vielzahl an kleinen Proteinen und sie übernehmen wichtige funktionelle oder strukturelle Rollen in der Zelle. Ein wichtiger Aspekt für diesen Wandel ist die Entwicklung neuer Methoden. Diese führten im letzten Jahrzehnt zu neuen Möglichkeiten der experimentellen Identifizierung kleiner Proteine. So erlaubt das Ribosomal Profiling das Identifizieren der Gesamtheit an Ribosomen-gebundener Fragmente (RBFs). Hierbei werden die kurzen, meist ca. 30 Nukleotid-langen, mRNA-Fragmente, die sogenannten footprints, isoliert, die während der Translation zu einem Zeitpunkt von einem Ribosom umschlossen und so vor einem Nuklease-Abbau geschützt sind (Mumtaz \& Couso, 2015; Ingolia et al., 2019). Aus den isolierten mRNA-Fragmenten werden cDNA-Bibliotheken erstellt und diese mittels Next Generation Sequencing (NGS) analysiert. Auf diese Weise erhält man die Gesamtheit aller Ribosomenpositionen auf allen mRNAs einer Zelle zu einem bestimmten Zeitpunkt. Es können Aussagen darüber getroffen werden, welche Transkripte und wie häufig diese gerade abgelesen werden und an welcher Stelle genau das Ribosom sich zum Zeitpunkt der Zelllyse befunden hat. Eine weitere Methodik, die durch Weiterentwicklung einzelner Schritte und Innovationen immer mehr an Bedeutung gewann und sich auch für die Identifikation kleiner Proteine qualifizierte, ist die Massenspektrometrie. Hier wurden essenzielle Schritte der Probenvorbereitung, 
wie die Aufreinigung mittels Flüssigchromatographie, soweit verbessert, dass dies einen enorm positiven Einfluss auf die Möglichkeiten anschließender Analysemethoden hatte (Issaq et al., 2009; Finoulst et al., 2011). Aber auch die Weiterentwicklung von lonisierungs- und Detektionsmethoden der Massenspektrometrie sowie Fortschritte in der bioinformatischen Verarbeitung der erzielten Daten führten zur Einführung eines ganz neuen Forschungsgebietes, den "peptidomics" (Schrader, 2018; Karunratanakul et al., 2019).

Einen Überblick geben und gleichzeitig den enormen Anstieg des Interesses am Forschungsgebiet kleiner Proteine zeigen aktuelle Reviews. Sowohl auf dem Gebiet der Prokaryoten (Storz et al., 2014; Baumgartner et al., 2016; Duval \& Cossart, 2017) als auch bei Eukaryoten (Cabrera-Quio et al., 2016; Plaza et al., 2017; Delcourt et al., 2018) sind Fortschritte zu verzeichnen und Schwerpunkte neu gesetzt worden. Inzwischen sind bereits Funktionen von einigen kleinen Proteinen bekannt. So konnte für eukaryotische kleine Proteine gezeigt werden, dass diese viele regulatorische Funktionen übernehmen. Sie können beispielsweise nachweislich in der Hefe, in Pflanzen oder Säugetieren als "peptoswitch" auftreten und hier durch Binden an kleine Signalmoleküle ihre Funktion der internen Translationsregulation aufnehmen, indem sie während der eigenen Translation mit dem Ribosom interagieren, so seine Translokation stoppen und dadurch die Translation von downstream ORFs auf dem Transkript verhindern (Andrews \& Rothnagel, 2014). Darüber hinaus wurde von kleinen Proteinen in der Hefe berichtet, welche die Rolle von Pheromonen oder Ionen-Chelatoren übernehmen, im Energiemetabolismus involviert, Stressproteine oder Transkriptionsregulatoren sind (Su et al., 2013). Auch als Membran-Mikroproteine treten sie auf, werden hier gehäuft in Mitochondrien gefunden und übernehmen beispielsweise die Regulation von lonen-Transportern (Makarewich, 2020). Im Menschen wurden viele von kleinen ORFs codierte, kleine Proteine gefunden, die hier ins 5'-mRNA decapping involviert sind oder die Apoptose verhindern (Guo et al., 2003; D'Lima et al., 2017). Prokaryotische kleine Proteine treten ebenso vielseitig auf. Wenn auch häufiger enzymatisch gespaltene Peptide nach ihrer Sekretion als Signalproteine wirken, können auch sORF-codierte kleine Proteine diese Aufgabe übernehmen (Liu et al., 2010; Hobbs et al., 2011). Darüber hinaus treten sie als Toxine oder Stabilisa- 
tionsfaktoren größerer Proteine auf. Wie bei eukaryotischen sind auch prokaryotische kleine Proteine häufig Regulatoren, Metallionen-Chaperone oder Membrankomponenten (Hobbs et al., 2011; Hartford \& Lal, 2020).

Während das Wissen über kleine Proteine in Bakterien und Eukaryoten inzwischen bereits seit einigen Jahren steigt, ist über archaeale Vertreter weniger bekannt. Und dies obwohl bereits im Jahre 2007 ein Vorstoß in diese Richtung gemacht wurde, indem das "Low Molecular Weight Proteome" von Halobacterium salinarum untersucht wurde (Klein et al., 2007). Hier wurden zunächst diverse Protokolle für kleine Proteine optimiert und diese dann massenspektrometrisch untersucht. Dabei konnten 380 Proteine von weniger als $20 \mathrm{kDa}$ identifiziert werden. Während knapp $12 \%$ ribosomale Proteine waren und $26 \%$ anderen Funktionen zugeordnet werden konnten, war von über $62 \%$ der Proteine keine Funktion bekannt. Innerhalb dieses Großteils der identifizierten Proteine ohne Funktion gab es 20 mit einem bestimmten Motiv. So ein später als putatives Zinkfingermotiv identifiziertes Motiv bestand aus zwei oder in Ausnahmen vier C(P)XCG-ähnlichen Mustern. Innerhalb dieser spezifischen Aminosäuresequenz befinden sich jeweils zwei Cysteine, denen die Eigenschaft der koordinativen Komplexierung eines Zink-lons zugesprochen wird. In einem der beiden Muster ist das erste Cystein häufig von einem Prolin gefolgt (daher P angedeutet in Klammern), während sich hier im zweiten Muster meist eine beliebige andere Aminosäure befindet. Einen Überblick über die Ergebnisse, die im Zuge dieser Pionierarbeit auf dem Gebiet haloarchaealer kleiner Proteine erhalten wurden, zeigt Abbildung 2. Betrachtet man die Größenordnung von fast zwei Dritteln der identifizierten Proteine unter 20 kDa ohne annotierte Funktion, stellt man erneut fest, dass noch viele Unbekannte einer ganzen Molekülklasse existieren. Dies zeigt, dass es innerhalb der ganzen Sparte kleiner Proteine noch an viel Forschungsaufwand bedarf, um die komplexen Zusammenhänge regulatorischer Netzwerke innerhalb der Zelle, aber auch vieler weiterer Funktionen, aufzuklären. 


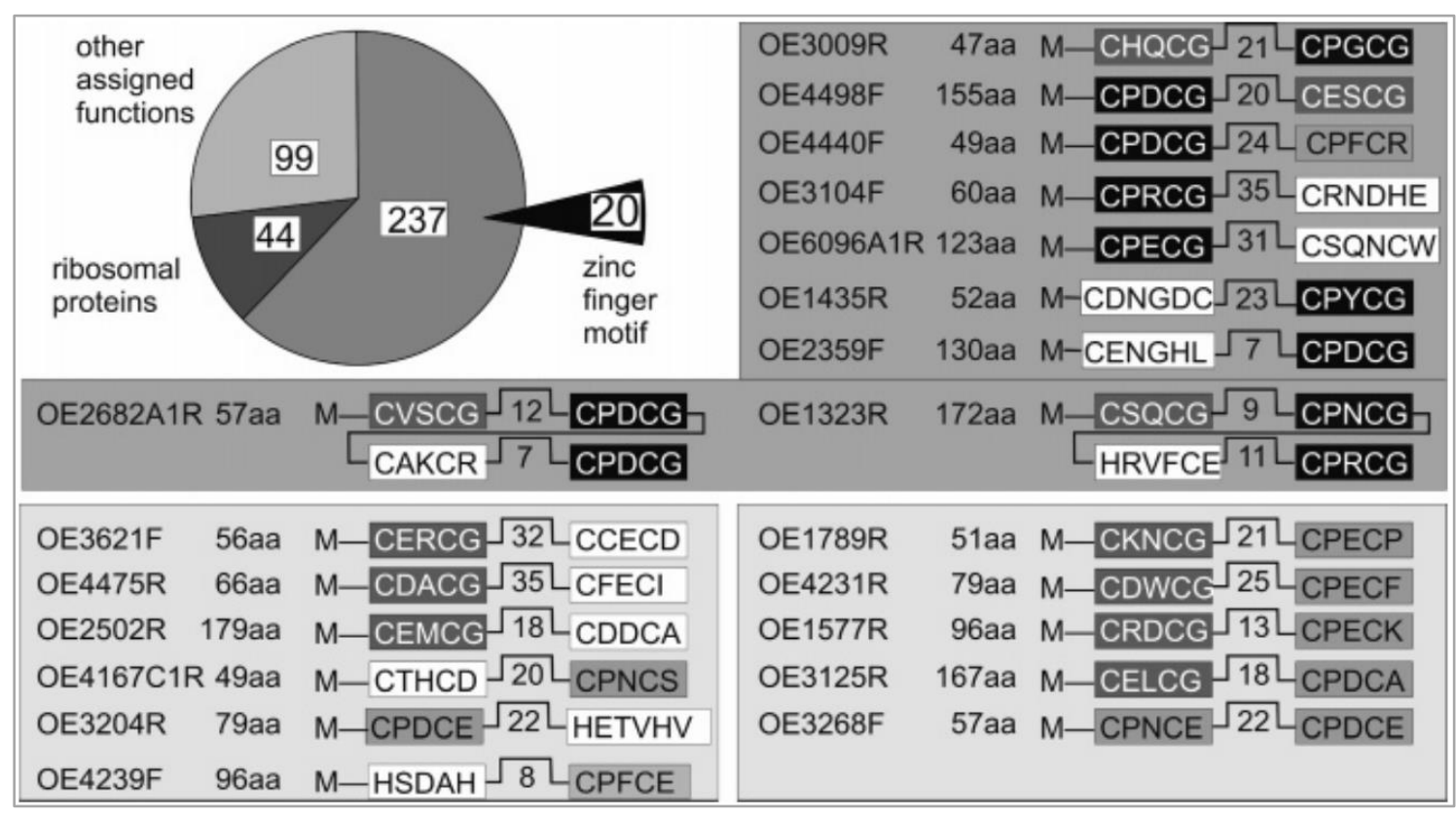

Abbildung 2: Übersicht und Klassifizierung der Funktionen der in Halobacterium salinarum identifizierten kleinen Proteine. Knapp zwölf Prozent der gefundenen Proteine sind ribosomale Proteine (44). $26 \%$ sind Proteine mit anderer bekannter Funktion (99), während mit über 62 \% vom Großteil der gefundenen Proteine keine Funktion bekannt ist. Fast $10 \%$ dieser Proteine (20) besitzen ein CPXCG-Muster (schwarze Kästen) und/oder relaxierte Formen eines solchen Musters (verschiedene Grautöne) bzw. verwandte Muster (weiße Kästen). Diese Muster treten in Paaren auf und sind von Linkern unterschiedlicher Länge getrennt. Abbildung entnommen und modifiziert aus Klein et al. (2007).

In der vorliegenden Arbeit werden nachfolgend die Begriffe $\mu$-Proteine und kleine Proteine synonym benutzt. Es handelt sich dabei immer um von kleinen ORFs codierte, ribosomal translatierte Proteine. Die hier bearbeiteten Proteine besitzen maximal 70 Aminosäuren. Dies ist die von der DFG im Rahmen des Schwerpunktprogrammes 2002 "Small Proteins in Prokaryotes, an Unexplored World“, innerhalb dessen diese Arbeit durchgeführt wurde, festgelegte Grenze.

\subsection{Zinkfinger-Proteine}

Zinkfinger sind in der Regel kleine Protein-Domänen, bei denen Zink eine strukturelle Rolle spielt und erheblich zur Stabilität beiträgt. Dabei sind Zinkfinger strukturell sehr vielfältig und in vielen verschiedenen Proteinen vorhanden, die in sehr unterschiedlichen zellulären Prozessen beteiligt sind. Zinkfinger selbst können mit einer Vielzahl an Molekülen interagieren und so Zinkfinger-Proteinen ihre 
vielen verschiedenen Funktionen ermöglichen. Noch lange bevor der Begriff "Zinkfinger" geprägt und etwas über eine solche spezielle Bindedomäne bekannt war, wusste man bereits, dass Zink-lonen eine zentrale Rolle in vielen Enzymen spielen und hierbei auch an der katalytischen Funktion beteiligt sind (Argos et al., 1978). Später wurde bei der Untersuchung eines Transkriptionsfaktors in Oozyten des Krallenfrosches Xenopus laevis entdeckt, dass dieser Transkriptionsfaktor A (TFIIIA) nicht nur Zink bindet, sondern dieses auch benötigt, um an das Gen der 5S RNA binden und so seine regulatorische Funktion ausüben zu können (Hanas et al., 1983). Dies war die erste Beobachtung eines Zink-abhängigen DNA-Bindeproteins. Bereits damals wurde berichtet, dass auffällig viele Cysteine in dem Protein vorhanden sind, obwohl noch keine Aminosäuresequenz des Transkriptionsfaktors bekannt war, die Aminosäurezusammensetzung jedoch schon. Darüber hinaus war bekannt, dass TFIIIA auch an die 5S RNA selbst bindet (Picard \& Wegnez, 1979). Dieses Protein, welches spezifisch sowohl an DNA aber auch an RNA bindet, war Gegenstand intensiver Untersuchungen verschiedener Arbeitsgruppen und die erste Beschreibung des Beispiels einer Art Proteine, die später Zinkfinger-Proteine genannt wurden (Frankel et al., 1987). So wurde im Zuge der Analysen bekannt, dass TFIIIA eine Anzahl an konsekutiven Wiederholungen mit einer Länge von circa 30 Aminosäuren in seiner Sequenz besitzt, bei der immer Paare von Cysteinen und Histidinen auftreten (Brown et al., 1985; Miller et al., 1985). Aufgrund der häufigen Assoziation von Cystein- und Histidinseitenketten mit Zink, wurden diese Wiederholungen bereits damals als Zinkbindedomänen identifiziert. Diese wiederum sollen wie die Finger einer Hand angeordnet sein und so die Interaktion mit der DNA bzw. RNA ermöglichen. Die Entdeckung des "klassischen Zinkfingers" hatte damals das Interesse an der Art der simplen, spezifischen Interaktion mit DNA geweckt. Diese kleine Proteindomäne kann vereinfacht als zurückgefaltetes Peptid, wessen simple Struktur durch koordinative Bindung eines Zink-lons stabilisiert wird, beschrieben werden (Rhodes \& Klug, 1993). Genauer gesagt wird dabei das Zink-Ion tetraedrisch von den vier Aminosäureseitenketten $\left(\mathrm{Cys}_{2} \mathrm{His}_{2}\right)$ koordiniert, die sich durch die $\beta \beta \alpha$-Struktur der Proteindomäne um dieses Ion herum falten. Zinkfinger-Proteine wurden demnach nicht nur zuerst in Eukaryoten gefunden, man ging zunächst auch davon aus, dass sie dieser Domäne auch exklusiv vorbehalten sind. 
Das erste prokaryotische Zinkfinger-Protein, der Transkriptionsregulator Ros, wurde in Agrobacterium tumefaciens, einem Pflanzenpathogen, entdeckt. Ros reguliert dabei Virulenzgene auf der sogenannten T-DNA, welche vom Bakterium auf den pflanzlichen Wirt übertragen und in dessen Genom integriert wird. Diese Entdeckung warf zunächst große Fragen auf und es wurde spekuliert, ob das dafür codierende Gen möglicherweise durch horizontalen Retrotransfer von der Pflanze auf das Bakterium übertragen wurde (Chou et al., 1998; Bouhouche et al., 2000; Moreira \& Rodríguez-Valera, 2000). Weitere Untersuchungen zeigten jedoch, dass dieses Zinkfinger-Protein kein Einzelfall ist und Zinkfinger auch in Prokaryoten eine große Rolle spielen (Malgieri et al., 2015). Denn es wurden immer mehr prokaryotische Homologe zum Ros Protein, Mitglieder der Ros/MucR-Familie, gefunden. Zunächst nur in Pflanzenpathogenen, was die ursprüngliche Theorie bestärkte, später aber auch in vielen anderen Bakterien sowie Archaeen, was vermuten ließ, dass auch innerhalb der Prokaryoten Zinkfinger weit verbreitet sind. Dieser zunächst im Ros Protein identifizierte Zinkfinger zeigt sowohl strukturelle als auch funktionale Unterschiede zum eukaryotischen klassischen Zinkfinger. Seine Zink-bindende globuläre Domäne ist mit 58 Aminosäuren signifikant gröBer als der klassische eukaryotische Zinkfinger und in einer $\beta \beta \beta \alpha \alpha$-Topologie angeordnet, während das Zink-lon gleichbleibend von zwei Cysteinen und zwei Histidinen koordiniert wird (Malgieri et al., 2007).

Im Laufe der Jahre wurden zunehmend mehr Zinkfinger-Proteine identifiziert und charakterisiert. Bereits im Jahre 2003 wurden die verschiedenen Ausprägungen von Zinkfingern in acht strukturelle Klassen gegliedert (Krishna et al., 2003). Bei diesen Klassen werden zum Beispiel $\mathrm{C}_{2} \mathrm{H}_{2}$-Ähnliche, dem auch der „klassische Zinkfinger" angehört, in einer Klasse zusammengefasst. Bei diesen wird das ZinkIon von zwei Cysteinen eines antiparallelen $\beta$-Faltblatts und zwei Histidinen des C-terminalen Endes einer $\alpha$-Helix komplexiert. Des Weiteren gibt es Gruppen wie den "Gag knuckle”. Bei diesem sind für die Koordination des Zink-lons zwei Aminosäureseitenketten eines knuckles (oder zinc knuckle; der linker/turn, der zwei Stränge eines $\beta$-Faltblatts verbindet) und zwei Aminosäureseitenketten einer kurzen Helix oder eines kurzen loops verantwortlich. Oder das "Zinc ribbon", bei dem jeweils zwei Seitenketten von einem knuckle kommen. Diese Gruppen enthalten teilweise noch weitere Untergruppen und zeigen dabei die Komplexität und den 
Umfang dieser Proteinklasse/-domäne sehr gut auf. Dabei wird der Begriff „Zinkfinger" als allgemeiner, übergeordneter Begriff verwendet.

In der Literatur sind zahlreiche Beispiele von bereits charakterisierten ZinkfingerProteinen beschrieben. Für die Taufliege Drosophila melanogaster ist beispielsweise für das Protein CLP gezeigt, dass es am C-Terminus zwei CCHC-zinc knuckles besitzt und dadurch seine Bindeaffinität zu G- und/oder C-reichen RNA-Clustern erhält. CLP ist ein Homolog der Endonuklease CPSF (cleavage and polyadenylation specificity factor), die RNA-hairpins spaltet. Für ein weiteres Protein der Taufliege, dem GAGA-Faktor, der für die normale Expression mehrerer homeotischen Gene benötigt wird, konnte gezeigt werden, dass dieser nur eine einzige Zinkfinger-Domäne besitzt (Granok et al., 1995). Seine spezifische DNA-Bindeaktivität mit der Consensus-Sequenz GAGAG erhält er durch Kombination des Zinkfingers, der die ersten drei Basen der Consensus-Sequenz bindet, mit zwei basischen Regionen in der Sequenz. Hierbei bildet eine Region eine Helix aus, interagiert so mit der großen Furche der DNA und erkennt dabei das letzte $G$ der Consensus-Sequenz, während sich die andere Region um die DNA im Bereich der kleinen Furche wickelt und das $A$ an der vierten Position der Consensus-Sequenz bindet (Omichinski et al., 1997). Auch für das humane HMD2 Protein, einem Onkogen, das an das Tumorsupressorgen p53 bindet und dieses dabei inaktiviert, konnte gezeigt werden, dass es neben seiner Proteinbinde-Domäne eine Zinkfinger-Domäne besitzt, die inm die Fähigkeit zur spezifischen Bindung an RNA vermittelt (Lai et al., 1998). Interessanterweise konnte dabei gezeigt werden, dass hier in vitro Zink nicht unbedingt nötig für die Faltung und Funktion der RNABindedomäne ist. In Mäusen konnte gezeigt werden, dass das Protein Ikaros, ein Regulator der Lymphozyten-Differenzierung, Homodimere mittels Interaktion jeweils seiner zwei C-terminalen $\mathrm{C}_{2} \mathrm{H}_{2}$-Zinkfingermotive formt (Sun et al., 1996). Darüber hinaus formt Aiolos, ein Ikaros-ähnliches Protein, mit seiner Zwei-Zinkfinger-Domäne sowohl Homodimere als auch Heterodimere mit Ikaros (Morgan et al., 1997). Für die FYVE-Domäne, die in vielen eukaryotischen Proteinen und Organismen vorkommt, konnte gezeigt werden, dass sie für die spezifische Erkennung des Phospholipids Phosphatidylinositol-3-Phosphat verantwortlich ist. Die FYVE-Domäne ist benannt nach den ersten vier Proteinen, in denen sie gefunden wurde (Fab 1, YOTB, Vac 1 und EEEA1) und konnte dabei als ZinkfingerDomäne identifiziert werden (Misra \& Hurley, 1999). 
In E. coli, dem am intensivsten untersuchten Modellorganismus gramnegativer Bakterien, existiert ein gründlich charakterisierter Chemosensor Ada. Dieser repariert Methyl-Phosphotriester-Läsionen in der DNA, indem er die aberrante Methylgruppe spezifisch auf die Seitenkette eines eigenen Cysteins überträgt. Diese Methylierung wiederum verstärkt seine eigene DNA-Bindeaktivität, mit der es ein Methylierungs-Resistenz Regulon aktiviert. Beide Aktivitäten des Proteins sind Zink-abhängig und werden durch einen Methylierungs-abhängigen elektrostatischen Schalter gesteuert (He et al., 2005). Zinkfinger-Proteine können eine Rolle bei der Regulation der Zink-Homöostase spielen, indem ihre Transkriptionsregulatorfunktion durch Binden von freiem Zink aktiviert wird, wie für das Beispiel des YJAI (ZRAP) in E. coli (Noll et al., 1998), aber auch für Proteine in Säugetierzellen, Hefe und Pflanzen gezeigt werden konnte (Chen et al., 1999).

Zusammenfassend lässt sich für eukaryotische Zinkfinger-Proteine sagen, dass hier immer zwei oder mehr Zinkfinger benötigt werden, um eine spezifische Interaktion mit DNA einzugehen. Eine Ausnahme bildet hier der GAGA-Faktor, bei dem ein einzelner Zinkfinger zusammen mit zwei weiteren Regionen des Proteins für eine spezifische Bindung sorgen. Dabei ist entscheidend, dass in der Regel jede Zinkfinger-Domäne in einer große Furche der DNA bindet und dort eine spezifische Interaktion mit drei Basen der DNA eingeht (Elrod-Erickson et al., 1996; Eom et al., 2016). Die größte Klasse an eukaryotischen Zinkfingern bilden die $\mathrm{Cys}_{2} \mathrm{His}_{2-}, \mathrm{C}_{2} \mathrm{H}_{2}$ - oder "klassischen" Zinkfinger. Dabei ist das häufigste Muster Cys- $\mathrm{X}_{4}-\mathrm{Cys}_{\mathrm{S}} \mathrm{X}_{12}-\mathrm{His}-\mathrm{X}_{3}-\mathrm{His}$, bei dem die beiden Cysteine durch vier beliebige, die beiden Histidine durch drei beliebige Aminosäuren verbunden sind, während diese beiden Muster wiederum ein Linker von zwölf beliebigen Aminosäuren trennt (Eom et al., 2016). Es konnte für eukaryotische Zinkfinger gezeigt werden, dass diese für spezifische DNA-, RNA- und Proteininteraktionen verantwortlich sind und dabei in der Transkriptions- und Translationsregulation eine Rolle spielen, aber auch für die Homöostase von Zink selbst wichtig sein können. Sie können in der Protein-Degradation, in der Signaltransduktion und weiteren Prozessen involviert sein (Cassandri et al., 2017).

Die strukturelle Evolution vom prokaryotischen zum eukaryotischen Zinkfinger muss in mehreren Schritten passiert sein und ein Szenario der Vererbung von Prokaryoten zu Eukaryoten mittels mitochondrieller Endosymbiose ist wahrscheinlich (Malgieri et al., 2015). Für prokaryotische Zinkfinger konnte gezeigt 
werden, dass der Zink-koordinierende Kern ähnlich dem eukaryotischen Zinkfinger ist, er aber um zusätzliche Elemente erweitert vorliegt und sich somit signifikant von den eukaryotischen Zinkfingern unterscheiden (Kluska et al., 2018). Zinkfinger in Prokaryoten können ebenfalls für spezifische DNA- und RNA-Interaktionen verantwortlich und dabei in der Transkriptions- und Translationsregulation eine Rolle spielen, aber auch für die Homöostase von Zink selbst wichtig sein. Darüber hinaus wurde von prokaryotischen Zinkfingern berichtet, die kein Zink mehr benötigen, da intramolekulare polare und hydrophobe Interaktionen die Rolle des Zink ersetzen (Malgieri et al., 2015).

Wie zuvor beschrieben, wurde bei der Untersuchung des "Low Molecular Weight Proteom" im Archaeon H. salinarum eine Vielzahl an Proteinen experimentell identifiziert, denen keinerlei Funktion zugeordnet werden konnte (Klein et al., 2007). Unter diesen 237 Proteinen befanden sich 20 potenzielle Zinkfinger-Proteine, von denen eines nachfolgend im Detail charakterisiert werden konnte. Es konnte gezeigt werden, dass dieses Zinkfinger-Protein mit dem C(P)XCG-Zinkfinger-Motiv an der Regulation der Expression des Bakteriorhodopsingens maßgeblich beteiligt ist (Tarasov et al., 2008). Darüber hinaus wurde bei der statistischen Analyse von 32 komplett sequenzierten Genomen gezeigt, dass $8 \%$ aller archaealen Proteine mit weniger als 100 Aminosäuren solche $C(P) X C G$-ähnlichen Zinkfinger-Motive enthalten. Dem gegenüber stehen lediglich 1,5\% der bakteriellen Proteine mit weniger als 100 Aminosäuren, die ein solches Motiv enthalten, wie die Untersuchung von 24 bakteriellen Genomen ergab (Tarasov et al., 2008). Diese Erkenntnisse wurden herangezogen um auch im Genom von $H$. volcanii Gene, die für solche $C(P) X C G$-Zinkfinger-Proteine codieren, zu annotieren. In $\mathrm{H}$. volcanii existieren $281 \mu$-Proteine (maximal 70 Aminosäuren), davon ist von lediglich 30 Proteinen eine Funktion bekannt. Von diesen $281 \mu$-Proteinen besitzen 43 solche Zinkfinger-Motive und von keinem dieser Zinkfinger- $\mu$-Proteine ist bisher die genaue Funktion bekannt. Allerdings wurden bereits 16 der 43 Zinkfinger-Proteincodierenden Gene ausgewählt, Deletionsmutanten erstellt und so Charakterisierungen durchgeführt (Nagel et al., 2019). Dabei wurden die Phänotypen der Deletionsmutanten mit dem des Wildtyps unter acht verschiedenen Bedingungen verglichen, wie zum Beispiel dem Wachstum mit Glycerin als Kohlenstoffquelle, den Einfluss von Gallensäuren auf das Wachstum oder die Fähigkeit Biofilme zu bilden oder zu Schwärmen. Es konnten hierbei Unterschiede zum Wildtyp in 12 
der 16 Deletionsmutanten bei jeweils mindestens einer Bedingung gefunden werden, was unterstreicht, dass viele dieser Proteine wichtige Rollen innerhalb der Zelle einnehmen.

\subsection{Zielsetzung dieser Arbeit}

Die letzten beiden Kapitel zeigen auf, welche wichtige Rolle kleine Proteine spielen können, die lange Zeit nicht die Aufmerksamkeit in der Forschung erhalten haben, die innen gebührt, aber auch wie vielseitig Zinkfinger-Proteine sein können. H. volcanii besitzt 43 Proteine, die in beide Kategorien von Proteinen gleichzeitig einzuordnen sind. Sie besitzen alle ein spezielles Zinkfinger-Motiv, ohne die maximale Länge von 70 Aminosäuren zu überschreiten. Während bereits 16 dieser 43 Proteine einer Charakterisierung unterzogen wurden, indem Deletionsmutanten ihrer Gene erstellt wurden, sollte im Zuge der vorliegenden Arbeit ein Ausgewähltes der 43 Zinkfinger-Proteine und damit das zweite archaeale Zinkfinger$\mu$-Protein überhaupt, einer tiefgreifenden Charakterisierung unterzogen werden.

Die Auswahl des zu charakterisierenden Proteins HVO_2753 wurde aufgrund einer Auffälligkeit in seiner Aminosäuresequenz getroffen. HVO_2753 stellt das einzige Zinkfinger- $\mu$-Protein in $H$. volcanii dar, welches vier der spezifischen $C(P) X C G$-ähnlichen Muster aufweist, während die übrigen 42 lediglich zwei dieser Muster enthalten. Die Charakterisierung des Proteins sollte bioinformatische Analysen umfassen, mit denen Homologe in anderen Spezies identifiziert und Gemeinsamkeiten und Unterschiede in der Aminosäuresequenz untersucht werden können. Des Weiteren sollten in vivo-Funktionsanalysen durchgeführt werden. Dabei sollte eine phänotypische Charakterisierung der erstellten Deletionsmutante des HVO_2753-Gens die Auswirkungen der Abwesenheit des kleinen Zinkfinger-Proteins zeigen. Weitere in vivo-Untersuchungen sollten auf den Ergebnissen dieser Analysen aufbauen und die Funktionsaufklärung weiter vorantreiben. Mithilfe einer RNA-Sequenzierung sollten die Auswirkungen der Abwesenheit von HVO_2753 auch auf Transkriptomebene untersucht werden.

Außerdem sollte die Überproduktion von HVO_2753 im homologen System etabliert und ein Aufreinigungsprotokoll erstellt und optimiert werden. Das dabei nativ aufgereinigte HVO_2753 sollte anschließend einer massenspektrometrischen Analyse und einer fluorimetrischen Untersuchung zum Zinkgehalt unterzogen 
werden. Zusätzlich sollten mittels Co-Affinitätsreinigung und anschließender massenspektrometrischer Analyse Interaktionspartner von HVO_2753 identifiziert werden. 


\section{Material und Methoden}

\subsection{Organismen}

\subsubsection{Haloferax volcanii}

Der Elternstamm Haloferax volcanii H26, der im Folgenden als Wildtyp (WT) bezeichnet wird, liegt allen anderen verwendeten Stämmen zugrunde. Dieser basiert auf dem Stamm DS70 (Allers et al., 2004). Alle in dieser Arbeit erstellten oder verwendeten Stämme sind in Tabelle 1 aufgeführt.

Tabelle 1: Übersicht über alle verwendeten $\boldsymbol{H}$. volcanii Stämme. Alle verwendeten Stämme basieren auf dem Ausgangsstamm H26 (Allers et al., 2004) und wurden in dieser Arbeit erstellt. Leervektorkontrollen (evc, empty vector control) besitzen den entsprechenden Vektor ohne inseriertes Gen in der MCS (multiple cloning site).

\begin{tabular}{|c|c|c|}
\hline Stamm & Genotyp & Plasmid \\
\hline $\mathrm{H} 26$ & $\triangle p y r E 2$ & N/A \\
\hline $\mathrm{H} 26 \mathrm{evc}$ & $\triangle p y r E 2$ & pTA929 \\
\hline$\Delta \mathrm{HVO} \_2753$ & ApyrE2 $\triangle H V O \_2753$ & N/A \\
\hline$\Delta \mathrm{HVO} \_2753 \mathrm{evc}$ & ApyrE2 $\triangle H V O \_2753$ & pTA929 \\
\hline $\begin{array}{l}\Delta \mathrm{HVO} \_2753 \\
+2753 \mathrm{n}\end{array}$ & $\begin{array}{l}\text { ApyrE2 } \triangle H V O \_2753 \\
\{p . t n a A:: 6 \times \text { His tag::HVO_2753\} }\end{array}$ & pTA929_HVO_2753_NHis \\
\hline $\begin{array}{l}\Delta \mathrm{HVO}_{-} 2753 \\
+2753 \mathrm{c}\end{array}$ & $\begin{array}{l}\text { ApyrE2 } \triangle H V O \_2753 \\
\left\{p . t n a A:: H V O \_2753:: 6 \times \text { His tag\} }\right.\end{array}$ & pTA929_HVO_2753_CHis \\
\hline $\begin{array}{l}\Delta \mathrm{HVO} \_2753 \\
+2753 C_{-} \mathrm{C} 12 \mathrm{~A}\end{array}$ & $\begin{array}{l}\text { ApyrE2 } \triangle H V O \_2753 \\
\left\{p . t n a A:: H V O \_2753^{-}:: 6 \times \text { His tag }\right\}\end{array}$ & pTA929_HVO_2753_C12A_CHis \\
\hline $\begin{array}{l}\Delta \mathrm{HVO} \_2753 \\
+2753 \mathrm{C} \_\mathrm{C} 29 \mathrm{~A}\end{array}$ & $\begin{array}{l}\text { ApyrE2 } \triangle H V O \_2753 \\
\left\{p . t n a A:: H V O \_2753^{-}:: 6 \times \text { His tag }\right\}\end{array}$ & pTA929_HVO_2753_C29A_CHis \\
\hline $\begin{array}{l}\Delta \mathrm{HVO} \_2753 \\
+2753 \mathrm{C} \_C 39 \mathrm{~A}\end{array}$ & $\begin{array}{l}\text { ApyrE2 } \triangle H V O \_2753 \\
\left\{p . t n a A:: H V O \_2753^{-}:: 6 \times \text { His tag }\right\}\end{array}$ & pTA929_HVO_2753_C39A_CHis \\
\hline $\begin{array}{l}\Delta \mathrm{HVO} \_2753 \\
+2753 \mathrm{C} \_\mathrm{C} 51 \mathrm{~A}\end{array}$ & SpyrE2 $\triangle H V O \_2753$ & pTA929_HVO_2753_C51A_CHis \\
\hline
\end{tabular}


\{p.tnaA.:HVO_2753-::6×His tag\}

\begin{tabular}{|c|c|c|}
\hline $\begin{array}{l}\Delta H V O \_2753 \\
+2753 c \_Q 34 A\end{array}$ & $\begin{array}{l}\text { ApyrE2 } \triangle H V O \_2753 \\
\left\{p . t n a A:: H V O \_2753^{-}:: 6 \times \text { His tag }\right\}\end{array}$ & pTA929_HVO_2753_Q34A_CHis \\
\hline $\begin{array}{l}\Delta \mathrm{HVO} 22753 \\
+2753 c_{-} Y 49 \mathrm{~F}\end{array}$ & $\begin{array}{l}\text { ApyrE2 } \triangle H V O \_2753 \\
\left\{p . t n a A:: H V O \_2753^{-}:: 6 \times \text { His tag }\right\}\end{array}$ & pTA929_HVO_2753_Y49F_CHis \\
\hline OE_2753n & $\begin{array}{l}\text { ApyrE2 } \triangle H V O \_2753 \\
\left\{p . f d x^{-}:: 6 \times \text { His tag::HVO_2753\} }\right.\end{array}$ & pSD1_R1/6_HVO_2753_NHis \\
\hline
\end{tabular}

\subsubsection{Escherichia coli}

Für Klonierungsarbeiten wurde der E. coli-Stamm XL1 blue MRF' von der Firma Agilent Technologies (Santa Clara, USA) verwendet. Der Genotyp dieses Stammes lautet $\Delta$ (mcrA)183; $\Delta$ (mcrCB-' hsdSMR-mrr)173; recA1; endA1; gyrA96; thi-1; hsdR17; supE44; relA1 lac [F'proAB+laclZ $\Delta \mathrm{M} 15$ Tn10 (TetR)].

\subsection{Materialien}

\subsubsection{Chemikalien}

\section{Tabelle 2: Chemikalienliste}

\begin{tabular}{ll}
\hline Bezeichnung & Hersteller \\
\hline B-Mercaptoethanol & Merck, Darmstadt \\
5-Fluor-Orotsäure & Roth, Karlsruhe \\
Acetanhydrid & Roth, Karlsruhe \\
Acrylamid & Sigma-Aldrich, Taufkirchen \\
Agarose LE & Biozym, Hessisch Oldendorf \\
Ammoniumperoxodisulfat (APS) & Merck, Darmstadt \\
Ampicillin & Roth, Karlsruhe \\
ATP (10 mM) & New England Biolabs, Ipswich, MA (USA) \\
BactoTM-Agar & BD, Heidelberg \\
BactoTM-Hefeextrakt & BD, Heidelberg \\
BactoTM-Trypton & BD, Heidelberg \\
BME-Vitaminlösung & Sigma-Aldrich, Taufkirchen \\
Blocking-Reagenz & Merck, Darmstadt
\end{tabular}


Borsäure

Bromphenolblau

Calciumdichlorid Dihydrat

Casaminosäuren

Chelating SepharoseTM Fast Flow

Coomassie Blue R-250

Cy3 / Cy5 dUTP

Desoxyribonukleosidtriphosphate (dNTPs)

Dichlorethan

Diethylether

Digoxygenin-Deoxyuridin-triphosphat

Dikaliumhydrogenphosphat

Dimethylsulfoxid (DMSO)

Dimethylsulfoxid, für die Spektroskopie

Dinatriumhydrogenphosphat

Entwickler Kodak GBX

Essigsäure $\geq 98 \%(v / v)$

Ethanol (EtOH) 99 \% p. a. (v/v)

Ethidiumbromid

Ethylendiamintetraessigsäure (EDTA)

Formaldehydlösung 37 \% (w/v)

Glukose-Monohydrat

Glycerin 87 \% p. a. (v/v)

Glycin

Guanidiniumthiocyanat

Harnstoff

Hefe-tRNA

Hexaammincobalt(III)-chlorid

Imidazol

Kaliumchlorid

Kaliumdihydrogenphosphat

Kanamycin

Kobaltchlorid Hexahydrat

Kupferchlorid Dihydrat

Magermilchpulver

Magnesiumdichlorid Hexahydrat

Magnesiumsulfat Heptahydrat
Roth, Karlsruhe

Merck, Darmstadt

VWR, Darmstadt

BD, Heidelberg

GE Healthcare, Little Chalfont (UK)

Roth, Karlsruhe

GE Healthcare, Little Chalfont (UK)

Fermentas, St. Leon-Rot

Roth, Karlsruhe

VWR, Darmstadt

Roche, Mannheim

Merck, Darmstadt

Roth, Karlsruhe

Merck, Darmstadt

Merck, Darmstadt

Sigma-Aldrich, Taufkirchen

Roth, Karlsruhe

VWR, Darmstadt

Fluka, Neu-UIm

Roth, Karlsruhe

Roth, Karlsruhe

Merck, Darmstadt

VWR, Darmstadt

Amresco, Ohio Solon (USA)

Roth, Karlsruhe

VWR, Darmstadt

Boehringer Ingelheim, Ingelheim

Thermo Fisher Scientific, Waltham, MA (USA)

Roth, Karlsruhe

VWR, Darmstadt

Roth, Karlsruhe

Roth, Karlsruhe

Merck, Darmstadt

Roth, Karlsruhe

VWR, Darmstadt

VWR, Darmstadt

VWR, Darmstadt 
Manganchlorid Tetrahydrat

Methanol

MOPS

$\mathbf{N}, \mathrm{N}^{\prime}$-Methylenbisacrylamid

$\mathrm{N}$-Lauroylsarcosinat $30 \%(\mathrm{w} / \mathrm{v})$

Natriumacetat

Natriumchlorid

Natriumchlorid, ultra trocken

tri-Natriumcitrat-Dihydrat

Natriumdodecylsulfat (SDS)

Natriumhydroxid

Natriummolybdat Monohydrat

Natriumnitrat

NEXTERION ${ }^{\circledR}$ Oligo Hyb

Nickelchlorid Hexahydrat

PEG 8000

Phusion GC Puffer

Polyethylen Glycol (PEG) 600

Rinderserumalbumin BSA

ROTI ${ }^{\circledR}$ Aqua-P/C/I

Salzsäure 37 \% (w/w)

Silbernitrat

Tetramethylethylenediamine (TEMED)

Tricin Puffer

Tris(hydroxymethyl)aminomethan (Tris)

Tween ${ }^{\circledR} 20$

Uracil

Zinkchlorid, ultra trocken
Merck, Darmstadt

VWR, Darmstadt

Roth, Karlsruhe

Sigma-Aldrich, Taufkirchen

Applichem, Darmstadt

Roth, Karlsruhe

Roth, Karlsruhe

Alfa Aesar, Ward Hill, MA (USA)

Roth, Karlsruhe

Roth, Karlsruhe

Roth, Karlsruhe

Roth, Karlsruhe

Roth, Karlsruhe

SCHOTT AG, Mainz

Merck, Darmstadt

New England Biolabs, Ipswich, MA (USA)

Thermo Fisher Scientific, Waltham, MA (USA)

Sigma-Aldrich, Taufkirchen

Sigma-Aldrich, Taufkirchen

Roth, Karlsruhe

Roth, Karlsruhe

Roth, Karlsruhe

Serva, Heidelberg

VWR, Darmstadt

Roth, Karlsruhe

Roth, Karlsruhe

Applichem, Darmstadt

Alfa Aesar, Ward Hill, MA (USA)

Sigma-Aldrich, Taufkirchen 


\subsubsection{Verbrauchsmaterialien}

\section{Tabelle 3: Verbrauchsmaterialienliste}

\begin{tabular}{|c|c|}
\hline Bezeichnung & Hersteller \\
\hline Eppendorf-Reaktionsgefäß (1,5 ml, 2 ml) & Eppendorf, Hamburg \\
\hline Erlenmeyerkolben & Duran Group, Wertheim \\
\hline Feuchtigkeitskammer & Sigma-Aldrich, Taufkirchen \\
\hline $\begin{array}{l}\text { Framed Dialysis Membrane (MW cutoff } 3000 \\
\text { Dalton) }\end{array}$ & Pierce, Rockford, IL (USA) \\
\hline Gel-Blotting-Papier $(0,37$ mm, 1,4 mm) & Roth, Karlsruhe \\
\hline Kodak ${ }^{\circledR}$ BioMax ${ }^{\circledR}$ light film & Carestream Health, Stuttgart \\
\hline Küvetten $10 * 4 * 45 \mathrm{~mm}$ & Sarstedt, Nümbrecht \\
\hline $\begin{array}{l}\text { Nitrocellulosemembran Whatman }{ }^{\circledR} \text { Protran }{ }^{\circledR} \\
\text { BA85 }\end{array}$ & GE Healthcare, Little Chalfont (UK) \\
\hline Nylonmembran Roti ${ }^{\circledR}$-Nylon plus & Roth, Karlsruhe \\
\hline $\begin{array}{l}\text { Membranfilterscheiben }(0,025 \mu \mathrm{m}, 13 \mathrm{~mm} \text {, } \\
\text { hydrophil, Zellulosemischester })\end{array}$ & Merck, Darmstadt \\
\hline Mikrotiterplatten 96-well, Flachboden & Sarstedt, Nürnbrecht \\
\hline $\begin{array}{l}\text { Mikrotiterplatten } 96 \text {-well, Flachboden, } \\
\text { schwarz, Microfluor }{ }^{\circledR} 1\end{array}$ & Thermo Fisher Scientific, Waltham, MA (USA) \\
\hline Multiply ${ }^{\circledR}$ Pro Gefäß & Sarstedt, Nümbrecht \\
\hline Pasteurpipetten & Hirschmann, Eberstadt \\
\hline Petrischalen & Sarstedt, Nümbrecht \\
\hline Pipettenspitzen $(2,200$ und $1000 \mu \mathrm{l})$ & Sarstedt, Nümbrecht \\
\hline Schraubröhre 15 ml, 50 ml & Sarstedt, Nümbrecht \\
\hline Zellkulturplatte TC-Platte 6 Well,Cell+,F & Sarstedt, Nümbrecht \\
\hline
\end{tabular}

\subsubsection{Geräte}

Tabelle 4: Geräteliste

\begin{tabular}{lll}
\hline Bezeichnung & Gerät/Modell & Hersteller \\
\hline Autoklav & FVS/2 & $\begin{array}{l}\text { Fedegari Autoclavi, Albuzzano } \\
\text { (Italien) }\end{array}$ \\
& SANOclav LaM-201 & $\begin{array}{l}\text { Maschinenbau Wolf, Bad } \\
\text { Überkingen }\end{array}$
\end{tabular}




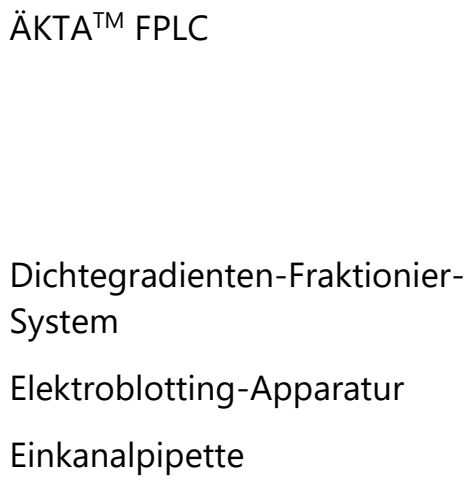

Mit Säule Superdex ${ }^{\mathrm{TM}} 75$ Increase 10/300 GL

GE Healthcare, Little Chalfont (UK)

und

Säule Superose ${ }^{\text {TM }} 6$ 10/300 GL

Teledyne ISCO, Lincoln (USA)

Fastblot B43

Research 0,01-2,5 $\mu$ l

Discovery Comfort 2-20 $\mu \mathrm{l}$

Discovery Comfort 20-200 $\mu \mathrm{l}$

Discovery Comfort 200$1000 \mu \mathrm{l}$

High Resolution System E.A.S.Y $440 \mathrm{~K}$

SE 250

SE 600

Biometra Minigel Twin

107

ЕРT-130-36-1,5

MR 3000

HB-1000

HS $400^{\text {TM }}$ Pro Hybridization Station

B6060

kelvitron $\mathrm{t}$

T257

Discovery Comfort 5-50 $\mu \mathrm{l}$

Discovery Comfort 20-200 $\mu \mathrm{l}$

Axiostar Plus

SPECTRAmax ${ }^{\circledR} 340 P C$

\section{CLARIOstar}

Gene Amp PCR-System 9700
Biometra, Göttingen

Eppendorf, Hamburg

HTL Lab Solution, Warschau (Polen)

HTL Lab Solution, Warschau (Polen)

HTL Lab Solution, Warschau (Polen)

Herolab, Wiesloch

Hoefer, Holliston (USA)

Hoefer, Holliston (USA)

Analytik Jena, Jena

BioComp Instruments, Fredericton (Kanada)

Liebisch, Bielefeld

Heidolph Instruments,

Schwabach

UVP, Upland (USA)

Tecan Trading, Männedorf, $\mathrm{CHE}$

Heraeus Instruments, Hanau

Heraeus Instruments, Hanau

Rubarth Apparate, Laatzen

HTL Lab Solution, Warschau (Polen)

HTL Lab Solution, Warschau (Polen)

Carl Zeiss, Göttingen

Molecular Devices, Sunnyvale (USA)

BMG LABTECH, Ortenberg

Applied Biosystems, Foster City (USA) 


\begin{tabular}{|c|c|c|}
\hline & Veriti 96-well Thermal Cycler & $\begin{array}{l}\text { Applied Biosystems, Foster } \\
\text { City (USA) }\end{array}$ \\
\hline pH-Meter & CG 825 & Schott, Mainz \\
\hline Pipettierhilfe & Accurpette & $\begin{array}{l}\text { VWR International, Radnor } \\
\text { (USA) }\end{array}$ \\
\hline \multirow[t]{2}{*}{ Schüttelinkubator } & innova 4300 & $\begin{array}{l}\text { New Brunswick Scientific, } \\
\text { New York (USA) }\end{array}$ \\
\hline & SI 20 (K30-300) & $\begin{array}{l}\text { Axon Labortechnik, Kaisers- } \\
\text { lautern }\end{array}$ \\
\hline \multirow[t]{2}{*}{ Spektralphotometer } & Specord S 600 & Analytik Jena, Jena \\
\hline & Nanodrop 2000c & $\begin{array}{l}\text { Thermo Fisher Scientific, Wal- } \\
\text { tham, MA (USA) }\end{array}$ \\
\hline \multirow[t]{2}{*}{ Ultraschall Homogenisator } & Ultrasonics Converter & Branson, Danbury, USA \\
\hline & Sonifier 250 & Branson, Danbury, USA \\
\hline UV-Stratalinker ${ }^{\mathrm{TM}}$ & 1800 & Stratagene, La Jolla (USA) \\
\hline \multirow[t]{3}{*}{ Waage } & PB300 & Mettler, Gießen \\
\hline & PM 4800 Delta Range ${ }^{\circledR}$ & Mettler, Gießen \\
\hline & TE1245OCE & Sartorius, Göttingen \\
\hline \multirow[t]{7}{*}{ Zentrifuge } & BioFuge Pico & Heraeus Instruments, Hanau \\
\hline & Centrifuge $5810 \mathrm{R}$ & Eppendorf, Hamburg \\
\hline & mit Rotor A-4-62 & \\
\hline & $\begin{array}{l}\text { Kühlzentrifuge Sorvall RC6+ } \\
\text { mit Rotor SS-34 (16.000 rpm) }\end{array}$ & $\begin{array}{l}\text { Thermo Fisher Scientific, Wal- } \\
\text { tham, MA (USA) }\end{array}$ \\
\hline & mit Rotor SH3000 (4.700 rpm) & \\
\hline & $\begin{array}{l}\text { mit Rotor F10S-6x500Y } \\
\text { (16.000 rpm) }\end{array}$ & \\
\hline & $\begin{array}{l}\text { Ultrazentrifuge Optima XPN- } \\
80 \text { mit Rotor SW } 41 \mathrm{Ti}\end{array}$ & $\begin{array}{l}\text { Beckman Coulter, Brea, CA } \\
\text { (USA) }\end{array}$ \\
\hline
\end{tabular}

\subsubsection{Molekularbiologische und biochemische Kit-Systeme}

Tabelle 5: Liste molekularbiologischer und biochemischer Kit-Systeme

\begin{tabular}{ll}
\hline Bezeichnung & Hersteller \\
\hline BC Assay : Protein Assay Kit & Montlucon Cedex, Frankreich \\
CDP Star & Roche, Mannheim \\
E.Z.N.A. Gel Extraction Kit & VWR International, Radnor (USA) \\
E.Z.N.A. Cycle Pure Kit & VWR International, Radnor (USA) \\
GenElute ${ }^{\text {TM }}$ Plasmid Midiprep Kit & Sigma-Aldrich, Taufkirchen \\
Monarch RNA Cleanup Kit & New England Biolabs, Ipswich, MA (USA)
\end{tabular}


Monarch PCR \& DNA Cleanup Kit

Nucleospin ${ }^{\circledR}$ Plasmid Kit

NucleoSpin ${ }^{\circledR}$ miRNA-Kit

Roti ${ }^{\circledR}$-Lumin

QuikChange II Site-Directed Mutagenesis Kit
New England Biolabs, Ipswich, MA (USA)

MACHEREY-NAGEL, Düren

MACHEREY-NAGEL, Düren

Roth, Karlsruhe

Agilent Technologies, Santa Clara (USA)

\subsubsection{Enzyme und Ähnliches}

Tabelle 6: Enzymliste

\begin{tabular}{ll}
\hline Bezeichnung & Hersteller \\
\hline Phusion High-Fidelity DNA Polymerase & Thermo Fisher Scientific, Waltham, MA (USA) \\
Lysozym & AppliChem, Darmstadt \\
RNase (DNase frei) & AppliChem, Darmstadt \\
T4 DNA-Ligase & New England Biolabs, Ipswich, MA (USA) \\
Taq-DNA-Polymerase & Eigenisolat \\
DNase I & Thermo Fisher Scientific, Waltham, MA (USA) \\
SUPERase-In ${ }^{\text {TM }}$ RNase Inhibitor & Thermo Fisher Scientific, Waltham, MA (USA) \\
GoScript ${ }^{\text {TM }}$ Reverse Transcriptase & Promega, Walldorf \\
RNase H & New England Biolabs, Ipswich, MA (USA) \\
T4 RNA Ligase 1 & New England Biolabs, Ipswich, MA (USA) \\
\hline
\end{tabular}

\subsubsection{Größenstandards}

Tabelle 7: Liste der Größenstandards

\begin{tabular}{|c|c|}
\hline Bezeichnung & Hersteller \\
\hline GeneRuler TM 100 bp Plus & Thermo Fisher Scientific, Waltham, MA (USA) \\
\hline GeneRuler $^{\mathrm{TM}} 1 \mathrm{~kb}$ Plus & Thermo Fisher Scientific, Waltham, MA (USA) \\
\hline PageRuler ${ }^{\mathrm{TM}}$ Prestained Protein Ladder & Thermo Fisher Scientific, Waltham, MA (USA) \\
\hline $\begin{array}{l}\text { PageRuler }{ }^{\mathrm{TM}} \text { Unstained Low Range Protein Lad- } \\
\text { der }\end{array}$ & Thermo Fisher Scientific, Waltham, MA (USA) \\
\hline RiboRuler $^{\mathrm{TM}}$ RNA Ladder High Range & Thermo Fisher Scientific, Waltham, MA (USA) \\
\hline RiboRuler $^{\mathrm{TM}}$ RNA Ladder Low Range & Thermo Fisher Scientific, Waltham, MA (USA) \\
\hline Color Marker Ultra-low Range & Sigma-Aldrich, Taufkirchen \\
\hline GeneRuler ${ }^{\mathrm{TM}} 1 \mathrm{~kb}$ Plus & Thermo Fisher Scientific, Waltham, MA (USA) \\
\hline
\end{tabular}




\subsubsection{Oligonukleotide}

Tabelle 8: Liste der Oligonukleotide. Alle verwendeten Oligonukleotide wurden von Sigma-Aldrich (Taufkirchen) bezogen.

\begin{tabular}{|c|c|c|}
\hline Bezeichnung & Sequenz $\left(5^{\prime}-3^{\prime}\right)$ & $\begin{array}{l}\text { Verwendungs- } \\
\text { zweck / Anmer- } \\
\text { kung }\end{array}$ \\
\hline HVO_2753_for_NHis & $\begin{array}{l}\text { GACTAGCATATGCACCACCACCACCACCA- } \\
\text { CAGCGAGTCCGAACAGCGACAC }\end{array}$ & \multirow{2}{*}{$\begin{array}{l}\text { Klonierung von } \\
\text { HVO_2753 mit N-ter- } \\
\text { minalem His-Tag in } \\
\text { pTA929 }\end{array}$} \\
\hline HVO_2753_rev_NHis & $\begin{array}{l}\text { GACTAGAAGCTTTTATGGACCCAT- } \\
\text { GAAGCCGCAGTCG }\end{array}$ & \\
\hline HVO_2753_for_CHis & $\begin{array}{l}\text { GACTAGCATAT- } \\
\text { GAGCGAGTCCGAACAGCGACAC }\end{array}$ & \multirow{2}{*}{$\begin{array}{l}\text { Klonierung von } \\
\text { HVO_2753 mit C-ter- } \\
\text { minalem His-Tag in } \\
\text { pTA929 }\end{array}$} \\
\hline HVO_2753_rev_CHis & $\begin{array}{l}\text { GACTAGAAGCTTT- } \\
\text { TAGTGGTGGTGGTGGTGGTGTGGACCCAT- } \\
\text { GAAGCCGCAGTCG }\end{array}$ & \\
\hline HVO_2753_C1A_for & & \multirow{2}{*}{$\begin{array}{l}\text { Einführung der } \\
\text { Punktmutation } \mathrm{C} 12 \mathrm{~A}\end{array}$} \\
\hline HVO_2753_C1A_rev & TGCCACAGGACACAGCCTGGTGCGCGTGTC & \\
\hline HVO_2753_C3A_for & GGCGACGTTCAAGGCCCCCGACTGCGGC & \multirow{2}{*}{$\begin{array}{l}\text { Einführung der } \\
\text { Punktmutation C29A }\end{array}$} \\
\hline HVO_2753_C3A_rev & GCCGCAGTCGGGGGCCTTGAACGTCGCC & \\
\hline HVO_2753_C5A_for & $\begin{array}{l}\text { CCAGGAGATTTCGCGTGCTT- } \\
\text { CCAAGTGCCGCAAG }\end{array}$ & \multirow{2}{*}{$\begin{array}{l}\text { Einführung der } \\
\text { Punktmutation C39A }\end{array}$} \\
\hline HVO_2753_C5A_rev & $\begin{array}{l}\text { CTTGCGGCACTTG- } \\
\text { GAAGCACGCGAAATCTCCTGG }\end{array}$ & \\
\hline HVO_2753_C7A_for & GCAACCTCTACGAGGCTCCCGACTGCGGCT & \multirow{2}{*}{$\begin{array}{l}\text { Einführung der } \\
\text { Punktmutation C51A }\end{array}$} \\
\hline HVO_2753_C7A_rev & AGCCGCAGTCGGGAGCCTCGTAGAGGTTGC & \\
\hline HVO_2753_Q34A_for & CCCCGACTGCGGCGCGGAGATTTCGCGT & \multirow{2}{*}{$\begin{array}{l}\text { Einführung der } \\
\text { Punktmutation Q34A }\end{array}$} \\
\hline HVO_2753_Q34A_rev & ACGCGAAATCTCCGCGCCGCAGTCGGGG & \\
\hline HVO_2753_Y49F_for & CAAGCAGAGCAACCTCTTCGAGTGTCCCG & \multirow{2}{*}{$\begin{array}{l}\text { Einführung der } \\
\text { Punktmutation Y49F }\end{array}$} \\
\hline HVO_2753_Y49F_rev & CGGGACACTCGAAGAGGTTGCTCTGCTTG & \\
\hline HVO_2752_for_NB & AATCAAGGTCATGCCGAACAGCCC & \multirow{2}{*}{$\begin{array}{l}\text { Sondengenerierung } \\
\text { gegen HVO_2753 für } \\
\text { den Northernblot }\end{array}$} \\
\hline HVO_2752_rev_NB & CAGATACGGCCGACGTTCTCGAC & \\
\hline
\end{tabular}




\begin{tabular}{|c|c|c|}
\hline $\begin{array}{l}\text { HVO_2753_Pstl_Ndel_N } \\
\text { His_fw }\end{array}$ & $\begin{array}{l}\text { GACTAGCTGCAGGACTAGGACCATATGCACCA- } \\
\text { CCACCACCACCA- } \\
\text { CAGCGAGTCCGAACAGCGACAC } \\
\text { GACTAGGGTACCTTATGGACCCAT- } \\
\text { GAAGCCGCAGTCG }\end{array}$ & $\begin{array}{l}\text { Klonierung von } \\
\text { HVO_2753 mit } \mathrm{N} \text {-ter- } \\
\text { minalem His-Tag in } \\
\text { pSD1-R1/6 }\end{array}$ \\
\hline $\begin{array}{l}\text { HVO_2753_Pstl_Ndel_f } \\
w\end{array}$ & $\begin{array}{l}\text { GACTAGCTGCAGGACTAGGACCATAT- } \\
\text { GAGCGAGTCCGAACAGCGACAC }\end{array}$ & \multirow{2}{*}{$\begin{array}{l}\text { Klonierung von } \\
\text { HVO_2753 mit C-ter- } \\
\text { minalem His-Tag in } \\
\text { pSD1-R1/6 }\end{array}$} \\
\hline $\begin{array}{l}\text { HVO_2753_Kpnl_CHis_r } \\
\text { ev }\end{array}$ & $\begin{array}{l}\text { GACTAGGGTACCT- } \\
\text { TAGTGGTGGTGGTGGTGGTGTGGACCCAT- } \\
\text { GAAGCCGCAGTCG }\end{array}$ & \\
\hline KolExpr_for & CACACACCAGTCCACGAGCGCC & \multirow{2}{*}{$\begin{array}{l}\text { Plasmidspezifische } \\
\text { Anwendungen } \\
\text { pTA929 }\end{array}$} \\
\hline KolExpr_rev & CTGGAGCTCCACCGCGCCG & \\
\hline M13-20_for & GTAAAACGACGGCCAGTG & \multirow{2}{*}{$\begin{array}{l}\text { Plasmidspezifische } \\
\text { Anwendungen } \\
\text { pBluescriptSK+ }\end{array}$} \\
\hline T3_rev & AATTAACCCTCACTAAAGGG & \\
\hline pSD1-R1/6_for & AGCGTCGTGATGGCGGTCACACCC & \multirow{2}{*}{$\begin{array}{l}\text { Plasmidspezifische } \\
\text { Anwendungen pSD1- } \\
\text { R1/6 }\end{array}$} \\
\hline pSD1-R1/6_rev & TGCGGGCCTCTTCGCTATTACGCC & \\
\hline DNA-Adapter & GGTCGACCGATCCGGATCGATATCGCCTGG & \multirow{2}{*}{$\begin{array}{l}\text { DNA-Adapter-Liga- } \\
\text { tion / mit 5'-Phosphat } \\
\text { und 3'-Amino-Modi- } \\
\text { fier-C3-CPG }\end{array}$} \\
\hline $\begin{array}{l}\text { DNA-Adapter } \\
\text { Primer rev }\end{array}$ & CCAGGCGATATCGATCCGGATCGG & \\
\hline
\end{tabular}

\subsubsection{Plasmide}

Tabelle 9: Liste der Plasmide. Wenn nicht anders angegeben, wurde das Plasmid im Rahmen dieser Arbeit generiert.

\begin{tabular}{|c|c|}
\hline Bezeichnung & Verwendungszweck und Referenz \\
\hline pBluescriptSK(+) & $\begin{array}{l}\text { Klonierungsarbeiten und ortsspezifische Mutagenese } \\
\text { (Agilent Technologies, Santa Clara, CA, USA) }\end{array}$ \\
\hline pQE60_HVO_2753_NHis & $\begin{array}{l}\text { Heterologe Überexpression des Gens HVO_2753 mit N- } \\
\text { terminalem His } \text { - }_{6} \text {-Tag. Basierend auf pQE60 (Qiagen, } \\
\text { Hilden) }\end{array}$ \\
\hline pMH101__HVO_2753 & $\begin{array}{l}\text { in frame Deletion des Gens HVO_2753. Basierend auf } \\
\text { pMH101 (Hammelmann \& Soppa, 2008) }\end{array}$ \\
\hline pTA929_HVO_2753_NHis & $\begin{array}{l}\text { Komplementation. } \\
\text { Basierend auf pTA929 (Allers et al., 2010) }\end{array}$ \\
\hline pTA929_HVO_2753_CHis & $\begin{array}{l}\text { Komplementation. } \\
\text { Basierend auf pTA929 (Allers et al., 2010) }\end{array}$ \\
\hline pTA929_HVO_2753_C12A_CHis & $\begin{array}{l}\text { Komplementation. } \\
\text { Basierend auf pTA929 (Allers et al., 2010) }\end{array}$ \\
\hline
\end{tabular}




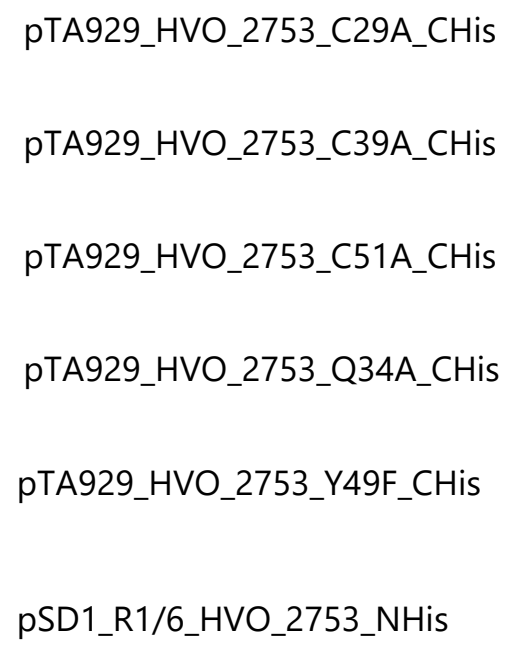

Komplementation.

Basierend auf pTA929 (Allers et al., 2010)

Komplementation.

Basierend auf pTA929 (Allers et al., 2010)

Komplementation.

Basierend auf pTA929 (Allers et al., 2010)

Komplementation.

Basierend auf pTA929 (Allers et al., 2010)

Komplementation.

Basierend auf pTA929 (Allers et al., 2010)

Homologe Überexpression des Gens HVO_2753 mit Nterminalem $\mathrm{His}_{6}$-Tag. Basierend auf pSD1/R1-6 (Danner \& Soppa, 1996)

\subsubsection{Software und Datenbanken}

\section{Tabelle 10: Tabelle der Software und der Datenbanken}

\begin{tabular}{ll}
\hline Bezeichnung & Hersteller/Referenz \\
\hline Clone Manager 8 & Scientific \& Educational Software, Denv \\
Mendeley & Mendeley, London (UK) \\
E.A.S.Y Win 32-Software & Herolab, Wiesloch \\
Softmax ${ }^{8}$ Pro Software & Molecular Devices, San José (USA) \\
MEGA X & Kumar et al. (2018) \\
Jalview Version 2 & Waterhouse et al. (2009) \\
Microsoft Office 365, Version 2002 & Microsoft Corporation, Redmond, USA \\
(Build 12527.20278) & \\
NanoDrop 3.5.1 & Coleman Technologies, Rockland, USA \\
BLAST & Altschul et al. (1990) \\
HaloLex (nicht öffentliche Datenbank) & Pfeiffer et al. (2008) \\
SnapGene Viewer 5.0.8 & GSL Biotech, Chicago (USA) \\
Integrated Genome Browser & Freese et al. (2016) \\
CLARIOstar V5.70 Edition 3 & BMG LABTECH, Ortenberg
\end{tabular}




\subsection{Mikrobiologische Methoden}

Alle Medien, Lösungen und Puffer wurden, insofern erforderlich, durch Autoklavieren bei $121^{\circ} \mathrm{C}$ und 1 bar Überdruck für 25 min oder durch Sterilfiltrieren $(0,4 \mu \mathrm{m}$ Porengröße) sterilisiert. Wenn nicht anders angegeben, erfolgte die Lagerung bei Raumtemperatur (RT). Festmedienplatten wurden bei $4{ }^{\circ} \mathrm{C}$ gelagert.

\subsubsection{Medien und Kultivierung von Haloferax volcanii}

$H$. volcanii wurde, insofern nicht anders angegeben, in Volumina von $30 \mathrm{ml}$ in $100 \mathrm{ml}$ Erlenmeyerkolben bei $42{ }^{\circ} \mathrm{C}$ und $250 \mathrm{rpm}$ kultiviert. Für Uracil-auxotrophe Stämme wurde dem entsprechenden Medium Uracil in einer Endkonzentration von $50 \mu \mathrm{g} / \mathrm{ml}$ zugegeben. Fand eine Selektion mittels Novobiocin statt, wurde dies in einer Endkonzentration von $0,4 \mu \mathrm{g} / \mathrm{ml}$ Medium hinzugefügt.

Für die Anzucht auf festem Medium wurde der Salzlösung des entsprechenden Mediums vor dem Autoklavieren 1,4\% (w/v) Agar hinzugefügt. Die Kultivierung erfolgte ebenfalls bei $42^{\circ} \mathrm{C}$.

In den folgenden Tabellen sind die Zusammensetzungen der verschiedenen Medienbestandteile und Medien für $H$. volcanii dargestellt (siehe Tabelle 11 und Tabelle 12, modifiziert nach Nieuwlandt \& Daniels (1990).

Tabelle 11: Zusammensetzung der Bestandteile des Komplexmediums für $\boldsymbol{H}$. volcanii. Dargestellt sind alle Komponenten des jeweiligen Bestandteils, die entsprechende Einwaage und die Endkonzentration im fertigen Medium.

\begin{tabular}{llll}
\hline Bestandteil & Komponente & Menge & Endkonzentration \\
\hline $\begin{array}{lll}\text { Salzlösung1) } \\
900 \mathrm{ml} / \mathrm{I}\end{array}$ & $\mathrm{NaCl}$ & $125 \mathrm{~g}$ & $2,1 \mathrm{M}$ \\
& $\mathrm{MgCl}_{2} \times 6 \mathrm{H}_{2} \mathrm{O}$ & $45 \mathrm{~g}$ & $220 \mathrm{mM}$ \\
& $\mathrm{MgSO}_{4} \times 7 \mathrm{H}_{2} \mathrm{O}$ & $10 \mathrm{~g}$ & $41 \mathrm{mM}$ \\
& $\mathrm{KCl}$ & $10 \mathrm{~g}$ & $13 \mathrm{mM}$
\end{tabular}




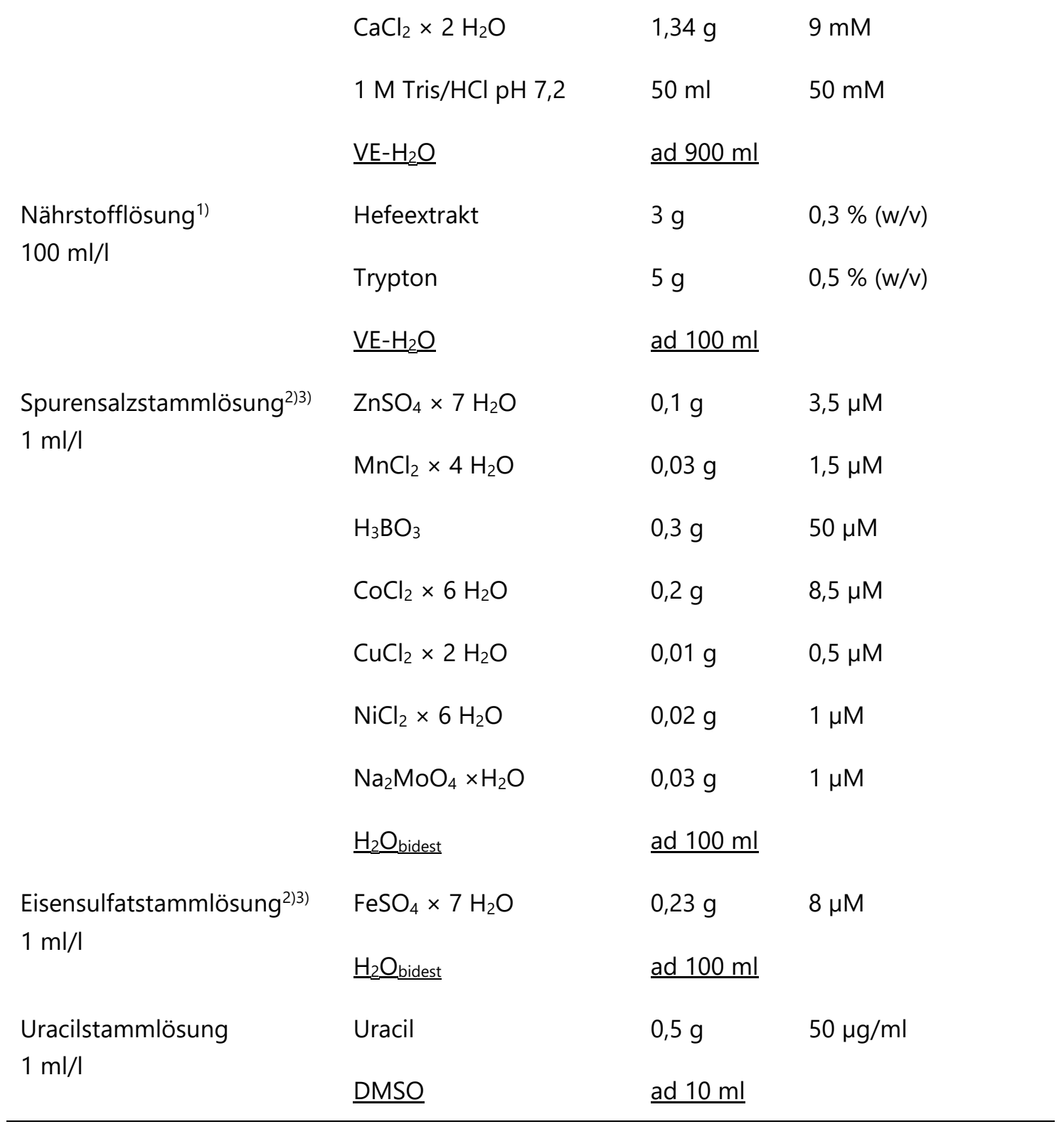

Diese Lösung wurde autoklaviert ${ }^{1)}$, sterilfiltriert ${ }^{2)}$ oder ihr $\mathrm{pH}-$ Wert auf 3-4 eingestellt ${ }^{3)}$

War es erforderlich $H$. volcanii unter definierten Bedingungen anzuziehen, wurde synthetisches Medium gewählt. Diesem lag als Hauptbestandteil ebenfalls die Salzlösung (siehe Tabelle 11) zu Grunde. Die weiteren Bestandteile sind in Tabelle 12 aufgeführt.

Zum Waschen von Zellen zum Beispiel beim Wechseln des Mediums oder um ein Inokulum zu erstellen, wurde Basalsalz verwendet. Diesem wiederum lag $900 \mathrm{ml}$ Salzlösung zu Grunde, welche mit sterilem VE- $\mathrm{H}_{2} \mathrm{O}$ auf 1 I aufgefüllt wurde. 
Tabelle 12: Zusammensetzung des synthetischen Mediums für $\boldsymbol{H}$. volcanii. Dargestellt sind alle Bestandteile, die entsprechende Einwaage und die Endkonzentration im fertigen Medium.

\begin{tabular}{|c|c|c|c|}
\hline Bestandteil & Komponente & Menge & Endkonzentration \\
\hline Salzlösung ${ }^{1)}$ & & $900 \mathrm{ml}$ & \\
\hline Spurensalzstammlösung ${ }^{1)}$ & & $1 \mathrm{ml}$ & \\
\hline Eisensulfatstammlösung ${ }^{1)}$ & & $1 \mathrm{ml}$ & \\
\hline Phosphatstammlösung ${ }^{2)}$ & $100 \mathrm{mM} \mathrm{K}_{2} \mathrm{HPO}_{4}$ & $10 \mathrm{ml}$ & $1 \mathrm{mM}$ \\
\hline $\begin{array}{l}\text { Ammoniumstammlö- } \\
\text { sung }{ }^{2)}\end{array}$ & $1 \mathrm{M} \mathrm{NH}_{4} \mathrm{Cl}$ & $10 \mathrm{ml}$ & $10 \mathrm{mM}$ \\
\hline Kohlenstoffquelle $\mathrm{e}^{2)}$ & $20 \%(w / v)$ Glukose & $25 \mathrm{ml}$ & $0,5 \%(w / v)$ \\
\hline Puffer ${ }^{2)}$ & $2 \mathrm{M}$ MOPS pH 7,2 & $50 \mathrm{ml}$ & $100 \mathrm{mM}$ \\
\hline Vitaminlösung ${ }^{3)}$ & & $1 \mathrm{ml}$ & $1 \mathrm{ml} / \mathrm{l}$ \\
\hline & $\underline{\text { steriles } V E-\mathrm{H}_{2}} \underline{\mathrm{O}}$ & $\underline{\operatorname{ad} 1000 \mathrm{ml}}$ & \\
\hline
\end{tabular}

Für diese Lösung ${ }^{1)}$ siehe Tabelle 1. Diese Lösung wurde autoklaviert²), oder kommerziell erworben ${ }^{3) !}$

\subsubsection{Medien und Kultivierung von Escherichia coli}

E. coli wurde, insofern nicht anders angegeben, in Volumina von $5 \mathrm{ml}$ in Reagenzgläsern oder $50 \mathrm{ml}$ in $100 \mathrm{ml}$ Erlenmeyerkolben bei $37^{\circ} \mathrm{C}$ und $250 \mathrm{rpm}$ kultiviert. Für eine Selektion mittels Ampicillin und/oder Kanamycin wurden diese in Endkonzentrationen von $100 \mu \mathrm{g} / \mathrm{ml}$ bzw. $50 \mu \mathrm{g} / \mathrm{ml}$ Medium hinzugefügt.

Für die Anzucht auf festem Medium wurde dem entsprechenden Medium vor dem Autoklavieren 1,2 \% (w/v) Agar hinzugefügt. Die Kultivierung erfolgte ebenfalls bei $37^{\circ} \mathrm{C}$.

In Tabelle 13 ist die Zusammensetzung des SOB Mediums nach Hanahan (1983) für E. coli dargestellt. 
Tabelle 13: Zusammensetzung des SOB Mediums für $\boldsymbol{E}$. coli. Die Zugabe von sterilfiltriertem $1 \mathrm{M} \mathrm{MgCl}_{2} / 1 \mathrm{M} \mathrm{MgSO}_{4}$ erfolgte nach dem Autoklavieren der anderen Komponenten.

\begin{tabular}{lll}
\hline Komponente & Menge & Endkonzentration \\
\hline Trypton & $20 \mathrm{~g}$ & $2 \%(\mathrm{w} / \mathrm{v})$ \\
Hefextrakt & $5 \mathrm{~g}$ & $0,5 \%(\mathrm{w} / \mathrm{v})$ \\
$\mathrm{NaCl}$ & $0,6 \mathrm{~g}$ & $10 \mathrm{mM}$ \\
$\mathrm{KCl}$ & $0,187 \mathrm{~g}$ & $2,5 \mathrm{mM}$ \\
$1 \mathrm{M} \mathrm{MgCl}_{2} / 1 \mathrm{M} \mathrm{MgSO}_{4}$ & $10 \mathrm{ml}$ & $10 \mathrm{mM} / 10 \mathrm{mM}$ \\
$\underline{\mathrm{VE} \mathrm{H}} 2 \mathrm{O}$ & $\underline{\mathrm{ad} 1000 \mathrm{ml}}$ & \\
\hline
\end{tabular}

\subsubsection{Erstellung von Dauerkulturen}

Für die dauerhafte Lagerung von $H$. volcanii wurden 25 ml einer stationären Kultur des jeweiligen Stamms in Szintillationsgefäße überführt und diese fest verschlossen. Diese Dauerkulturen wurden bei Raumtemperatur gelagert.

Für die dauerhafte Lagerung von E. coli wurde $1 \mathrm{ml}$ einer Übernachtkultur zu $1 \mathrm{ml}$ einer autoklavierten $67 \%$ igen Glycerinlösung gegeben, gemischt und bei $-80{ }^{\circ} \mathrm{C}$ gelagert.

\subsubsection{Wachstum in Mikrotiterplatten}

Die Wachstumsversuche wurden in Mikrotiterplatten mit Rundboden nach Jantzer et al. (2011) durchgeführt. Während der äußere Ring an Vertiefungen einer Mikrotiterplatte, um Verdunstungen der Kulturen zu minimieren, mit jeweils $200 \mu$ l einer sterilen $1 \mathrm{M} \mathrm{NaCl}$ Lösung befüllt wurde, befanden sich in den TestVertiefungen $150 \mu \mathrm{l}$ Kultur. Diese bestanden zu $130 \mu \mathrm{l}$ aus vorgelegtem Medium, welches anschließend mit $20 \mu \mathrm{l}$ Inokulum so beimpft wurde, dass eine Optische Dichte $\left(\mathrm{OD}_{600}\right)$ von 0,05 zu Beginn des Versuchs entstand. Das Inokulum ist eine Suspension von Zellen in Basalsalz, die zuvor mit Basalsalz gewaschen wurden, mit einer $\mathrm{OD}_{600}$ von 0,375. Die Inkubation der Zellen erfolgte bei $1050 \mathrm{rpm}$ und $42{ }^{\circ} \mathrm{C}$. Ein Wasserreservoir im Brutschrank sorgte für eine humide Umgebung. Die 
optische Dichte der Kulturen in den Vertiefungen wurde in regelmäßigen Abständen mittels Mikrotiterplattenphotometer bestimmt.

\subsubsection{Zelldichtebestimmung}

Die Bestimmung der Zelldichte einer Kultur bzw. Zellsuspension erfolgte in Küvetten mittels Spektralphotometer bei $600 \mathrm{~nm}$. Die Zellzahlbestimmung erfolgte mittels Neubauer-Zählkammer. Hierbei wurden 4 Großquadrate mit je 16 Kleinquadraten am Mikroskop ausgezählt und die Zellzahl pro Milliliter wie folgt berechnet:

$$
\text { Zellen } / m l=\frac{\text { gezählte Zellen } \times \text { Verdünnungsstufe }}{4 \times 16} \times 2 \times 10^{7}
$$

\subsubsection{Schwärmversuche}

Zur Analyse des Schwärmverhaltens verschiedener $H$. volcanii Stämme wurden Schwärmversuche durchgeführt. Hierfür wurde halbfestes Medium in Petrischalen oder Zellkulturplatten mit 6 Vertiefungen verwendet und definierte Volumina (30 $\mathrm{ml}$ in der Petrischale bzw $5 \mathrm{ml}$ pro Vertiefung) synthetischen Mediums mit 0,3\% (w/v) Agar und Glukose als Kohlenstoffquelle eingesetzt. Zur Inokulation der Platten wurde in die Mitte des abgekühlten Halbfestmediums mit einer sterilen Pipettenspitze eingestochen und $2 \mu$ l eines Inokulums in das halbfeste Medium pipettiert. Die Inokula wurden zuvor aus exponentiellen Vorkulturen erstellt. Dabei wurden die sedimentierten Zellen in entsprechenden Volumina Basalsalz aufgenommen, sodass alle Suspensionen eine einheitliche $\mathrm{OD}_{600}$ von 20 aufwiesen. Zum Schutz vor Austrocknung erfolgte die Inkubation zusammen mit einem Wasserreservoir in einer Styroporbox im Brutschrank bei $42{ }^{\circ} \mathrm{C}$.

\subsubsection{Biofilm-Assay}

Um die Biofilmbildung verschiedener $H$. volcanii Stämme vergleichen zu können, wurden Biofilm-Assays, modifiziert nach Legerme et al. (2016), durchgeführt. Die Herstellung der Inokula und die Anzuchtbedingungen waren hierbei identisch zu denen der Wachstumsversuche in Mikrotiterplatten (siehe 3.3.4). Die Inkubation erfolgte ebenfalls bei $1050 \mathrm{rpm}$ und $42^{\circ} \mathrm{C}$. Jedoch wurden hier Mikrotiterplatten mit Flachboden verwendet und es fand in jedem 20-minütigen Inkubationsintervall eine 4-minütige statische Inkubationsphase, ohne Schütteln der Platten, statt. 
Nach 32 h dieser Inkubationsintervalle fand eine abschließende statische Inkubation von $8 \mathrm{~h}$ statt. Bei vorläufigen Versuchen zur Biofilmbildung fand eine abweichende Inkubationsperiode der Zellen in den Mikrotiterplatten statt. Hier fand nach Inokulation der Medien in den Vertiefungen lediglich eine Inkubation bei $42{ }^{\circ} \mathrm{C}$ ohne Schütteln für $6 \mathrm{~h}$ statt.

Anschließend wurde der Biofilm-Assay wie folgt durchgeführt: Das Medium inklusive der planktonischen Zellen wurde vorsichtig abgenommen und die verbleibenden, adhärenten Zellen wurden mit $200 \mu$ l Fixierlösung (2 \% (v/v) Essigsäure in $1 \mathrm{M} \mathrm{NaCl}$ ) pro Vertiefung für 10 min fixiert. Die Fixierlösung wurde anschlieBend vorsichtig abgenommen und die Mikrotiterplatte für $30 \mathrm{~min}$ bei $37^{\circ} \mathrm{C}$ getrocknet. Nachfolgend fand die Färbung der Zellen mittels Färbelösung $(0,1 \%(w / v)$ Kristallviolett) für 10 min bei RT statt, bevor die Zellen dreimal mit jeweils $200 \mu \mathrm{H}_{2} \mathrm{O}_{\text {bidest }}$ gewaschen wurden. Danach wurden die Zellen in jeder Vertiefung mit $200 \mu$ l Entfärbelösung (10 \% (v/v) Essigsäure, 30 \% (v/v) Methanol) für 10 min bei RT entfärbt und die Lösung in eine neue Mikrotiterplatte überführt. Die Detektion fand im Mikrotiterplattenphotometer bei $\mathrm{OD}_{600}$ statt.

\subsection{Molekularbiologische Methoden}

\subsubsection{DNA-basierte Methoden}

\subsubsection{Isolierung plasmidischer DNA aus E. coli}

Die Isolierung von Plasmid-DNA aus E. coli im kleinen Maßstab erfolgte mittels Nucleospin ${ }^{\circledR}$ Plasmid Kit von Macherey-Nagel. Hierfür wurden 2-4 ml einer Übernachtkultur verwendet und nach Angaben des Herstellers verfahren.

Für die Isolierung im größeren Maßsstab wurde das GenElute ${ }^{\text {TM }}$ Plasmid Midiprep Kit von Sigma-Aldrich eingesetzt. Hierfür wurde eine $50 \mathrm{ml}$ Übernachtkultur verwendet und nach Angaben des Herstellers verfahren.

\subsubsection{Isolierung genomischer DNA aus $H$. volcanii}

Die Isolation genomischer DNA (gDNA) aus $H$. volcanii erfolgte mittels EthanolFällung. Zunächst wurden die Zellen aus $10 \mathrm{ml}$ einer exponentiellen Kultur bei 4000 rpm für 15 min bei RT sedimentiert (Centrifuge 5810 R mit Rotor A-4-62; Eppendorf, Hamburg). Das Sediment wurde in $300 \mu$ l Basalsalz resuspendiert, die 
Suspension mit 2,5 ml Lysepuffer versetzt und das Gefäß bis zur vollständigen Zelllyse geschwenkt. Die vorhandene wässrige Phase wurde anschließend mit $5 \mathrm{ml}$ Ethanol überschichtet und die dabei an der Phasengrenze ausfallende genomische DNA um eine Glaskapillare gewickelt. Die beiden Phasen wurden nach und nach mit der Glaskapillare vermischt und diese zur partiellen Dehydrierung der gDNA im Gefäß belassen. Die gebundene DNA konnte anschließend zweimal in Ethanol gewaschen und dieses danach durch zweimaliges Waschen in Diethylether entfernt werden. Nach 15-30 min Trocknen an der Luft wurde die Kapillare in $1 \mathrm{ml}$ TE-Puffer inkubiert, um die DNA vollständig zu lösen. Die Lagerung der gDNA erfolgte bei $4^{\circ} \mathrm{C}$. Die benötigten Lösungen sind in Tabelle 14 dargestellt.

Tabelle 14: Zusammensetzung der Lösungen für die Isolierung genomischer DNA aus $\boldsymbol{H}$. volcanii

\begin{tabular}{|c|c|c|c|}
\hline Bezeichnung & Komponente & Menge & Endkonzentration \\
\hline \multirow[t]{5}{*}{ Lyse-Puffer } & $\mathrm{NaCl}$ & $5,844 \mathrm{~g}$ & $100 \mathrm{mM}$ \\
\hline & $\begin{array}{l}1 \mathrm{M} \text { Tris/HCl-Stammlösung } \\
\mathrm{pH} 8\end{array}$ & $10 \mathrm{ml}$ & $10 \mathrm{mM}$ \\
\hline & $\mathrm{Na}_{2} \mathrm{EDTA}$ & $0,372 \mathrm{~g}$ & $1 \mathrm{mM}$ \\
\hline & SDS & $0,5 \mathrm{~g}$ & $0,05 \%(w / v)$ \\
\hline & $\underline{\mathrm{VE}-\mathrm{H}_{2}} \underline{\underline{\mathrm{O}}}$ & ad $1000 \mathrm{ml}$ & \\
\hline \multirow[t]{3}{*}{ TE-Puffer } & $\begin{array}{l}1 \mathrm{M} \text { Tris/HCl-Stammlösung } \\
\mathrm{pH} 8\end{array}$ & $10 \mathrm{ml}$ & $10 \mathrm{mM}$ \\
\hline & $\mathrm{Na}_{2} \mathrm{EDTA}$ & $0,372 \mathrm{~g}$ & $1 \mathrm{mM}$ \\
\hline & $\underline{\mathrm{VE}-\mathrm{H}_{2}} \underline{\mathrm{O}}$ & ad $1000 \mathrm{ml}$ & \\
\hline
\end{tabular}

\subsubsection{Photometrische Konzentrationsbestimmung von DNA}

Die photometrische Konzentrationsbestimmung von DNA erfolgte mittels Nanodrop 2000c (Thermo Fisher Scientific, Waltham, MA, USA). Hierbei wurden jeweils $1 \mu \mathrm{l}$ der zu analysierenden Probe als auch einer geeigneten Referenz eingesetzt. Bei der photometrischen Messung geben die Verhältnisse der Extinktion bei $260 \mathrm{~nm}$ und $280 \mathrm{~nm}$ (A260/A280) als auch bei $260 \mathrm{~nm}$ und $230 \mathrm{~nm}$ (A260/A230) 
Aufschluss über die Reinheit der DNA. Für nachfolgende Arbeiten mit der jeweiligen DNA-Probe wurde auf eine geeignete hohe Reinheit der DNA und entsprechende Verhältnisse von 1,8 (A260/A280) bzw. 1,8-2,2 (A260/A230) geachtet.

\subsubsection{Polymerase-Kettenreaktion (PCR)}

Die gezielte Amplifikation gewünschter DNA-Sequenzen erfolgte mittels Polymerase-Kettenreaktion (PCR). Das Prinzip der PCR basiert auf der Hitzedenaturierung einer doppelsträngigen DNA, die als Template dient, welches dabei in zwei Einzelstränge gespalten wird (Denaturierung). Am 5'- und 3'-Ende des zu amplifizierenden Bereichs lagern sich spezifische Oligonukleotidmoleküle an (Annealing), welche durch eine DNA-abhängige Polymerase in Anwesenheit freier dNTPs in 3'-Richtung verlängert werden (Elongation). Dieser Amplifikationszyklus wird anschließend wiederholt, wobei im vorangegangenen Zyklus erstellte Amplikons ebenfalls als Template dienen. Diese Amplifikation ist annährend exponentiell, sodass am Ende einer PCR eine sehr stark vervielfältigte Template-DNA vorliegt.

Auf diese Weise wurden DNA-Inserts für Klonierungen und DNA-Sonden für Northern-Blots (siehe 3.4.4.4) erstellt, ortsspezifische Punktmutationen eingebracht oder Transformanden mittels Kolonie-PCR überprüft. Da in dieser Arbeit mit dem Haloarchaeon $H$. volcanii gearbeitet wurde, der evolutionär bedingt aufgrund des hohen intrazellulären Salzgehaltes auch einen höheren GC-Gehalt in seiner DNA besitzt, wurde hier ein entsprechend angepasster GC-Gehalt im Desoxynukleosidtriphosphat-Mix (dNTP-Mix) verwendet. Des Weiteren kamen je nach Bedarf zwei verschiedene DNA-Polymerasen zum Einsatz. Die kommerziell erhältliche Phusion-Polymerase wurde verwendet, wenn eine hohe Präzision erforderlich war, da diese eine Korrekturlesefähigkeit (3'-5'-Exonukleaseaktivität) aufweist. Sie hat eine Syntheserate von circa 2000 bp pro Minute. Im Gegenzug dazu besitzt die Taq-Polymerase, welche in einer laborinternen Eigenisolation hergestellt wurde, keine Korrekturlesefähigkeit und eine Syntheserate von ca. 1000 bp pro Minute. Die Zusammensetzung des Taq-Polymerase-Puffers und der dNTP-Mix-Stammlösung befindet sich in Tabelle 15. 
Tabelle 15: Zusammensetzung des Taq-Polymerase-Puffers und des StandarddNTP-Mixes für $\boldsymbol{H}$. volcanii-PCRs

\begin{tabular}{llll}
\hline Bezeichnung & Komponente & Menge & Endkonzentration \\
\hline dNTP-Mix & $100 \mathrm{mM}$ dATP & $100 \mu \mathrm{l}$ & $1 \mathrm{mM}$ \\
& $100 \mathrm{mM} \mathrm{dTTP}$ & $100 \mu \mathrm{l}$ & $1 \mathrm{mM}$ \\
& $100 \mathrm{mM} \mathrm{dGTP}$ & $150 \mu \mathrm{l}$ & $1,5 \mathrm{mM}$ \\
& $100 \mathrm{mM}$ dCTP & $150 \mu \mathrm{l}$ & $1,5 \mathrm{mM}$ \\
& $\underline{\mathrm{H}}_{2} \underline{\mathrm{O}}_{\text {bidest }}$ & $\underline{\text { ad } 10 \mathrm{ml}}$ & \\
10×Taq-Polymerase- & $\mathrm{KCl}$ & $3,75 \mathrm{~g}$ & $500 \mathrm{mM}$ \\
Puffer & Tris/HCl pH 9 & $1,2 \mathrm{~g}$ & $100 \mathrm{mM}$ \\
& Triton X-100 & $1 \mathrm{~g}$ & $1 \%(\mathrm{w} / \mathrm{v})$ \\
& $\underline{\mathrm{H}}_{2} \underline{\mathrm{O}_{\text {bidest }}}$ & $\underline{\mathrm{ad} 100 \mathrm{ml}}$ & \\
\hline
\end{tabular}

$\underline{\text { Standard-PCR }}$

In der Standard-PCR wurden Inserts erstellt, die anschließend in einen geeigneten Vektor kloniert werden konnten. Der PCR-Ansatz, der für die Standard-PCR eingesetzt wurde, ist in Tabelle 16 gezeigt. Hier wurde die Taq-DNA-Polymerase aus laborinterner Eigenisolation verwendet.

Tabelle 16: Zusammensetzung eines Standard-PCR-Ansatzes. Dargestellt sind alle Komponenten, die entsprechende Menge für drei verschiedene Reaktionsvolumina und die Endkonzentration im fertigen Reaktionsansatz.

\begin{tabular}{lccccl}
\hline Komponente & \multicolumn{3}{c}{ Menge } & \multicolumn{1}{c}{ Endkonzentration } \\
\hline $25 \mathrm{mM} \mathrm{MgCl}_{2}$ & 1,2 & 3 & 6 & $\mu \mathrm{l}$ & $1,5 \mathrm{mM}$ \\
$\begin{array}{l}10 \times \text { Taq-Polymerase-Puf- } \\
\text { fer }\end{array}$ & 2 & 5 & 10 & $\mu \mathrm{l}$ & $1 \times$ \\
dNTP-Mix & 3,2 & 8 & 16 & $\mu \mathrm{l}$ & $160 / 240 \mu \mathrm{M}$ \\
$\begin{array}{l}10 \mu \mathrm{M} \text { Oligonukleotid- } \\
\text { Primer forward }\end{array}$ & 1 & 2,5 & 5 & $\mu \mathrm{l}$ & $0,5 \mu \mathrm{M}$ \\
$10 \mu \mathrm{M}$ Oligonukleotid- & 1 & 2,5 & 5 & $\mu \mathrm{l}$ & $0,5 \mu \mathrm{M}$ \\
Primer reverse & & & & &
\end{tabular}




$\begin{array}{lccccc}\text { DMSO } & 1,2 & 3 & 6 & \mu \mathrm{l} & 6 \%(\mathrm{v} / \mathrm{v}) \\ \text { Taq-Polymerase } & 0,2 & 0,5 & 1 & \mu \mathrm{l} & - \\ \text { Template-DNA } & \mathrm{x} & \mathrm{x} & \mathrm{x} & \mu \mathrm{l} & 1-5 \mathrm{ng} / \mu \mathrm{l} \\ \underline{\mathrm{H}}_{2} \underline{\mathrm{O}}_{\text {bidest }} & \underline{\mathrm{ad} 20} & \underline{\mathrm{ad} 50} & \underline{\mathrm{ad} 100} & \mu \mathrm{l} & \end{array}$

Eine solche Standard-PCR wurde nach dem PCR-Cycler-Programm durchgeführt, das in Tabelle 17 beschrieben ist.

Tabelle 17: PCR Cycler-Programm für eine Standard-PCR

$\left.\begin{array}{lll}\text { Initiale Denaturierung } & 96{ }^{\circ} \mathrm{C} & 5 \mathrm{~min} \\ \hline \text { Denaturierung } & 96{ }^{\circ} \mathrm{C} & 30 \mathrm{sec} \\ \text { Annealing } & 3-7^{\circ} \mathrm{C} \text { unter } \mathrm{T}_{\mathrm{m}} \mathrm{der} & 30 \mathrm{sec} \\ \text { Oligonukleotid-Primer } & 1 \mathrm{~min} / \mathrm{kb}\end{array}\right] 25 \times$

\section{Fusions-PCR}

Für die Erstellung von Deletionsplasmiden für die Pop-In/Pop-Out-Methode (siehe 3.4.3) war es zunächst nötig, ein jeweils circa 500 bp großes upstream- und ein downstream-Fragment vom zu deletierenden Bereich mittels PCR zu amplifizieren. Nach der Aufreinigung der beiden Fragmente mittels E.Z.N.A. Cycle Pure Kit von VWR International wurden diese in einer Fusions-PCR miteinander fusioniert, sodass ein Bereich entstand, der gegenüber dem wildtypischen Bereich die entsprechende in frame-Deletion aufwies. Für die Fusions-PCR wurden zunächst 200 ng jedes Fragments in einen PCR-Ansatz ohne Oligonukleotid-Primer eingesetzt und ein erster Fusionsschritt mit 5 Zyklen durchgeführt, bei dem sich die beiden Fragmente aufgrund komplementärer Überhänge an den OligonukleotidPrimern der einander zugewandten Seiten anlagerten und mittels Polymerase die komplementären Stränge synthetisiert wurden. Die anschließende Zugabe des 5'und 3'-terminalen Oligonukleotid-Primers des Fusionsfragmentes und der zweite Fusionsschritt ermöglichten die exponentielle Amplifikation des gesamten Fusi- 
onsfragmentes. Der Ablauf der Zweischritt-Fusions-PCR ist in Tabelle 18 dargestellt. Für die hier eingesetzten PCRs wurde die Phusion ${ }^{\mathrm{TM}}$ High-Fidelity DNA-Polymerase nach Angaben des Herstellers verwendet.

Tabelle 18: PCR Cycler-Programm für eine Zweischritt-Fusions-PCR

$\left.\begin{array}{lll}\text { Initiale Denaturierung } & 98{ }^{\circ} \mathrm{C} & 5 \mathrm{~min} \\ \hline \text { Denaturierung } & 98{ }^{\circ} \mathrm{C} & 30 \mathrm{sec} \\ \text { Annealing } & 68{ }^{\circ} \mathrm{C} & 1 \mathrm{~min} \\ \text { Elongation } & 72{ }^{\circ} \mathrm{C} & 1 \mathrm{~min} / \mathrm{kb}\end{array}\right] 5 \times$

\section{Sonden-PCR}

Die Sonden-PCR diente der Herstellung von spezifischen Digoxigenin-11-dUTP (DIG-dUTP)-markierten Doppelstrang- und Einzelstrang-DNA-Sonden (dsDNA/ssDNA-Sonden). Mithilfe dieser lassen sich im Northern-Blot spezifisch Zielfragmente nachweisen, an welche die Sonden hybridisieren (siehe 3.4.4.4). Diese PCR setzt dTTP-limitierende Bedingungen voraus, weshalb hierbei ein dNTP-Mix verwendet wird, der im Vergleich zum Standard-dNTP-Mix (siehe Tabelle 15) nur 0,2 mM dTTP enthält. Die Taq-Polymerase verwendet nun anteilig DIG-dUTP anstelle von dTTPs bei der Synthese. Diese Synthese ist jedoch verlangsamt, weshalb die Elongationszeit entsprechend verlängert wurde. Als Template-DNA diente bei einer Sonden-PCR immer H. volcanii Wildtyp gDNA und wurde in einer Menge von $250 \mathrm{ng}$ pro $100 \mu \mathrm{l}$ Reaktion eingesetzt. Für die Generierung jeder Sonde wurde zunächst ein Standard-PCR-Ansatz (siehe Tabelle 16), mit dem veränderten dNTP-Mix, angesetzt, jedoch nur auf $99 \mu$ aufgefüllt. Dieser wurde anschließend auf zwei gleiche Teile aufgeteilt und zum einen Teil, dem Kontroll-Ansatz, 0,5 $\mu$ l $\mathrm{H}_{2} \mathrm{O}$ gegeben, während dem Sonden-Ansatz 0,5 $\mu$ I DIG-dUTP zugefügt wurde. 
Nach der PCR wurden $5 \mu$ des Sonden-Ansatzes und $5 \mu l$ des Kontroll-Ansatzes zusammen mit Ladepuffer mittels Agarose-Gelelektrophorese aufgetrennt und analysiert (siehe 3.4.1.5). Durch das DIG-dUTP in der Sonde, muss diese in der Elektrophorese ein verzögertes Laufverhalten zeigen. Tabelle 19 zeigt das PCRCycler-Programm für eine dsDNA-Sonde.

Tabelle 19: PCR Cycler-Programm für eine dsDNA-Sonden-PCR

$\left.\begin{array}{lll}\text { Initiale Denaturierung } & 96{ }^{\circ} \mathrm{C} & 5 \mathrm{~min} \\ \hline \text { Denaturierung } & 96{ }^{\circ} \mathrm{C} & 30 \mathrm{sec} \\ \text { Annealing } & \begin{array}{l}3-7^{\circ} \mathrm{C} \text { unter } \mathrm{T}_{\mathrm{m}} \text { der } \\ \text { Oligonukleotid-Primer }\end{array} & 30 \mathrm{sec} \\ \text { Elongation } & 72{ }^{\circ} \mathrm{C} & 4 \mathrm{~min} / \mathrm{kb}\end{array}\right] 25 \times$

Die Erstellung einer ssDNA-Sonde erforderte ein doppelsträngiges Template, das genau dem Bereich der künftigen Sonde entspricht. Hierzu wurde eine $100 \mu \mathrm{l}-$ Standard-PCR mit den Forward- und Reverse-Oligonukleotid-Primern durchgeführt und das doppelsträngige PCR-Produkt zunächst mit dem E.Z.N.A. Cycle Pure Kit von VWR International aufgereinigt. Für die Generierung der eigentlichen ssDNA-Sonde wurde nun eine PCR-Reaktion ähnlich zur dsDNA-Sonden-PCR durchgeführt, bei der jedoch nur der Oligonukleotid-Primer eingesetzt wurde, der für die Synthese des Strangs benötigt wurde, der komplementär zum sense Strang liegt. Auch das PCR-Cycler-Programm für die ssDNA-Sonde weicht von dem der dsDNA-Sonde $a b$, da durch die Verwendung nur eines Primers keine exponentielle Amplifikation, sondern nur eine lineare Amplifikation erreicht wird. Das entsprechende Programm ist in Tabelle 20 zu sehen.

\section{Tabelle 20: PCR Cycler-Programm für eine ssDNA-Sonden-PCR}

$\left.\left.\begin{array}{lll}\text { Initiale Denaturierung } & 96{ }^{\circ} \mathrm{C} & 5 \mathrm{~min} \\ \hline \text { Denaturierung } & 96{ }^{\circ} \mathrm{C} & 30 \mathrm{sec} \\ \text { Annealing } & 3-7^{\circ} \mathrm{C} \text { unter } \mathrm{T}_{\mathrm{m}} \mathrm{der} & 30 \mathrm{sec} \\ \text { Oligonukleotid-Primer } & 4 \mathrm{~min} / \mathrm{kb}\end{array}\right]\right\} 100 \times$




\section{Ortsspezifische Mutagenese}

Zur Einbringung ortsspezifischer Mutationen wurde eine site-directed mutagenesis durchgeführt. Dabei wurden Oligonukleotid-Primer nach Vorgaben des QuikChange ${ }^{\circledR}$ Site-Directed Mutagenesis Kit von Stratagene (San Diego, USA) designt. Der PCR-Ansatz und das PCR-Cylcer-Programm für die ortsspezifische Mutagenese sind in Tabelle 21 und Tabelle 22 dargestellt.

Tabelle 21: Zusammensetzung eines PCR-Ansatzes für die ortsspezifische Mutagenese. Dargestellt sind alle Komponenten, die entsprechende Menge und die Endkonzentration im fertigen Reaktionsansatz.

\begin{tabular}{|c|c|c|}
\hline Komponente & Menge & Endkonzentration \\
\hline $5 \times G C$-Puffer & $10 \mu \mathrm{l}$ & $1 \times$ \\
\hline dNTP-Mix & $8 \mu \mathrm{l}$ & $160 / 240 \mu \mathrm{M}$ \\
\hline $10 \mu \mathrm{M}$ Oligonukleotid- & $x$ & 125 ng/Ansatz \\
\hline \multicolumn{3}{|l|}{ Primer forward } \\
\hline $10 \mu \mathrm{M}$ Oligonukleotid- & $x$ & 125 ng/Ansatz \\
\hline \multicolumn{3}{|l|}{ Primer reverse } \\
\hline DMSO & $1,5 \mu \mathrm{l}$ & $3 \%(v / v)$ \\
\hline Phusion-Polymerase & $1 \mu l$ & - \\
\hline Template-Plasmid-DNA & $x$ & 50 ng/Ansatz \\
\hline$\underline{\mathrm{H}}_{2} \underline{\mathrm{O}}_{\text {bidest }}$ & $\underline{\operatorname{ad} 50 \mu \mathrm{l}}$ & \\
\hline
\end{tabular}

Bei der Ortsspezifischen Mutagenese wird das Klonierungsplasmid pBluescriptSK(+) verwendet, in das zuvor das entsprechende Gen, in das die Mutation eingeführt werden soll, kloniert wurde. Während eines Zyklus der PCR wird jeweils das ganze Plasmid amplifiziert, weshalb eine DNA-Polymerase mit Korrekturlesefunktion eingesetzt werden musste und die Dauer des Elongationschrittes dementsprechend lange war. Nach Abschluss der PCR wurde die Template-Plasmid-DNA mit dem Restriktionsenzym Dpnl gespalten, indem dieses im Überschuss $(2 \mu \mathrm{l})$ direkt in den $50 \mu \mathrm{l}$ Reaktionsansatz gegeben wurde und eine 60minütige Inkubation bei $37^{\circ} \mathrm{C}$ erfolgte. Die enzymatische Reaktion wurde anschließend für 7 min bei $80^{\circ} \mathrm{C}$ gestoppt. 
Tabelle 22: PCR Cycler-Programm für die Ortsspezifische Mutagenese

$\left.\begin{array}{lll}\text { Initiale Denaturierung } & 98{ }^{\circ} \mathrm{C} & 5 \mathrm{~min} \\ \hline \text { Denaturierung } & 98{ }^{\circ} \mathrm{C} & 30 \mathrm{sec} \\ \text { Annealing } & 55^{\circ} \mathrm{C} & 30 \mathrm{sec} \\ \text { Elongation } & 72{ }^{\circ} \mathrm{C} & 4 \mathrm{~min}\end{array}\right]=16 \times$

\section{$\underline{\text { Kolonie-PCR }}$}

Die Kontrolle einer Vielzahl an Transformanden erfolgte mittels Kolonie-PCR. Hierbei wurden Einzelkolonien von E. coli oder $H$. volcanii von der Selektivagarplatte mit einer sterilen Pipettenspitze auf eine Sicherungsagarplatte und anschließend, im Falle von E. coli, direkt weiter als Template in den entsprechenden Reaktionsansatz überführt. Bei $H$. volcanii erfolgte nach der Sicherungsplatte die Überführung zunächst in $50 \mu \mathrm{H}_{2} \mathrm{O}_{\text {bidest, }}$ um zu vermeiden, dass die hohen intrazellulären Salzkonzentrationen die Effizienz der PCR mindern oder diese gar behindern. Als Template für die PCR wurde in diesem Fall $1 \mu$ l der $50 \mu$ l Lösung eingesetzt. Der Zellaufschluss erfolgte bei der Kolonie-PCR automatisch durch den

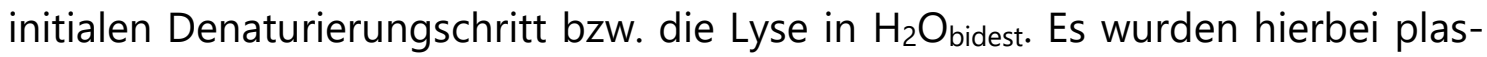
midspezifsche Oligonukleotid-Primer verwendet. Die restlichen Komponenten und das PCR-Cycler-Programm waren analog zur Standard-PCR.Gelelektrophoretische Auftrennung von DNA

Die Auftrennung von DNA fand mittels Agarose-Gelelektrophorese statt. Hierfür wurden Agarosekonzentrationen von 0,7 \% bis 1,8 \% (w/v) eingesetzt. Tris-BoratEDTA diente hierbei als Puffersystem. Je nach Größe und Agarosekonzentration wurde eine Spannung von 80-180 V angelegt, bis die gewünschte Auftrennung erreicht war. Aufschluss hierfür gab die Bromphenolblau-Laufbande aus dem Ladepuffer. Die Zusammensetzung der Stammlösungen der verwendeten Puffer sind in Tabelle 23 dargestellt. Nach der Elektrophorese fand eine Inkubation für $15 \mathrm{~min}$ im Ethidiumbromidfärbebad $(2 \mu \mathrm{l} / \mathrm{ml})$ statt, bevor die Ergebnisse unter UV-Licht dokumentiert werden konnten. 
Tabelle 23: Zusammensetzungen der Puffer für die DNA-Gelelektrophorese

\begin{tabular}{|c|c|c|c|}
\hline Bezeichnung & Komponente & Menge & Endkonzentration \\
\hline \multirow[t]{4}{*}{ 10× TBE-Puffer } & Tris & $107,82 \mathrm{~g}$ & $0,89 \mathrm{M}$ \\
\hline & $\mathrm{H}_{3} \mathrm{BO}_{3}$ & $55,03 \mathrm{~g}$ & $0,89 \mathrm{M}$ \\
\hline & $\mathrm{Na}_{2}$ EDTA & $7,45 \mathrm{~g}$ & $0,02 \mathrm{M}$ \\
\hline & $\underline{\text { VE- }-\mathrm{H}_{2}} \underline{\mathrm{O}}$ & $\underline{\text { ad } 1000 \mathrm{ml}}$ & \\
\hline \multirow[t]{6}{*}{$6 \times$ Ladepuffer } & Tris & $121 \mathrm{mg}$ & $10 \mathrm{mM}$ \\
\hline & Harnstoff & $42 \mathrm{~g}$ & $7 \mathrm{M}$ \\
\hline & EDTA & $813 \mathrm{mg}$ & $28 \mathrm{mM}$ \\
\hline & 87 \% Glycerin & $40 \mathrm{ml}$ & $34,8 \%(v / v)$ \\
\hline & Bromphenolblau & $100 \mathrm{mg}$ & $0,1 \%(w / v)$ \\
\hline & $\underline{\mathrm{VE}-\mathrm{H}_{2}} \underline{\mathrm{O}}$ & $\underline{\text { ad } 100 \mathrm{ml}}$ & \\
\hline
\end{tabular}

3.4.1.6 Spaltung von DNA mittels Restriktionsenzymen

Die Spaltung von DNA fand mittels Restriktionsenzymen von Thermo Fisher Scientific (Waltham, MA, USA) nach Herstellerangaben statt. Hierbei wurden sowohl die gewöhnlichen als auch die modifizierten FastDigest Enzyme verwendet.

\subsubsection{Ligation von DNA-Fragmenten}

Für die Ligation von DNA-Fragmenten wurde zunächst für das molare Verhältnis 1:3 von Vektor zu Insert die Menge an Insert berechnet, die eingesetzt werden musste. Die sticky end-Ligationen wurden nach Herstellerangaben durchgeführt. Für blunt end-Ligationen fand das Schema in Tabelle 24 Anwendung. Hierfür wurde eine Inkubation bei einem Temperaturgradienten über Nacht, mittels Eisbades bei $37^{\circ} \mathrm{C}$, verwendet.

Tabelle 24: Zusammensetzung eines Ansatzes einer Blunt-end-Ligation in Anwesenheit des entsprechenden Restriktionsenzyms

\begin{tabular}{lc}
\hline Komponente & Menge \\
\hline Plasmid $(50 \mathrm{ng})$ & variabel \\
Insert & variabel \\
T4 DNA-Ligase & $1 \mu \mathrm{l}$
\end{tabular}


10x Puffer des jew. Restriktionsenzyms

Restriktionsenzym

10 mM ATP
$2 \mu l$
$1 \mu \mathrm{l}$
$2 \mu \mathrm{l}$

$\underline{\operatorname{ad} 20 \mu \mathrm{l}}$

\subsubsection{Sequenzierung}

Die Sequenzierung von DNA-Bereichen in Plasmiden oder von PCR-Produkten wurde von Eurofins GATC (Köln) durchgeführt. Die Probenvorbereitung und - zusammensetzung erfolgte nach Vorgaben des Dienstleisters.

\subsubsection{Transformationen von Mikroorganismen}

\subsubsection{Herstellung kompetenter E. coli}

Für die Herstellung kompetenter E. coli-Zellen nach Inoue et al. (1990) für nachfolgende Hitzeschock-Transformationen wurden zunächst $250 \mathrm{ml}$ SOB-Medium mit einer Übernachtkultur auf eine Start- $\mathrm{OD}_{600}$ von 0,05 angeimpft. Die Kultur wurde bei $37^{\circ} \mathrm{C}$ unter Schütteln bis zu einer $\mathrm{OD}_{600}$ von 0,6 angezogen und anschließend zunächst für 10 min auf Eis abgekühlt und danach für 10 min bei $2.500 \times \mathrm{g}$ und $4{ }^{\circ} \mathrm{C}$ zentrifugiert. Der Überstand wurde verworfen und das Zellsediment in $80 \mathrm{ml}$ eiskaltem TB-Puffer (siehe Tabelle 25) resuspendiert, für 10 min auf Eis inkubiert und erneut für $10 \mathrm{~min}$ bei $2.500 \times \mathrm{g}$ und $4{ }^{\circ} \mathrm{C}$ zentrifugiert. Der Überstand wurde wieder verworfen und das Sediment in $20 \mathrm{ml}$ TB-Puffer resuspendiert. Nach Zugabe von 1,4 ml DMSO zu einer Endkonzentration von $7 \%(\mathrm{v} / \mathrm{v})$ und vorsichtigem Schwenken, erfolgte eine erneute Inkubation auf Eis für 10 min. Abschließend wurden $200 \mu \mathrm{l}$ Aliquots hergestellt, diese in flüssigem Stickstoff eingefroren und bei $-80^{\circ} \mathrm{C}$ bis zur Verwendung für eine Hitzeschock-Transformation gelagert. 
Tabelle 25: Zusammensetzung des TB-Puffers für die Herstellung kompetenter E. coli

\begin{tabular}{|c|c|c|}
\hline Komponente & Menge & Endkonzentration \\
\hline MOPS & $0,21 \mathrm{~g}$ & $10 \mathrm{mM}$ \\
\hline $\mathrm{CaCl}_{2}$ & $0,22 \mathrm{~g}$ & $15 \mathrm{mM}$ \\
\hline $\mathrm{KCl}$ & $1,86 \mathrm{~g}$ & $250 \mathrm{mM}$ \\
\hline$\underline{\mathrm{H}}_{2} \underline{\mathrm{O}}_{\text {bidest }}$ & ad $90 \mathrm{ml}$ & \\
\hline \multicolumn{3}{|l|}{$\mathrm{pH} 6,8$ mit $\mathrm{KOH}$} \\
\hline $\mathrm{MnCl}_{2}$ & $0,89 \mathrm{~g}$ & $55 \mathrm{mM}$ \\
\hline$\underline{\mathrm{H}}_{2} \underline{\mathrm{O}}_{\text {bidest }}$ & ad $100 \mathrm{ml}$ & \\
\hline
\end{tabular}

\subsubsection{Transformation von E. coli}

Die Transformation von E. coli erfolgte mittels Hitzeschock. Hierfür wurde zunächst ein Aliquot kompetenter Zellen auf Eis aufgetaut und anschließend pro Transformations-Ansatz $100 \mu$ l Zellen mit 50 ng Plasmid-DNA oder $5 \mu$ l Ligationsansatz versetzt und zunächst für 10 min auf Eis inkubiert. Anschließend erfolgte der Hitzeschock bei $42^{\circ} \mathrm{C}$ für $60 \mathrm{sec}$. Nach dem anschließenden Abkühlen auf Eis für mindestens 2 min wurde sowohl eine 1:100 Verdünnung als auch der verbleibende gesamte Ansatz auf jeweils eine SOB-Festmediumplatte, die das entsprechende Antibiotikum enthielt, ausplattiert und diese über Nacht bei $37^{\circ} \mathrm{C}$ inkubiert.

\subsubsection{Transformation von $H$. volcanii}

Für die Transformation von $H$. volcanii wurden $2 \mathrm{ml}$ einer Kultur in der exponentiellen Wachstumsphase bei 8.000 rpm für 2 min abzentrifugiert. Das Zellsediment wurde in $180 \mu \mathrm{l}$ SBL/EDTA-Lösung vorsichtig resuspendiert und mit $20 \mu \mathrm{l}$ DNA-Lösung versetzt. Vor einer 5-minütigen Inkubation erfolgte das Mischen durch 20-maliges Umdrehen der Reaktionsgefäße. Nun wurden $210 \mu$ l PEG-Lösung in den Deckel des Reaktionsgefäßes pipettiert, dieses geschlossen und durch rasches Schwenken beide Lösungen miteinander vermischt, bis keine Schlieren mehr vorhanden waren. Nach einer Inkubation bei RT für 20 min erfolgte die Zugabe von $1600 \mu \mathrm{l}$ SVL. Abschließend konnten $100 \mu$ les Ansatzes 
und von geeigneten Verdünnungen auf entsprechende Selektivfestmedienplatten ausplattiert und bei $42^{\circ} \mathrm{C}$ für mehrere Tage inkubiert werden. Die Zusammensetzung aller benötigten Lösungen ist Tabelle 26 dargestellt.

Tabelle 26: Zusammensetzung aller benötigten Lösungen für die Transformation von $\boldsymbol{H}$. volcanii

\begin{tabular}{|c|c|c|c|}
\hline Bezeichnung & Komponente & Menge & Endkonzentration \\
\hline \multirow{5}{*}{$\begin{array}{l}\text { Sphäroblastenbil- } \\
\text { dungslösung (SBL) }\end{array}$} & $\mathrm{NaCl}$ & $23,37 \mathrm{~g}$ & $0,8 \mathrm{M}$ \\
\hline & $\mathrm{KCl}$ & $1 \mathrm{~g}$ & $27 \mathrm{mM}$ \\
\hline & $1 \mathrm{M}$ Tris/HCl pH 8,2 & $25 \mathrm{ml}$ & $50 \mathrm{mM}$ \\
\hline & Saccharose & $75 \mathrm{~g}$ & $15 \%(w / v)$ \\
\hline & $\underline{\mathrm{H}}_{2} \underline{\mathrm{O}}_{\text {bidest }}$ & ad $500 \mathrm{ml}$ & \\
\hline \multirow{7}{*}{$\begin{array}{l}\text { Sphäroblastenver- } \\
\text { dünnungslösung } \\
\text { (SVL) }\end{array}$} & $\mathrm{NaCl}$ & $100 \mathrm{~g}$ & $3,4 \mathrm{M}$ \\
\hline & $\mathrm{MgSO}_{4} \times 7 \mathrm{H}_{2} \mathrm{O}$ & $21,6 \mathrm{~g}$ & $175 \mathrm{mM}$ \\
\hline & $\mathrm{KCl}$ & $1,25 \mathrm{~g}$ & $34 \mathrm{mM}$ \\
\hline & $1 \mathrm{M}$ Tris/HCl pH 7,2 & $25 \mathrm{ml}$ & $50 \mathrm{mM}$ \\
\hline & $\mathrm{CaCl}_{2} \times 2 \mathrm{H}_{2} \mathrm{O}$ & $0,36 \mathrm{~g}$ & $5 \mathrm{mM}$ \\
\hline & Saccharose & $75 \mathrm{~g}$ & $15 \%(w / v)$ \\
\hline & $\underline{\mathrm{H}}_{2} \underline{\mathrm{O}}_{\text {bidest }}$ & ad $500 \mathrm{ml}$ & \\
\hline \multirow{2}{*}{$\begin{array}{l}\text { EDTA-Lösung } \\
\mathrm{pH} 8\end{array}$} & EDTA & $18,5 \mathrm{~g}$ & $0,5 \mathrm{M}$ \\
\hline & $\underline{\mathrm{H}}_{2} \underline{\mathrm{O}}_{\text {bidest }}$ & ad $100 \mathrm{ml}$ & \\
\hline \multirow[t]{2}{*}{ SBL/EDTA-Lösung } & SBL & $900 \mu \mathrm{l}$ & $90 \%(v / v)$ \\
\hline & EDTA-Lösung & $100 \mu \mathrm{l}$ & $10 \%(v / v)$ \\
\hline \multirow[t]{2}{*}{ PEG-Lösung } & PEG 600 & $6 \mathrm{ml}$ & $60 \%(v / v)$ \\
\hline & SBL & $4 \mathrm{ml}$ & $40 \%(v / v)$ \\
\hline \multirow[t]{3}{*}{ DNA-Lösung } & Plasmid-DNA & $3 \mu \mathrm{g}$ & \\
\hline & $4 \mathrm{M} \mathrm{NaCl}$ & $4 \mu l$ & $0,8 \mathrm{M}$ \\
\hline & $\underline{\mathrm{H}}_{2} \underline{\mathrm{O}}_{\text {bidest }}$ & $\underline{\operatorname{ad} 20 \mu \mathrm{l}}$ & \\
\hline
\end{tabular}




\subsubsection{Erzeugung von Deletionsmutanten mittels Pop-In/Pop-Out-Methode}

Die Pop-In/Pop-Out-Methode nach Bitan-banin et al. (2003) erlaubt eine markerlose und basengenaue Deletion von chromosomalen Genen und Genabschnitten in $H$. volcanii. Eine Weiterentwicklung dieser Methode erfolgte durch Hammelmann \& Soppa (2008).

Für die Deletion des Zielbereichs müssen zunächst seine beiden miteinander fusionierten flankierenden Bereiche in den, in $H$. volcanii nicht-replikativen Ausgangsvektor pMH101, eingebracht werden. Die Fusionierung der flankierenden Bereiche fand zuvor in einer Fusions-PCR statt (siehe 3.4.1.4, Abschnitt "Fusions$\left.P C R^{\prime \prime}\right)$. Der so generierte Deletionsvektor wird dann für eine Transformation mit dem entsprechenden Uracil-auxotrophen Elternstamm, zumeist $H$. volcanii $\mathrm{H} 26$, verwendet. Der Deletionsvektor trägt das pyrE2-Gen, welches in dem Elternstamm deletiert vorliegt. Nach der Transformation des nicht-replikativen Vektors muss dieser über ein homologes Rekombinationsereignis ins Genom an die Stelle der zukünftigen Deletion eingebracht werden. Die Selektion erfolgt anschließend über ein Uracil-freies Festmedium, sodass nur Zellen erhalten werden, die den Deletionsvektor ins Genom integriert haben, den sogenannten Pop-In-Mutanten. Diese wurden anschließend durch Umsetzen auf Festmedienplatten, welche sowohl Uracil als auch 5-Fluororotsäure (5-FOA) enthielten, selektiert. Nur durch ein zweites homologes Rekombinationsereignis, bei dem der Vektor wieder aus dem Genom entfernt wird, waren die Zellen überlebensfähig. Denn das Umsetzen von 5-FOA durch das pyrE2-codierte Enzym resultiert in dem toxischen 5-Fluoruracil. So wurden nach der Selektion nur die sogenannten Pop-Out-Methoden erhalten. Die homologen Rekombinationsereignisse konnten jeweils über den ersten oder den zweiten komplementären Bereich stattfinden, was beim ersten Mal nur zu unterschiedlichen Anordnungen des Wildtyp-Gens und der Deletionskassette führte, beim zweiten Ereignis jedoch wiederum zum Entstehen des Wildtyps (zu 50 \%) oder der gewünschten Deletionsmutante (zu 50 \%). Eine schematische Darstellung der Pop-In-/Pop-Out-Methode ist in Abbildung 3 dargestellt. Die per Kolonie-PCR (siehe 3.4.1.4, Abschnitt „Kolonie-PCR”) identifizierten Deletionsmutanten wurden anschließend 5-mal in Komplexmedium überimpft, bevor eine abschließende Analyse mittels 40-Zyklen-Test-PCR durchgeführt wurde. In dieser PCR wurde der Bereich amplifiziert, der die Deletion überspannt, sodass zwischen 
Wildtyp, Pop-In-Mutante und Deletionsmutante hochsensitiv unterschieden und eine homozygote Deletionsmutante nachgewiesen werden kann.

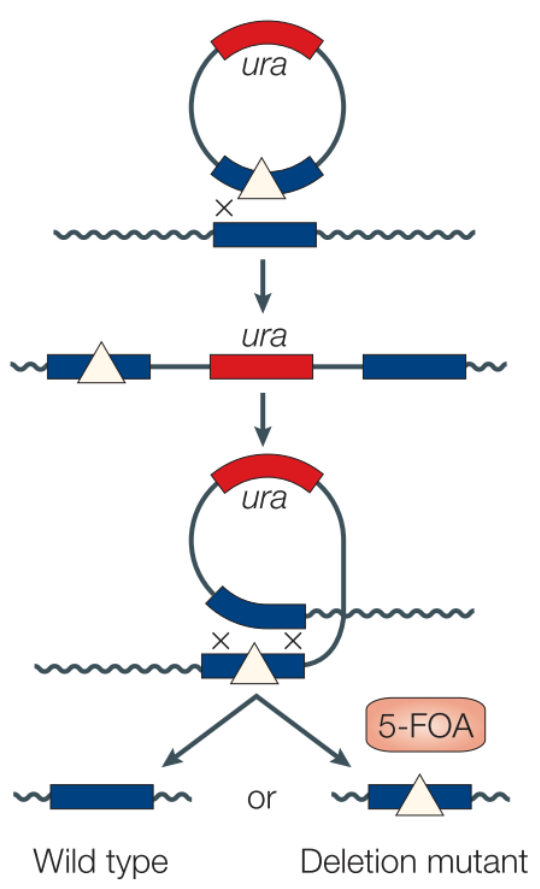

Abbildung 3: Schematische Darstellung der Pop-In/Pop-Out-Methode. Zwei homologe Rekombinationsereignisse führen zunächst zum chromosomalen Einbau des Deletionsvektors und später zum Verlust dessen. Am Ende entstehen mit gleicher Wahrscheinlichkeit Wildtyp oder Deletionsmutante. Abbildung entnommen und modifiziert aus Allers \& Mevarech (2005).

\subsubsection{RNA-basierte Methoden}

\subsubsection{Isolierung und Reinigung von RNA}

Alle RNA-basierten Arbeiten wurden in einer RNase-freien Umgebung durchgeführt. Für die Herstellung aller Lösungen und Puffer wurde DEPC-behandeltes Wasser verwendet. Hierfür wurde $\mathrm{H}_{2} \mathrm{O}_{\text {bidest }}$ mit $0,1 \%(\mathrm{v} / \mathrm{v})$ DEPC versetzt, über Nacht gerührt und anschließend für 45 min autoklaviert.

Für die Isolierung von RNA aus $H$. volcanii mittels Phenol-Chloroform-Isoamylalkohol-Extraktion wurden zunächst $2 \mathrm{ml}$ einer exponentiellen Kultur bei 13.000 rpm für 1 min zentrifugiert und das Sediment in $400 \mu$ l Aufschlusslösung (siehe Tabelle 27) resuspendiert. Nach Zugabe von $50 \mu \mathrm{l} 2 \mathrm{M}$ Natriumacetat ( $\mathrm{pH} 4$ ) wurde das $2 \mathrm{ml}$ Reaktionsgefäß verschlossen und für $15 \mathrm{~s}$ geschüttelt. Nach der Zugabe von $500 \mu \mathrm{I}$ ROTI ${ }^{\circledR}$ Aqua-P/C/I wurde erneut 15 s geschüttelt. Jetzt erfolgte eine Inkubation bei $-20{ }^{\circ} \mathrm{C}$ für mindestens $30 \mathrm{~min}$ und anschließend eine 
Zentrifugation bei $4{ }^{\circ} \mathrm{C}$ und $13.000 \mathrm{rpm}$ für $15 \mathrm{~min}$. Die hierbei entstandene obere, wässrige Phase wurde nun abgenommen und in ein frisches 1,5 $\mathrm{ml}$ Reaktionsgefäß überführt. Für alle nachfolgenden Schritte wurde die RNA auf Eis gehalten. Die Fällung der RNA erfolgte anschließend durch Zugabe von $1 \mathrm{ml}$ eiskaltem, $96 \%$ igem ( $/ \mathrm{v}$ ) Ethanol und einer Inkubation bei $-20^{\circ} \mathrm{C}$ für mindestens $30 \mathrm{~min}$. Sollte besonders die Isolation von kleinen RNAs sichergestellt werden, wurde hier über Nacht inkubiert. Es erfolgte eine Zentrifugation bei $4{ }^{\circ} \mathrm{C}$ und 13.000 rpm für $30 \mathrm{~min}$. Der Überstand wurde verworfen und das Sediment mit $1 \mathrm{ml}$ eiskaltem, 70 \%igem (v/v) Ethanol gewaschen - es erfolgte hier keine Resuspension. Nach der Wiederholung des eben erfolgten Zentrifugationsschrittes, wurde der Überstand erneut verworfen und das RNA-Sediment nach Lufttrocknung in $30 \mu \mathrm{LEPC}-\mathrm{H}_{2} \mathrm{O}$ für $10 \mathrm{~min}$ bei $60^{\circ} \mathrm{C}$ gelöst. Die erhaltene RNA wurde einer photometrischen Konzentrationsbestimmung (siehe 3.4.4.2) und einer Integritätskontrolle mittels RNA-Gelelektrophorese (siehe 3.4.4.3) unterzogen. Wurde der Qualitätsstandard erreicht, war die so erhaltene RNA verfügbar für analytische RNA-Gelelektrophorese und Northern Blots.

Für Anwendungen wie RNA-Sequenzierung oder DNA-Adapter-Ligationen und cDNA-Synthese war eine höhere Reinheit der RNA und vollständige Abwesenheit von DNA erforderlich. Hierfür erfolgten im Anschluss an die zuvor beschriebene RNA-Isolierung folgende weitere Schritte, in Anlehnung an Heidrich et al. (2015):

Das entsprechende Volumen für ca. $20 \mu \mathrm{g}$ RNA wurde in ein frisches Reaktionsgefäß überführt und mit DEPC- $\mathrm{H}_{2} \mathrm{O}$ auf 39,5 $\mu$ l aufgefüllt. Nach einer Denaturierung bei $65^{\circ} \mathrm{C}$ für $5 \mathrm{~min}$, wurde die Probe für 5 min auf Eis abgekühlt. Um DNAVerunreinigungen in der Probe zu beseitigen erfolgte ein DNase I-Verdau. Hierfür wurden $5 \mu$ l DNase I-Puffer (inkl. $\mathrm{MgCl}_{2}$ ), 0,5 $\mu$ l SUPERase. $\ln ^{\mathrm{TM}}$ RNase Inhibitor $(20 \mathrm{U} / \mu \mathrm{l})$ und $5 \mu \mathrm{l}$ DNase I $(1 \mathrm{U} / \mu \mathrm{l})$ zugegeben und der Ansatz für $30 \mathrm{~min}$ bei $37^{\circ} \mathrm{C}$ inkubiert. Um die nun enthaltene DNase zu entfernen erfolgte wieder eine Phenol-Chloroform-Extraktion. Zunächst wurde die Probe mit DEPC- $\mathrm{H}_{2} \mathrm{O}$ auf ein Volumen von $100 \mu \mathrm{l}$ aufgefüllt und diese anschließend zu $100 \mu \mathrm{l}$ ROTI ${ }^{\circledR}$ Aqua-P/C/I, vorgelegt in einem frischen $2 \mathrm{ml}$-Reaktionsgefäß, gegeben. Das verschlossene Gefäß wurde $15 \mathrm{~s}$ geschüttelt und anschließend für $15 \mathrm{~min}$ bei $4^{\circ} \mathrm{C}$ und 13.000 rpm zentrifugiert. Der Überstand wurde in ein frisches Reaktionsgefäß überführt. Die RNA-Fällung erfolgte durch Zugabe von 2,5 Volumina eines 30:1 
RNA-Präzipitations-Mixes (Ethanol: 3 M Natriumacetat, $\mathrm{pH}$ 6,5) und einer Inkubation bei $-20{ }^{\circ} \mathrm{C}$ über Nacht. Jetzt konnte durch eine 30-minütige Zentrifugation bei $4{ }^{\circ} \mathrm{C}$ und $13.000 \mathrm{rpm}$ die RNA gefällt und der Überstand anschließend verworfen werden. Das Sediment wurde mit $1 \mathrm{ml}$ eiskaltem, 70 \%igem (v/v) Ethanol gewaschen - es erfolgte insbesondere keine Resuspension. Nach der Wiederholung des eben erfolgten Zentrifugationsschrittes, wurde der Überstand erneut verworfen und das RNA-Sediment nach Lufttrocknung in $20 \mu \mathrm{DEPC}-\mathrm{H} 2 \mathrm{O}$ für $10 \mathrm{~min}$ bei $60{ }^{\circ} \mathrm{C}$ gelöst. Die erhaltene RNA wurde hier erneut einer photometrischen Konzentrationsbestimmung (siehe 3.4.4.2) und einer Integritätskontrolle mittels RNAGelelektrophorese (siehe 3.4.4.3) unterzogen. Zusätzlich wurde die Abwesenheit von genomischer DNA mittels 40 Zyklen-Test-PCR überprüft, bei der Oligonukleotide gegen das kleine, beliebig ausgewählte Gen HVO_2983A verwendet wurden. Wurde der Qualitätsstandard erreicht, war die so erhaltene RNA verfügbar für RNA-Sequenzierung oder DNA-Adapter-Ligationen und CDNA-Synthese (siehe 3.4.4.5).

Tabelle 27: Zusammensetzung der Aufschlusslösung für die RNA-Isolierung aus H. volcanii

\begin{tabular}{lll}
\hline Komponente & Menge & Endkonzentration \\
\hline $\begin{array}{l}750 \mathrm{mM} \text { Natriumcitrat } \\
(\mathrm{pH} 7)\end{array}$ & $7 \mathrm{ml}$ & $25 \mathrm{mM}$ \\
$30 \%(\mathrm{w} / \mathrm{v}) \mathrm{N}$-Lauroylsarco- & $3,5 \mathrm{ml}$ & $0,5 \%(\mathrm{w} / \mathrm{v})$ \\
sinat & $1 \mathrm{ml}$ & $0,48 \%(\mathrm{v} / \mathrm{v})$ \\
$\beta$-Mercaptoethanol & $100 \mathrm{~g}$ & $4 \mathrm{M}$ \\
Guanidiniumthiocyanat & $\underline{\text { ad } 210 \mathrm{ml}}$ & \\
$\underline{\mathrm{H}_{2}}$ & & \\
\hline
\end{tabular}

3.4.4.2 Photometrische Konzentrationsbestimmung von RNA

Die photometrische Konzentrationsbestimmung von RNA erfolgte analog zu der von DNA (siehe 3.4.1.3). Für nachfolgende Arbeiten mit der jeweiligen RNA-Probe wurde auf eine geeignete hohe Reinheit der RNA und entsprechende Verhältnisse von 2,0 (A260/A280) bzw. 1,8-2,2 (A260/A230) geachtet. 


\subsubsection{Gelelektrophoretische Auftrennung von RNA}

Für die Kontrolle der Integrität isolierter RNA oder zur gezielten Transkriptanalyse mittels nachfolgendem Northern Blot wurde eine analytische, denaturierende RNA-Gelelektrophorese durchgeführt. Hierfür wurden zwischen 100 und 500 ng bzw. 2 bis $10 \mu \mathrm{g}$ RNA pro Spur eingesetzt.

Das Agarosegel wurde immer frisch hergestellt. Dabei wurde zunächst die entsprechende Menge an Agarose für ein 1-1,6 \%iges Gel mit dem Endvolumen von ca. $80 \mathrm{ml}$ in 68,6 ml DEPC- $\mathrm{H}_{2} \mathrm{O}$ aufgekocht und unter Rühren $8 \mathrm{ml}$ 10-fach MOPSPuffer (siehe Tabelle 28) zugegeben. Nachdem die Lösung auf ca. $60{ }^{\circ} \mathrm{C}$ abgekühlt war, wurden 2,86 ml 37 \%-ige (w/v) Formaldehydlösung zugegeben. Nach weiterem Rühren konnte das Gel gegossen werden. Die RNA-Proben und $1 \mu$ l pro Spur der Größenstandards RiboRuler ${ }^{\mathrm{TM}}$ RNA Ladder High Range bzw. RiboRuler ${ }^{\mathrm{TM}}$ RNA Ladder High Range wurden mit dem 3-fachen an RNA-Probenpuffer versetzt und für 10 min bei $60^{\circ} \mathrm{C}$ inkubiert, bevor sie auf Eis abgekühlt wurden. Die Gelelektrophorese wurde bei $120 \mathrm{~V}$, unter Verwendung von 1-fach MOPS-Puffer als Laufpuffer, durchgeführt, bis die gewünschte Auftrennung erreicht war. Die Ergebnisse konnten unter UV-Licht dokumentiert werden.

Tabelle 28: Zusammensetzungen der für die RNA-Gelelektrophorese benötigten Puffer

\begin{tabular}{|c|c|c|c|}
\hline Bezeichnung & Komponente & Menge & Endkonzentration \\
\hline \multirow{4}{*}{$\begin{array}{l}\text { 10-fach MOPS- } \\
\text { Puffer } \\
\text { pH } 7\end{array}$} & MOPS & $104,7 \mathrm{~g}$ & $500 \mathrm{mM}$ \\
\hline & & & \\
\hline & EDTA & $3,7 \mathrm{~g}$ & $10 \mathrm{mM}$ \\
\hline & $\underline{\mathrm{DEPC}-\mathrm{H}_{2}} \underline{\mathrm{O}}$ & ad $1000 \mathrm{ml}$ & \\
\hline \multirow[t]{7}{*}{ RNA-Probenpuffer } & 10-fach MOPS-Puffer & $1 \mathrm{ml}$ & 1-fach \\
\hline & $100 \%$ Formamid & $5 \mathrm{ml}$ & $50 \%(v / v)$ \\
\hline & 37 \% Formaldehyd & $1,84 \mathrm{ml}$ & $6,8 \%(v / v)$ \\
\hline & 87 \% Glycerin & $1,34 \mathrm{ml}$ & $11,7 \%(v / v)$ \\
\hline & $3 \%(w / v)$ Bromphenolblau & $100 \mu l$ & $0,03 \%(w / v)$ \\
\hline & Ethidiumbromid $(0,1 \mathrm{mg} / \mathrm{ml})$ & $150 \mu l$ & $1,5 \mu \mathrm{g} / \mathrm{ml}$ \\
\hline & $\underline{\mathrm{DEPC}-\mathrm{H}_{2}} \underline{\underline{\mathrm{O}}}$ & $\underline{570 \mu \mathrm{l}}$ & \\
\hline
\end{tabular}




\subsubsection{Northern Blot}

Die Northern-Blot Analyse stellt eine hochsensitive Methode zur Untersuchung von Transkripten dar. Hierbei kann eine relative, quantitative Transkriptlevelbestimmung erfolgen und eine Aussage über die Transkriptlänge getroffen werden. Für einen Northern Blot werden RNA-Gele nach der Elektrophorese verwendet, wie sie unter 3.4.4.3 erstellt werden.

Auf 15 Blatt Blottingpapier der Stärke 1,4 mm wurden 3 Blatt Blottingpapier der Stärke 0,37 mm gestapelt. Darauf wurde eine positiv geladene Nylonmembran, das Gel und erneut 3 Blatt Blottingpapier der Stärke 0,37 mm gelegt. Die Nylon-

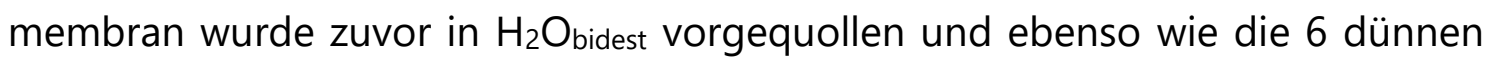
Blatt Blottingpapier in 20 × SSC-Puffer äquilibriert. Auf den Stapel wurde nun eine Pufferbrücke aus Blottingpapier der Stärke 0,37 mm gelegt, die den Blottstapel mit zwei Reservoirs an 20x SSC-Puffer links und rechts davon verband. Der so entstandene Stapel wurde mit dem Gelschlitten und einem Gewicht darauf beschwert und über Nacht stehen gelassen. Alle benötigten Lösungen sind in Tabelle 29 dargestellt.

Tabelle 29: Zusammensetzung der benötigten Lösungen und Puffer für den Northern-Blot

\begin{tabular}{|c|c|c|c|}
\hline Bezeichnung & Komponente & Menge & Endkonzentration \\
\hline \multirow{3}{*}{$\begin{array}{l}\text { Methylenblaulösung } \\
\text { pH } 5\end{array}$} & Methylenblau & $0,04 \mathrm{~g}$ & $0,04 \%(w / v)$ \\
\hline & Natriumacetat & $4,1 \mathrm{~g}$ & $0,5 \mathrm{M}$ \\
\hline & $\underline{\mathrm{DEPC}-\mathrm{H}_{2}} \underline{\mathrm{O}}$ & ad $100 \mathrm{ml}$ & \\
\hline \multirow{3}{*}{$\begin{array}{l}20 \times \text { SSC-Puffer } \\
\mathrm{pH} 7\end{array}$} & $\mathrm{NaCl}$ & $175,3 \mathrm{~g}$ & $3 \mathrm{M}$ \\
\hline & tri-Natriumcitrat $\times 2 \mathrm{H}_{2} \mathrm{O}$ & $88,2 \mathrm{~g}$ & $300 \mathrm{mM}$ \\
\hline & $\underline{\mathrm{VE}-\mathrm{H}_{2}} \underline{\mathrm{O}}$ & $\underline{\mathrm{ad}} 1000 \mathrm{ml}$ & \\
\hline
\end{tabular}

Nach ca. 18 h Kapillarblotting wurde der Blot abgebaut, die Geltaschen mit einem Bleistift auf der Membran angezeichnet und diese im UV-Stratalinker bei $120 \mathrm{~mJ} / \mathrm{cm}^{2}$ mit der DNA quervernetzt.

Die Hybridisierung der Membran mit der Sonde erfolgte in einem Hybridisierungsröhrchen im Hybridisierungsofen. Zunächst wurde die Membran mit $10 \mathrm{ml}$ Hybridisierungspuffer mit $180 \mu \mathrm{g} / \mathrm{ml}$ Hefe-tRNA für $1 \mathrm{~h}$ unter langsamem Drehen 
bei $50{ }^{\circ} \mathrm{C}$ vorhybridisiert. Die verbleibenden $45 \mu \mathrm{l}$ des Sonden-Ansatzes (siehe 3.4.1.4, Abschnitt "Sonden-PCR") wurden für 10 min bei $95 \mathrm{C}$ denaturiert und zu frischen $10 \mathrm{ml}$ Hybridisierungspuffer mit $180 \mu \mathrm{g} / \mathrm{ml}$ Hefe-tRNA gegeben. Nach der Vorhybridisierung wurden die $10 \mathrm{ml}$ verworfen und die Sonde im Hybridisierungspuffer zugegeben. Die Hybridisierung erfolgte ebenfalls bei $50^{\circ} \mathrm{C}$ unter langsamem Drehen über Nacht. Die benötigten Lösungen sind in Tabelle 30 dargestellt.

Tabelle 30: Zusammensetzung der benötigten Lösungen und Puffer für die Hybridisierung beim Northern-Blot

\begin{tabular}{|c|c|c|c|}
\hline Bezeichnung & Komponente & Menge & Endkonzentration \\
\hline \multirow{4}{*}{$\begin{array}{l}\text { 100× Denhardt- } \\
\text { Lösung }^{1)}\end{array}$} & Rinderserumalbumin & $10 \mathrm{~g}$ & $2 \%(w / v)$ \\
\hline & Ficoll 400 & $10 \mathrm{~g}$ & $2 \%(w / v)$ \\
\hline & Polyvinylpyrolidon & $10 \mathrm{~g}$ & $2 \%(w / v)$ \\
\hline & $\underline{\mathrm{VE}-\mathrm{H}_{2}} \underline{\underline{\mathrm{O}}}$ & $\underline{\text { ad } 500 \mathrm{ml}}$ & \\
\hline \multirow{7}{*}{$\begin{array}{l}\text { Hybridisierungs- } \\
\text { puffer }^{2)}\end{array}$} & $20 \times$ SSC-Puffer & $250 \mathrm{ml}$ & $5 \times$ \\
\hline & $100 \times$ Denhardt-Lösung ${ }^{1}$ & $30 \mathrm{ml}$ & $3 x$ \\
\hline & SDS & $5 \mathrm{~g}$ & $0,5 \%(w / v)$ \\
\hline & $30 \%(\mathrm{w} / \mathrm{v}) \mathrm{N}$-Laroylsarcosin & $6,7 \mathrm{ml}$ & $0,2 \%(w / v)$ \\
\hline & Dextransulfat & $50 \mathrm{~g}$ & $5 \%(w / v)$ \\
\hline & $\underline{\mathrm{VE}-\mathrm{H}_{2}} \underline{\underline{\mathrm{O}}}$ & ad $500 \mathrm{ml}$ & \\
\hline & Formamid & $500 \mathrm{ml}$ & $50 \%(v / v)$ \\
\hline
\end{tabular}

Zunächst durch Faltenfilter filtriert und anschließend bei $-20^{\circ} \mathrm{C}$ gelagert ${ }^{1}$. Lösung vor der Zugabe von Formamid autoklaviert ${ }^{2}$.

Für den abschließenden Chemolumineszenz-Nachweis wurde die Hybridisierungslösung mit der Sonde nach der Inkubation über Nacht entfernt, die Membran gewaschen und anschließend entwickelt. Alle dafür nötigen Schritte zeigt Tabelle 31 und die verwendeten Puffer und Lösungen zeigt Tabelle 32. 
Tabelle 31: Schritte der Entwicklung während dem Chemolumineszenz-Nachweis beim Northern-Blot

\begin{tabular}{lllll}
\hline Dauer & $\begin{array}{l}\text { Tempe- } \\
\text { ratur }\end{array}$ & Komponente & Anzahl & $\begin{array}{l}\text { Drehge- } \\
\text { schwindigkeit }\end{array}$ \\
\hline $5 \mathrm{~min}$ & $50^{\circ} \mathrm{C}$ & $2 \times \mathrm{SSC}$-Puffer, $0,1 \% \mathrm{SDS}(\mathrm{w} / \mathrm{v})$ & $2 \times$ & schnell \\
$15 \mathrm{~min}$ & $50^{\circ} \mathrm{C}$ & $1 \times \mathrm{SSC}-$ Puffer, $0,1 \% \mathrm{SDS}(\mathrm{w} / \mathrm{v})$ & $2 \times$ & schnell \\
$10 \mathrm{sec}$ & $\mathrm{RT}$ & Waschpuffer & $1 \times$ & schnell \\
$30 \mathrm{~min}$ & $\mathrm{RT}$ & 20 ml Blockingpuffer & $1 \times$ & langsam \\
$30 \mathrm{~min}$ & $\mathrm{RT}$ & Antikörperlösung & $1 \times$ & langsam \\
$15 \mathrm{~min}$ & $\mathrm{RT}$ & Waschpuffer & $2 \times$ & schnell \\
$5 \mathrm{~min}$ & RT & Detektionspuffer & $1 \times$ & langsam \\
$5 \mathrm{~min}$ & RT & CDP-Star-Lösung & $1 \times$ & langsam \\
\hline
\end{tabular}

Tabelle 32: Zusammensetzung der Puffer und Lösungen für den Chemolumineszenz-Nachweis beim Northern-Blot

\begin{tabular}{|c|c|c|c|}
\hline Bezeichnung & Komponente & Menge & Endkonzentration \\
\hline \multirow{3}{*}{$\begin{array}{l}\text { Maleinsäurepuffer } \\
\mathrm{pH} 7,5\end{array}$} & Maleinsäure & $11,6 \mathrm{~g}$ & $100 \mathrm{mM}$ \\
\hline & $\mathrm{NaCl}$ & $8,77 \mathrm{~g}$ & $150 \mathrm{mM}$ \\
\hline & $\underline{\mathrm{H}}_{2} \underline{\mathrm{O}}_{\text {bidest }}$ & $\underline{\mathrm{ad}} 1000 \mathrm{ml}$ & \\
\hline \multirow[t]{2}{*}{ Waschpuffer } & Tween ${ }^{\circledR} 20$ & $1,5 \mathrm{ml}$ & $0,3 \%(v / v)$ \\
\hline & $\underline{\text { Maleinsäurepuffer }}$ & $\underline{\text { ad } 500 \mathrm{ml}}$ & \\
\hline \multirow[t]{2}{*}{ Blockingpuffer } & Blocking Reagenz & $10 \mathrm{~g}$ & $1 \%(w / v)$ \\
\hline & $\underline{\text { Maleinsäurepuffer }}$ & ad $1000 \mathrm{ml}$ & \\
\hline \multirow[t]{2}{*}{ Antikörperlösung } & Anti-DIG-AP & $1 \mu \mathrm{l}$ & $1: 20.000$ \\
\hline & Blockingpuffer & $\underline{\text { ad } 20 \mathrm{ml}}$ & \\
\hline
\end{tabular}




\begin{tabular}{|c|c|c|c|}
\hline \multirow{4}{*}{$\begin{array}{l}\text { Detektionspuffer } \\
\mathrm{pH} \mathrm{9,5}\end{array}$} & Tris/HCl & $12,11 \mathrm{~g}$ & $100 \mathrm{mM}$ \\
\hline & $\mathrm{NaCl}$ & $5,84 \mathrm{~g}$ & $100 \mathrm{mM}$ \\
\hline & $\mathrm{MgCl}_{2} \times 6 \mathrm{H}_{2} \mathrm{O}$ & $10,17 \mathrm{~g}$ & $50 \mathrm{mM}$ \\
\hline & $\underline{\mathrm{H}}_{2} \underline{\mathrm{O}}_{\text {bidest }}$ & ad $1000 \mathrm{ml}$ & \\
\hline \multirow[t]{2}{*}{ CDP-Star-Lösung } & CDP-Star & $10 \mu \mathrm{l}$ & 1:1.500 \\
\hline & Detektionspuffer & $\underline{\text { ad } 15 \mathrm{ml}}$ & \\
\hline
\end{tabular}

3.4.4.5 DNA-Adapter-Ligation und cDNA-Synthese

Zur Identifikation von möglichen RNA-Bindepartnern des Zielproteins wurde nachfolgendes Protokoll etabliert. Hierfür wurde zunächst das Zielprotein homolog überproduziert und aus Elutionsfraktionen der Affinitätsaufreinigung (siehe 3.5.1.1) RNA isoliert (siehe 3.4.4.1). Diese konnte dann im nachfolgenden Ablauf, wie in Tabelle 33 zu sehen ist, verwendet werden. 
Tabelle 33: Ablauf der DNA-Adapter-Ligation und cDNA-Synthese zur Identifikation von RNA-Bindepartnern. Die Protokollnummern beziehen sich auf die jeweiligen Pipettierschemata in Tabelle 34.

\begin{tabular}{|c|c|c|c|c|}
\hline Nr. & Bezeichnung & Temperatur & Dauer & $\begin{array}{l}\text { Protokoll- } \\
\text { Nummer }\end{array}$ \\
\hline 1 & DNA-Adapter Ligation ans 3'-Ende der RNA & $25^{\circ} \mathrm{C}$ & $2 \mathrm{~h}$ & (1) \\
\hline 2 & $\begin{array}{l}\text { Aufreinigung mittels Monarch RNA Cleanup } \\
\text { Kit (Elution in } 20 \mu \mathrm{l} \text { ) }\end{array}$ & - & - & - \\
\hline 3.1 & First-Strand cDNA-Synthese & $\begin{array}{l}70^{\circ} \mathrm{C} \\
\text { auf Eis }\end{array}$ & $\begin{array}{l}5 \min \\
5 \min \end{array}$ & (2) \\
\hline 3.2 & First-Strand cDNA-Synthese & $\begin{array}{l}25^{\circ} \mathrm{C} \\
42^{\circ} \mathrm{C} \\
70^{\circ} \mathrm{C}\end{array}$ & $\begin{array}{l}5 \mathrm{~min} \\
1 \mathrm{~h} \\
15 \mathrm{~min}\end{array}$ & (3) \\
\hline 4 & $\begin{array}{l}\text { RNase H-Verdau der RNA im RNA:DNA- } \\
\text { Hybrid }\end{array}$ & $37^{\circ} \mathrm{C}$ & $30 \mathrm{~min}$ & (4) \\
\hline 5 & $\begin{array}{l}\text { Aufreinigung mittels Monarch PCR \& DNA } \\
\text { Cleanup Kit (Elution in } 10 \mu \mathrm{l} \text { ) }\end{array}$ & - & - & - \\
\hline 6 & $\begin{array}{l}\text { DNA-Adapter Ligation ans 3'-Ende der } \\
\text { CDNA }\end{array}$ & $25^{\circ} \mathrm{C}$ & $>16 \mathrm{~h}$ & (5) \\
\hline 7 & $\begin{array}{l}\text { Aufreinigung mittels Monarch PCR \& DNA } \\
\text { Cleanup Kit (Elution in } 10 \mu \mathrm{l} \text { ) }\end{array}$ & - & - & - \\
\hline 8 & $\begin{array}{l}\text { Second-Strand cDNA-Synthese } \\
\text { wie Standard-PCR, jedoch } 5 \text { min Elongation } \\
\text { und } 40 \text { Zyklen }\end{array}$ & & & (6) \\
\hline 9 & $\begin{array}{l}\text { Aufreinigung mittels Monarch PCR \& DNA } \\
\text { Cleanup Kit (Elution in } 20 \mu \mathrm{l} \text { ) }\end{array}$ & - & - & - \\
\hline
\end{tabular}

Tabelle 34: Pipettierschemata der verschiedenen Reaktionsansätze während der DNA-Adapter-Ligation und cDNA-Synthese

\begin{tabular}{lll}
\hline Nr. & Komponente & Menge \\
\hline (1) & 10× T4 RNA Ligase 1 Puffer & $2,5 \mu \mathrm{l}$ \\
& 10 mM ATP & $2,5 \mu \mathrm{l}$ \\
& $50 \%$ PEG 8000 & $9,5 \mu \mathrm{l}$ \\
& DMSO & $2,0 \mu \mathrm{l}$
\end{tabular}




\begin{tabular}{|c|c|c|}
\hline & SUPERase $\cdot$ In $^{\mathrm{TM}}$ RNase Inhibitor & $0,5 \mu l$ \\
\hline & T4 RNA Ligase 1 & $2,5 \mu l$ \\
\hline & RNA $(1-5 \mu g)$ & $4,0 \mu \mathrm{l}$ \\
\hline & DNA-Adapter $(100 \mu \mathrm{M})$ & $1,5 \mu l$ \\
\hline & gesamt & $25,0 \mu \mathrm{l}$ \\
\hline \multirow[t]{2}{*}{ (2) } & $\begin{array}{l}\text { Adapter-ligierte RNA nach „3.2“, siehe } \\
\text { Tabelle } 33\end{array}$ & $4 \mu l$ \\
\hline & $10 \mu \mathrm{M}$ DNA-Adapter Primer rev & $1 \mu \mathrm{l}$ \\
\hline \multirow[t]{8}{*}{ (3) } & Ansatz (2) nach „3.1”, siehe Tabelle 33 & $5 \mu l$ \\
\hline & GoScript $^{\mathrm{TM}} 5 \mathrm{X}$ Reaction Buffer & $4 \mu l$ \\
\hline & $25 \mathrm{mM} \mathrm{MgCl} 2$ & $2 \mu l$ \\
\hline & dNTP-Mix & $3 \mu l$ \\
\hline & SUPERase.In ${ }^{T M}$ RNase Inhibitor & $0,5 \mu \mathrm{l}$ \\
\hline & GoScript $^{\mathrm{TM}}$ Reverse Transcriptase & $1 \mu l$ \\
\hline & $\mathrm{H}_{2} \mathrm{O}$ & $4,5 \mu l$ \\
\hline & gesamt & $20 \mu \mathrm{l}$ \\
\hline \multirow[t]{2}{*}{ (4) } & Ansatz (3) nach „3.2”, siehe Tabelle 33 & $20 \mu \mathrm{l}$ \\
\hline & RNase H & $1 \mu l$ \\
\hline \multirow[t]{8}{*}{ (5) } & 10× T4 RNA Ligase 1 Puffer & $3,0 \mu \mathrm{l}$ \\
\hline & $10 \mathrm{mM}$ ATP & $3,0 \mu \mathrm{l}$ \\
\hline & $50 \%$ PEG 8000 & $15,0 \mu \mathrm{l}$ \\
\hline & T4 RNA Ligase 1 & $2,0 \mu \mathrm{l}$ \\
\hline & $\begin{array}{l}\text { einzelsträngige cDNA nach " } 5^{\prime \prime} \text {, siehe Ta- } \\
\text { belle } 33\end{array}$ & $4,0 \mu \mathrm{l}$ \\
\hline & DNA-Adapter $(100 \mu \mathrm{M})$ & $1,5 \mu \mathrm{l}$ \\
\hline & 20 mM Hexaammincobalt(III)-chlorid & $1,5 \mu \mathrm{l}$ \\
\hline & gesamt & $30 \mu \mathrm{l}$ \\
\hline \multirow[t]{8}{*}{ (6) } & $25 \mathrm{mM} \mathrm{MgCl} 2$ & $1,2 \mu l$ \\
\hline & $10 \times$ Taq-Polymerase-Puffer & $2 \mu l$ \\
\hline & dNTP-Mix & $3,2 \mu \mathrm{l}$ \\
\hline & 100 uM DNA-Adapter Primer rev & $1 \mu l$ \\
\hline & DMSO & $0,6 \mu \mathrm{l}$ \\
\hline & Taq-Polymerase & $0,4 \mu \mathrm{l}$ \\
\hline & $\begin{array}{l}\text { Adapter-ligierte einzelsträngige cDNA } \\
\text { nach "7", siehe Tabelle } 33\end{array}$ & $1 \mu l$ \\
\hline & $\mathrm{H}_{2} \mathrm{O}$ & $10,6 \mu \mathrm{l}$ \\
\hline
\end{tabular}


Die mittels dieses Protokolls erhaltene doppelsträngige cDNA von unbekannten RNAs konnte nachfolgend mit dem blunt end-Restriktionsenzym "EcoRV“ behandelt werden, da über die DNA-Adapter eine entsprechende Schnittstelle eingebracht wurde. Zeitgleich wurde das Klonierungsplasmid pBluescriptSK(+) mit einem anderen blunt end-Restriktionsenzym linearisiert. Nach anschließender Ligation und der Transformation von E. coli konnten positive Transformanden identifiziert und von entsprechenden Kulturen Plasmide isoliert werden. Jedes Plasmid, das aus der Kultur isoliert wurde, die aus einer Einzelkolonie entstand, sollte so einen unbekannten RNA-Bindepartner des Zielproteins enthalten. Mit einem plasmidspezifischen Oligonukleotid als Primer konnte abschließend eine Sequenzierung die DNA-Sequenz identifizieren. Alle hier abschließend verwendeten Klonierungstechniken sind in den Abschnitten 3.4.1 und 3.4.2 beschrieben.

\subsubsection{Protein-basierte Methoden}

\subsubsection{Gelelektrophoretische Auftrennung von Proteinen}

Die gelelektrophoretische Auftrennung von Proteinen erfolgte mit einer TricinNatriumdodecylsulfat-Polyacrylamid-Gelelektrophorese (Tricin-SDS-PAGE). Der entscheidende Unterschied zur herkömmlichen SDS-PAGE besteht in der Verwendung von Tricin anstelle von Glycin als Leit-Ion im Laufpuffer. Die Tricin-SDSPAGE besitzt bessere Auftrennungskapazitäten bei kleineren Molmassen und wird bevorzugt für Proteine im Bereich von $1 \mathrm{kDa}$ bis $20 \mathrm{kDa}$ verwendet. In der vorliegenden Arbeit wurden Tricin-SDS-Gele nach Schägger (2006) hergestellt und verwendet. Dafür wurde der in der Literatur aufgeführte Probenpuffer „Buffer A“ und die Acrylamid-Bisacrylamid-Stocklösung „AB-6” verwendet.

Wenn das Gel nach der Elektrophorese nicht geblottet werden sollte, sondern eine direkte Visualisierung erwünscht war, wurde eine Coomassie-Färbung durchgeführt. Hierfür wurde das Gel mit der Coomassie-Färbelösung für 30 min langsam schüttelnd bei RT inkubiert und anschließend unter Verwendung und mehrfachem Wechsel von Entfärbelösung entfärbt. Die Zusammensetzung der beiden verwendeten Lösungen sind in Tabelle 35 aufgeführt. 
Tabelle 35: Zusammensetzung der Lösungen für die Visualisierung von Tricin-SDSGelen

\begin{tabular}{|c|c|c|c|}
\hline Bezeichnung & Komponente & Menge & Endkonzentration \\
\hline \multirow{4}{*}{$\begin{array}{l}\text { Coomassie-Färbe- } \\
\text { lösung }\end{array}$} & Coomassie Blue R-250 & $0,5 \mathrm{~g}$ & $0,05 \%(w / v)$ \\
\hline & Methanol & $545 \mathrm{ml}$ & $54,5 \%(v / v)$ \\
\hline & $\geq 98 \%(v / v)$ Essigsäure & $92 \mathrm{ml}$ & $9,2 \%(v / v)$ \\
\hline & $\underline{\mathrm{H}}_{2} \underline{\mathrm{O}}_{\text {bidest }}$ & ad $1000 \mathrm{ml}$ & \\
\hline \multirow[t]{3}{*}{ Entfärbelösung } & Methanol & $500 \mathrm{ml}$ & $25 \%(v / v)$ \\
\hline & $\geq 98 \%(v / v)$ Essigsäure & $100 \mathrm{ml}$ & $5 \%(v / v)$ \\
\hline & $\underline{\mathrm{H}}_{2} \underline{\mathrm{O}}_{\text {bidest }}$ & $\underline{\mathrm{ad} 2000 \mathrm{ml}}$ & \\
\hline
\end{tabular}

\subsubsection{Western Blot}

Für eine spätere spezifische Immundetektion von Zielproteinen, wurden mittels Western Blot die Proteine nach der gelelektrophoretischen Auftrennung auf eine Nitrocellulosemembran übertragen.

Hierfür wurde das Trenngel direkt nach der Tricin-SDS-PAGE verwendet. In der Elektroblotting-Apparatur (Fastblot B43 Blotting Apparatur; Biometra, Göttingen) wurden zunächst 5 Blatt 0,37 mm starkes Blotting-Papier, die Nitrocellulosemembran, das Trenngel und abschließend weitere 5 Blatt 0,37 mm starkes Blotting-Papier mittig platziert. Die Blotting-Papiere wurden zuvor in Transferpuffer equillibriert. Der elektrophoretische Transfer erfolgte bei $3 \mathrm{~mA} / \mathrm{cm}^{2}$ für $1 \mathrm{~h}$. Der erfolgreiche Transfer wurde anschließend mittels Coomassie-Färbung des Gels und einer Tintenfärbung der Membran überprüft.

Anschließend wurde die Membran mittels Inkubation entweder für $1 \mathrm{~h}$ bei RT oder über Nacht bei $4{ }^{\circ} \mathrm{C}$ in $5 \%(\mathrm{w} / \mathrm{v})$ Magermilchpulver in PBS geblockt. Anschließend konnte zuerst eine Hybridisierung mit dem Primär-Antikörper, danach mit dem Sekundär-Antikörper, jeweils in $5 \%(w / v)$ Magermilchpulver in PBS für jeweils $1 \mathrm{~h}$ bei RT stattfinden. Nach jedem Hybridisierungsschritt wurde die Membran dreimal für je 10 min in PBS-T gewaschen und abschließend einmal mit PBS gespült. Danach konnte die Membran unter Verwendung von Roti ${ }^{\circledR}$-Lumin und Autoradiographiefilmen entwickelt und die Ergebnisse visualisiert werden. 


\subsubsection{Produktion spezifischer polyklonaler Antikörper}

Für die Herstellung von polyklonalen Antikörpern für die Immundetektion von HVO_2753 wurde zunächst das Protein in reiner Form benötigt. Hierfür wurde aus methodischen Gründen die Variante mit His-Tag ausgewählt und selbige homolog überproduziert und mittels Affinitäts- und anschließend Größenausschlusschromatographie, wie unter 4.3.1 und 4.3.2 beschrieben, aufgereinigt. Die erhaltene Proteinlösung wurde dann mittels Dialyse umgepuffert, um den Anforderungen des Dienstleisters Davids Biotechnologie GmbH (Regensburg), die den Antikörper herstellten, zu entsprechen. Anschließend wurde die Proteinlösung mit einer Konzentration von $1 \mathrm{mg} / \mathrm{ml}$ und einem Volumen von $1 \mathrm{ml}$ zum Dienstleister versandt.

\subsection{Biochemische Methoden}

\subsubsection{Aufreinigung von Proteinen}

\subsubsection{Homologe Überproduktion von HVO_2753}

Für die homologe Überproduktion des Zielproteins wurde die ÜberexpressionsMutante OE_2753n verwendet. Diese enthält das Plasmid pSD1_R1/6_HVO_2753_NHis, mit welchem eine Variante mit $n$-terminalem Hexahistidin-Tag produziert wird. Das Plasmid basiert auf dem pSD1/R1-6, welchem neben der Sequenz für HVO_2753n eine Ndel-Schnittstelle eingefügt wurde. Dabei steht das Gen unter einem starken, konstitutiven Promotor, der vom Ferredoxin-Promotor abgeleitet wurde (Danner \& Soppa, 1996).

Es wurde hierfür immer aus einer frischen stationären Kultur von OE_2753n eine Vorkultur angeimpft und diese über Nacht inkubiert. Nach 20 h Inkubation konnte mit $2 \mathrm{ml}$ dieser Vorkultur in der exponentiellen Wachstumsphase die $500 \mathrm{ml}$-Hauptkultur angeimpft werden. Diese wurde wiederum für $24 \mathrm{~h}$ inkubiert. Für alle hier verwendeten Kulturen kam Komplexmedium mit Novobiocin zum Einsatz.

\subsubsection{In vivo Crosslink}

Für die Suche nach einem Protein-Bindepartner von HVO_2753 wurde ein in vivoCrosslink durchgeführt. Hierfür wurden die Zellen nach der Zellsedimentation bei 
$6.500 \times \mathrm{g}$ und $4{ }^{\circ} \mathrm{C}$ für 30 min (Sorvall RC6+ mit mit Rotor F10S-6x500Y) zunächst mit $20 \mathrm{ml}$ Basalsalz gewaschen und erneut sedimentiert $\left(15 \mathrm{~min}, 4{ }^{\circ} \mathrm{C}, 4000 \mathrm{rpm}\right.$, Centrifuge 5810 R mit Rotor A-4-62).

Nach Resuspension der Zellen in $5 \mathrm{ml}$ Basalsalz wurde der Crosslink durch Zugabe von Formaldehyd in $5 \mathrm{ml}$ Basalsalz gestartet. Die Menge an Formaldehyd wurde ebenso variiert wie die Dauer der nachgeschalteten Inkubation rotierend bei RT, während die Formaldehyd-Basalsalzlösung immer frisch angesetzt wurde. Der Crosslink wurde durch Zugabe von 0,75 M Glycin in 5 ml Basalsalz (0,25 M GlycinEndkonzentration) gestoppt und die Inkubation rotierend bei RT für 10 min fortgeführt. Abschließend fand eine erneute Sedimentation der Zellen statt, bevor diese mit $15 \mathrm{ml}$ Bindepuffer (siehe Tabelle 36) gewaschen und danach in $5 \mathrm{ml}$ Bindepuffer resuspendiert wurden.

\subsubsection{Zellaufschluss mittels Sonifikation}

Für den Zellaufschluss konnten die Zellen nach dem in vivo Crosslink eingesetzt werden. Sollte kein Crosslink erfolgen, wurden die Zellen der Hauptkultur analog bei $6.500 \times \mathrm{g}$ und $4{ }^{\circ} \mathrm{C}$ für 30 min (Sorvall RC6+ mit mit Rotor F10S-6x500Y) sedimentiert, zunächst mit $20 \mathrm{ml}$ Basalsalz gewaschen und erneut sedimentiert (15 min, $4{ }^{\circ} \mathrm{C}, 4000 \mathrm{rpm}$, Centrifuge $5810 \mathrm{R}$ mit Rotor A-4-62). Hier erfolgte die Resuspension direkt in $5 \mathrm{ml}$ Bindepuffer.

Der Aufschluss der Zellen konnte nun mittels Ultraschalles für $3 \times 30$ s (duty cycle $50 \%$, output ctrl. 3; Sonifier 250 und Ultrasonics Converter, Branson, Danbury, USA) auf Eis erfolgen. Das Abscheiden der Zelltrümmer erfolgte durch Zentrifugation für $60 \mathrm{~min}$ bei $16.000 \times \mathrm{g}$ und $4^{\circ} \mathrm{C}$. Der Überstand stellte das geklärte Gesamtzellextrakt dar und konnte für die Affinitätsaufreinigung weiterverwendet werden.

\subsubsection{Native Affinitätsaufreinigung von HVO_2753n}

Für die native Affinitätsaufreinigung wurde das geklärte Zelllysat auf eine NickelChelat-Sepharose-Matrix in einer Schwerkraftsäule gegeben. Zuvor wurden zur Herstellung der Affinitätsmatrix $500 \mu$ l Chelating Sepharose ${ }^{\mathrm{TM}}$ Fast Flow in die Schwerkraftsäule gegeben, diese mit 10 ml H $\mathrm{H}_{2} \mathrm{O}_{\text {bidest }}$ gewaschen, mittels $4 \mathrm{ml}$ einer 0,2 molaren NiCl-Lösung mit Nickel-Ionen beladen und anschließend mit Bindepuffer equillibriert. Nach dem Durchfließen des Zelllysats wurde die Matrix mit 
$20 \mathrm{ml}$ Bindepuffer gewaschen und die spezifisch gebundenen Proteine mit $4 \mathrm{ml}$ Elutionspuffer eluiert. Alle benötigten Puffer sind in Tabelle 36 dargestellt.

Tabelle 36: Lösungen und Puffer für die Affinitätsaufreinigung von HVO_2753n

\begin{tabular}{|c|c|c|c|}
\hline Bezeichnung & Komponente & Menge & Endkonzentration \\
\hline \multirow{5}{*}{$\begin{array}{l}\text { Bindepuffer } \\
\text { pH 7,5 }\end{array}$} & HEPES & $4,77 \mathrm{~g}$ & $20 \mathrm{mM}$ \\
\hline & $\mathrm{NaCl}$ & $122,7 \mathrm{~g}$ & $2,1 \mathrm{M}$ \\
\hline & Imidazol & $1,36 \mathrm{~g}$ & $20 \mathrm{mM}$ \\
\hline & PMSF-Lösung ${ }^{1)}$ & $5 \mathrm{ml}$ & $1 \mathrm{mM}$ \\
\hline & $\underline{\mathrm{H}}_{2} \underline{\underline{\mathrm{O}}}$ bidest & $\underline{\text { ad } 1000 \mathrm{ml}}$ & \\
\hline \multirow{5}{*}{$\begin{array}{l}\text { Elutionspuffer } \\
\mathrm{pH} \mathrm{7,5}\end{array}$} & HEPES & $4,77 \mathrm{~g}$ & $20 \mathrm{mM}$ \\
\hline & $\mathrm{NaCl}$ & $122,7 \mathrm{~g}$ & $2,1 \mathrm{M}$ \\
\hline & Imidazol & $20,42 \mathrm{~g}$ & $300 \mathrm{mM}$ \\
\hline & PMSF-Lösung ${ }^{1)}$ & & $1 \mathrm{mM}$ \\
\hline & $\underline{\mathrm{H}}_{2} \underline{\mathrm{O}}_{\text {bidest }}$ & $\underline{\text { ad } 1000 \mathrm{ml}}$ & \\
\hline \multirow[t]{2}{*}{ PMSF-Lösung } & PMSF & $523 \mathrm{mg}$ & $200 \mathrm{mM}$ \\
\hline & Ethanol & ad $15 \mathrm{ml}$ & \\
\hline
\end{tabular}

Wurde immer frisch und nur in entsprechend benötigte Aliquots zugegeben ${ }^{11}$.

\subsubsection{Größenausschlusschromatographie}

Für die Größenausschlusschromatographie wurde eine ÄKTA ${ }^{\mathrm{TM}}$ FPLC mit den Grö-

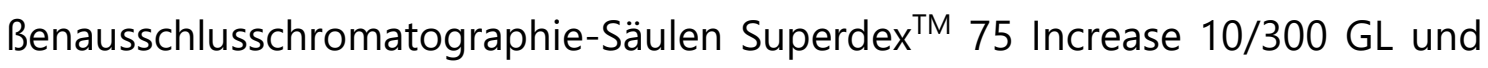
Superose $^{\mathrm{TM}} 6$ 10/300 GL verwendet. Die entsprechenden Flow Rates waren $0,5 \mathrm{ml} / \mathrm{min}$ bzw. 0,3 ml/min und die verwendete Mobile Phase 2,1 M NaCl, $20 \mathrm{mM}$ HEPES pH 7,5. Die Standardkurven wurde mit den Proteinen Conalbumin (76 kDa), Ovalbumin (44 kDa), RNase A (13,7 kDa) und Aprotinin (6,5 kDa) für die Superdex ${ }^{\mathrm{TM}} 75$-Säule und Thyroglobulin (670 kDa), Gamma-Globulin (150 kDa), Ovalbumin (44,3 kDa), RNase A (13,7 kDa) und Aprotinin (6,5 kDa) für die Superose $^{\mathrm{TM}}$ 6-Säule erstellt. 


\subsubsection{Konzentrationsbestimmungen von Proteinen}

\subsubsection{Photometrische Konzentrationsbestimmung}

Die photometrische Konzentrationsbestimmung von Proteinen erfolgte mittels Nanodrop 2000c (Thermo Fisher Scientific, Waltham, MA, USA). Hierbei wurden jeweils $1 \mu \mathrm{l}$ der zu analysierenden Probe als auch einer geeigneten Referenz eingesetzt. Der jeweilige Extinktionskoeffizient wurde entweder zuvor mittels ProtParam (https://web.expasy.org/protparam/) und der entsprechenden Aminosäuresequenz berechnet oder es wurde bei einer Proteinmischung der Extinktionskoeffizient von BSA (Bovines Serum Albumin) als Standard verwendet. Die photometrische Messung erfolgte bei $280 \mathrm{~nm}$.

\subsubsection{BC-Assay}

Da bei Proteinen mit geringer Anzahl an Trypthophan und Tyrosin eine photometrische Konzentrationsbestimmung bei $280 \mathrm{~nm}$ eine hohe Ungenauigkeit aufweist, wurde gegebenenfalls die Konzentration mittels BC-Assay (Interchim, Montlucon Cedex, Frankreich) bestimmt. Hierbei wurde nach Herstellerangaben verfahren. Die hier durchgeführte photometrische Messung erfolgte am SPECTRA$\max { }^{\circledR}$ 340PC Photometer.

\subsubsection{Dichtegradienten-Zentrifugation}

Zur Erstellung von Ribosomenprofilen wurden die Bestandteile des Zelllysats von H. volcanii-Stämmen mittels Dichtegradienten-Zentrifugation der Größe nach aufgetrennt und photometrisch analysiert.

Zur Herstellung eines Saccharosegradienten wurden Zentifugenröhrchen zur Hälfte mit einer 10 \%igen (w/v) Saccharoselösung (in Gradientenpuffer, siehe Tabelle 37) befüllt und diese anschließend mit einer 30 \%-igen (w/v) Saccharoselösung (in Gradientenpuffer) mittels einer Spritze unterschichtet. Mit einem Gradientenmischer (Gradient Master 107) wurden nun 10-30 \%ige Gradienten durch Rotieren erzeugt. Auf diesen Gradienten wurde nun geklärtes $H$. volcanii-Zelllysat gegeben und die Zelllysatbestandteile mittels Zentrifugation bei $19.000 \mathrm{rpm}$ und $4{ }^{\circ} \mathrm{C}$ für $19 \mathrm{~h}$ ihrer Größe nach aufgetrennt (Ultrazentrifuge Optima XPN-80 mit Rotor SW 41 Ti). Nach der Zentrifugation wurde mittels Dichtegradienten-Fraktionier-System (Teledyne ISCO, Lincoln, USA) der Gradient durch Unterschichten 
mit $60 \%(w / v)$ Saccharose abgenommen, photometrisch bei $260 \mathrm{~nm}$ untersucht und anschließend fraktioniert. Die Fraktionen konnten anschließend noch, nach RNA-Isolierung, mittels analytischer, denaturierender RNA-Gelelektrophorese untersucht werden.

Tabelle 37: Zusammensetzung des Gradientenpuffers für die DichtegradientenZentrifugation

\begin{tabular}{llll}
\hline Bezeichnung & Komponente & Menge & Endkonzentration \\
\hline Gradientenpuffer & HEPES & $11,9 \mathrm{~g}$ & $50 \mathrm{mM}$ \\
$\mathrm{pH} 7,5(\mathrm{KOH})$ & $\mathrm{NaCl}$ & $122,7 \mathrm{~g}$ & $2,1 \mathrm{M}$ \\
& $\mathrm{NH}_{4} \mathrm{Cl}$ & $5,35 \mathrm{~g}$ & $100 \mathrm{mM}$ \\
& $\underline{\mathrm{DEPC}-\mathrm{H}_{2} \mathrm{O}}$ & $\underline{\text { ad } 1000 \mathrm{ml}}$ & \\
\hline
\end{tabular}

\subsubsection{Fluorimetrischer Zink-Assay}

Um den Zinkgehalt von HVO_2753 zu bestimmen, wurde eine Quantifizierung unter Verwendung des Fluorophors ZnAF-2F durchgeführt. ZnAF-2F ist hochspezifisch für Zink-lonen und kann diese gegen alle anderen zweiwertigen MetallIonen diskriminieren (Hirano et al., 2002).

Zum Einsatz kam hochreines HVO_2753 nach der zweistufigen Aufreinigung (siehe 3.5.1.4 und 3.5.1.5). Dieses wurde in einer Endkonzentration von $1 \mu \mathrm{M}$ in den Zink-Assay eingesetzt und zunächst gegen $25 \mathrm{mM} \mathrm{NaCl}, 20 \mathrm{mM}$ HEPES bei $\mathrm{pH}$ 7,5 dialysiert. Die anschließende Behandlung mit $100 \mu \mathrm{g} / \mathrm{ml}$ Proteinase $\mathrm{K}$ über Nacht bei $37^{\circ} \mathrm{C}$ sollte die restlose Freigabe von gebundenem Zink sicherstellen. Die Messungen fanden mit $3 \mu \mathrm{M}$ ZnAF-2F in Fluoreszenz-Mikrotiterplatten statt. Als Anregungswellenlänge wurde $492 \mathrm{~nm}$ und als Detektionswellenlänge $517 \mathrm{~nm}$ gewählt. Als Standardreihe diente eine Zinkchlorid-Verdünnungsreihe. Alle verwendeten Lösungen und Puffer sind in Tabelle 38 zu sehen. 
Tabelle 38: Zusammensetzungen der Lösungen und Puffer für den Zink-Assay

\begin{tabular}{|c|c|c|c|}
\hline Bezeichnung & Komponente & Menge & Endkonzentration \\
\hline \multirow{4}{*}{$\begin{array}{l}\text { Zink-Assay Puffer } \\
\mathrm{pH} 7,5\end{array}$} & HEPES & $4,77 \mathrm{~g}$ & $20 \mathrm{mM}$ \\
\hline & Natriumchlorid, ultra trocken & $1,46 \mathrm{~g}$ & $25 \mathrm{mM}$ \\
\hline & $\geq 99,998 \%$ & & \\
\hline & $\underline{\mathrm{H}}_{2} \underline{\mathrm{O}}_{\text {bidest }}$ & $\underline{\text { ad } 1000 \mathrm{ml}}$ & \\
\hline \multirow{3}{*}{$\begin{array}{l}\mathrm{ZnCl}_{2}-\text { Stammlö- } \\
\text { sung }\end{array}$} & Zinkchlorid, ultra trocken & $2,73 \mathrm{~g}$ & $2 \mathrm{M}$ \\
\hline & $\geq 99,99 \%$ & & \\
\hline & $\underline{\mathrm{H}}_{2} \underline{\mathrm{O}}_{\text {bidest }}$ & $\underline{\text { ad } 10 \mathrm{ml}}$ & \\
\hline \multirow[t]{2}{*}{ Zinc Standard Stock } & $\mathrm{ZnCl}_{2}$ - Stammlösung & $0,5 \mathrm{ml}$ & $10 \mathrm{mM}$ \\
\hline & Zink-Assay Puffer & $\underline{\operatorname{ad} 100 \mathrm{ml}}$ & \\
\hline \multirow{2}{*}{$\begin{array}{l}\text { ZnAF-2F - Stamm- } \\
\text { lösung }{ }^{1)}\end{array}$} & $\mathrm{ZnAF}-2 \mathrm{~F}$ & $1 \mathrm{mg}$ & $3 \mathrm{mM}$ \\
\hline & DMSO (für die Spektroskopie) & $\underline{\operatorname{ad} 547,7 \mu \mathrm{l}}$ & \\
\hline
\end{tabular}

In $10 \mu$ l Aliquots im Dunkeln bei $-20^{\circ} \mathrm{C}$ gelagert ${ }^{1)}$.

\subsection{Bioinformatische Methoden}

Die für die nachfolgenden in silico Analysen verwendeten Sequenzen von Orthologen von HVO_2753 stammen aus der nicht-redundanten Protein-Sequenz Datenbank des NCBI (National Center for Biotechnology Information, USA) und wurden mittels Standard Protein BLAST analysiert.

\subsubsection{Multiple Sequence Alignment}

Es wurden Multiple Sequence Alignments (Multipler Sequenz Abgleich, MSA) von ausgewählten Orthologen von HVO_2753 durchgeführt. Hierfür wurde das Tool "MEGA-X" und der Algorithmus "MUSCLE" verwendet (Kumar et al., 2018). Das MSA wurde anschließend unter Zuhilfenahme des Tools "Jalview" visualisiert.

\subsubsection{Phylogenetische Stammbäume}

Phylogenetische Stammbäume wurden ebenfalls mit "MEGA-X" und den Methoden "Maximum Parsimony" bzw. "Maximum-Likelihood” berechnet. Dafür wurden 
jeweils 1000 bootstrap Wiederholungen berechnet und die Anteile der jeweiligen Verzweigungspunkte in den Stammbäumen vermerkt.

\subsubsection{RNA und dRNA-Sequenzvergleiche}

Für den Vergleich von in dieser Arbeit erhaltenen RNA-Sequenzierungsergebnissen mit Daten aus vorangegangenen RNA- und dRNA-Sequenzierungsdaten und die Visualisierung kam der "Integrated Genome Browser" zum Einsatz (Freese et al., 2016). 


\section{Ergebnisse}

Umfassende Ergebnisse auf dem Gebiet kleiner Proteine in Archaeen wurden bereits vor über 10 Jahren erzielt. Hierbei wurden erstmalig experimentelle Nachweise über die Häufigkeit kleiner Proteine in einem Archaeum erhalten (Klein et al., 2007). Bestimmte Erkenntnisse konnten nun auf verwandte Organismen angewandt werden. Die sogenannten C(P)XCG-Muster, zunächst identifiziert im Haloarchaeon $H$. salinarum, wurden auch in $H$. volcanii gefunden. Im Zuge dessen, konnten 43 Proteine, nicht größer als 70 Aminosäuren, mit Paaren solcher C(P)XCG-Muster in H. volcanii annotiert werden. Die Buchstaben dieser Muster stellen den Einbuchstaben-Code von Aminosäuren dar. Während Prolin (P) meist nur in einem der beiden Muster eines Paares vorkommt, steht " $\mathrm{X}$ " für eine beliebige Aminosäure. Ein Paar solcher Muster stellt ersten Erkenntnissen nach ein Zinkfinger-Motiv dar, in dem die vier enthaltenen Cysteine ein Zink-Ion komplexieren können und somit für die Ausbildung einer speziellen Tertiärstruktur verantwortlich sind. Im Gegensatz zu allen anderen 42 dieser Proteine, die jeweils ein Zinkfinger-Motiv besitzen, besitzt eines dieser Proteine, HVO_2753, trotz seiner geringen Größe von 59 Aminosäuren, vier C(P)xCG-Muster und kann, so wurde vermutet, zwei Zinkfinger ausbilden und zwei Zink-Ionen komplexieren. Dieses Protein sollte nun genaueren Analysen unterzogen werden.

\subsection{Bioinformatische Analyse von HVO_2753}

\subsubsection{Charakteristika von HVO_2753}

Die in der 59 Aminosäuren langen Sequenz von HVO_2753 enthaltenen C(P)XCGoder C(P)XCG-ähnlichen Muster sind ungefähr gleichmäßig verteilt und machen $34 \%$ des gesamten Proteins aus (siehe Abbildung 4). Verglichen mit dem Proteom von $H$. volcanii ist der Anteil an geladenen und hydrophilen Aminosäuren hoch (siehe Tabelle 39). 


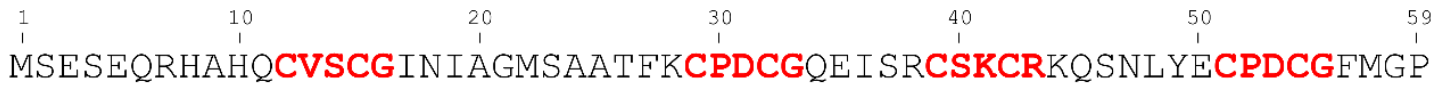

MSESEQRHAHQCVSCGINIAGMSAATFKCPDCGQEISRCSKCRKQSNLYECPDCGFMGP

Abbildung 4: Aminosäuresequenz von HVO_2753. In der oberen Sequenz sind die vier $C(P) X C G$ Motive rot hervorgehoben. Die untere Sequenz zeigt saure Aminosäuren in rot, Basische in blau, Aminosäuren mit Amid-Seitenkette in gelb und mit Hydroxygruppen in der Seitenkette in grün. Abbildung entnommen aus Zahn et al. (2020).

Mindestens zweifach erhöht ist hier Lysin und Cystein, aber auch Methionin, Glutamin und Serin. Im Gegenzug dazu ist der Anteil an aliphatischen Aminosäuren niedriger als im Proteom. Zweifach verringert sind Alanin, Leucin, Valin und Threonin, aber auch Asparaginsäure. HVO_2753 enthält kein Tryptophan. In der Aminosäuresequenz ebenfalls auffällig ist der N-Terminus, welcher einen sehr hohen Anteil an funktionellen Aminosäuren enthält.

Tabelle 39: Aminosäurezusammensetzung von HVO_2753 im Vergleich zum H. volcanii Proteom. Rot oder blau markiert sind Anteile, die in HVO_2753 mehr als zweifach höher bzw. niedriger sind als im Proteom. Die Anzahl an Aminosäuren, auf der die Berechnungen beruhen, sind 1.168 .832 im Proteom und 59 bei HVO_2753. Tabelle entnommen und modifiziert aus Zahn et al. (2020).

\begin{tabular}{ccc|ccc} 
Aminosäure & Proteom & HVO_2753 & Aminosäure & Proteom & HVO_2753 \\
& Anteil [\%] & Anteil [\%] & & Anteil [\%] & Anteil [\%] \\
\hline A & 11,0 & 5 & M & 1,8 & 5 \\
C & 0,7 & 14 & N & 2,4 & 3 \\
D & 8,4 & 3 & P & 4,6 & 5 \\
E & 8,0 & 7 & Q & 2,4 & 7 \\
F & 3,5 & 3 & R & 6,7 & 5 \\
G & 8,5 & 8 & S & 5,9 & 12 \\
H & 2,0 & 3 & T & 6,2 & 2 \\
I & 3,8 & 5 & V & 9,2 & 2 \\
K & 2,0 & 5 & W & 1,1 & 0 \\
L & 9,1 & 2 & Y & 2,7 & 2
\end{tabular}

Zusätzlich zur Aminosäuresequenz wurde auch der genomische Bereich von HVO_2753 untersucht. Das Gen HVO_2753 ist auf dem reversen Strang des 
Hauptchromosoms lokalisiert. Es besitzt lediglich einen Abstand von zwei Nukleotiden zum nachfolgenden Gen HVO_2752, was auf eine Co-Transkription schlieBen lässt. HVO_2752 ist als Translations-Elongationsfaktor annotiert.

Vorangegangene Studien, bei denen eine dRNA-Sequenzierung und eine RNASequenzierung von $H$. volcanii durchgeführt wurden, ließen bereits Einblicke in das Transkriptom zu und zeigten potenzielle Transkriptionsstartstellen auf (Babski et al., 2016; Laass et al., 2019). Die Visualisierung dieser Daten mittels Genome Browser zeigten lediglich eine Transkriptionsstartstelle vor dem ersten Gen HVO_2753 (grün, dRNA-Seq) und ein bicistronisches Transkript der beiden Gene mit kurzer 3'-UTR (untranslated region; rot, RNA-Seq), wie Abbildung 5 zeigt.

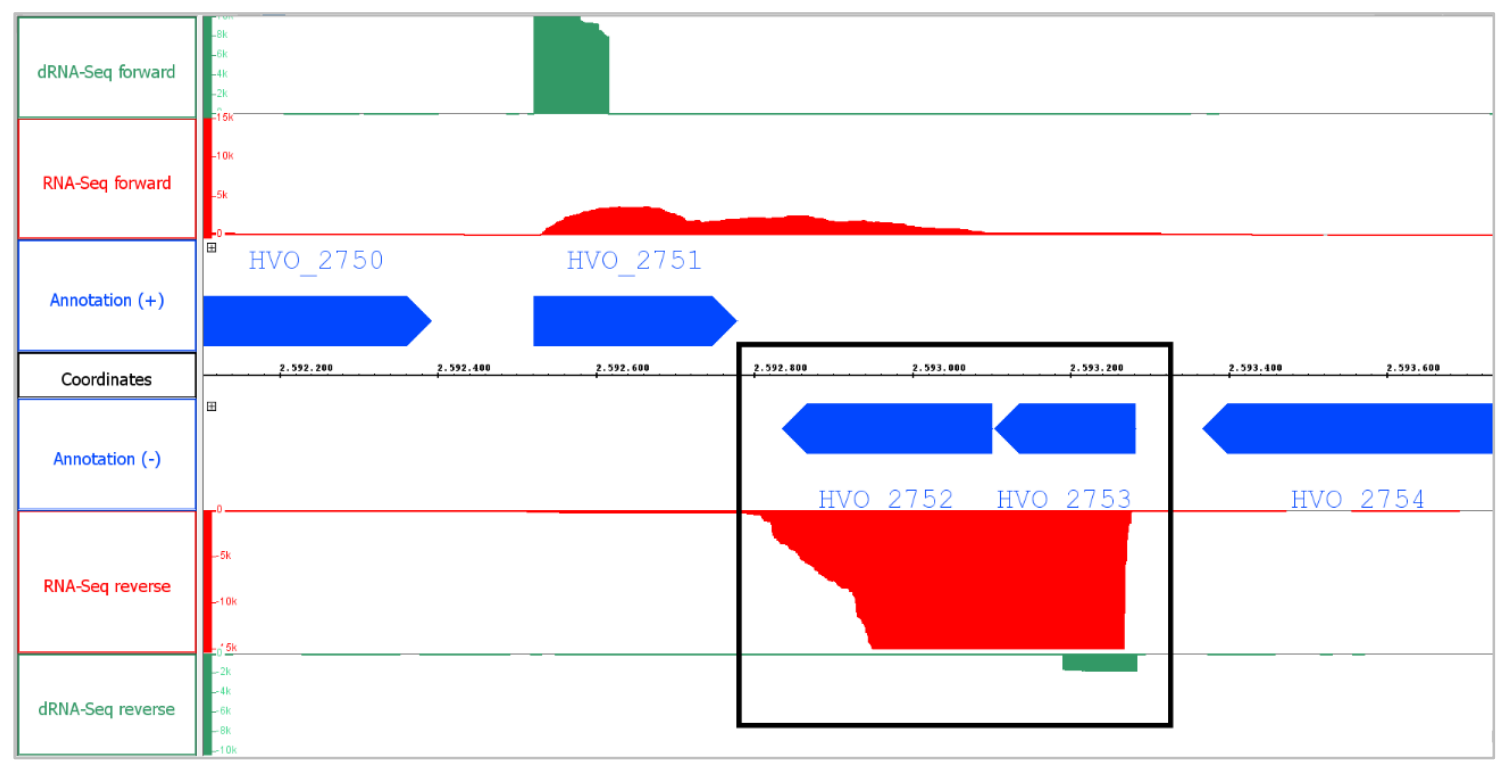

Abbildung 5: Übersicht über den genomischen Bereich von HVO_2753. Visualisiert mit dem Genome Browser sind in blau die annotierten protein-codierenden Gene, in rot die Ergebnisse einer RNA-Seq Studie (Laass et al., 2019) und in grün die Ergebnisse einer dRNA-Seq Studie (Babski et al., 2016). Abbildung entnommen aus Zahn et al. (2020).

\subsubsection{Homologie von HVO_2753}

Mittels Protein-BLAST Suchen (NCBI, Bethesda, USA) konnte untersucht werden, wie verbreitet HVO_2753 innerhalb der eigenen Domäne ist, aber auch darüber hinaus. Es konnte gezeigt werden, dass innerhalb der Euryarchaeota eine Vielzahl an nah verwandten Orthologen zu finden sind. Von keinem dieser Orthologen ist jedoch die Funktion bekannt, wenige davon sind jedoch als putatives Zink-Ribbon RNA-Bindeprotein annotiert. Sehr wenige weiter entfernte Orthologe konnten in Bakterien, jedoch keine in Eukaryoten identifiziert werden. 
HVO_2753 wurde mit einer Auswahl an Orthologen aus 20 Spezies indes genauer untersucht und in einem MSA miteinander verglichen (siehe Abbildung 6). Die oberen 14 Sequenzen stammen von Orthologen aus halophilen Gattungen bzw. Spezies, die unteren 7 Sequenzen von Methanogenen. Der Grad an Konservierung ist besonders hoch in den Bereichen der C(P)xCG-Mustern. Während viele Aminosäuren darüber hinaus in allen gezeigten Proteinen konserviert sind, zeigt sich dennoch innerhalb der halophilen bzw. methanogenen Spezies ein jeweils spezifisch noch höherer Grad an Konservierung. Besonders auffällig ist der NTerminus. Was bereits allein beim Betrachten von HVO_2753 (siehe 4.1.1) durch die hohe Anzahl an funktionellen Aminosäuren auffiel, zeigt sich hier erneut. Alle halophilen Varianten besitzen einen hochfunktionellen N-Terminus, der in den Orthologen der Methanogenen verkürzt vorliegt.

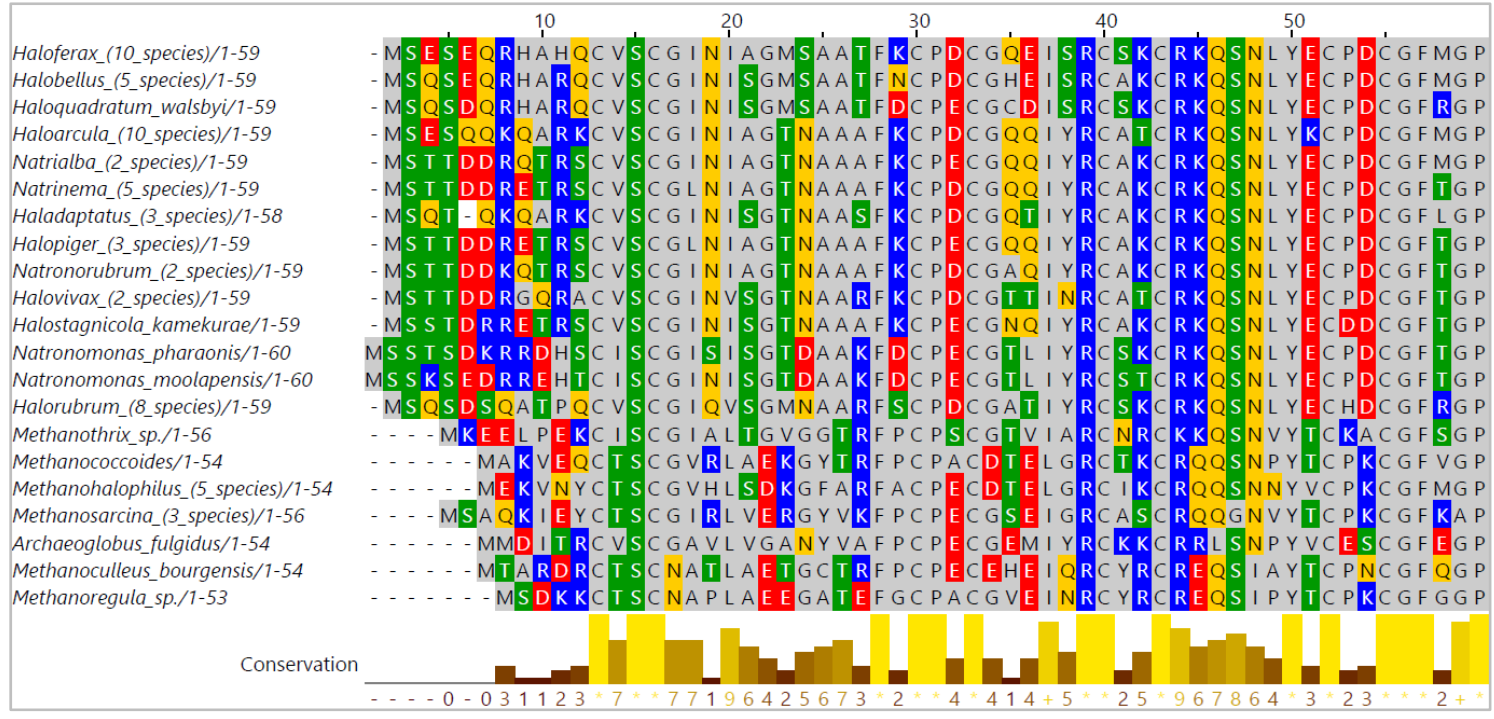

Abbildung 6: Multiple Sequence Alignment von HVO_2753 und 20 weiteren Orthologen ausgewählter halophiler und methanogener Gattungen und Spezies. Saure Aminosäuren sind in rot, Basische in blau, Aminosäuren mit Amid-Seitenkette in gelb und mit Hydroxygruppen in der Seitenkette in grün dargestellt. Der Grad an Konservierung ist unter dem MSA dargestellt. Abbildung entnommen aus Zahn et al. (2020).

Die Sequenzen, die auch im MSA Anwendung fanden, wurden abschließend für die Berechnung von phylogenetischen Stammbäumen herangezogen. Dabei kamen die Methoden der Maximum Parsimony und der Maximum-Likelihood mit jeweils 1000 bootstrap Wiederholungen zum Einsatz. Die Ergebnisse sind in Abbildung 7 gezeigt. Beide Stammbäume zeigen ein ähnliches Bild der Verwandtschaft, wie es auch das MSA bereits vermuten ließ. Darüber hinaus stimmen diese 
Ergebnisse gut mit der anerkannten Taxonomie überein, die mittels 16S rRNASequenzierungen ermittelt wurde.
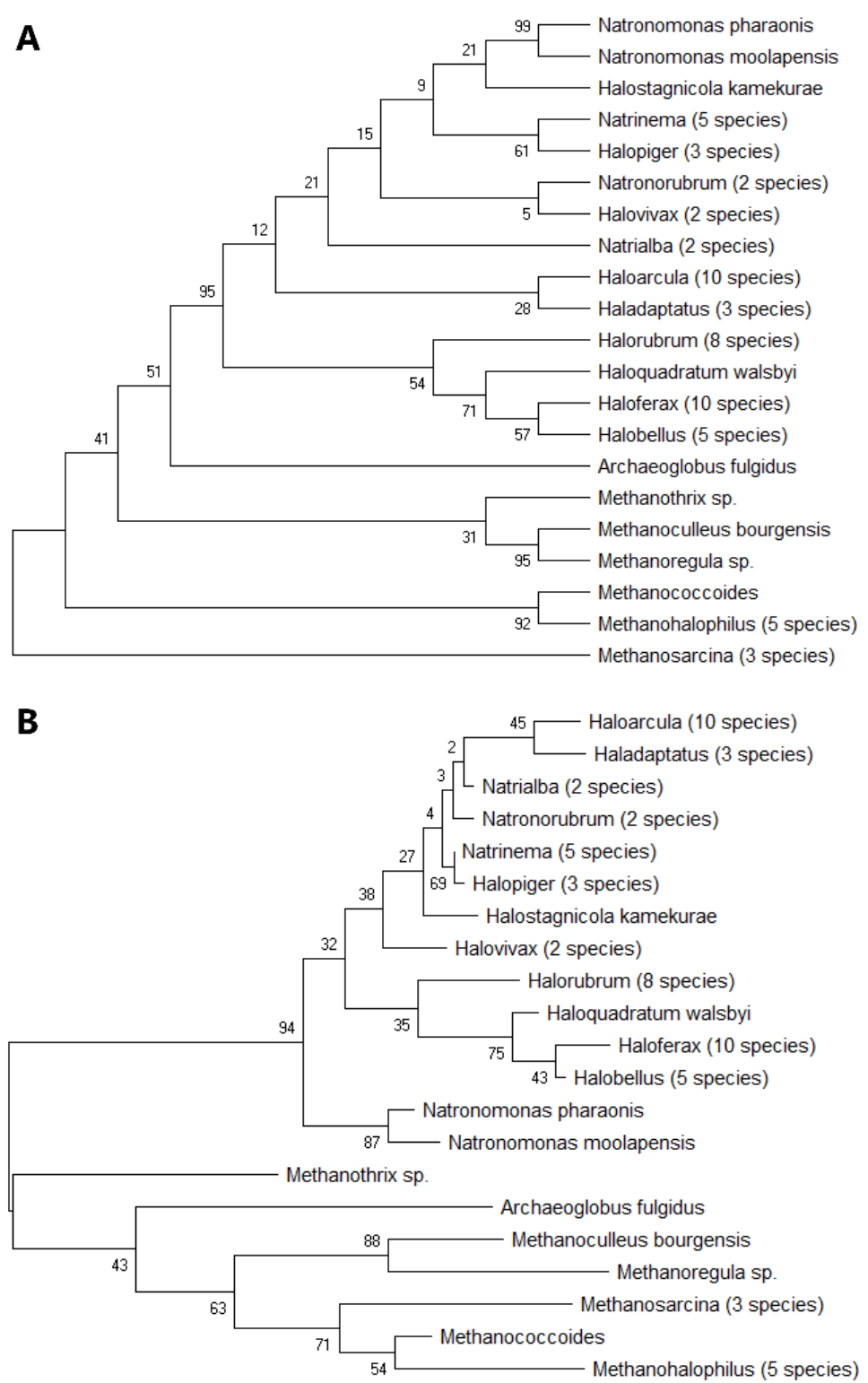

\section{Abbildung 7: Phylogenetische Stammbäume von HVO_2753 und seinen Ortholo-}

gen. Für die Berechnung der Stammbäume wurden die Sequenzen der Proteine aus Abbildung 6 verwendet. Gezeigt sind die Berechnungen mit 1000 bootstrap replications der Methoden Maximum Parsimony (A) und Maximum Likelihood (B). Angaben der Anteile der jeweiligen Verzweigungspunkte in Prozent (\%). Abbildung entnommen und modifiziert aus Zahn et al. (2020). 


\subsection{Funktionsanalyse von HVO_2753 in vivo}

\subsubsection{Herstellung der Deletionsmutante}

Als erster Schritt zur Aufklärung möglicher biologischer Funktionen von HVO_2753 wurde eine in frame-Deletionsmutante des Gens erstellt. Auf diese Weise konnten anschließend mögliche phänotypische Abweichungen zum Wildtyp H26 gesucht werden. Die eingeführte Deletion erfolgte mittels Pop-In/PopOut-Methode (siehe 3.4.3) und umfasste eine Länge von 153 bp, wobei die ersten 3 Codons und die letzten 6 Codons, inklusive des Stopp-Codons, nicht deletiert wurden. Dies resultierte in einer Verkürzung des Genprodukts von 59 Aminosäuren auf 8 Aminosäuren. Da das Gen allen Annahmen nach mit dem nachfolgenden Gen HVO_2752 co-transkribiert wird, sollte eine Beeinflussung dessen möglichst ausgeschlossen werden. Die erfolgreiche Deletion des Genabschnitts in allen Chromosomen des polyploiden Organismus wurde mittels mittels 40-ZyklenTest-PCR bestätigt.

\subsubsection{Phänotypische Charakterisierung der Deletionsmutante}

Um eine mögliche biologische Funktion von HVO_2753 identifizieren zu können, wurde die erstellte in frame Deletionsmutante unter verschiedenen Bedingungen mit dem Wildtyp verglichen.

\subsubsection{Wachstum unter verschiedenen Bedingungen}

In den durchgeführten Versuchen, bei denen das Wachstum in Flüssigkulturen miteinander verglichen wurde, war kein signifikanter Unterschied zwischen Wildtyp und Deletionsmutante festzustellen. Abbildung 8 zeigt die Wachstumskurven der beiden Stämme in Komplexmedium (K) und in synthetischem Medium mit Glukose als Kohlenstoffquelle (S). 


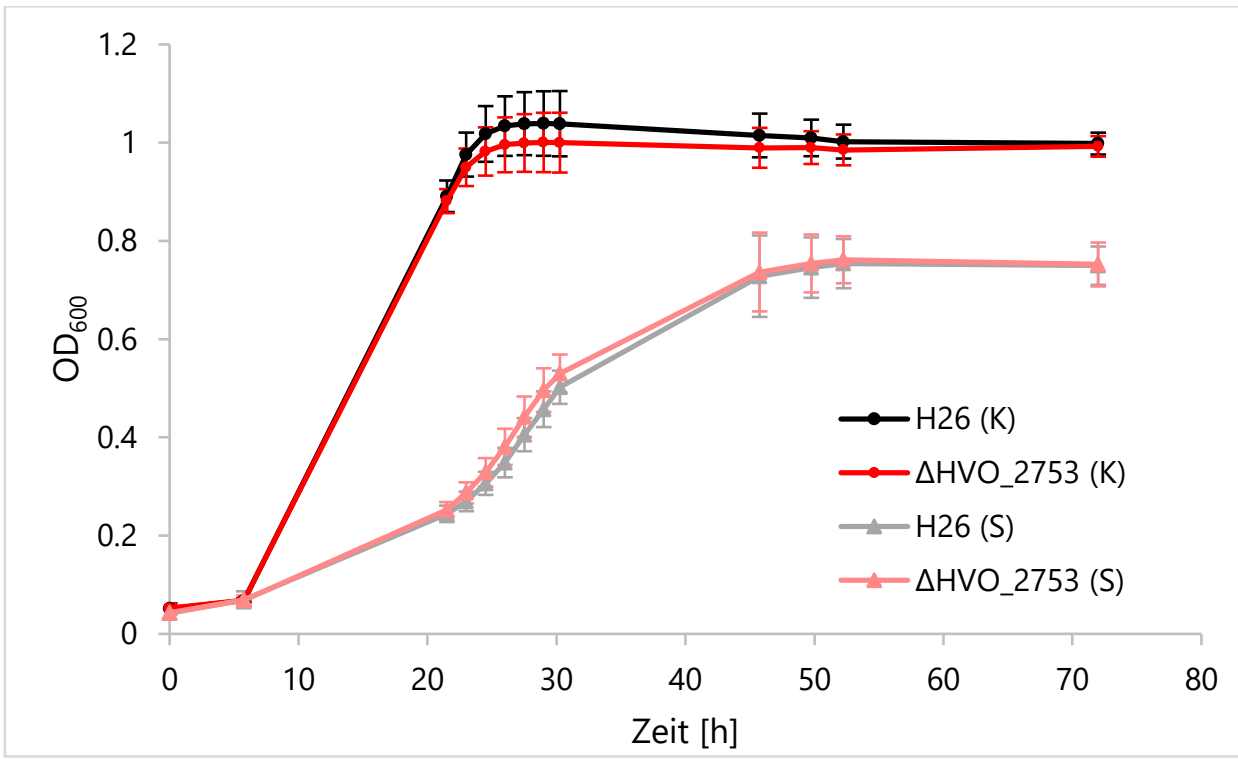

Abbildung 8: Wachstumskurven des Wildtyps H26 und der Deletionsmutante DHVO_2753. Gezeigt sind die Mittelwerte und Standardabweichungen von jeweils 18 biologischen Replikaten der Stämme in Komplexmedium (K) und synthetischem Medium mit Glukose als Kohlenstoffquelle (S).

\subsubsection{Biofilmbildung und Schwärmverhalten}

Weitere Untersuchungsparameter, die der Suche nach einer möglichen biologischen Funktion von HVO_2753 beitragen können, ist die Fähigkeit der Zellen zur Bildung von Biofilmen auf der einen Seite und die Fähigkeit zur Motilität auf der Anderen.

Um Unterschiede in der Befähigung zur Motilität analysieren zu können, wurden Schwärmversuche durchgeführt. Hierbei wird Chemotaxis und Motilität gekoppelt untersucht. $H$. volcanii schwärmt in mikroaerober Umgebung und halbfestem Medium ringförmig um eine Inokulationseinstichstelle einem Nährstoffgradienten entgegen. Hierbei kann leicht zwischen Stämmen unterschieden werden, die in unterschiedlichen Geschwindigkeiten schwärmen bzw. die Fähigkeit des Schwärmens nicht besitzen oder besitzen. Vorläufige Untersuchungen zum Schwärmen der Deletionsmutante $\Delta$ HVO_2753 verglichen mit dem Wildtyp H26 zeigten leichte Unterschiede im Schwärmverhalten. Die Deletionsmutante wies ein verlangsamtes Schwärmverhalten dem Wildtyp gegenüber auf. Sie bildete auf der Oberfläche des halbfesten Mediums jedoch schneller einen Zellrasen als der Wildtyp. 
Bei der Untersuchung der Biofilmbildung wurde ein Biofilm-Assay durchgeführt. Hierbei werden Zellen in Flüssigkulturen angezogen und Medien in Vertiefungen von Mikrotiterplatten mit Flachboden mit diesen Zellen inokuliert. Nach einer Inkubation können die planktonischen Zellen abgenommen und der verbleibende Biofilm fixiert und gefärbt werden. Die optische Dichte der Entfärbelösung stellt dann ein Maß für die Menge an Zellen im Biofilm dar. Hier wurden Zellen des Wildtyps und der Deletionsmutante zunächst bis zur exponentiellen Wachstumsphase bzw. bis zur stationären Wachstumsphase angezogen und mit diesen Zellen der Biofilmversuch durchgeführt. Hier zeigte sich ein hochsignifikanter Unterschied zwischen Wildtyp und Deletionsmutante bei Zellen beider Wachstumsphasen (siehe Abbildung 9). Die Deletionsmutante zeigte eine um $63 \%$ verringerte Biofilmbildung bei Zellen, die aus der exponentiellen Wachstumsphase stammen und eine um 50 \% verringte Biofilmbildung bei Zellen aus der stationären Wachstumsphase.

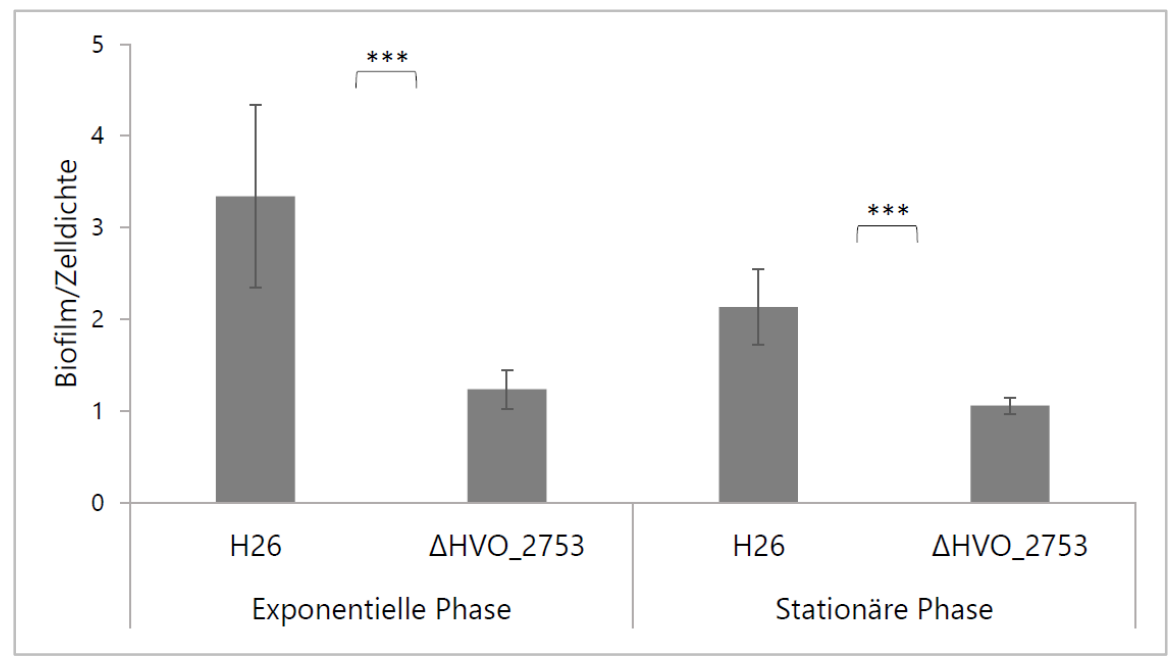

Abbildung 9: Biofilm-Assay des Wildtyps H26 und der Deletionsmutante $\Delta$ HVO_2753. Gezeigt ist das Verhältnis von $\mathrm{OD}_{600}$ des Biofilms und der entsprechenden eingesetzten Zellsuspension. Die Zellen stammten aus einer Kultur in exponentieller bzw. stationärer Wachstumsphase in synthetischem Medium mit Glukose als Kohlenstoffquelle. Die Inkubationsdauer für die Biofilmbildung betrug 6 h. Statistische Signifikanzen wurden mittels ungepaartem, zweiseitigen t-Test ermittelt: ${ }^{* *}$ - $p$-Wert $<0,001$. Herangezogen wurden jeweils 10 unabhängige biologische Replikate.

\subsubsection{Komplementationsversuche}

Um Ursachen von phänotypischen Abweichungen einer Deletionsmutante vom Wildtyp sicher auf die Deletion zurückführen und artifizielle Einflüsse ausschließen 
zu können, wird standardmäßig eine Komplementation durchgeführt. Dabei wird das deletierte Gen plasmidisch, meist unter Kontrolle eines induzierbaren Promotors, in die Zelle eingebracht und anschließend unter entsprechenden Bedingungen überprüft, ob durch plasmidische Expression des Gens der wildtypische Phänotyp wiederhergestellt werden kann.

\subsubsection{Herstellung der Komplementationsmutanten}

Im Zuge dieser Arbeit wurde für die Komplementation als Ausgangsplasmid pTA929 verwendet (Allers et al., 2010). Dieses besitzt den origin of replication des pHV2-Plasmides, welcher beim Wildtyp H26 fehlt und so die gezielte Verwendung des Origins ermöglicht. Transformanden können mittels des pyrE2-Gens auf dem Plasmid, welches im Uracil-auxotrophen Wildtyp H26 deletiert vorliegt, selektiert werden. Das Gen pyrE2 codiert für die Orotat-Phosphoribosyltransferase, ein Enzym des Uracilbiosynthese-Stoffwechsels, und befähigt die Transformanden wieder zur Synthese von Uracil. In dem Ausgangsplasmid wurde die bereits vorhandene Sequenz für einen Hexahistidin-Tag (His-Tag) entfernt, da hier zusätzliche Codons für einen linker zwischen His-Tag und ORF vorgesehen waren, und durch Genvarianten von HVO_2753 ersetzt. Dabei wurden Genvarianten mit Sequenzen für einen N-terminalen bzw. C-terminalen His-Tag ohne linker gewählt, um das Genprodukt nicht unnötig zu vergrößern. Der His-Tag wurde jedoch eingebracht um später, zusätzlich zu Komplementationsversuchen, das Protein überproduzieren und leicht mittels Affinitätschromatographie für weitere Versuche aufreinigen zu können. Die Gene HVO_2753n bzw. HVO_2753c stehen dann hier unter der Kontrolle des Tryptophan-induzierbaren Promotors p.tnaA.

Als Kontrolle zu den Komplementationsmutanten $\triangle \mathrm{HVO} 2753+2753 \mathrm{n}$ (mit pTA929_HVO_2753_NHis) und 4 HVO_2753 +2753c (mit pTA929_HVO_2753_CHis wurden ab hier immer Kontrollstämme mit Leervektoren (empty vector control, evc) mitgeführt. Somit unterschieden sich die Komplementationsmutanten und der Kontrollstamm $\Delta$ HVO_2753 evc lediglich in der An- bzw. Abwesenheit der plasmidisch codierten Sequenz für HVO_2753. Auch der Wildtyp lag ab hier mit dem Leervektor transformiert vor: H26 evc. Des Weiteren konnten die Stämme auch im identischen Medium kultiviert werden und es musste für keinen Stamm Uracil supplementiert werden. 


\subsubsection{Phänotypische Charakterisierung}

Zunächst wurden erneut Wachstumsversuche durchgeführt und die Komplementationsstämme mit den Kontrollstämmen verglichen. Dabei wurde getestet ob und wie sehr die Induktion des Tryptophanase-Promotors (p.tnaA) und die damit verbundene plasmidische Expression, aber auch die Anwesenheit verschiedener Konzentrationen an Tryptophan im Kulturmedium einen Einfluss auf die Wachstumsgeschwindigkeiten der verschiedenen Stämme hat. Abbildung 10 zeigt die Wachstumskurven der 4 Stämme bei den Tryptophan-Konzentrationen 0 mM, 0,3 mM, $1 \mathrm{mM}$ und $4 \mathrm{mM}$. Diese spiegeln verschiedene Induktionslevel des Promotors wider. In Abwesenheit von Tryptophan ist lediglich eine sehr geringe, basale Transkription vorhanden, während diese mit der Konzentration von Tryptophan ansteigt. Zwischen den Stämmen zeigte sich hier bei keiner der Tryptophan-Konzentrationen ein signifikanter Unterschied. Der Wildtyp H26 evc wies lediglich eine gering verlängerte Anlauf-(lag-)Phase auf, während die Wachstumsgeschwindigkeiten in der exponentiellen Phase annähernd identisch waren. Auch zwischen den verschiedenen Trp-Konzentrationen gibt es keine signifikanten Unterschiede im Wachstum. Generell ist eine sehr leicht erhöhte Zelldichte bei höheren Trp-Konzentrationen messbar.

Dies zeigt deutlich, dass die Tryptophan-Konzentration bis $4 \mathrm{mM}$ im Medium und die damit verbundene Induktionsstärke des plasmidischen p.tnaA-Promotors keinen Einfluss auf die Wachstumsgeschwindigkeit der Zellen haben. Darüber hinaus ist sichergestellt, dass keiner der getesteten Stämme ein Wachstumsdefizit durch das jeweilige Plasmid aufweist. 


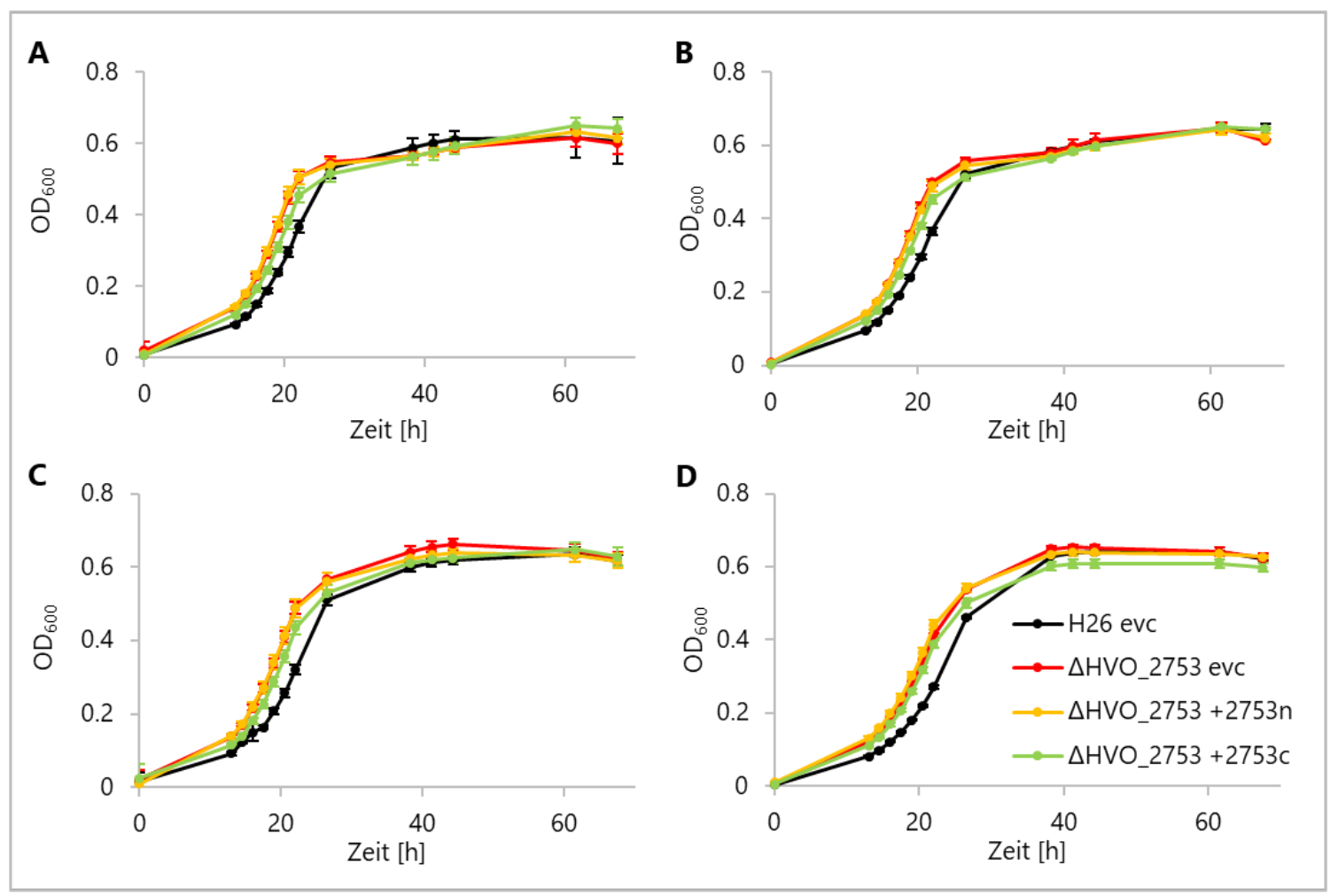

Abbildung 10: Wachstumskurven der Komplementationsmutanten und der Kon-

trollstämme. Gezeigt sind die Mittelwerte und Standardabweichungen von jeweils drei biologischen Replikaten des Wildtyps mit Leervektor (H26 evc), der Deletionsmutante mit Leervektor ( $\triangle \mathrm{HVO} \_2753 \mathrm{evc}$ ) und der beiden Komplementationsmutanten ( $\triangle \mathrm{HVO}$ _2753 +2753n bzw. $\Delta \mathrm{HVO}_{-} 2753+2753 \mathrm{c}$ ) in synthetischem Medium mit Glukose als Kohlenstoffquelle. Das Medium wurde supplementiert mit (A) $0 \mathrm{mM}$, (B) 0,3 mM, (C) 1 mM oder (D) 4 mM L-Tryptophan.

Anschließend wurden mit den Stämmen Schwärmversuche durchgeführt. Da hier zuvor eine leichte Abweichung des Phänotyps zum Wildtyp gefunden wurde, sollte nun untersucht werden, ob diese Abweichung komplementiert werden kann. Die Schwärmversuche wurden wie die zuvor beschriebenen Wachstumsversuche bei verschiedenen Konzentrationen an L-Tryptophan im halbfesten Schwärmmedium durchgeführt. Abbildung 11 zeigt die gemessenen Schwärmdurchmesser der 4 Stämme über einen zeitlichen Verlauf von 144 h. Besonders auffällig ist hierbei zunächst das absolute Schwärmdefizit von $\Delta \mathrm{HVO}_{2} 2753$ evc. Während die Deletionsmutante ohne Leervektor nur ein leichtes Defizit aufwies, besitzt $\triangle$ HVO_2753 evc keine Fähigkeit mehr zu Schwärmen. Während der Leervektor hier einen negativen Einfluss auf das Schwärmen zu haben scheint, ist der Wildtyp H26 nach Transformation mit dem Leervektor nicht negativ im 
Schwärmen beeinflusst. H26 evc besitzt überdies eine leicht erhöhte Schwärmgeschwindigkeit im Vergleich zu H26 (Daten nicht gezeigt). Die Komplementationsstämme besaßen bei den Schwärmversuchen im Gegensatz zu dem Kontrollstamm $\Delta \mathrm{HVO} 2753$ evc die Fähigkeit zu schwärmen. Auch wenn durch die plasmidische Expression des deletierten Gens hier keine vollständige Komplementation des hervorgerufenen Schwärmdefizits herbeigeführt wird, kann ein verzögertes Schwärmen beobachtet werden. Dieses setzt nahezu unabhängig von der Tryptophankonzentration bzw. Induktionsstärke ca. 48 h später ein als beim wildtypischen Kontrollstamm, erreicht jedoch ebenso den maximalen Durchmesser von 33 mm. Der verwendete Tryptophan-induzierbare Promotor besitzt auch in Abwesenheit von Tryptophan eine basale Aktivität, was die Komplementierbarkeit ab bereits 0 mM Tryptophan zur Folge hat. Zwischen den beiden Komplementatiosstämmen konnte hier kein signifikanter Unterschied festgestellt werden. Die hohe Induktionsstärke scheint auch hier keinen entscheidenden Einfluss auf die Komplementationsfähigkeit der Mutanten zu haben. Eine TryptophanKonzentration von 4 mM zeigt in allen schwärmenden Stämmen eine leichte Reduktion der Schwärmgeschwindigkeit.

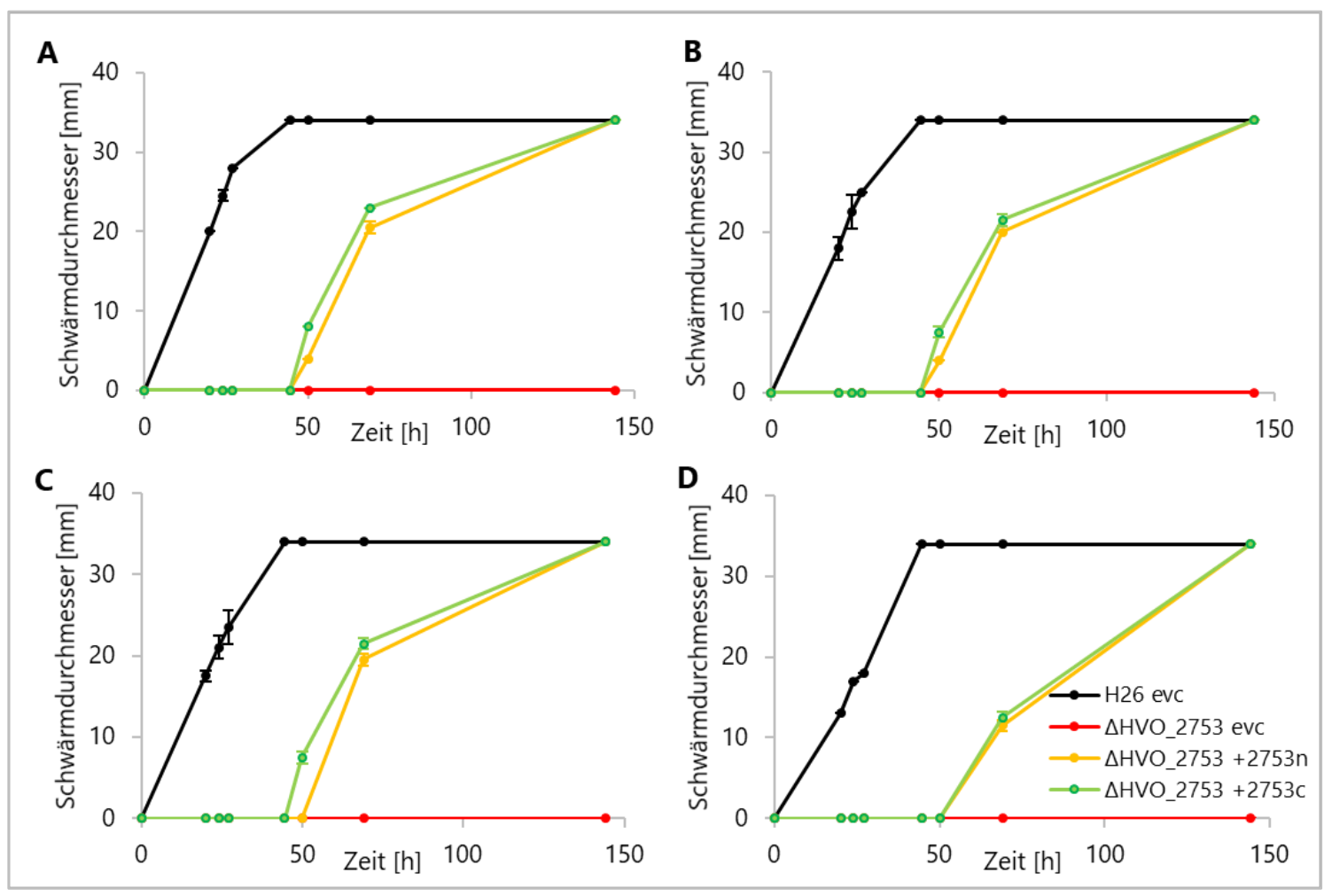

Abbildung 11: Schwärmverhalten der Komplementationsmutanten und der Kontrollstämme. Gezeigt sind die Mittelwerte und Standardabweichungen von jeweils vier biologischen Replikaten des Wildtyps mit Leervektor (H26 evc), der Deletionsmutante mit 
Leervektor ( $\triangle \mathrm{HVO}$ _2753 evc) und der beiden Komplementationsmutanten ( $\triangle \mathrm{HVO}$ _2753 $+2753 \mathrm{n}$ bzw. $\Delta$ HVO_2753 +2753c) in halbfestem synthetischen Medium mit Glukose als Kohlenstoffquelle und 0,3\% (w/v) Agar. Das Medium wurde supplementiert mit (A) $0 \mathrm{mM}$, (B) 0,3 mM, (C) $1 \mathrm{mM}$ oder (D) $4 \mathrm{mM}$ Tryptophan.

Abbildung 12 zeigt eine Schwärmplatte nach $144 \mathrm{~h}$ Inkubation am Ende des Schwärmversuchs. Zu sehen sind H26 evc (1), $\Delta \mathrm{HVO} 2753$ evc (2), $\Delta \mathrm{HVO} 2753$ +2753n (3) und $\Delta \mathrm{HVO}_{2} 2753$ +2753c (4). Die beiden Komplementationsstämme sind jeweils doppelt vorhanden. Zu diesem Zeitpunkt sind die Zellen aller schwärmenden Stämme bis an den Rand der Vertiefungen geschwärmt und haben die stationäre Wachstumsphase erreicht. Dies ist leicht an der Trübung und der purpurnen Farbe zu erkennen. Der Stamm $\Delta$ HVO_2753 evc weist keinerlei Fähigkeit zu Schwärmen auf. Man sieht lediglich eine große Kolonie rund um die Inokulationsstelle in der Mitte der Vertiefung. Diese Kolonie sitzt auf dem halbfesten Schwärmmedium auf. In einem weiterführenden Versuch zeigte $\Delta \mathrm{HVO} 2753$ evc auch nach 312 h Inkubation keinerlei Schwärmring (Daten nicht gezeigt).

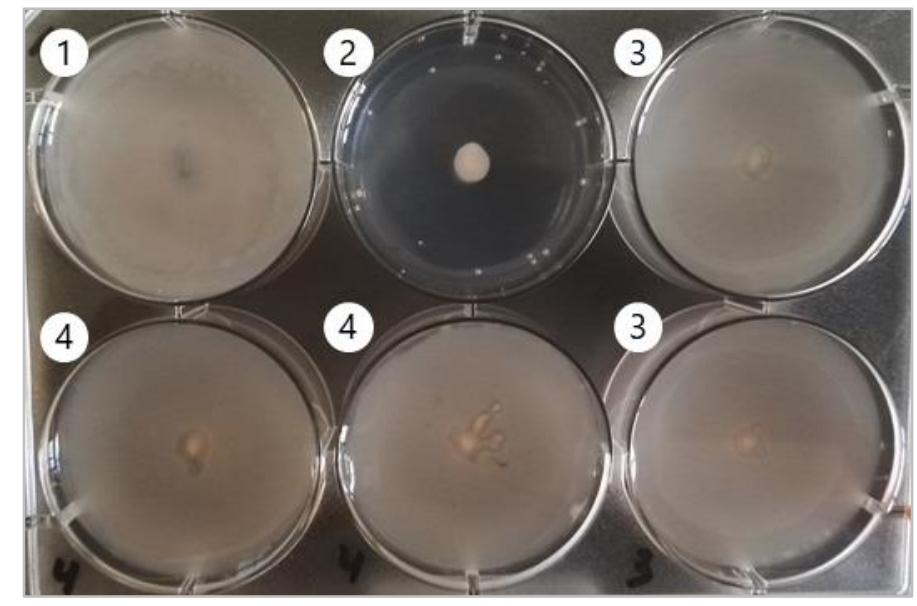

Abbildung 12: Schwärmplatte der Komplementationsmutanten und der Kontrollstämme. Gezeigt ist eine 6-Well Platte mit halbfestem synthetischem Medium mit Glukose als Kohlenstoffquelle und 0,3\% Agar nach $144 \mathrm{~h}$ Inkubation. (1) Wildtyp mit Leervektor (H26 evc), (2) Deletionsmutante mit Leervektor ( $\triangle \mathrm{HVO} 2753$ evc), (3) Komplementationsmutante $\Delta \mathrm{HVO} \_2753+2753 \mathrm{n}$ und (4) Komplementationsmutante $\Delta$ HVO_2753 +2753c. Abbildung entnommen und modifiziert aus Zahn et al. (2020).

Neben dem Schwärmphänotyp der Deletionsmutante, wies diese ebenso eine verminderte Biofilmbildung auf. Analog zu den Schwärmversuchen wurden auch hier mit den vier Stämmen Komplementationsversuche durchgeführt und über- 
prüft, ob eine plasmidische Expression einer Genvariante von HVO_2753 die Abweichung im Phänotyp komplementieren kann. Hierfür wurden Biofilm-Assays durchgeführt. Diese zeigten für die mit dem Leervektor transformierten Stämme H26 evc und $\Delta \mathrm{HVO}_{2} 2753$ evc das gleiche Bild wie für den Wildtyp H26 und die Deletionsmutante $\Delta \mathrm{HVO}_{2} 2753$ zuvor, eine über $60 \%$ reduzierte Biofilmbildung von $\triangle \mathrm{HVO} 2753$ evc dem Wildtyp H26 evc gegenüber (siehe Abbildung 13). Hier konnte in keiner der beiden Komplementationsmutanten weder das wildtypische Level an Biofilmbildung wieder erreicht noch eine Änderung zur Deletionsmutante hervorgerufen werden. In den Biofilm-Assays wurde somit keine Komplementation der Verminderung der Biofilmbildung erreicht.

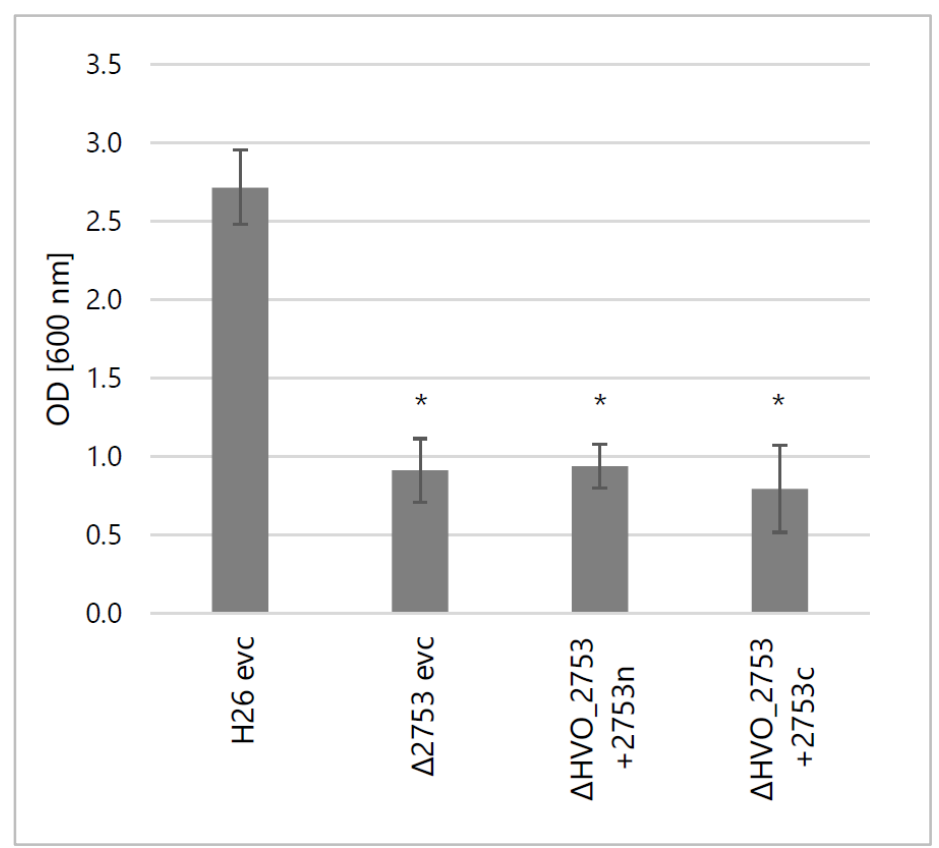

\section{Abbildung 13: Biofilm-Assay der Komplementationsmutanten und der Kontroll-} stämme. Die in den Assay eingesetzten Zellen stammten aus einer Kultur in exponentieller Wachstumsphase in Synthetischem Medium mit Glukose als Kohlenstoffquelle. Statistische Signifikanzen beziehen sich auf den Vergleich des Stammes zum Wildtyp $\mathrm{H} 26$ evc und wurden mittels ungepaartem, zweiseitigen t-Test ermittelt: * - pWert $<0,05$. Herangezogen wurden jeweils drei unabhängige biologische Replikate. Abbildung entnommen und modifiziert aus Zahn et al. (2020).

\subsubsection{Herstellung und Untersuchung von Punktmutanten}

In vorangegangenen Versuchen konnte gezeigt werden, dass die Deletion des Gens HVO_2753 in Anwesenheit des Leerplasmids zum Totalverlust der Schwärmfähigkeit der Zelle führt, während eine plasmidische Expression einer Genvariante 
von HVO_2753 diesen Verlust teilweise komplementieren kann. Deshalb sollte nachfolgend, der Funktionsaufklärung wegen, eine Untersuchung durchgeführt werden, bei der bestimmte, ausgewählte Aminosäuren auf ihre Wichtigkeit hin überprüft werden. Hierfür wurden mittels ortsspezifischer Mutagenese (siehe 3.4.1.4, Abschnitt Ortsspezifische Mutagenese) Punktmutationen in das Gen eingebracht. Diese hatten Aminosäuresubstitutionen an den gewünschten Stellen zur Folge. Die mutierten Genvarianten basierten alle auf der Variante mit einer Sequenz für einen C-terminalen His-Tag und wurden nach der Mutagenese analog zu den Komplementationsplasmiden in das Ausgangsplasmid pTA929 eingebracht. Eine Übersicht über die 6 Aminosäuresubstitutionen, die einzeln vorlagen und zu 6 Punktmutanten führten, zeigt Abbildung 14. Für die Untersuchung wurde jeweils das erste Cystein eines jeden C(P)XCG-Musters, also das erste, dritte, fünfte und siebte Cystein im Protein (C12, C29, C39 und C51) für eine Substitution ausgewählt. Standardmäßig wurde gegen ein Alanin ausgetauscht. Hierbei sollte untersucht werden, ob alle vier Muster und somit beide potenzielle Zinkfinger-Motive für die Funktion essenziell sind. Fehlt ein Cystein im Muster, ist die Bindung eines Zink-lons gestört und die für die Funktion wichtige Tertiärstruktur kann nicht korrekt ausgebildet werden. Zusätzlich zu den vier Cysteinen wurden zwei weitere Aminosäuren für eine Substitution ausgewählt. Glutamin 34 wurde ebenfalls durch Alanin substituiert. Da Q34 innerhalb der Halobacteriaceae nicht konserviert vorliegt, war zunächst nicht zu erwarten, dass diese Aminosäure eine essenzielle Funktion einnimmt. Tyrosin 49 hingegen liegt hochkonserviert, auch in den Orthologen der Methanomicrobia, vor. Zur Substitution von Y49 wurde die strukturell ähnliche Aminosäure Phenylalanin (F) gewählt. Da zu erwarten war, dass diese Aminosäure eine essenzielle Funktion trägt, blieb es zunächst offen, ob die Änderung zu Phenylalanin bereits zu einem Funktionsverlust des Proteins führen wird.

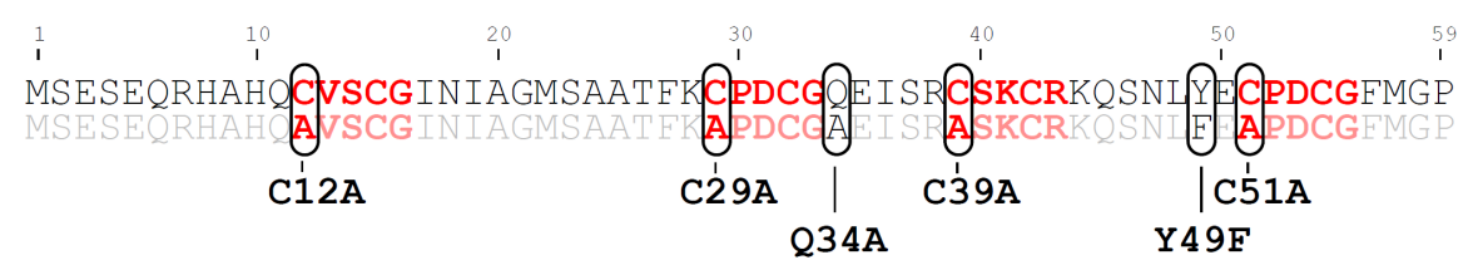

Abbildung 14: Aminosäuresequenz von HVO_2753 mit eingeführten Punktmutationen. Gezeigt sind alle substituierten Aminosäuren und deren Position. 
Die erstellten Punktmutanten, basierend auf der Deletionsmutante $\Delta$ HVO_2753, unterschieden sich zu der Komplementationsmutante $\Delta \mathrm{HVO} 2753+2753 \mathrm{C}$ in lediglich der einen jeweils substituierten Aminosäure in dem plasmidisch exprimierten Genprodukt von HVO_2753c. Die Mutanten zeigten bei der Zellkulturzucht keine signifikanten Abweichungen zu den bisherigen Stämmen (Daten nicht gezeigt.) Um nun die Wichtigkeit der jeweils substituierten Aminosäuren untersuchen zu können, wurde der Phänotyp gewählt, in dem sich Wildtyp und Deletionsmutante unterschieden, bei dem die Abweichung in der Deletionsmutante jedoch durch plasmidische Expression von Genvarianten teilweise komplementiert werden konnte. Die dafür durchgeführten Schwärmversuche zeigten, dass jede der getesteten Aminosäuren eine essenzielle Funktion trägt, wie Abbildung 15 zeigt. Keine der Mutanten zeigte eine Befähigung zum Schwärmen. Analog zum Kontrollstamm $\Delta$ HVO_2753 evc, waren zu keinem Zeitpunkt des Versuchs schwärmende Zellen zu beobachten. Es bildete sich lediglich auf der Oberfläche des halbfesten Schwärmmediums eine Kolonie rund um die Inokulationseinstichstelle. Dieser Versuch wurde indes mit jeweils drei biologischen Replikaten durchgeführt.

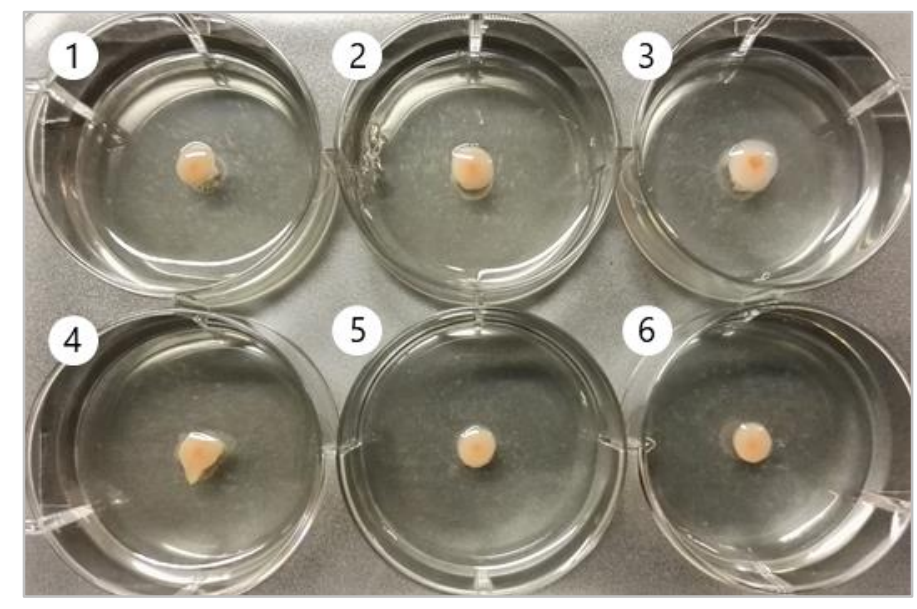

Abbildung 15: Schwärmplatte der Punktmutanten. Gezeigt ist eine 6-Well Platte mit halbfestem synthetischem Medium mit Glukose als Kohlenstoffquelle und 0,3\% Agar nach $192 \mathrm{~h}$ Inkubation. (1) $\Delta \mathrm{HVO} 2753$ +2753c_C12A, (2) $\Delta \mathrm{HVO} 2753$ +2753c_C29A,

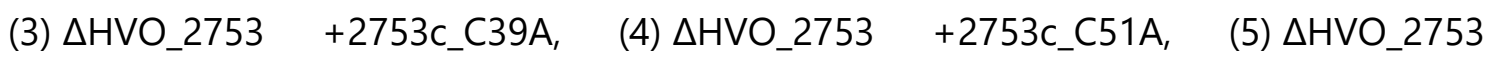
+2753c_Q34A und (6) $\triangle \mathrm{HVO} 2753$ +2753c_Y49F. Abbildung entnommen und modifiziert aus Zahn et al. (2020). 


\subsubsection{Analyse der Genexpression}

Zum Erkenntnisgewinn auf Transkriptebene von HVO_2753 und für die tiefergehende Untersuchung zu den Informationen aus vorangegangenen bioinformatischen Untersuchungen wurden Genexpressionsanalysen mittels Northern Blot durchgeführt. Daten aus vorausgegangenen Studien (Babski et al., 2016; Laass et al., 2019), in denen dRNA- und RNA-Sequenzierungen durchgeführt wurden, gaben bereits Hinweise auf eine Co-Transkription von HVO_2753 und dem Translationsfaktor HVO_2752 (siehe 4.1.1). Um dies experimentell bestätigen zu können, wurde aus Zellen der Stämme H26, 4 HVO_2753, H26 evc, $\Delta$ HVO_2753 evc, $\Delta \mathrm{HVO} 2753+2753 \mathrm{n}$ und $\Delta \mathrm{HVO} 2753+2753 \mathrm{C}$ in der exponentiellen Wachstumsphase RNA isoliert. Diese Gesamt-RNA wurde mittels denaturierender RNA-Gelelektrophorese ihrer Größe nach aufgetrennt, mittels Northern Blot auf eine Nylonmembran übertragen und diese Membran anschließend mit spezifischen Sonden gegen die beiden Transkripte hybridisiert. Nach weiterer Prozessierung der Membran wurde eine Immundetektion durchgeführt und so die entsprechenden Transkripte identifiziert.

Da auf dem forward-Strang, den beiden Genen gegenüber, potenziell eine lange 3'-UTR des Gens HVO_2751 codiert liegt (siehe Abbildung 5), kam hier für diese Genexpressionsanalysen spezifische einzelsträngige DNA-Sonden gegen das jeweilige Transkript zum Einsatz. Dies war nötig, um ausschließen zu können, dass eben diese, gegenüber codierte, 3'-UTR zusätzlich detektiert wird und keine eindeutige Zuordnung der Fragmente geschehen kann. Abbildung 16 zeigt die entwickelten Filme der Genexpressionsanalyse (oben) und die entsprechende GelLadekontrolle (unten). Auf der linken Seite der Abbildung wurde der Wildtyp H26 (1) und die Deletionsmutante $\Delta \mathrm{HVO}_{2} 2753$ (2) mit den Einzelstrang-Sonden $\alpha H V O \_2752$ und $\alpha H V O \_2753$ untersucht. Dabei zeigte sich eindeutig, dass im Wildtyp mit beiden Sonden das gleiche Transkript detektiert werden konnte. Die Transkriptlänge stimmt mit der erwarteten Länge einer bicistronischen mRNA von HVO_2753_HVO_2752 inkl. kurzer 3'-UTR überein (ca. 480 nt). In der Deletionsmutante kann die verkürzte Variante des Transkripts (ca. $330 \mathrm{nt}$ ), wie erwartet, nur mit der Sonde gegen HVO_2752 detektiert werden. Auf der rechten Seite der Abbildung wurden neben dem Wildtyp H26(1) und der Deletionsmutante $\Delta \mathrm{HVO}_{2} 2753$ (2) noch die Kontrollstämme mit Leervektor H26 evc (3) und $\Delta \mathrm{HVO} 2753$ evc (4) und die Komplementationsmutanten $\Delta \mathrm{HVO}_{2} 2753+2753 \mathrm{n}$ (5) 
und $\Delta \mathrm{HVO} 2753+2753 \mathrm{C}$ (6) mit der Sonde gegen HVO_2752 untersucht. Hier zeigte sich ebenfalls ein erwartetes Ergebnis und der Genotyp der verschiedenen Stämme sowie die Ergebnisse der ersten Genexpressionsanalyse konnten bestätigt werden. Die Northern Blot-Analyse der Komplementationsmutanten mit der Sonde gegen HVO_2753 war aufgrund plasmidspezifischer Kreuzhybridisierungen nicht auswertbar (Daten nicht gezeigt).

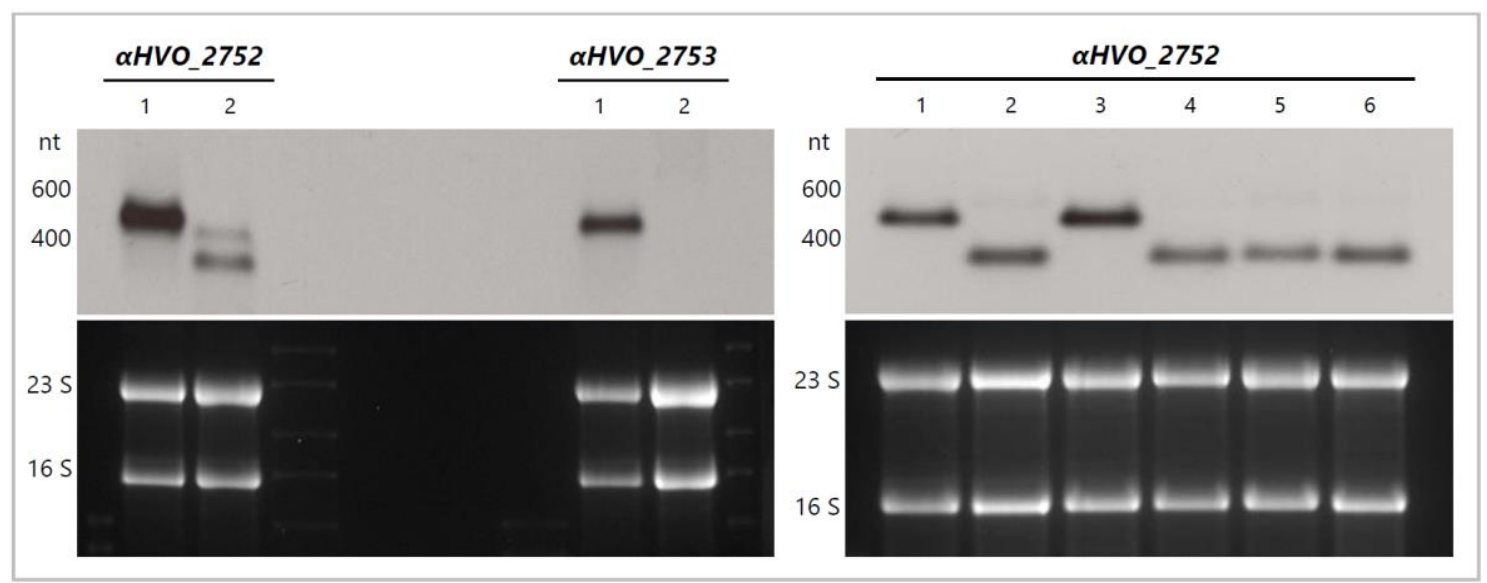

Abbildung 16: Genexpressionsanalyse mittels Northern Blot. Die Hybridisierung erfolgte mit einer Sonde gegen HVO_2752 bzw. HVO_2753 wie angedeutet. Die Spuren entsprechen (1) H26, (2) $\Delta \mathrm{HVO} 2753$, (3) H26 evc, (4) $\Delta \mathrm{HVO} 2753$ evc, (5) $\Delta H V O \_2753$ +2753n und (6) $\Delta \mathrm{HVO} 2753$ +2753c. Als Ladekontrolle sind die 16S und 23S rRNA gezeigt. Abbildung teilweise entnommen und modifiziert aus Zahn et al. (2020).

\subsubsection{Ribosomenprofil durch Dichtegradientenzentrifugation}

Da HVO_2753 mit dem Translationsfaktor HVO_2752 co-transkribiert wird, wurde untersucht, ob zwischen der Mutante mit der Deletion von HVO_2753 und der Überexpression ein signifikanter Unterschied im Ribosomenprofil besteht. Hierfür wurde geklärtes Zelllysat von Zellen aus der exponentiellen Wachstumsphase verwendet und mittels Dichtegradientenzentrifugation im 10-30 \%igen SaccharoseGradienten zentrifugiert (siehe 3.5.1.3 und 3.5.3). Die anschließende spektrometrische Analyse des Gradienten, der hierfür aus dem Zentrifugationsröhrchen von oben nach unten abgepumpt wurde, ergab das Ribosomenprofil, welches in Abbildung 17 dargestellt ist. Hierbei ist zu erkennen, dass die beiden getesteten Stämme keine signifikanten Unterschiede im Ribosomenprofil zueinander aufwiesen. Das Signalrauschen bis 1,5 min ist auf Luftblasen im System zurückzuführen, während die drei Peaks ab ca. 1,5 min bis 4 min der kleinen ribosomalen Unterein- 
heit, der großen ribosomalen Untereinheit und dem Gesamtribosom zugeschrieben werden kann. Um dies abschließend zu bestätigen, wurde von den hierbei gesammelten Fraktionen RNA isoliert und diese in einer denaturierenden RNAGelelektrophorese analysiert.

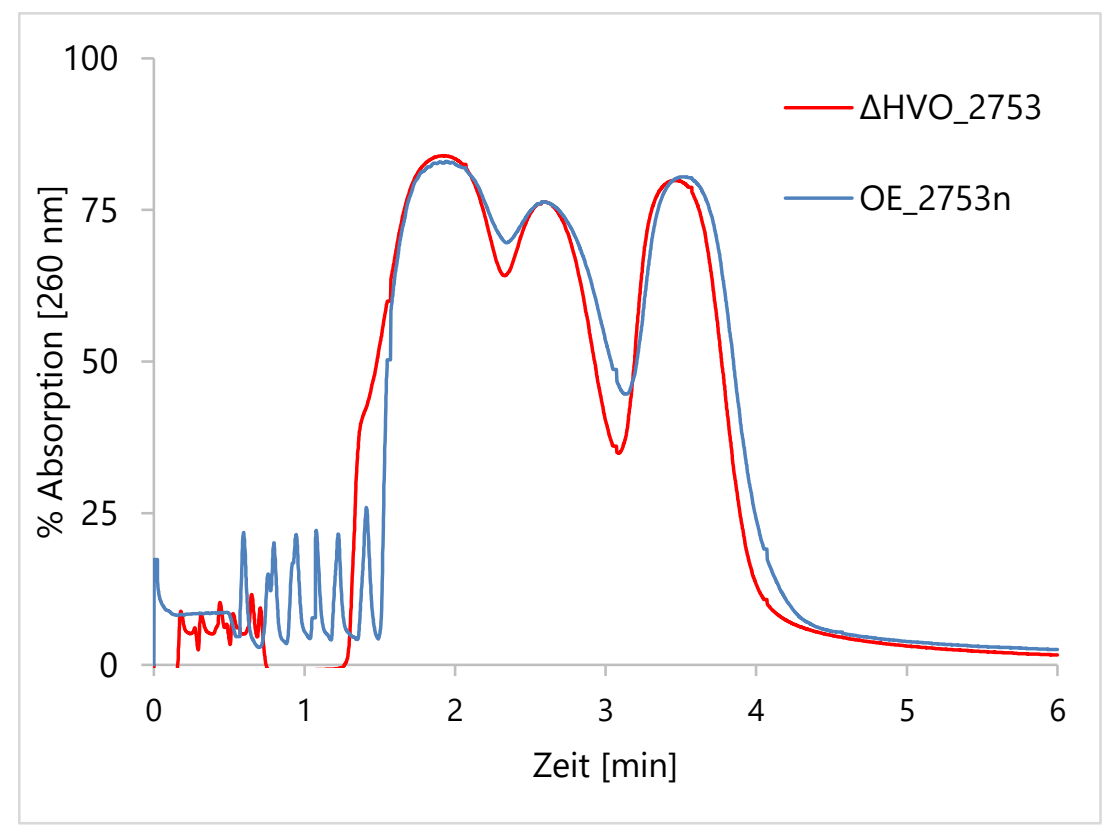

Abbildung 17: Ribosomenprofil nach der Dichtegradientenzentrifugation. Zelllysate von $\triangle H$ HVO_2753 und OE_2753n wurden in einem 10-30 \% Saccharose-Gradienten zentrifugiert und die Zellbestandteile ihrer Größe nach aufgetrennt. Die anschließende spektrometrische Analyse des Gradienten bei $260 \mathrm{~nm}$ von oben nach unten wird als Ribosomenprofil dargestellt.

Für die denaturierende RNA-Gelelektrophorese der Ribosomenprofilfraktionen wurden nach der RNA-Isolierung gleiche Mengen aufgetragen. Die in Abbildung 18 gezeigten Fraktionen entsprechen jeweils einer 30-sekündigen Fraktion zwischen 1,4 min und 4,4 min des entsprechenden Dichtegradienten. Die hier identifizierten ribosomalen RNAs sprechen mit den in den Ribosomenprofilen zugeordneten Ribosomeneinheiten überein. So ist in der ersten Fraktion die 5S rRNA zu sehen, in der zweiten und dritten Fraktion hauptsächlich die 16S rRNA, in der vierten Fraktion hauptsächlich 23S rRNA, während in den Fraktionen 5 und 6 die $16 \mathrm{~S}$ und $23 \mathrm{~S}$ rRNA zu sehen sind, welche vor der RNA-Isolierung noch innerhalb von vollständigen Ribosomen vorlagen. Die Erstellung von Ribosomenprofilen konnte aus zeitlichen Gründen in der vorliegenden Arbeit nur einmal mit den beiden gezeigten Stämmen durchgeführt werden. Dennoch konnte bei der vergleichenden Untersuchung der Ribosomenprofile der Deletionsmutante $\triangle \mathrm{HVO} 2753$ 
und der Überexpressionsmutante OE_2753n gezeigt werden, dass kein signifikanter Unterschied zwischen den Stämmen vorlag.

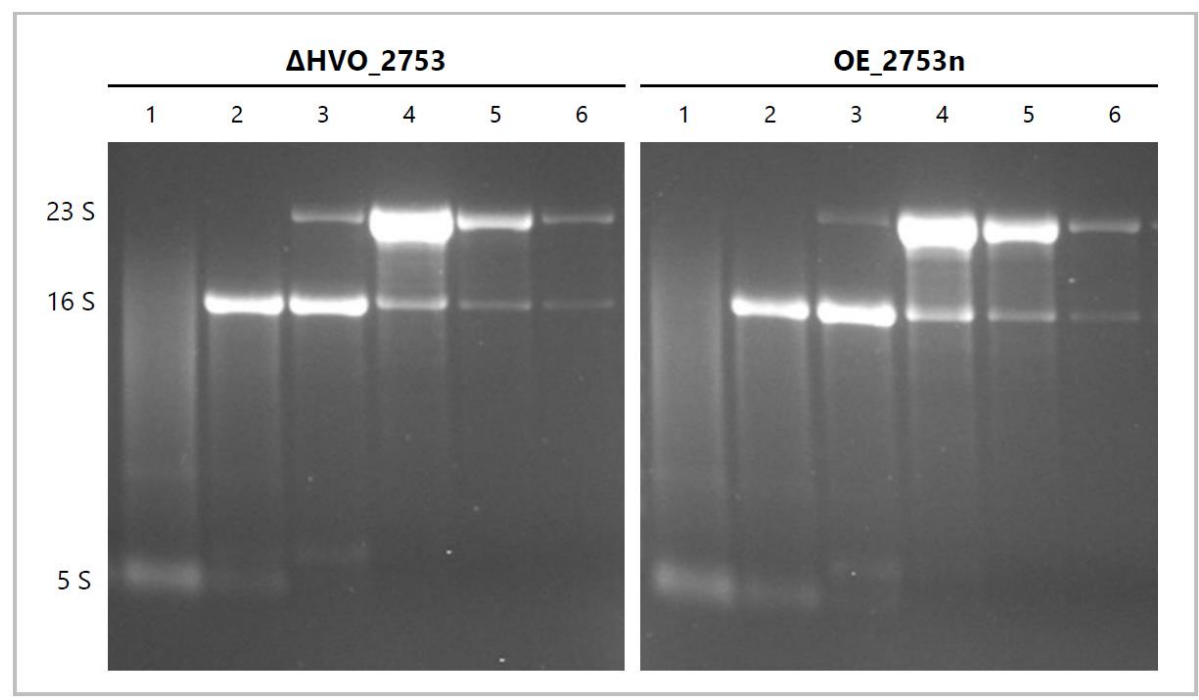

Abbildung 18: Denaturierende RNA-Gelelektrophorese ausgewählter Fraktionen nach der Dichtegradientenzentrifugation. Aufgetragen wurden gleiche Mengen nach einer RNA-Isolierung aus den entsprechenden Fraktionen der Dichtegradientenzentrifugation.

\subsubsection{Die homologe Überproduktion von HVO_2753 zur Erzeugung von spezifischen Antikörpern}

Um in nachfolgenden Experimenten das Protein HVO_2753 in verschiedenen Proben spezifisch mittels Immundetektion nach einem Western Blot nachweisen zu können, sollte ein polyklonaler Antikörper gegen HVO_2753 erzeugt werden. Hierfür wurde die Variante mit N-terminalem His-Tag im homologen System $H$. volcanii plasmidisch überproduziert und mittels Affinitätschromatographie und anschießender Größenausschlusschromatographie aufgereinigt. Die Fraktionen, die HVO_2753n enthielten, wurden gesammelt, dialysiert und dem Dienstleister Davids Biotechnologie $\mathrm{GmbH}$ übergeben, um polyklonale Antikörper im Kaninchen herstellen zu lassen.

Nach Erhalt der Antikörper $\alpha$ HVO_2753n wurden diese zunächst mit verschiedenen Elutionsfraktionen nach der Affinitätschromatographie von überproduziertem HVO_2753n in Western Blot-Analysen getestet (Daten nicht gezeigt). Dabei zeigte sich eine große Anzahl an unspezifischen Signalen. Daher wurde anschlieBend eine Untersuchung von Gesamtzellextrakten vom Wildtyp H26, der Deletionsmutante $\Delta \mathrm{HVO}_{2} 2753$ und der Komplementationsmutante $\Delta \mathrm{HVO}_{-} 2753$ 
+2753n durchgeführt. Als Positivkontrolle wurde HVO_2753n nach der zweistufigen Aufreinigung mittels Affinitäts- und Größenausschlusschromatographie und anschließender Dialyse mitgeführt. Der entwickelte Film ist in Abbildung $19 \mathrm{zu}$ sehen. Während die hochreine Positivkontrolle ein spezifisches, einzelnes Signal auf der erwarteten Höhe zeigt, konnte in keinem der Zellextrakte ein spezifisches Signal von HVO_2753 detektiert werden. Darüber hinaus zeigte sich eine Reihe unspezifischer Signale bei höheren Molekulargewichten. Aufgrund der Unspezifität und der mangelnden Sensitivität des Antikörpers aHVO_2753n wurde dieser für keine weiteren Versuche eingesetzt.

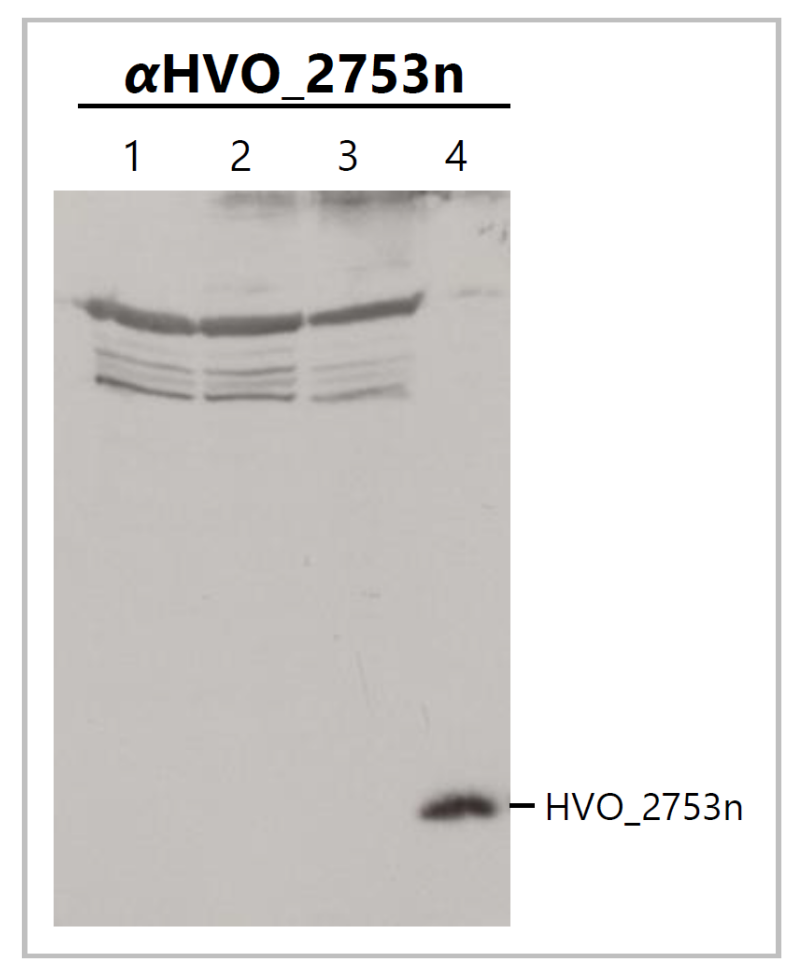

Abbildung 19: Western Blot-Analyse zur Spezifität des Antikörpers aHVO_2753n. Haloferax volcanii-Zelllysate wurden mittels einer Tricin-SDS-PAGE aufgetrennt und das

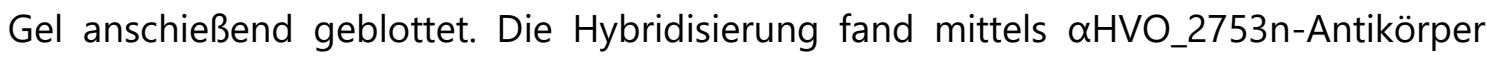
statt. Zu sehen sind Zelllysat von (1) H26, (2) $\triangle H V O \_2753$ und (3) $\Delta H V O \_2753+2753 n$. In (4) wurden $4 \mu \mathrm{g}$ HVO_2753n als Positivkontrolle aufgetragen.

\subsection{Struktur- und Funktionsanalyse von HVO_2753 in vitro}

Neben den vorangegangenen in vivo Untersuchungen, die bereits zahlreiche Hinweise für eine Funktion des Proteins gegeben haben und unabdingbar für eine vollständige Charakterisierung von HVO_2753 sind, können in vitro Untersuchun- 
gen in vielen Bereichen daran anknüpfen und bereits erhaltene Erkenntnisse ausbauen. Voraussetzung aller nachfolgenden Versuche war es, das Protein in einer ausreichend reinen Form vorliegen zu haben. Zu diesem Zwecke wurde in der vorliegenden Arbeit die Überproduktion von HVO_2753 im homologen System entwickelt und optimiert. Viele der nachfolgend beschriebenen Methoden zunächst mussten für die Analyse des kleinen Proteins angepasst und weiterentwickelt werden.

\subsubsection{Die homologe Überexpression von HVO_2753}

Um das reine Protein für nachfolgende Untersuchungen vorliegen zu haben, sollte zunächst mittels einer der für die Komplementationsversuche erstellten Stämme eine Überproduktion durchgeführt werden. Es galt zu ermitteln, welche Lokalisierung des His-Tags besser geeignet ist, das Protein in großer Menge aufreinigen zu können. Hierfür wurden verschiedene Induktionsstärken, mittels verschiedener Tryptophan-Konzentrationen im Kulturmedium, getestet sowie verschiedene Inkubationsperioden. Da zwischen den Protein-Varianten HVO_2753n und HVO_2753c keine signifikanten Unterschiede in der Ausbeute festzustellen waren, diese jedoch insgesamt sehr gering ausfiel, wurde nach einem alternativen Überexpressionsplasmid gesucht. In einer früheren Studie zur Untersuchung des archaealen "distal promoter elements", wurde eine randomisierte Promotorbibliothek, basierend auf dem Ferredoxin(fdx)-Promotor erstellt (Danner \& Soppa, 1996). Im Zuge dieser Studie konnten mittels Selektionsdruck Promotorvarianten identifiziert werden, die eine höhere Aktivität aufwiesen, da sie den entsprechenden Zellen eine höhere Resistenz verliehen, wenn das Resistenzgen unter Kontrolle des jeweiligen Promotors stand. Das Plasmid pSD1_R1/6 dieser Bibliothek, das einen sehr starken Promotor trägt, wurde ausgewählt und so modifiziert, dass es eine zusätzliche Ndel-Schnittstelle nach dem Promotor aufweist. Die Genvariante HVO_2753n mit dem N-terminalen His-Tag wurde ebenso in dieses modifizierte Plasmid kloniert. Durch Transformation der Deletionsmutante $\Delta \mathrm{HVO} 2753$ mit diesem Plasmid pSD1_R1/6_HVO_2753_NHis wurde die Überexpressions(overexpression, oe)-Mutante OE_2753n erstellt. Diese wies nun keinen induzierbaren, sondern einen starken konstitutiven Promotor auf und wurde zunächst in vorläufigen Versuchen getestet. Die Ausbeute von HVO_2753n war sehr stark 
erhöht und es konnte nach einer Inkubationszeit der Überexpressionshauptkulturen von $24 \mathrm{~h}$ kein Abbau des Proteins festgestellt werden (Daten nicht gezeigt).

\subsubsection{Die Aufreinigung von HVO_2753}

\subsubsection{Affinitätsaufreinigung mittels Nickel-Chelat-Sepharose}

Nach der Überproduktion von HVO_2753n im homologen System H. volcanii und erfolgtem Zellaufschluss mittels Sonifikation, wurde durch Sedimentation der Zellfragmente ein geklärtes Zelllysat erzeugt (siehe 3.5.1.1 und 3.5.1.3). Dieses konnte nachfolgend verwendet werden, um das überproduzierte Protein mit HisTag aufzureinigen. Dieser erste Schritt der Aufreinigung, die Nickel-Affinitätsaufreinigung, wurde in einer Gravitationssäule durchgeführt (siehe 3.5.1.4). Entscheidend war hier, dass alle Puffer einen hohen Salzgehalt aufwiesen, um zu gewährleisten, dass die Proteine, die im halophilen Organismus an hohe lonenkonzentrationen angepasst sind, ihre Faltung beibehalten und so eine native Aufreinigung gewährleistet ist. Ein Aufreinigungsgel der Affinitätsaufreinigung, bei der bei jedem Schritt Proben genommen wurden, ist in Abbildung 20 auf der linken Seite zu sehen. Hier sieht man das geklärte Lysat (L) nach der Zellfragmentsedimentation, den Lysatdurchfluss (FT) nach dem Binden an die Matrix, die erste und eine weitere Waschfraktion (W1, W5) und die Elutionsfraktionen (E1-E5). Alle Proben mussten gegen $25 \mathrm{mM}$ Tris/ $\mathrm{HCl} \mathrm{pH} \mathrm{7,5}$ dialysiert werden, bevor sie in die TricinSDS-PAGE eingesetzt werden konnten. Die Dialyse von jeweils $40 \mu$ wurde mittels Membranfilterscheiben (Merck, Darmstadt) für 30 min schwimmend auf dem Puffer in Petrischalen durchgeführt. Von den Proben L, FT und W1 konnte aufgrund der sehr hohen Proteinkonzentration nur eine 1:10-Verdünnung aufgetragen werden, daher ist auf Höhe von 10-12 kDa keine Fraktion eindeutig zu erkennen, die HVO_2753n zugeordnet werden kann. Bei dem Fortschreiten des Waschvorgangs wurden nach und nach viele der unspezifisch gebundenen Proteine weggewaschen und sind in späteren Waschfraktionen, wie W5, nicht mehr vorhanden. Ab E2 ist HVO_2753n in den Elutionsfraktionen zunächst in sehr großer, dann absteigender Menge vorhanden. Das Protein läuft, wie viele halophile Proteine, aufgrund seiner physikochemischen Eigenschaften in der Tricin-SDS-PAGE bei signifikant höheren Molekülmassen (Tokunaga et al., 1999; Madern et al., 2000). 


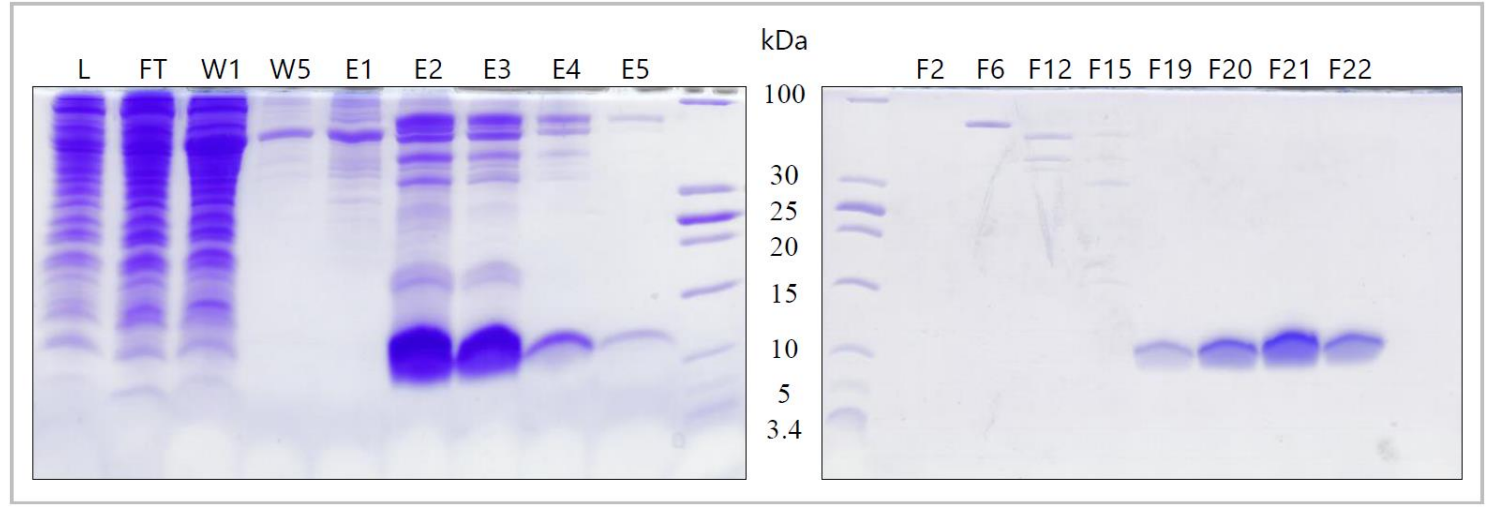

Abbildung 20: Tricin-SDS-PAGE ausgewählter Fraktionen der beiden Aufreinigungsschritte von HVO_2753n. Links sind Fraktionen der Affinitätsaufreinigung mittels Nickel-Chelat-Sepharose und rechts der Größenausschlusschromatographie zu sehen. (L) Lysat, (FT) Durchfluss, (W1, W5) Waschfraktionen, (E1-E5) Elutionsfraktionen, (F2F22) ausgewählte Fraktionen der Größenausschlusschromatographie. Die Gele sind Coomassie gefärbt, als Größenstandard kam PageRuler ${ }^{\mathrm{TM}}$ Unstained Low Range Protein Ladder zum Einsatz. Abbildung entnommen und modifiziert aus Zahn et al. (2020).

\subsubsection{Aufreinigung mittels Größenausschlusschromatographie}

Aufgrund der Anzahl an unspezifischen Proteinen in den Elutionsfraktionen der vorangegangenen Affinitätschromatographie, wurde mit der Größenausschlusschromatographie ein zweiter Aufreinigungsschritt angehängt. Bei dieser läuft die Probe über eine poröse Matrix und kleine Moleküle werden proportional länger retentiert als Große. Ein Chromatogramm einer Größenausschlusschromatographie ist beispielhaft in Abbildung 21 gezeigt. Hier wurde eine Elutionsfraktion nach der Nickel-Affinitätschromatographie aufgereinigt. Neben den Kontaminanten im Bereich $7 \mathrm{ml}$ bis $17 \mathrm{ml}$ eluiert das später als HVO_2753n identifizierte Protein bei knapp $20 \mathrm{ml}$. Im Chromatogramm sind die gesammelten Fraktionen, die einem Peak zugeordnet wurden, entsprechend vermerkt. Diese wurden zusammen mit weiteren Fraktionen rund um den HVO_2753n-Peak mittels einer TricinSDS-PAGE aufgetrennt. Das zugehörige Coomassie-gefärbte Gel ist in Abbildung 20 auf der rechten Seite zu sehen. Hier ist zu erkennen, dass sich die Kontaminanten höherer Molekülmassen in den ersten Fraktionen befinden, während ab Fraktion F19 bis Fraktion 22 das überproduzierte Protein zu finden ist. 


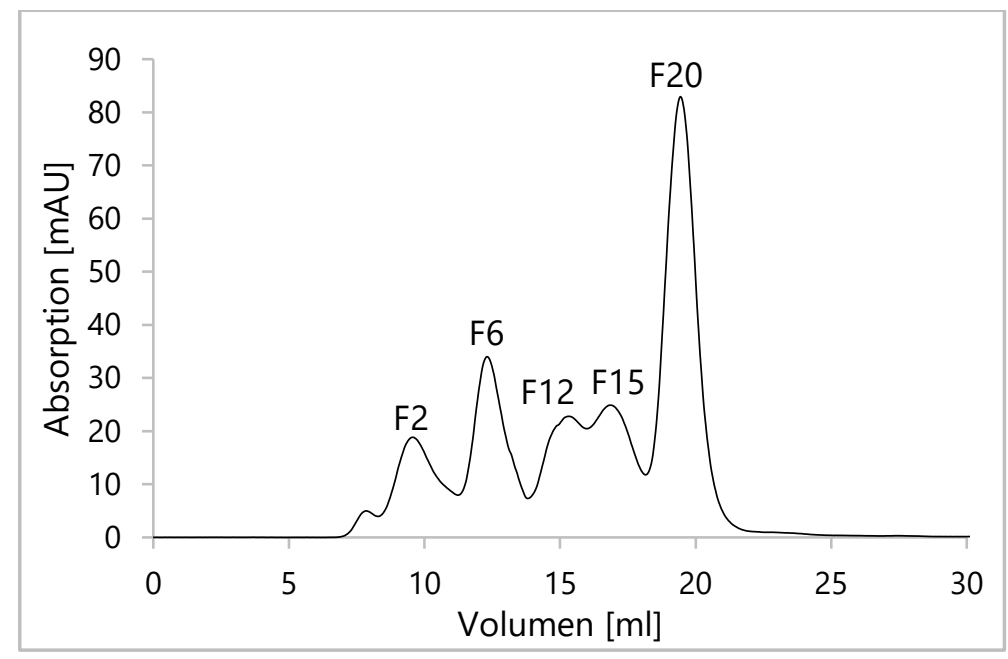

Abbildung 21: Chromatogramm der Größenausschlusschromatographie von HVO_2753n. Eingesetzt wurde hier Elutionsfraktion 2 aus der Affinitätsaufreinigung (siehe Abbildung 20). Die angedeuteten Fraktionen (F2-F20) entsprechen den jeweiligen Peaks und den jeweiligen Spuren in Abbildung 20. Als Säule kam hier die Superose ${ }^{\mathrm{TM}} 6$ 10/300 GL zum Einsatz.

\subsubsection{Massenspektrometrische Analyse von HVO_2753}

Um zunächst die monoisotopische Masse des überproduzierten Proteins mit HisTag und mögliche posttranslationale Modifikationen zu identifizieren, wurde HVO_2753n nach der Zwei-Schritt-Aufreinigung mittels Nickel-Affinitäts- und Größenausschlusschromatographie massenspektrometrisch analysiert. Diese Top-down und bottom-up MS-Analyse wurde innerhalb des Z1-Projekts des Schwerpunktprogramms 2002 von Liam Cassidy (Arbeitsgruppe Tholey) der Universität zu Kiel durchgeführt. Dabei konnte eine monoisotopische Masse von $7250.02 \mathrm{Da}$ festgestellt werden, welche in starker Übereinkunft mit der theoretischen Masse von $7250.10 \mathrm{Da}(\Delta$ mass: - $0.083 \mathrm{Da}$ ) steht. Abbildung A1 im Anhang zeigt beispielhaft eine Messung intakten Proteins. Darüber hinaus gaben diese Experimente keinen Hinweis auf Proteoformen, die für posttranslationale Modifikationen sprechen, obwohl HVO_2753 eine hohe Anzahl an Aminosäuren trägt, die potenziell modifiziert werden können.

\subsubsection{Quantitative Analyse von gebundenem Zink}

HVO_2753 ist das einzige der 43 Zinkfinger-Proteine kleiner 70 Aminosäuren von $H$. volcanii, das zwei Zinkfinger-Motive beinhaltet. Die Annahme, dass es daher zwei Zink-lonen bindet, sollte zunächst bestätigt werden. Zu diesem Zwecke 
wurde eine quantitative Analyse mittels fluorimetrischem Zink-Assay durchgeführt. Bei diesem Assay wird das hochsensitive, für Zink hochspezifische, Fluorophor ZnAF-2F verwendet, um die Menge an gelösten Zink-Ionen relativ zu einer Standardreihe messen zu können (Hirano et al., 2002). Hierfür wurde HVO_2753n verwendet, welches homolog überproduziert und unter nativen Bedingungen im zweistufigen Aufreinigungsprozess hochrein erhalten wurde. In Vorversuchen wurde bereits herausgefunden, dass HVO_2753n, nicht wie erwartet, bei niedrigen Salzkonzentrationen wie $25 \mathrm{mM} \mathrm{NaCl}$ nicht völlig unlöslich vorliegt und ausfällt. Daher musste, um das Protein zu denaturieren bzw. zu zerstören, eine Protease-Behandlung mit Proteinase $\mathrm{K}$ herangezogen werden. Dies war nötig, da die Zink-Ionen für die Quantifizierung gelöst vorliegen müssen. Anschließend konnte mittels $3 \mu \mathrm{M}$ ZnAF-2F im Überschuss die Menge an Zink-Ionen aus $1 \mu \mathrm{M}$ HVO_2753 im Vergleich zu einer Standardreihe von $\mathrm{ZnCl}_{2}$ gemessen werden. Abbildung 22 zeigt das Ergebnis von sieben unabhängigen biologischen Replikaten. Während ohne Proteasebehandlung bei den für den Assay benötigten Niedrigsalz-Bedingungen mit 0,2 äquimolar $\mathrm{Zn}^{2+}$ zu HVO_2753 nur ein geringer Teil an Zink-Ionen gelöst vorliegt, kann bei vollständigem Proteaseverdau eine etwa 0,7 äquimolare Menge an Zink-Ionen zu Protein gemessen werden. Dies spricht für ein Vorhandensein von lediglich einem Zink-Ion pro HVO_2753-Molekül. 


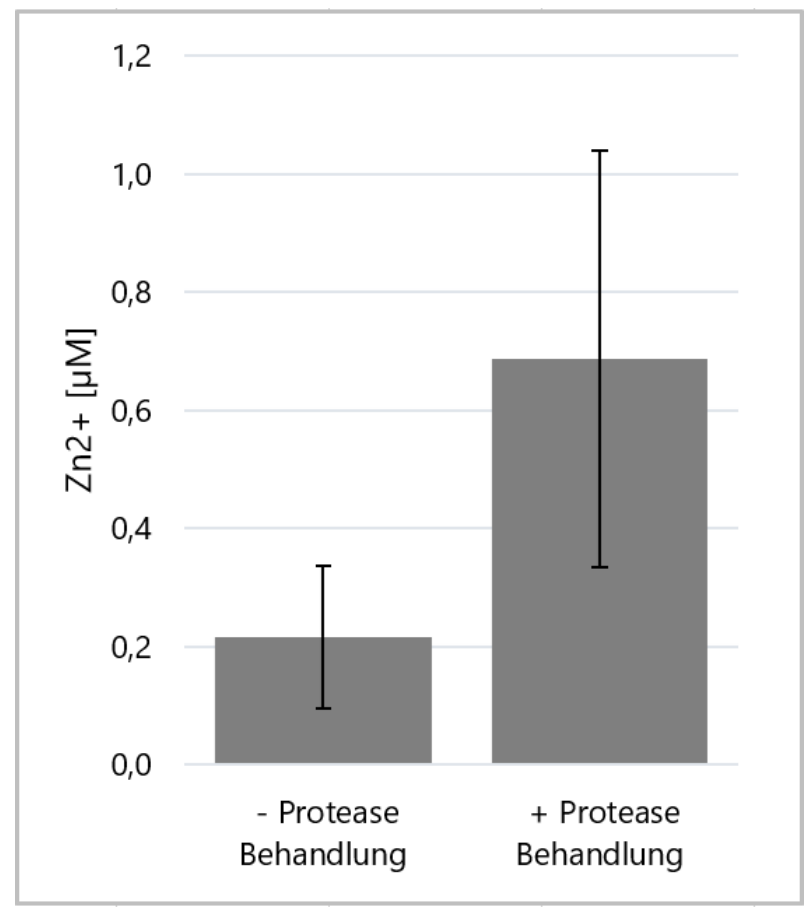

Abbildung 22: Quantifizierung von Zink-Ionen mittels fluorimetrischem Zink-Assay. HVO_2753n wurde homolog überproduziert, mittels Zwei-Schritt Aufreinigung gereinigt und gegen Zink-Assay Puffer dialysiert. Es wurde jeweils $1 \mu \mathrm{M}$ Protein mit (+) oder ohne voheriger (-) Protease-Behandlung für die hochsensitive und hochspezifische Quantifizierung mittels ZnAF-2F eingesetzt. Gezeigt sind Mittelwerte und Standardabweichungen von sieben unabhängigen biologischen Replikaten. Abbildung entnommen und modifiziert aus Zahn et al. (2020).

\subsubsection{Bindepartnersuche mittels Co-Affinitätsaufreinigung}

Eine Möglichkeit der Funktionsaufklärung von Proteinen liegt darin deren Bindepartner zu identifizieren. Wenn die Funktion der Bindepartner oder Orthologen davon in verwandten Organismen bekannt ist, können möglicherweise auch für das Protein Funktionen abgeleitet werden.

\subsubsection{Suche nach potenziellen RNA-Bindepartnern}

Da manche Orthologe von HVO_2753 als putative Zink-Ribbon RNA-Bindeproteine annotiert sind, lag es nahe, zu überprüfen, ob man einen potenziellen RNABindepartner von HVO_2753 identifizieren kann. Hierzu wurde eine Co-Affinitätsaufreinigung durchgeführt, indem HVO_2753n homolog überproduziert und nativ mittels Nickel-Affinitätschromatographie aufgereinigt wurde. Von ausgewählten Elutionsfraktionen, die das überproduzierte Protein in großer Menge enthalten, wurde RNA mittels Phenol-Chloroform-Isoamylalkohol-Methode isoliert. Im 
Nachgang erfolgte eine komplexe Prozessierung der hierbei erhaltenen RNA (siehe 3.4.4.5). Es wurde zunächst ein DNA-Adapter an das 3'-Ende der unbekannten RNAs ligiert. Der Adapter besaß ein 5'-Phosphat und war am 3'-Ende mit einem Amino-Modifier-C3-CPG blockiert. Anschließend konnte von den unbekannten Adapter-ligierten RNAs eine einzelsträngige cDNA synthetisiert werden. Nach Abbau der RNA im nun vorliegenden DNA:RNA-Hybrid konnte wiederum ans 3'Ende der cDNA der DNA-Adapter ligiert werden. Jetzt konnten abschließend mittels PCR doppelsträngige CDNAs hergestellt werden, die unbekannte, potenzielle RNA-Bindepartner und an beiden Enden den DNA-Adapter umfassten. Über den DNA-Adapter wurde eine Erkennungssequenz für ein Restriktionsenzym eingebracht, mithilfe dessen die cDNAs in Plasmide kloniert werden konnten. AnschlieBend fand eine Transformation von E. coli statt und mittels Kolonie-PCR wurden Transformanden ausgewählt. Diese wurde in Mini-Kulturen angezogen, die Plasmide isoliert und sequenziert. Der gesamte Prozess wurde ebenso mit einer Überproduktion eines Kontroll-Proteins, der Dihydrofolat-Reduktase, durchgeführt. Hiermit sollten unter anderem unspezifisch gebundene RNAs identifiziert werden können.

Nach Etablierung und Optimierung dieser Methode konnte aus zeitlichen Gründen im Zuge dieser Arbeit der Versuch nur einmal komplett durchgeführt werden. Nach der Transformation von E. coli wurden sowohl 48 Klone mit Konstrukten basierend auf HVO_2753-Bindepartnern als auch 45 Klone der Kontrollgruppe mittels Kolonie-PCR getestet. Die PCR-Bedingungen waren hierbei so gewählt, dass mit den plasmidspezifischen Oligonukletid-Primern theoretisch Inserts bis zu einer Länge von 6000 bp amplifiziert werden können. Von 48 getesteten Klonen wiesen vier Klone die PCR-Fragmentgröße des Leerplasmids auf und 22 wiesen Doppel- oder Mehrfachbanden in der Kontrollgelelektrophorese der KoloniePCR auf. Die restlichen 22 Klone wurden für die weitere Identifizierung ausgewählt. Die Kontrollen zeigten nach der Kolonie-PCR viele Fragmente der Größe des Leerplasmids oder geringfügig Größere. Diese wurden in Vorversuchen bereits identifiziert und waren auf einzelne oder mehrfach aneinander ligierte, klonierte DNA-Adapter Inserts zurückzuführen (Daten nicht gezeigt). Darüber hinaus gab es auch in der Kontrolle 23 Transformanden, die Doppel- oder Mehrfachbanden im Kontrollgel aufwiesen. Von der Kontrolle wurden fünf Klone ausgewählt, 
die in der Kolonie-PCR Einzelfragmente größer der Leerplasmid-Kontrolle aufwiesen. Die durch die Sequenzierung der Plasmide erhaltenen Sequenzen wurden mittels Nukleotid-BLAST (NCBI, Bethesda, USA) mit dem H. volcanii-Genom abgeglichen. Die Sequenzen wiesen Längen von 78 bis 397 bp (Ø 187 bp) auf. Die jeweils zugeordneten Elemente und Häufigkeiten sind in Tabelle 40 gezeigt. Es zeigte sich, dass sowohl mit HVO_2753 als auch mit der Kontrolle ribosomale RNA co-aufgereinigt wurde. Während 23S rRNA mit beiden Proteinen, war die 16S rRNA nur mit der DHFR und die 5S rRNA nur mit HVO_2753 co-isoliert worden. Die 7S Signal Recognition Particle RNA wurde einmal mit HVO_2753 gefunden. Neun Sequenzen der HVO_2753- und 2 Sequenzen der DHFR-Aufreinigung erzielten keine Treffer in der Nukleotid-BLAST Suche. Mit HVO_2753 konnte ein 155 bp-langes Element co-isoliert werden, das dem 3'-Bereich von HVO_0598 und HVO_0599 auf dem Gegenstrang zugeordnet werden konnte. Jedoch ist von keinem der Gene eine Funktion bekannt. Des Weiteren wurde die tRNA (Glu) viermal mit HVO_2753 co-isoliert. Alle vier Sequenzen wiesen hier eine Identität über eine Länge von 63 bp zueinander und noch mehr zur tRNA (Glu) auf. Mithilfe dieses Protokolls konnten mit verschiedenen ribosomalen RNAs und der tRNA (Glu) potenzielle RNA-Interaktionspartner von HVO_2753 identifiziert werden. Jedoch müssen diese in weiteren Versuchen als solche zunächst bestätigt werden.

Tabelle 40: Ergebnisse der RNA-Bindepartner-Suche von HVO_2753. Gezeigt sind die jeweils gefundenen Elemente und deren Häufigkeit bei Konstrukten basierend auf Bindepartnern von HVO_2753 und der Kontrolle DHFR.

\begin{tabular}{lll}
\hline Gefundenes Element & HVO_2753 & DHFR \\
\hline 5S rRNA & $4 \times$ & - \\
16S rRNA & - & $1 \times$ \\
23S rRNA & $3 \times$ & $1 \times$ \\
7S Signal Recognition Particle RNA & $1 \times$ & - \\
tRNA (Glu) & $4 \times$ & - \\
ATP-abhängige Protease Lon & - & $1 \times$ \\
unbekannte Sequenz & $9 \times$ & $2 \times$ \\
3'-Bereich von HVO_0598 & $1 \times$ & - \\
\hline
\end{tabular}




\subsubsection{Suche nach potenziellen Protein-Bindepartnern}

Von Zinkfinger-Proteinen ist bekannt, dass diese verschiedenste Bindepartner besitzen können (Krishna et al 2003). So gibt es neben Zinkfinger-Proteinen, die an RNA binden, auch welche die Proteine als Bindepartner besitzen. Die Möglichkeit, dass auch HVO_2753 mit anderen Proteinen interagieren kann, sollte näher untersucht werden. Hierfür wurde eine Crosslink-Methode zu Hilfe genommen, mit der man Proteine und andere Moleküle bereits in vivo miteinander vernetzen kann. Dieser Crosslink mittels Formaldehyd ist unspezifisch, setzt jedoch eine unmittelbare räumliche Nähe der beiden zu vernetzenden Moleküle voraus.

Für diesen Versuch wurden Zellen des Überexpressionsstamms OE_2753n aus der exponentiellen Wachstumsphase verwendet. Diese wurden sedimentiert und mit Basalsalz gewaschen und anschließend in Basalsalz resuspendiert. Hier fand nun der in vivo Crosslink statt, indem Formaldehyd in einer Endkonzentration von 0,75\% zugegeben und das Gemisch für 10 min bei RT rotierend inkubiert wurde. Die optimale Konzentration an Formaldehyd und die Dauer der Inkubation für den Crosslink wurde in Vorversuchen ermittelt und anhand der dadurch erhaltenen Daten festgelegt (Daten nicht gezeigt). Nach Abstoppen des Crosslinks, weiteren Waschschritten und der Zellyse mittels Sonifikation, fand unter nativen Bedingungen eine Nickel-Affinitätschromatographie statt. Mit ausgewählten Elutionsfraktionen wurde eine Größenausschlusschromatographie durchgeführt. Abbildung 23 zeigt die Chromatogramme von drei unabhängigen biologischen Replikaten einer solchen Co-Affinitätsaufreinigung und einer Kontrolle, die identisch behandelt, bei der jedoch kein Formaldehyd-Crosslink durchgeführt wurde. Es zeigte sich zunächst eine sehr gute Reproduzierbarkeit innerhalb der biologischen Replikate. Bei ca. 16 ml ist das Signal von HVO_2753n zu sehen, welches in der Kontrolle erwartet hoch ausfällt, in den Proben mit Crosslink jedoch stark vermindert vorliegt. Die Zuordnung des Signals zu HVO_2753n ist durch Tricin-SDSPAGE und durch massenspektrometrische Analysen erfolgt (Daten nicht gezeigt). Des Weiteren ist im Bereich zwischen 12 und $13 \mathrm{ml}$ durch in vivo Crosslinking ein weiterer Peak entstanden. Der Bereich 7 bis $11 \mathrm{ml}$ ist in den Crosslink-Proben durch ein sehr starkes Signal gekennzeichnet. Dieser Bereich konnte in vorangegangenen Untersuchungen in Proben ohne Crosslinking bereits ribosomalen Untereinheiten zugeordnet werden (Daten nicht gezeigt). 


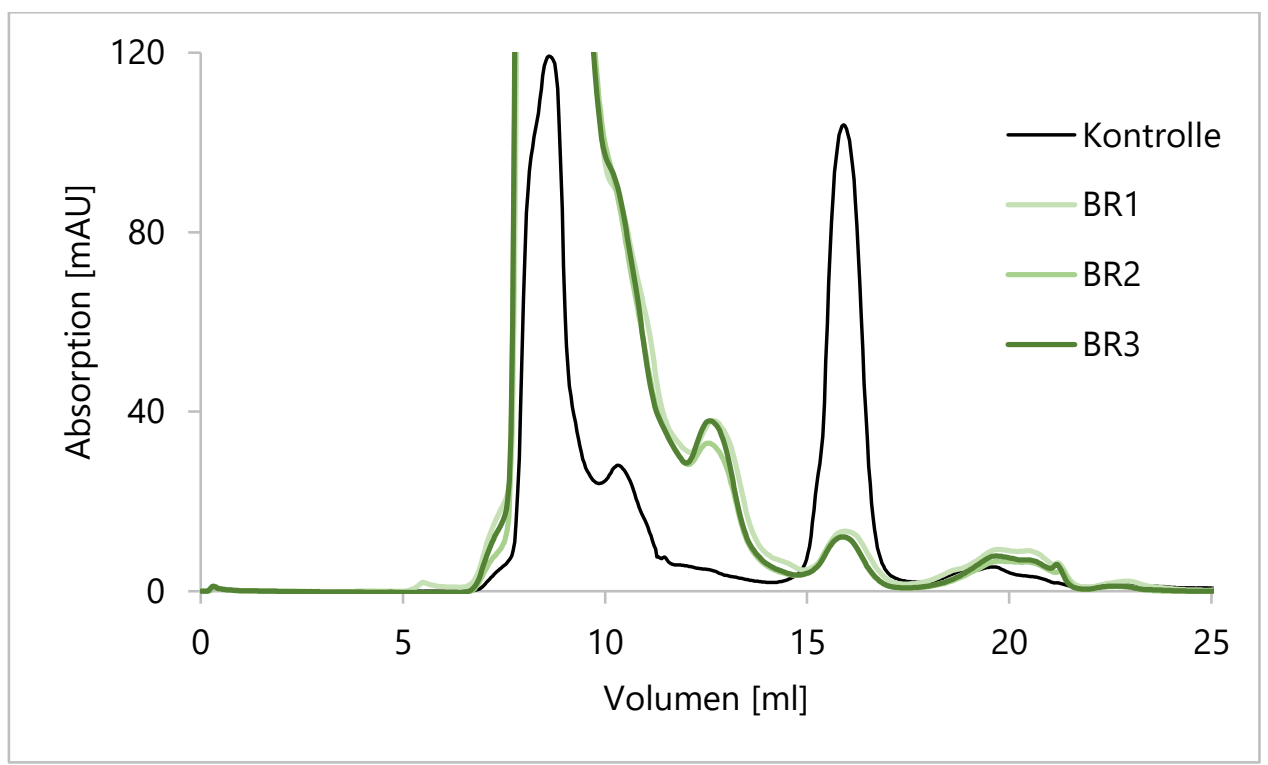

Abbildung 23: Chromatogramme der Größenausschlusschromatographie von HVO_2753n mit und ohne in vivo Crosslink. Eingesetzt wurden hier jeweils Elutionsfraktionen aus vorangegangenen Affinitätsaufreinigungen. Gezeigt sind die Chromatogramme dreier unabhängiger biologischer Replikate (BR1-3) nach in vivo Crosslink und einer Kontrolle ohne Crosslink. Als Säule kam hier die Superdex ${ }^{\mathrm{TM}} 75$ Increase 10/300 GL zum Einsatz.

Dieser starke Unterschied zwischen der Menge von HVO_2753n-Monomeren in Proben mit Crosslink und Proben ohne Crosslink und das Entstehen eines weiteren Signals bei höheren Molekulargewichten nach dem Crosslink sollte anschlieBend mittels massenspektrometrischer Analyse weiter untersucht werden. Hierfür wurden Fraktionen nach der nativen Größenausschlusschromatographie ausgewählt, über Nacht bei $4{ }^{\circ} \mathrm{C}$ gegen 25 mM Tris ( $\mathrm{pH} \mathrm{7,2)} \mathrm{dialysiert} \mathrm{und} \mathrm{ans} \mathrm{Geräte-}$ zentrum für Massenspektrometrie und Elementanalytik (Arbeitskreis Prof. Uwe Linne) geschickt. Dort erfolgte eine Untersuchung mittels Orbitrap Velos Pro nanoRSLC.

Ausgewählt wurden jeweils drei $1 \mathrm{ml}$-Fraktionen jedes biologischen Replikats aus dem Bereich 10,5 $\mathrm{ml}$ bis 13,5 ml des Chromatogramms (siehe Abbildung 23). Als Kontrolle dienten zusammengeführte Fraktionen der Kontrolle aus dem Bereich nach $10 \mathrm{ml}$, sodass insgesamt zehn Proben für die Analyse vorlagen. Eine genauere Aufzeichnung der jeweiligen Fraktionen befindet sich im Anhang in Abbildung A2. Die Rohdaten der MS-Analyseergebnisse wurden für die Auswertung prozessiert. Hier erfolgte neben einer Auswahl relevanter Werte auch die Kuration der Daten. Die Annotation aus der HaloLex-Datenbank und die Funktionsklassen der 
jeweiligen Proteine wurde hinzugefügt. Die Werte zueinandergehörender Fraktionen der verschiedenen biologischen Replikate (BR1-3) wurden zusammengeführt. Alle potenziell identifizierten Proteine, die nicht in mindestens zwei der drei Replikate gefunden wurden, wurden gelöscht. Das entscheidende Kriterium hierfür waren die PSM-Werte (Peptide Spectrum Matches). Alle potenziell identifizierten Proteine, die mit mindestens $10 \%$ des PSM-Durchschnitts der drei biologischen Replikate auch in der Kontrolle gefunden wurden, wurden gelöscht. Der Bereich kleiner 10 \% PSM im PSM-Durchschnitt der drei biologischen Replikate und größer als 0 PSM in der Kontrolle enthielt keine Ergebnisse, weshalb alle in den Ergebnistabellen enthaltenen, identifizierten Proteine genau 0-mal in der Kontrolle gefunden wurden. Nach Anwendung all dieser Kriterien lagen für jede der drei Proben (BR1-3) eine Ergebnistabelle vor (siehe Tabelle A1 bis A3 im Anhang). Hier waren alle Proteine die potenziell mit HVO_2753n nach einem in vivo Crosslink zusammen aufgereinigt werden konnten, aus einem ausgewählten Molekülmassenbereich des Größenausschlusschromatogramms, aufgelistet. In den Ergebnistabellen sind für Fraktion 1 (ca. 10,5-11,5 ml) 131 potenziell identifizierte Proteine, für Fraktion 2 (ca. 11,5-12,5 ml) sind 78 und für Fraktion 3 (ca. 12,5$13,5 \mathrm{ml}$ ) sind 134 potenziell identifizierte Proteine vorhanden. Aufgrund zugrundeliegender Standardreihen der Größenausschlusschromatographie mit Proteinen verschiedener, bekannter Größen, lässt sich den entsprechenden Fraktionen ein ungefähres, entsprechendes Molekulargewicht der enthaltenen Proteine/Proteinkomplexe zuordnen (Daten nicht gezeigt). Fraktion 1 entspräche einem Molekulargewicht von 42-30,5 kDa, Fraktion 2 dementsprechend 30,5-22 kDa und Fraktion 3 einem Molekulargewicht von 22-16 kDa. Wenn in den Fraktionen nun Proteine vorliegen, die mit HVO_2753n kovalent verbunden sind, reduziert sich das entsprechende Molekulargewicht der gefundenen Bindepartner um das von HVO_2753n, also um 7,2 kDa. Im Folgenden wird nun davon ausgegangen, dass HVO_2753n mit jeweils nur einem Bindepartner vernetzt wurde und dieser mit keinem Weiteren. Der Mittelwert der Molekulargewichte aller identifizierten Proteine in den drei Ergebnistabellen beträgt 27,8 kDa (F1), 19,3 kDa (F2) und 13,9 kDa. Addiert man nun jeweils die 7,2 kDa von HVO_2753n erhält man ca. $35 \mathrm{kDa}, 26,5 \mathrm{kDa}$ und 21,2 kDa für die drei Fraktionen. Diese Werte liegen innerhalb der erwarteten Bereiche. Jedoch ließ die große Anzahl an potenziellen Bin- 
departnern keine eindeutige Zuordnung oder gar eine Identifizierung der Funktion von HVO_2753 zu. Potenzielle Bindepartner mit hohen durchschnittlichen PSM-Werten der drei biologischen Replikate stellen mit der höchsten Wahrscheinlichkeit einen wirklichen Bindepartner dar. Neben vielen uncharakterisierten Proteinen und Proteinen ohne bekannte Funktion befindet sich unter diesen Proteinen mit den höchsten PSM-Werten HVO_2040, eine GalE family Epimerase/Dehydratase. Eine tiefergehende Untersuchung und Validierung dieser potenziellen Bindepartner konnten in dieser Arbeit jedoch aus zeitlichen Gründen nicht stattfinden.

\subsection{Transkriptomanalyse mittels RNA-Sequenzierung}

Eine weitere Herangehensweise der Funktionsaufklärung besteht in der Suche nach Unterschieden zwischen Wildtyp und Deletionsmutante und zwischen Deletionsmutante und Komplementationsmutante auf transkriptionaler Ebene. Die Untersuchung des gesamten Transkriptoms erfolgte hier mittels RNA-Sequenzierung. Auch hier können theoretisch sowohl direkte als auch indirekte Regulationen von HVO_2753 identifiziert werden.

Für die RNA-Sequenzierung wurden zunächst Zellen der Stämme H26 evc, $\Delta H_{V O} 2753$ evc und $\triangle H V O \_2753+2753 \mathrm{c}$ in synthetischem Medium mit Glukose als Kohlenstoffquelle bis zur exponentiellen Wachstumsphase kultiviert. AnschlieBend wurde mittels Phenol-Chloroform-Isoamylalkohol-Methode die GesamtRNA der Zellen isoliert. Nach einer Behandlung mit DNase I wurde eine weitere RNA-Isolierung durchgeführt, bei der DNase-freie Gesamt-RNA erhalten wurde. Abschließend wurde die RNA-Integrität und die Abwesenheit genomischer DNA überprüft (siehe 3.4.4.1). Diese Gesamt-RNA der drei Stämme, wiederum in jeweils zwei biologischen Replikaten, wurde an den Arbeitskreis Prof. Sharma der Universität Würzburg versandt, die weitere Prozessierungsschritte und die RNA-Sequenzierung im Rahmen des Z2-Projektes des Schwerpunktprogramms 2002 durchführte. Diese weitere Prozessierung umfasste vor allem eine Depletion der ribosomalen RNA, die störend für die nachfolgende Erstellung der CDNA library wäre. Im Anschluss erfolgte die Adapter-Ligation, eine Amplifikation mittels PCR und die Sequenzierung mittels NextSeq500 Sequenziergerät (Illumina, CA, USA). Die in der RNA-Sequenzierung erhaltenen Daten wurden anschließend innerhalb 
des Z2-Projektes im Arbeitskreis Prof. Backofen bioinformatisch mittels der Galaxy Web Platform (http://galaxyproject.org/) prozessiert und ausgewertet. Die Prozessierung umfasste die üblichen Abläufe wie Primer-Entfernung, Qualitätscheck und mappen auf das Genom. Die RNA-Sequenzierung resultierte in mehr als 1 Million unique reads und 10 Millionen inklusive duplicated reads. $64-70 \%$ der reads konnten einzigen Stellen zugeordnet werden, 18-25\% wurden auf mehrere Stellen gemapped, während 9-12 \% der reads zu kurz für das Mappen waren. Neben fortlaufenden Sequenzierungs-Daten, die mittels Integrated Genome Browser visualisiert werden können, wurden Tabellen mit Feature counts erhalten. Dies sind quantitative Daten, die die Menge an Transkripten für jedes proteincodierende Gen, darstellen.

Mit diesen zuvor beschriebenen Daten wurde dann im Zuge dieser Arbeit weitergearbeitet. Zunächst wurde innerhalb jeder der 6 feature counts-Datensätze (drei Stämme in je zwei unabhängigen biologischen Replikaten) eine Normierung der Werte durchgeführt. Hierfür wurde der feature count eines jeden proteincodierenden Gens durch die Gesamtanzahl der feature counts innerhalb des Replikats geteilt und das Ergebnis mit einer Million multipliziert. Dies hatte eine höhere Vergleichbarkeit der jeweiligen beiden biologischen Replikate und der Stämme untereinander zur Folge, da allgemeine Trends in der Gesamttranskriptmenge so herausgerechnet wurden. Nun wurden die Mittelwerte der normierten counts der beiden biologischen Replikate berechnet und alle Gene herausgefiltert, bei denen in nicht mindestens einem der drei Stämme der Mittelwert der normierten counts über 30 lag. Hiermit wurden nur noch Gene, für die eine relevante Menge an Transkripten vorhanden war und gleichzeitig aber dennoch Gene, bei denen eine starke Regulation stattgefunden hatte, betrachtet. Abschließend wurden die Verhältnisse der feature counts berechnet, die widerspiegeln, ob ein Gen hoch- bzw. herunterreguliert in einem der Stämme vorlag. Verglichen wurden hier Wildtyp H26 evc mit der Deletionsmutante $\Delta$ HVO_2753 evc und die Deletionsmutante wiederum mit der Komplementationsmutante $\Delta$ HVO_2753 +2753c. Tabelle A4 und Tabelle A5 im Anhang zeigen die Gene mit Funktionsklassen und entsprechenden Proteinnamen, feature counts in den drei Stämmen mit den Graden an Regulation. Gezeigt sind nur Gene, die eine Regulation von mehr als zweifach hoch oder zweifach herunter aufwiesen. 
Für die Funktionsaufklärung wurden nun vorrangig die Gene betrachtet, die in Abwesenheit von HVO_2753 signifikant hoch- oder herunterreguliert vorlagen. Diese sind im Anhang in Tabelle A4 aufgelistet. Es konnten 57 Gene identifiziert werden, die in der Deletionsmutante signifikant herunterreguliert vorlagen (Regulation $\leq$ 0,5), während 109 Gene signifikant hochreguliert waren (Regulation 2 2). 46 dieser regulierten Gene codieren für hypothetische oder konservierte hypothetische Proteine und spielen in der Funktionsaufklärung von HVO_2753 zum aktuellen Stand der Forschung keine Rolle. Jedoch konnten zwei stark regulierte Cluster identifiziert werden. Eines dieser Cluster umfasst $30 \mathrm{Gene}$, die für Proteine des Bewegungsapparates oder der Chemotaxis-Signaltransduktion codieren. Diese sind in der Deletionsmutante sehr stark herunterreguliert und in Tabelle 41 aufgelistet. Während die ersten 25 der aufgelisteten Gene einen gemeinsamen Lokus auf dem Chromosom besitzen (HVO_1201 bis HVO_1225), sind die fünf weiteren Gene an anderer Stelle lokalisiert. Diese 30 Gene codieren für Proteine wie das Achaellin A1 und A2, Achaellum Cluster Proteine (ArICE, ArID etc.; früher FlaCE, FlaD etc.), Chemotaxis Response Regulatoren, Chemotaxis Cluster Proteine etc. Dieses Ergebnis stimmt sehr gut mit dem zuvor identifizierten Schwärmdefizit der Deletionsmutante überein (siehe 4.2.3.2). Die zuvor beschriebene unzureichende Komplementierbarkeit des Unterschieds im Phänotyp Schwärmen spiegelt sich auch in den Graden der Regulation in der Komplementationsmutante (gegenüber der Deletionsmutante), siehe letzte Spalte in Tabelle 41, wider. Über alle beschriebenen Gene hinweg kann durch plasmidische Expression von HVO_2753 keine wildtypische Expression wiederhergestellt werden. 
Tabelle 41: Auswahl an Genen, die in Abwesenheit von HVO_2753 herunterreguliert vorlagen. Gezeigt ist eine Auswahl der Ergebnisse der RNA-Sequenzierung. Die Tabelle umfasst die Gene mit ihrer Funktionsklasse (FC, siehe Abkürzungsverzeichnis), dem Namen des Genprodukts (Protein Name) und den feature counts in den drei Stämmen Wildtyp H26 evc, Deletionsmutante $\Delta \mathrm{HVO}_{2} 2753$ evc und Komplementationsmutante $\Delta \mathrm{HVO} \_2753+2753 c$. Die letzten beiden Spalten zeigen den Grad der Regulation des jeweiligen Gens in der Deletionsmutante (im Vergleich zum Wildtyp) und in der Komplementationsmutante (im Vergleich zur Deletionsmutante). Gezeigt sind nur Gene, die mindestens 2-fach herunterreguliert vorliegen und den biologischen Prozessen Chemotaxis bzw. Motilität zugeordnet werden können.

\begin{tabular}{|c|c|c|c|c|c|c|c|}
\hline Gene ID & FC & Protein Name & 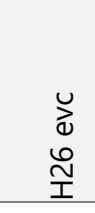 & $\begin{array}{l}n_{n} \\
\stackrel{N}{N} \\
\stackrel{1}{\gtrless} \\
\stackrel{x}{\triangleleft}\end{array}$ & 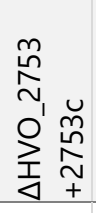 & 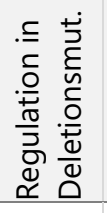 & 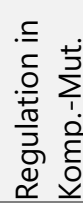 \\
\hline HVO_1201 & SIG & sensor box histidine kinase & 2801 & 392 & 336 & 0,14 & 0,86 \\
\hline HVO_1202 & $\mathrm{CHY}$ & conserved hypothetical protein & 249 & 54 & 56 & 0,22 & 1,03 \\
\hline HVO_1203 & MIS & arl cluster protein ArID & 1829 & 469 & 403 & 0,26 & 0,86 \\
\hline HVO_1204 & HY & hypothetical protein & 1681 & 439 & 343 & 0,26 & 0,78 \\
\hline HVO_1205 & SIG & taxis cluster protein CheD & 254 & 10 & 7 & 0,04 & 0,69 \\
\hline HVO_1206 & SIG & taxis cluster protein $\mathrm{CheC}$ & 465 & 0 & 1 & 0,00 & 2,85 \\
\hline HVO_1207 & SIG & response regulator $\mathrm{CheY}$ & 414 & 0 & 0 & 0,00 & - \\
\hline HVO_1208 & $\mathrm{CHY}$ & conserved hypothetical protein & 433 & 0 & 0 & 0,00 & - \\
\hline HVO_1209 & GEN & HTH domain protein & 296 & 0 & 0 & 0,00 & 1,00 \\
\hline HVO_1210 & MOT & archaellin A1 & 1929 & 0 & 0 & 0,00 & 0,43 \\
\hline HVO_1211 & MOT & archaellin A2 & 6840 & 2 & 1 & 0,00 & 0,63 \\
\hline HVO_1212 & MIS & KaiC-type circadian clock protein CirA & 224 & 0 & 0 & 0,00 & 1,14 \\
\hline HVO_1213 & MIS & arl cluster protein ArICE & 631 & 0 & 1 & 0,00 & 2,85 \\
\hline HVO_1214 & MIS & arl cluster protein ArlF & 195 & 0 & 0 & 0,00 & - \\
\hline HVO_1215 & MIS & arl cluster protein ArlG & 257 & 0 & 0 & 0,00 & 0,00 \\
\hline HVO_1216 & MIS & arl cluster protein $\mathrm{ArlH}$ & 288 & 2 & 1 & 0,01 & 0,55 \\
\hline HVO_1217 & MOT & $\begin{array}{l}\text { archaellar motor/biogenesis protein } \\
\text { Arll }\end{array}$ & 645 & 0 & 0 & 0,00 & 0,51 \\
\hline HVO_1218 & MOT & $\begin{array}{l}\text { archaellar motor/biogenesis protein } \\
\text { ArlJ }\end{array}$ & 565 & 1 & 1 & 0,00 & 1,02 \\
\hline HVO_1219 & SIG & taxis protein CheF2 & 469 & 1 & 0 & 0,00 & 0,62 \\
\hline HVO_1220 & $\mathrm{CHY}$ & conserved hypothetical protein & 108 & 0 & 0 & 0,00 & - \\
\hline HVO_1221 & SIG & taxis protein CheF1 & 317 & 4 & 2 & 0,01 & 0,57 \\
\hline HVO_1222 & SIG & $\begin{array}{l}\text { protein-glutamate O-methyltransfer- } \\
\text { ase CheR }\end{array}$ & 328 & 0 & 1 & 0,00 & - \\
\hline HVO_1223 & SIG & taxis sensor histidine kinase $\mathrm{CheA}$ & 411 & 111 & 98 & 0,27 & 0,88 \\
\hline HVO_1224 & SIG & $\begin{array}{l}\text { protein-glutamate methylesterase / } \\
\text { protein-glutamine glutaminase CheB }\end{array}$ & 133 & 27 & 24 & 0,20 & 0,89 \\
\hline HVO_1225 & SIG & purine-binding taxis protein $\mathrm{CheW}$ & 1271 & 180 & 143 & 0,14 & 0,79 \\
\hline HVO_1999 & SIG & transducer protein $\mathrm{Htr} 7$ & 140 & 45 & 54 & 0,33 & 1,18 \\
\hline HVO_0555 & SIG & transducer protein Htr15 & 287 & 38 & 31 & 0,13 & 0,81 \\
\hline
\end{tabular}




\begin{tabular}{l|l|l|r|r|r|r|r}
\hline HVO_3005 & SIG & transducer protein Htr15 & 387 & 99 & 103 & $\mathbf{0 , 2 6}$ & 1,04 \\
\hline HVO_2220 & SIG & transducer protein Htr38 & 61 & 29 & 33 & $\mathbf{0 , 4 8}$ & 1,12 \\
\hline & & & & & & \\
\hline HVO_1126 & SIG & transducer protein HemAT & 272 & 41 & 41 & $\mathbf{0 , 1 5}$ & 1,00 \\
\hline
\end{tabular}

Das zweite interessante Cluster, dessen Gene in Abwesenheit von HVO_2753 signifikant hoch- bzw. herunterreguliert vorlagen, umfasst 25 Gene, die für Transportproteine codieren. Diese Auswahl an Genen ist in Tabelle 42 dargestellt. Während die Gene von zwei SNF family Transportproteinen herunterreguliert vorlagen, sind 23 Transportproteine in der Deletionsmutante signifikant hochreguliert. Diese Transportproteine umfassen zahlreiche putative Metallionen-Transporter. Daran anknüpfend konnten unter den stark hochregulierten Genen fünf Gene (HVO_B0042-46, siehe Tabelle A4 im Anhang) identifiziert werden, die für Enzyme der Eisen(III)-Siderophor-Biosynthese codieren. Der Großteil der hochregulierten Gene, die nicht für Transportproteine oder Enzyme der Siderophor-Biosynthese codieren, sind Gene hypothetischer Proteine, von denen man nicht ausschließen kann, dass sie ebenfalls in den Metallionentransport involviert sind.

Tabelle 42: Auswahl an Genen, die für Transportproteine codieren und in Abwesenheit von HVO_2753 reguliert vorliegen. Gezeigt ist eine Auswahl der Ergebnisse der RNA-Sequenzierung. Die Tabelle umfasst die Gene mit ihrer Funktionsklasse (FC, siehe Abkürzungsverzeichnis), dem Namen des Genprodukts (Protein Name) und den feature counts in den drei Stämmen Wildtyp H26 evc, Deletionsmutante $\Delta H_{V}$ O_2753 evc und Komplementationsmutante $\Delta \mathrm{HVO} 2753+2753 \mathrm{c}$. Die letzten beiden Spalten zeigen den Grad der Regulation des jeweiligen Gens in der Deletionsmutante (im Vergleich zum Wildtyp) und in der Komplementationsmutante (im Vergleich zur Deletionsmutante). Gezeigt sind nur Gene, die in der Deletionsmutante mindestens 2-fach herunter- oder hochreguliert vorliegen und für Transportproteine codieren. Gene, deren Regulation hier nicht komplementiert werden konnte, sind in grau dargestellt.

\begin{tabular}{|c|c|c|c|c|c|c|c|}
\hline Gene ID & FC & Protein Name & $\begin{array}{l}\stackrel{\cup}{d} \\
\stackrel{\mathfrak{I}}{I}\end{array}$ & $\begin{array}{l}m \\
\stackrel{n}{N} \\
\stackrel{1}{\sim} \\
\stackrel{1}{\prime} \\
\stackrel{1}{\triangleleft}\end{array}$ & 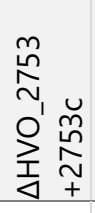 & 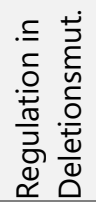 & 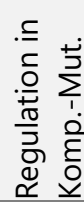 \\
\hline HVO_2469 & TP & SNF family transport protein & 610 & 227 & 413 & 0,37 & 1,82 \\
\hline HVO_2470 & TP & SNF family transport protein & 152 & 60 & 122 & 0,40 & 2,03 \\
\hline HVO_1991 & TP & $\begin{array}{l}\text { ABC-type transport system periplas- } \\
\text { mic substrate-binding protein }\end{array}$ & 337 & 715 & 261 & 2,12 & 0,36 \\
\hline HVO_1707 & TP & $\begin{array}{l}\text { ABC-type transport system ATP-bind- } \\
\text { ing protein }\end{array}$ & 52 & 112 & 66 & 2,14 & 0,59 \\
\hline HVO_2032 & TP & $\begin{array}{l}\text { ABC-type transport system ATP-bind- } \\
\text { ing protein (probable substrate } \\
\text { sugar) }\end{array}$ & 73 & 184 & 177 & 2,52 & 0,96 \\
\hline
\end{tabular}




\begin{tabular}{|c|c|c|c|c|c|c|c|}
\hline HVO_1706 & $\mathrm{TP}$ & $\begin{array}{l}\text { ABC-type transport system permease } \\
\text { protein }\end{array}$ & 105 & 264 & 122 & 2,52 & 0,46 \\
\hline HVO_2031 & TP & $\begin{array}{l}\text { ABC-type transport system periplas- } \\
\text { mic substrate-binding protein (prob- } \\
\text { able substrate sugar) }\end{array}$ & 82 & 235 & 234 & 2,87 & 0,99 \\
\hline HVO_1705 & TP & $\begin{array}{l}\text { ABC-type transport system periplas- } \\
\text { mic substrate-binding protein }\end{array}$ & 94 & 307 & 82 & 3,27 & 0,27 \\
\hline HVO_1586 & TP & $\begin{array}{l}\text { SDF family transport protein (proba- } \\
\text { ble substrate glutamate/aspartate) }\end{array}$ & 30 & 102 & 44 & 3,36 & 0,43 \\
\hline HVO_2033 & TP & $\begin{array}{l}\text { ABC-type transport system permease } \\
\text { protein (probable substrate sugar) }\end{array}$ & 18 & 71 & 71 & 3,86 & 1,00 \\
\hline HVO_1696 & TP & LctP family transport protein & 90 & 372 & 436 & 4,15 & 1,17 \\
\hline HVO_B0144 & TP & $\begin{array}{l}\text { ABC-type transport system periplas- } \\
\text { mic substrate-binding protein }\end{array}$ & 90 & 394 & 92 & 4,40 & 0,23 \\
\hline HVO_1760 & TP & $\begin{array}{l}\text { ABC-type transport system ATP-bind- } \\
\text { ing protein }\end{array}$ & 89 & 430 & 90 & 4,85 & 0,21 \\
\hline HVO_2034 & TP & $\begin{array}{l}\text { ABC-type transport system permease } \\
\text { protein (probable substrate sugar) }\end{array}$ & 21 & 110 & 124 & 5,22 & 1,13 \\
\hline HVO_1464 & TP & $\begin{array}{l}\text { ABC-type transport system periplas- } \\
\text { mic substrate-binding protein }\end{array}$ & 20 & 117 & 22 & 5,90 & 0,19 \\
\hline HVO_2093 & TP & $\begin{array}{l}\text { probable NhaC-type sodium/proton } \\
\text { antiporter }\end{array}$ & 26 & 159 & 27 & 6,06 & 0,17 \\
\hline HVO_1759 & TP & $\begin{array}{l}A B C \text {-type transport system permease } \\
\text { protein }\end{array}$ & 29 & 183 & 32 & 6,20 & 0,17 \\
\hline & TP & $\begin{array}{l}\text { ABC-type transport system periplas- } \\
\text { mic substrate-binding protein }\end{array}$ & 30 & 202 & 31 & 6,71 & 0,15 \\
\hline HVO_A0541 & TP & $\begin{array}{l}\text { ABC-type transport system periplas- } \\
\text { mic substrate-binding protein }\end{array}$ & 122 & 852 & 150 & 6,97 & 0,18 \\
\hline HVO_B0150 & TP & $\begin{array}{l}\text { ABC-type transport system periplas- } \\
\text { mic substrate-binding protein }\end{array}$ & 23 & 176 & 23 & 7,71 & 0,13 \\
\hline HVO_B0197 & TP & $\begin{array}{l}A B C \text {-type transport system permease } \\
\text { protein }\end{array}$ & 58 & 539 & 53 & 9,24 & 0,10 \\
\hline & TP & $\begin{array}{l}\text { mechanosensitive channel protein } \\
\text { MscS (nonfunctional) }\end{array}$ & 83 & 838 & 74 & 10,05 & 0,09 \\
\hline /O_B0198 & TP & $\begin{array}{l}\text { ABC-type transport system periplas- } \\
\text { mic substrate-binding protein }\end{array}$ & 60 & 601 & 60 & 10,06 & 0,10 \\
\hline HVO_B0047 & TP & $\begin{array}{l}\text { ABC-type transport system periplas- } \\
\text { mic substrate-binding protein }\end{array}$ & 28 & 438 & 40 & 15,84 & 0,09 \\
\hline HVO_2038 & TP & $\begin{array}{l}\text { ABC-type transport system periplas- } \\
\text { mic substrate-binding protein }\end{array}$ & 14 & 390 & 51 & 28,04 & 0,13 \\
\hline
\end{tabular}

Gene, die durch plasmidische Expression von HVO_2753 in der Komplementationsmutante, verglichen mit der Deletionsmutante signifikant hoch- oder herunter reguliert vorlagen, sind in Tabelle A5 im Anhang dargestellt. Hierbei zeigte sich, dass durch plasmidische Expression von HVO_2753 nur bei einem der beiden in der Deletionsmutante differenziell regulierten Cluster wildtypische Transkriptlevel wiederhergestellt werden konnten. Während bei den Genen der Chemotaxis und Motilität, keine Wiederherstellung des Transkriptlevels des Wildtyps zu sehen ist, trifft dies beim Großteil an Genen von Transportproteinen nicht zu. Hier sind von den 23 Genen von Transportproteinen, die in der Deletionsmutante signifikant hochreguliert waren, wiederum 18 signifikant herunterreguliert und annähernd 
auf dem Niveau des Wildtyps. Auch die Transkriptlevel der Siderophor-Biosyntheseenzyme entsprachen wieder denen des Wildtyps. Die Gene von Transportproteinen, auf die dies nicht zutrifft, sind in Tabelle 42 in grau dargestellt. Auch bei den beiden Genen HVO_2469 und HVO_2470, die in der Deletionsmutante nicht hoch-sondern herunterreguliert vorlagen, waren in der Komplementationsmutante Transkriptlevel vorhanden, die wiederum näher an denen des Wildtyps lagen. 


\section{Diskussion}

Seit mehreren Jahren steigt das Interesse an kleinen Proteinen. Denn es wurde erkannt, mit welcher Häufigkeit sie auftreten und welche wichtige Rolle sie zu spielen scheinen. Die Anzahl an Reviews innerhalb der letzten Jahre, die sich speziell mit kleinen Proteinen beschäftigen, zeigt auf, mit welchem Interesse dieser neuen Klasse an Molekülen nachgegangen wird (Storz et al., 2014; Baumgartner et al., 2016; Cabrera-Quio et al., 2016; Duval \& Cossart, 2017; Plaza et al., 2017; Delcourt et al., 2018). In Bakterien und Eukaryoten konnte bereits an vielen Beispielen gezeigt werden, welche biologische Funktionen kleine Proteine übernehmen können. In Archaeen hingegen sind weniger Beispiele bekannt. Jedoch wurde bereits im Jahre 2007 das "Low Molecular Weight Proteom" des Haloarchaeons H. salinarum untersucht und publiziert (Klein et al., 2007). Diese Ergebnisse zeigten das Ausmaß der bislang übersehenen kleinen Proteine, lenkten den Fokus aber auch auf dabei identifizierte kleine Zinkfinger-Proteine.

In allen drei Domänen des Lebens wurden bisher nur sehr wenige kleine Zinkfinger-Proteine untersucht. In Eukaryoten wurde beispielsweise bereits gezeigt, dass dort kleine Zinkfinger-Proteine RNA-assoziiert vorliegen und an der Zelldifferenzierung und Morphogenese beteiligt sind (Caro et al., 2005), an Proteine des Photosystems binden und dort an der Instandhaltung beteiligt sind (Lu et al., 2011) oder potenziell an DNA binden und in die Zellproliferation involviert zu sein scheinen (Fernandez-Pol et al., 1993). Für ein bakterielles kleines putatives ZinkfingerProtein konnte eine Zink-abhängige Induktion der Expression nachgewiesen werden (Noll et al., 1998). Auch für das Gen com des Bakteriophagen Mu konnte gezeigt werden, dass es für ein kleines Zinkfinger-Protein codiert. Für dieses konnte nachgewiesen werden, dass es an seine bicistronische mRNA bindet und so die Translation des downstream-Gens aktiviert (Nowacka et al., 2019). In Archaeen wurde mit Brz bis dato lediglich ein einziges Zinkfinger- $\mu$-Protein intensiv untersucht. Es konnte gezeigt werden, dass Brz eine wichtige Rolle in der Regulation der Transkription des Bakterioopsin-Gens spielt (Tarasov et al., 2008).

Die in $\mathrm{H}$. salinarum identifizierten kleinen Zinkfinger-Proteine enthielten charakteristische Zinkfingermotive bestehend aus C(P)XCG- und/oder C(P)XCG-ähnlichen Mustern. Die Entdeckung dieser Zinkfinger-Proteine in $H$. salinarum führte zur Suche und Annotation von Homologen in anderen Haloarchaea, wie auch 
H. volcanii. Dort konnten 43 dieser kleinen Zinkfingerproteine einer maximalen Länge von 70 Aminosäuren annotiert werden, von denen bereits 16 einer Charakterisierung unterzogen wurden (Nagel et al., 2019). Während dabei ein paralleles Screening der Deletionsmutanten der kleinen Zinkfinger-Proteine bei mehreren Bedingungen durchgeführt wurde, konnte in der vorliegenden Arbeit mit HVO_2753 ein weiteres kleines Zinkfinger-Protein einer tiefergehenden Untersuchung unterzogen werden.

\subsection{Die Strukturelemente des Eindomänen-Zinkfinger-Proteins HVO_2753}

Das Protein HVO_2753 besitzt mit einer Länge von lediglich 59 Aminosäuren vier $C(P) X C G$ - bzw. C(P)XCG-ähnliche Muster und damit zwei putative Zinkfinger-Motive. Der ersten Annahme der Bindung von zwei Zink-lonen pro Protein wurde mittels fluorimetrischem Zink-Assay nachgegangen. Dieser konnte zeigen, dass lediglich ca. 0,7 Äquivalente Zink pro Protein vorhanden sind. Innerhalb einer Zusammenarbeit wurde eine Vielzahl an Experimenten zur Strukturaufklärung von HVO_2753 mittels NMR-(nuclear magnetic resonance, Kernspinresonanz)-Spektroskopie durchgeführt (Zahn et al., 2020). In diesem Zusammenhang wurde ebenfalls der Frage der Zinkbindung nachgegangen. Dabei wurde dem heterolog in E. coli überproduzierten HVO_2753 mittels EDTA-Behandlung zunächst gebundenes Zink entzogen, das Protein dabei denaturiert und anschließend in 0,25-äquimolaren Schritten wieder Zink zutitriert und die Rückfaltung bzw. Struktur mittels NMR analysiert. Bereits die Zugabe von 0,25 Äquivalenten an $\mathrm{Zn}^{2+}$ hat die Rückfaltung der Proteine induziert und die native Struktur der Proteine war bereits bei 0,75 Äquivalenten an Zink wiederhergestellt (Zahn et al., 2020). Vergleicht man nun die Ergebnisse der NMR-Analyse des heterolog überproduzierten Proteins mit denen der fluorimetrischen Untersuchung des homolog überproduzierten Proteins, stellt man überzeugende Übereinstimmungen fest, die den Schluss zulassen, es sei trotz Vorhandenseins zweier Zinkfinger-Motive nur ein Zink gebunden und für die korrekte Faltung des Proteins nötig. Die Zugabe von weiterem Zink hat keine weitere Veränderung in der Faltung hervorgerufen (Zahn et al., 2020). HVO_2753 enthält nun ein zweites putatives Zinkfinger-Motiv, das kein Zink bindet und dieses nicht für seine Faltung benötigt. In der Literatur ist bereits 
ein Zinkfinger-Protein beschrieben, bei dem beispielsweise in vitro gezeigt werden konnte, dass dieses das Zink, das in vivo gebunden vorliegt, nicht benötigt, um seine Funktion auszuüben oder gar, um seine Struktur auszubilden. In dem beschriebenen Fall war die Funktion die spezifische Bindung an RNA bei dem humanen Onkogen Hdm2 (Lai et al., 1998). Darüber hinaus sind Fälle beschrieben, bei denen die Faltung und Struktur des Proteins nicht mehr durch Komplexierung eines Zink-lons, sondern durch intramolekulare polare und hydrophobe Wechselwirkungen von Aminosäureseitenketten gewährleistet wird (Malgieri et al., 2015). Im Zuge der NMR-Analyse von HVO_2753, wie in Zahn et al. (2020) beschrieben, konnte die Struktur des haloarchaealen Proteins bestimmt werden. Bei der Untersuchung der Relevanz der C(P)XCG-Muster wurde durch Aminosäuresubstitution das jeweils erste Cystein eines jeden C(P)XCG-Musters durch Alanin ersetzt und mittels NMR-Analyse die Strukturen der mutierten Spezies von HVO_2753 mit der des nativen Proteins verglichen. Hier konnte gezeigt werden, dass jede einzelne Aminosäuresubstitution zu einem schweren Verlust in Struktur und Stabilität führte. Darüber hinaus wurden diese mutierten Spezies von HVO_2753 auch im homologen System für Komplementationsversuche in der Deletionsmutante $\triangle \mathrm{HVO} \_2753$ verwendet, wie in 4.2.3.3 beschrieben. Dabei konnte gezeigt werden, dass keine der Mutanten die Funktion des nativen HVO_2753 aufweist. Hier konnte durch Kombination von in vivo Experimenten in $\mathrm{H}$. volcanii und der NMR-spektroskopischen Strukturanalyse von heterolog überexprimiertem HVO_2753 die Notwendigkeit der vier C(P)XCG-Muster für Struktur und Funktion gezeigt werden. Zusätzlich konnte gezeigt werden, dass die homologe Überexpression der Aminosäure-substituierten Spezies von HVO_2753, zu lediglich sehr geringen Proteinleveln führten, was vermutlich auf eine falsche Faltung und einen damit verbundenen schnellen Abbau der Proteine zurückzuführen ist (Daten nicht gezeigt). Des Weiteren wurden für die Komplementationsversuche in $H$. volcanii zwei weitere Mutanten mit jeweils einer Aminosäuresubstitution erstellt und getestet. Die beiden Substitutionen Q34A und Y49F führten ebenfalls zu einem Funktionsverlust des Proteins und sind somit entweder für eine spezifische Funktion, die Ausbildung der Struktur oder für beides notwendig. Die Cysteine in HVO_2753 sind nicht nur essenziell für Funktion und Faltung, sondern liegen auch innerhalb der Haloarchaea und vieler methanogener Archaea hochkonserviert vor. Die hohe Konservierung der Cysteine spricht dagegen, dass hier 
lediglich intramolekulare polare und/oder hydrophobe Wechselwirkungen anderer Aminosäureseitenketten als Ersatz für ein Zink-Ion dienen. Dies konnte beispielsweise zuvor für seltene Fälle von prokaryotischen Zinkfinger-Proteinen beschrieben werden (Baglivo et al., 2014). Denn sollte dies der Fall sein, wäre zu erwarten, dass die Zink-koordinierenden Aminosäuren nicht mehr vollständig sind. Dies konnte für die Ros Homologe Ml4 und Ml5 gezeigt werden, welche kein Zink mehr binden. Dort sind die Zink-koordinierenden Aminosäuren teilweise ersetzt, während die dreidimensionale Struktur den Zink-bindenden Ros Homologen entspricht (Baglivo et al., 2014). Konkret heißt das für MI4 und Ml5, dass im Vergleich zum strukturell nahezu übereinstimmenden Ros87, ohne Verlust der spezifischen DNA-Bindeeigenschaft, die beiden Cysteine und eines der beiden Histidine in der Aminosäuresequenz durch andere Aminosäuren ersetzt sind, während die Sequenzen grundsätzlich eine hohe Identität aufweisen. Dennoch kann hier nicht vollständig ausgeschlossen werden, dass der intramolekulare Zusammenhalt in HVO_2753 an Stelle des Zinkfinger-Motivs ohne Zink durch Wechselwirkungen anderer Aminosäureseitenketten übernommen wird und die nachweislich essenziellen Cysteine entweder darin involviert sind oder eine andere wichtige Rolle im Protein übernehmen. Die Aufklärung der Struktur, die in Abbildung 24 dargestellt ist, zeigte außerdem, dass die Zinkbindetaschen (ZBP, zinc binding pockets), überraschenderweise nicht von den C(P)XCG-Mustern $1+2$ und $3+4$ gebildet werden, sondern von den Mustern $1+3$ (ZBP1) und $2+4$ (ZBP2). Berechnungen konnten zeigen, dass ZBP2 die Zink-bindende Tasche im Protein darstellt (Zahn et al., 2020). Die Cysteine der Muster 2 (CPDCG) und 4 (CPDCG) ZBP2 sind so angeordnet, dass sie ein Zink-Ion in symmetrisch tetrahedrischer Weise binden können. Die zunächst unerwartete verschachtelte Art der Bildung zweier potenzieller Zinkfinger (Muster $1+3$ und $2+4$ ) konnte jedoch bereits für die RING-finger Domäne, beispielsweise in $\mathrm{Hdm} 2$, dem humanen Onkogen, gezeigt werden (Lai et al., 1998). Die RING-finger Domäne, hier die kleine C-terminale Domäne des sehr viel größeren $\mathrm{Hdm} 2$, unterscheidet sich jedoch strukturell von HVO_2753 und bindet nachweislich zwei Zink-lonen gleichzeitig mit einem $\mathrm{C}_{4}$ - und einem $\mathrm{C}_{2} \mathrm{H}_{2}$-Muster (Kostic et al., 2006). 

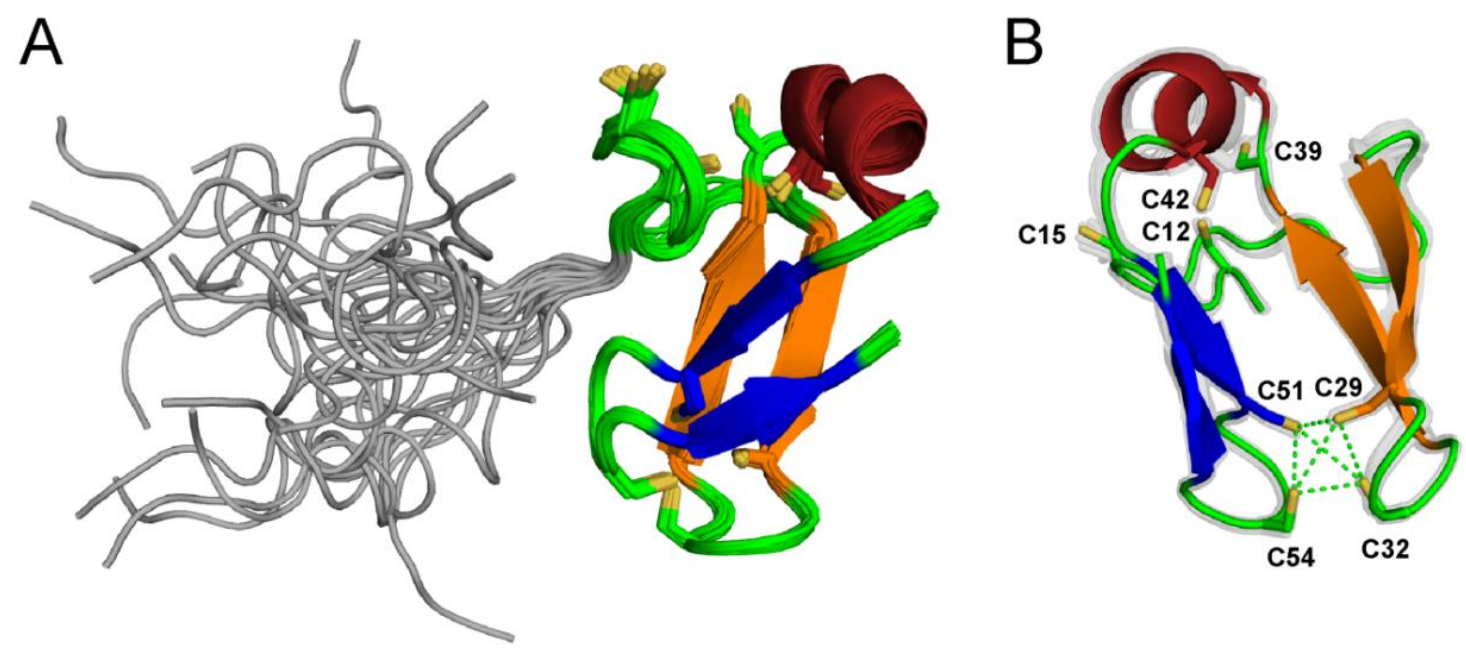

Abbildung 24: 3D-Struktur von HVO_2753. Gezeigt ist die mittels NMR-Spektroskopie aufgeklärte Struktur des Proteins. (A) Ribbon-Struktur der 20 besten volllängen Strukturen. (B) Ribbon-Struktur des Proteinkerns der niedrigsten Energiestruktur des um $90^{\circ} \mathrm{ge}-$ drehten Proteins. Der flexible N-Terminus ist in grau, $\beta$-Faltblätter in orange und blau, die $\alpha$-Helix in rot und die Schwefelatome der Cysteine in gelb dargestellt. Die manuell definierte Zinkbinde-Tasche ist mit grünen, unterbrochenen Linien dargestellt. Abbildung entnommen und modifiziert aus Zahn et al. (2020).

Die Zinkbindetasche 1, bestehend aus Muster 1 (CVSCG) und Muster 3 (CSKCR), konnte in den NMR-spektroskopischen Untersuchungen als die Zink-freie Tasche identifiziert werden. Eine Erklärung für die dennoch vorhandenen und essenziellen Cysteine dieses Motivs besteht darin, dass diese eine andere unbekannte Funktion erfüllen. Darüber hinaus ist vorstellbar, dass dennoch ein Zink bindet, jedoch erst nach Bindung von HVO_2753 an seinen unbekannten Bindepartner.

Der starre Kern von HVO_2753, der die beiden Zinkbindetaschen enthält, setzt sich aus zwei verdrehten antiparallelen $\beta$-Faltblättern und einer $\alpha$-Helix zusammen. Die Zinkbindetasche 2, in der Zink gebunden vorliegt, wird von den knuckles der beiden $\beta$-hairpins gebildet. Diese Konstellation entspricht der des sogenannten zinc ribbons, welche die größte strukturelle Gruppe von Zinkfingern darstellen und in diversen Gruppen von Proteinen vertreten sind (Krishna et al., 2003). Die putative Zinkbindetasche 1, bei der kein gebundenes Zink-lon nachgewiesen werden konnte, kann keiner der von Krishna et al. beschriebenen Gruppen eindeutig zugeordnet werden. Hier stellt ein loop die ersten beiden Cysteine für die Bindung des Zinks bereit, während der N-Terminus einer $\alpha$-Helix die anderen beiden Cysteine präsentiert. Die strukturelle Konstellation entspricht am ehesten der des 
Zn2/Cys6 Zinkfingers, jedoch sind bei dem Motiv in HVO_2753 keine 6 Cysteine und nur höchstens ein Zink-lon involviert.

Ein weiteres interessantes strukturelles Merkmal von HVO_2753 ist der N-Terminus. Dieser liegt in methanogenen Archaea verkürzt vor, während der Rest des Proteins darüber hinaus konserviert ist. Dieser stark hydrophile N-Terminus könnte ein Element darstellen, welches für die Löslichkeit des Proteins bei den intrazellulären Hochsalz-Bedingungen der Haloarchaea essenziell ist. Für das haloarchaeale Ferredoxin von $\mathrm{H}$. salinarum konnte beispielsweise gezeigt werden, dass es im Vergleich zu pflanzlichen Homologen eine hydrophile extra Domäne enthält und diese für die Löslichkeit des Proteins bei seinen gegebenen Bedingungen essenziell ist (Marg et al., 2005). Unterstützt wird diese Theorie dadurch, dass der N-Terminus durch die NMR-Analyse als nicht strukturiert vorliegend identifiziert wurde. Diesen flexiblen Bereich des Proteins zeigt Abbildung $24 \mathrm{~A}$. Für ihn sind mehrere Funktionen denkbar. So scheint er im Falle des monomeren HVO_2753 flexibel und die Löslichkeit vermittelnd vorzuliegen. Er könnte aber im Falle einer Bindung an einen Bindepartner an eben jener Bindung beteiligt sein. Bei eukaryotischen Zinkfinger-Domänen konnte gezeigt werden, dass im Falle der $\mathrm{Cys}_{2} \mathrm{His}_{2}$-Zinkfinger in der Regel mehrere dieser Motive als Tandem in der Aminosäuresequenz vorliegen und nur dadurch eine spezifische Bindung vermitteln können (Malgieri et al., 2015). Während prokaryotische Cys ${ }_{2} \mathrm{His}_{2}$-Zinkfinger häufig einzeln vorliegen und ihre Spezifität durch Kombination mit einem verlängerten C-Terminus erhalten, der für weitere Wechselwirkungen mit dem Bindepartner verantwortlich ist (Omichinski et al., 1997). So könnte der N-Terminus von HVO_2753 in ähnlicher Weise durch Wechselwirkungen mit dem Bindepartner die Spezifität der Bindung erhöhen, da im gebundenen Zustand seine Löslichkeitsvermittelnde Rolle überflüssig sein kann. Eine spezifische Interaktion mit einem Bindepartner ist jedoch auch ohne Beteiligung des N-Terminus vorstellbar. Denn für andere prokaryotische Cys $2 \mathrm{His}_{2}$-Zinkfinger oder eukaryotische Cys $3 \mathrm{His}_{\text {/Cys4- }}$ Zinkfinger, wie die der LIM Domäne, konnte gezeigt werden, dass sie ihre Spezifität durch Dimerisierung deutlich erhöhen können (Gill, 1995; Fumeaux et al., 2014). Eine weitere Besonderheit bezüglich der Löslichkeit war die Stabilität und Löslichkeit bei niedrigen Salzkonzentrationen. Gelten halophile Proteine generell als sehr instabil bei niedrigen Salzkonzentrationen (Eisenberg et al., 1992), war dies bei HVO_2753 nicht zu beobachten. Das heterolog überproduzierte Protein 
lag sehr stabil vor, was die NMR-Analysen überhaupt in dem durchgeführten Ausmaß ermöglichte, da hier niedrige Natriumchloridkonzentrationen bevorzugt werden. Es wurden strukturelle Unterschiede des Proteins bei $200 \mu \mathrm{M}$ und $1 \mathrm{M} \mathrm{NaCl}$ gesucht, jedoch konnte kein Einfluss der Konzentration auf die Struktur gefunden werden. Auch das homolog überproduzierte Protein, welches nach nativer Aufreinigung bei hohen Salzbedingungen gegen niedrigere Salzkonzentrationen dialysiert wurde, wies hier eine hohe Stabilität auf. Die Analyse der Menge an gebundenem Zink mittels fluorimetrischem Zink-Assay konnte beispielsweise nur in Kombination mit einer Proteasebehandlung erfolgen, da die Entfernung des Natriumchlorids zu keiner Freigabe des Zinks führte, was bedeuten muss, dass das Protein nach wie vor gefaltet vorlag. Dass das Zink-Ion mit einer hohen Affinität gebunden vorliegt, zeigte auch die Quantifizierung mittels NMR-Spektrometrie. Bei dieser musste, um das Zink-Ion aus dem Protein zu entfernen und dieses zu entfalten, ein dreifacher Überschuss an EDTA und eine 3-stündige Inkubation bei $65^{\circ} \mathrm{C}$ erfolgen (Zahn et al., 2020). Die Affinität von Zinkfinger-Motiven zu Zink können jedoch innerhalb einer größeren Bandbreite variieren. In der Literatur sind sowohl höhere als auch niedrigere Dissoziationskonstanten von Zinkbinde-Motiv und Zink, verglichen mit EDTA, beschrieben (Kluska et al., 2018). Dass Proteine von $\mathrm{H}$. volcanii bei niedrigen Salzbedingungen stabil vorliegen, ist auch von wenigen weiteren Proteinen bekannt. Beispielsweise von der tRNase $Z$, deren optimale Reaktionsbedingungen darüber hinaus bei niedrigen Salzbedingungen in vitro liegen (Hölzle et al., 2008). Ebenfalls stabil bei niedrigeren Salzbedingungen ist das $\mu$-Protein HVO_2922 und wenige weitere $\mu$-Proteine (Kubatova, Jonker, et al., 2020; Kubatova, Pyper, et al., 2020).

\subsection{Interaktionen von HVO 2753 mit RNA und Proteinen}

Eine zusätzliche Möglichkeit der Funktionsaufklärung besteht darin, Interaktionspartner von HVO_2753 zu identifizieren. Wenn die Funktion eines nachgewiesenen Interaktionspartners oder von einem Homolog in einem anderen Organismus bekannt ist, können so anschließend zielgerichtetere Studien folgen. Erste Hinweise auf potenzielle Interaktionspartner ergab die bioinformatische Analyse von HVO_2753. Homologe innerhalb der Euryarchaeota sind teilweise als putative Zink-Ribbon RNA-Bindeproteine annotiert. Jedoch wurde keines davon bisher 
charakterisiert und es sind keine Funktionen bekannt. Um diesen Hinweisen nachzugehen wurde in der vorliegenden Arbeit ein Protokoll entwickelt, mit dem potenziell an HVO_2753 gebundene RNA co-isoliert, aufgereinigt, in cDNA umgeschrieben, anschließend in einen Vektor kloniert und abschließend sequenziert werden konnte. Auf diese Weise konnten verschiedene gebundene RNAs gefunden werden. Es konnten ribosomale RNAs identifiziert werden, die jedoch teilweise auch in der Kontrolle, für die die Dihydrofolatreduktase (DHFR) überproduziert und identisch behandelt wurde, gefunden wurden. Es konnte hier nicht ausgeschlossen werden, dass eine unspezifische Bindung der rRNA an die NickelSepharose-Matrix oder eine Interaktion mit den überproduzierten Proteinen im Zuge der eigenen Translation dafür verantwortlich ist. Die Identifikation einiger unbekannter Sequenzen und unspezifischer Interaktionen zeigt, dass die Methode weiteren Optimierungsschritten unterzogen werden muss. Dennoch konnte spezifisch mit HVO_2753 mehrfach die tRNA für Glutaminsäure co-isoliert und identifiziert werden. Es konnte nicht gezeigt werden, zu welchem Zweck diese Interaktion stattfindet. Möglicherweise besteht eine Korrelation zu tRNA-abgeleiteten Fragmenten, welche regulatorische Funktionen in der Zelle übernehmen. Die Anwesenheit und Funktion solcher Fragmente konnte bereits für $H$. volcanii gezeigt werden (Gebetsberger et al., 2012, 2017). Wenn dies für $H$. volcanii auch bisher für keine Fragmente der Glutaminsäure-tRNA gezeigt werden konnte (Heyer et al., 2012) und die in dieser Arbeit identifizierten Bereiche der tRNA mit jeweils über 63 nt nahezu die gesamte tRNA abdecken. Für ein tRNA(Glu)-abgeleitetes Fragment konnte in Säugetieren allerdings eine regulatorische Rolle nachgewiesen werden, jedoch wies dieses auch hier mit lediglich 32 nt nur einen Bruchteil der tRNA auf (Falconi et al., 2019).

Darüber hinaus wurde auch nach potenziellen Protein-Bindepartnern gesucht. Denn bei einer Analyse des RNA-Metabolismus und der Suche nach Interaktionspartnern des Lsm-Proteins in $H$. volcanii, dessen bakterielle und eukaryotische Homologe Schlüsselrollen im RNA-Metabolismus übernehmen, konnten neben RNA-Bindepartnern auch Protein-Bindepartner identifiziert werden (Fischer et al., 2010). Für die Protein-Bindepartnersuche wurde ebenfalls HVO_2753 homolog überproduziert. Bevor anschließend eine zweistufige Aufreinigung folgte, wurde ein in vivo Crosslink mittels Formaldehyd durchgeführt. Dieses erzeugt kovalente Bindungen unter anderem zwischen Proteinen in unmittelbarer Nähe zueinander. 
Für diesen Zweck wird Formaldehyd seit langer Zeit intensiv eingesetzt (Sutherland et al., 2008; Srinivasa et al., 2015). Auf diese Weise waren potenzielle Interaktionspartner über den gesamten nativen Aufreinigungsprozess mit HVO_2753 verbunden und konnten anschließend durch eine massenspektroskopische Analyse identifiziert werden. Der in vivo Crosslink wurde bei HVO_2753 verwendet, da hier ohne Crosslink keine Bindepartner identifiziert werden konnten. Ein in vivo Crosslink war bei anderen kleinen haloarchaealen Zinkfinger-Proteinen (A. Essig und N. Kassner, persönliche Kommunikation, 06.12.2019) oder größeren Proteinen des archaealen Translationsapparates (F. Schramm, persönliche Kommunikation, 30.04.2019) nicht nötig, um Bindepartner co-isolieren zu können. Auf diese Weise wurden dann jedoch zahlreiche potenzielle Bindepartner von HVO_2753 identifiziert. Aufgrund der großen Anzahl an identifizierten Proteinen stellte es sich als schwierig heraus eine klare Funktion abzuleiten. Neben verschiedenen Regulatoren und Proteinen, die in diverse zelluläre metabolische Prozesse involviert sind, konnte jedoch eine große Anzahl an Proteinen des Translationsapparats identifiziert werden. So wurden 16 30S ribosomale und $2150 \mathrm{~S}$ ribosomale Proteine gefunden. Jedoch wiesen diese Proteine sehr unterschiedliche und auch teilweise sehr niedrige PSM-Werte auf, was eine eindeutige Identifikation als Interaktionspartner ohne weitere Untersuchungen nicht zulässt. AuBerdem wurden die Translations-Initiationsfaktoren 1A, 5A, 2-beta und der Translations-Elongationsfaktor 1-beta (HVO_2752). Das Gen des Letzteren wird zusammen mit HVO_2753 co-transkribiert und aEF1-beta wurde in allen drei Fraktionen gefunden, die mittels MS-Analyse untersucht wurden. Zukünftig sollte die Interaktion von HVO_2753 mit aEF1-beta genauer untersucht werden, da hier eine der potenziellen Funktionen von HVO_2753 liegen könnte. Eine weitere Analyse dieses potenziellen Interaktionspartners konnte in der vorliegenden Arbeit aus zeitlichen Gründen nicht stattfinden.

Eine Erklärung für die große Menge an gefundenen Interaktionspartnern des Translationsapparates kann in der indirekten Interaktion liegen. Interagiert das spezifisch aufgereinigte HVO_2753 mit aEF1-beta und dieses wiederum mit weiteren ribosomalen Proteinen, kann das Formaldehyd-Crosslinking auch zur Vernetzung dieser Interaktionspartner führen. Diese indirekt gebundenen Proteine können ebenfalls in der massenspektrometrischen Analyse gefunden werden. Dabei ist zu berücksichtigen, dass in den untersuchten Fraktionen aufgrund ihres 
Molekulargewichts keine großen Proteinkomplexe enthalten sein können, sondern nur maximal Teile davon. Des Weiteren wird bei der Überproduktion HVO_2753 in sehr großen Mengen synthetisiert, während potenzielle Bindepartner nicht überproduziert werden und möglicherweise nur in geringen Mengen in der Zelle vorliegen. Proteine des Translationsapparates hingegen liegen auch ohne artifizielle Überproduktion in großer Menge in der Zelle vor und können im Falle einer Interaktion mit HVO_2753 sehr leicht identifiziert werden. Besitzt HVO_2753 nun weitere Protein-Interaktionspartner und liegen diese nativ nur in geringer Menge in der Zelle vor, werden diese leicht übersehen bzw. sind schwer von potenziell unspezifisch gebundenen Proteinen zu unterscheiden. Darüber hinaus kann nicht völlig ausgeschlossen werden, dass manche der identifizierten Interaktionen mit ribosomalen Proteinen auf die eigene Translation von HVO_2753 während der Überproduktion zurückzuführen sind.

Mit den jeweils höchsten PSM-Werten in zwei der drei untersuchten Fraktionen wurde HVO_2040 identifiziert. HVO_2040 ist als GalE family Epimerase/Dehydratase annotiert. Sieben weitere Gene im Genom von $H$. volcanii sind als GalE family Epimerase/Dehydratase-Gene annotiert. In den meisten Organismen wird Galaktose über den Leloir-Pathway metabolisiert. Dabei katalysiert den vierten und letzten Schritt die UDP-Galaktose-4-Epimerase (GalE), bei dem UDP-Galaktose zu UDP-Glukose umgelagert wird (Holden et al., 2003). Für den Galaktose-Abbau ist mit dem DeLey-Doudoroff-Pathwayjedoch noch ein zweiter Stoffwechselweg bekannt, der GalE nicht involviert (De Ley \& Doudoroff, 1957). In Halobacterium sp. NRC-1 konnten die Enzyme beider Wege identifiziert werden (Hochstein et al., 1976; Reshma et al., 2015). Welcher Stoffwechselweg in Halobacterium sp. für den Abbau von Galaktose verantwortlich ist, wurde jedoch bisher nicht gezeigt. Für $H$. volcanii hingegen konnte kürzlich gezeigt werden, dass Galaktose über den DeLey-Doudoroff-Pathway abgebaut wird, welcher GalE nicht benötigt (Tästensen et al., 2020). Die von GalE katalysierte Umlagerung von UDP-Galaktose zu UDP-Glukose und umgekehrt ist jedoch, wie für $E$. coli gezeigt werden konnte, dort auch im Biosyntheseweg von extrazellulären Polysacchariden relevant (Hua \& Markovitz, 1972). Ähnlich könnte GalE auch bei $H$. volcanii in die Synthese extrazellulärer Moleküle involviert sein. Beispielsweise konnte gezeigt werden, dass das Oberflächenglykoprotein von $H$. volcanii neben Glukose- auch GalaktoseReste enthält (Sumper et al., 1990). 
Eine Interaktion mit seinem Bindepartner ist mit mehreren Bereichen von HVO_2753 möglich, denn das Protein liegt hochfunktionalisiert vor. Es besitzt im Vergleich zum $H$. volcanii Proteom neben einer überdurchschnittlichen Anzahl an Cysteinen auch überdurchschnittlich viele Serine, Glutamine und Lysine, während Aminosäuren mit aliphatischen Seitenketten unterdurchschnittlich häufig vertreten sind. Sobald ein Interaktionspartner von HVO_2753 identifiziert ist, kann mittels NMR-Spektroskopie der Komplex beider Partner untersucht werden. Auf diese Weise können die Aminosäureseitenketten, die für die Interaktion mit dem Bindepartner verantwortlich sind, identifiziert werden. Für den Fall der ProteinProtein-Interaktion einer Zinkfinger-Domäne eines größeren Proteins konnte dies bereits detailreich gezeigt werden (Kostic et al., 2006). Innerhalb der vielen Aminosäureseitenketten, die potenziell an einer Interaktion beteiligt sein können, fällt bei näherer Betrachtung der Struktur und Aminosäuresequenz von HVO_2753 auf, dass im Bereich der Helix, gebildet von den Aminosäuren C42 bis S46, drei Aminosäureseitenketten nach außen gerichtet sind (siehe Abbildung 24). Diese Aminosäuren Lysin (K41), Arginin (R43) und Lysin (K44), die sich teilweise im

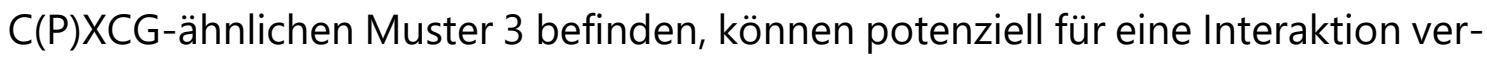
antwortlich sein. Wenn auch für diese Aminosäuren bereits gezeigt werden konnte, dass sie in $\mathrm{C}_{2} \mathrm{H}_{2}$-Zinkfingern für eine spezifische Bindung an DNA verantwortlich sind (Wolfe et al., 2000), so lässt sich hier nicht ausschließen, dass sie für die Bindung an andere Moleküle zuständig sind. ZBP1 besteht aus Muster 1 und 3, von denen keines ein Prolin an zweiter Stelle besitzt. Darüber hinaus besitzt Muster 3 auch das hochkonservierte Glycin an fünfter Stelle nicht. Hier weist es hingegen das bereits beschriebene, mit seiner Seitenkette nach außen ragende, Arginin R43 auf. Künftige Untersuchungen werden Klarheit darüber schaffen, mit welchen Bindepartnern HVO_2753 interagiert und welche Aminosäuren für die spezifische Bindung verantwortlich sind.

Darüber hinaus könnte man Lokalisationsstudien mittels fluoreszierenden Fusions-Tags durchführen. Das grün-fluoreszierende Protein (GFP) wurde bereits für den halophilen Organismus optimiert und es existiert eine Split-GFP Methode, mit der in vivo Interaktionsstudien durchgeführt werden können (Winter et al., 2018; Born \& Pfeifer, 2019). Hier wird an beide Bindepartner jeweils ein Teil des GFPs fusioniert. Dieses erhält seine fluoreszierende Eigenschaft erst durch die 
räumliche Nähe, welche durch Bindung der beiden Bindepartner aneinander hervorgerufen wird. Lediglich die geringe Größe von HVO_2753 könnte ein Hindernis darstellen, da durch Fusion mit einem deutlich größeren GFP Probleme in seiner Funktion hervorgerufen werden können.

\subsection{Das Zinkfinger- $\mu$-Protein HVO_2753 als Regulator für Schwärmen, Adhäsion und mehr}

Vor einigen Jahren konnte bereits der workflow der Erstellung und Charakterisierung von Deletionsmutanten von Interesse so optimiert werden, dass eine hohe Parallelisierung der einzelnen Abschnitte möglich ist und diverse Schritte von PCRs zur Generierung benötigter Fragmente über PCRs zur Klonierung und zur Kontrolle über Wachstumsversuche der phänotypischen Charakterisierung in Mikrotiterplatten durchgeführt werden können (Jaschinski et al., 2014). Dem Vorbild dieser Optimierungen nach wurden auch Untersuchungen zu Zinkfinger- $\mu$ Proteinen durchgeführt und es konnten viele Einsichten zu ihren putativen Funktionen bzw. zu Stoffwechselwegen oder regulatorischen Netzwerken, in denen sie eine Rolle spielen können, gewonnen werden (Nagel et al., 2019). In der vorliegenden Arbeit lag der Fokus auf dem einen Zinkfinger- $\mu$-Protein, welches in viel größerer Detailstufe untersucht wurde. Dennoch bestanden die initialen Ansätze der Untersuchung zur Funktion darin, zunächst eine Deletionsmutante herzustellen und phänotypische Charakterisierungen durchzuführen. Die in frame Deletion des Gens HVO_2753 führte zu keiner Einschränkung im Wachstum der Mutante in Komplexmedium oder synthetischem Medium mit Glukose als Kohlenstoffquelle. Da HVO_2753 mit nur 2 Nukleotiden Abstand upstream von HVO_2752, der beta-Untereinheit des Translations-Elongationsfaktors 1, liegt und mit diesem co-transkribiert wird, war dies zunächst unerwartet und lässt eine tragende Rolle innerhalb des Translationsapparats oder in seiner Regulation ausschließen. Darüber hinaus konnte zwischen der Deletionsmutante und der Überproduktionsmutante im Ribosomenprofil kein signifikanter Unterschied festgestellt werden. Unter den getesteten normalen Wachstumsbedingungen konnte somit kein signifikanter Unterschied zwischen Deletionsmutante, Wildtyp und Überexpressionsmutante festgestellt werden. Die Co-Transkiption der beiden Gene konnte bereits in vorangegangenen Studien, bei denen dRNA- bzw. RNA-Sequenzierungen von $H$. volcanii durchgeführt wurden, gezeigt werden (Babski et al., 2016; Laass et 
al., 2019). Diese Ergebnisse konnten hier mittels Northern Blot-Analyse bestätigt werden. Dabei wurden die Transkripte von HVO_2752 und HVO_2753 mittels einzelsträngiger DNA-Sonden in verschiedenen Stämmen untersucht. Mit den beiden Sonden gegen jeweils eines der Gene konnten die gleichen Transkripte detektiert werden. Lag HVO_2753 deletiert vor, konnte ein verkürztes Transkript mit der Sonde gegen HVO_2752 detektiert werden. Unterschiede im Transkriptlevel von HVO_2752 zwischen Wildtyp und Deletionsmutante fielen hingegen gering aus. Unterschiede im Proteinlevel von HVO_2752 und HVO_2753 hingegen konnten in einer quantitativen Proteomanalyse von $H$. volcanii gezeigt werden, bei der ein Wildtyp unter verschiedenen Stressbedingungen getestet wurde (Jevtić et al., 2019). Dabei wurde festgestellt, dass das Zinkfinger- $\mu$-Protein HVO_2753 unter getesteten Stressbedingungen wie Niedrig- und Hochsalz und niedrigen und hohen Temperaturen, eines der beiden Proteine ist, die in der Untersuchung am stärksten herunterreguliert vorlagen. Im Gegenzug dazu, lag HVO_2752 bei niedrigen und hohen Temperaturen stark hochreguliert, bei Niedrigsalzbedingungen jedoch herunterregliert vor. Unabhängig von der Co-Transkription ihrer Gene, werden HVO_2752 und HVO_2753 demnach, auf der Ebene der Translation oder der Proteinstabilität, differenziell reguliert.

Die weitere phänotypische Charakterisierung zeigte, dass die Deletionsmutante eine um über $60 \%$ verringerte Bildung von Biofilm im Vergleich zum Wildtyp aufweist. Neben dem Biofilm-Assay, der die Befähigung zur sessilen Lebensweise der Zellen überprüft, wurden Schwärmversuche durchgeführt, mit welchen die Motilität und Chemotaxis der Zellen überprüft werden kann. Diese zeigten ein verlangsamtes Schwärmverhalten bei der Deletionsmutante auf. Die Regulation der Motilität und Chemotaxis, also einer planktonischen Lebensweise der Zellen ist grundsätzlich stark mit der Regulation einer sessilen Lebensweise verknüpft, da beide Lebensweisen gegensätzliche Ziele verfolgen. So kann man zunächst davon ausgehen, dass wenn eine negative Regulation auf die Motilität erfolgt, auch eine positive Regulation auf die Adhäsion bzw. Biofilmbildung ausgeübt wird. Dies konnte bereits für fünf Beispiele von Zinkfinger- $\mu$-Proteinen gezeigt werden (Nagel et al., 2019). Hier wurden bei der Untersuchung von 16 Deletionsmutanten von Genen von Zinkfinger- $\mu$-Proteinen sechs Mutanten mit einem Schwärmdefizit gefunden, von denen fünf gleichzeitig eine erhöhte Biofilmbildung aufwiesen. Nur bei einer der sechs Mutanten war die Biofilmbildung nicht beeinflusst. Auch 
im Bakterium Vibrio parahaemolyticus sind mit ScrABC Beispiele bekannt, die gleichzeitig gegensetzliche Regulationen auf die Motilität und die Adhäsion an Oberflächen ausüben (Boles \& McCarter, 2002; Ferreira et al., 2008). Außerdem ist in E. coli ein globaler Regulator CsrA sehr gut untersucht, der unter anderem auch die Motilität positiv reguliert, während er auf die Biofilmbildung eine negative Regulation ausübt (Romeo \& Babitzke, 2018). Im Falle der Deletion von HVO_2753 ist nun jedoch eine negative Regulation beider Mechanismen geschehen. Die Regulation dieser beiden gegensätzlichen Lebensweisen, sessil oder planktonisch, findet bei $H$. volcanii nicht nur auf transkriptioneller Ebene gekoppelt statt, sondern ebenfalls auf einer sehr schnellen post-translationalen Ebene (Esquivel \& Pohlschroder, 2014). Das Vorhandensein eines so komplexen Systems bringt eine Vielzahl an regulatorischen Einheiten mit sich und es gibt potenziell zahlreiche Stellen, an denen die Deletion eines beteiligten Proteins keine gegenteilige Wirkung in den beiden Lebensweisen hervorruft, sondern beide Mechaniken in gleicher Weise beeinflusst werden.

Zum Beispiel konnte für die Regulation des Wechsels zwischen planktonischer und sessiler Lebensweise in Bakterien zyklisches di-GMP (c-di-GMP) als Schlüsselmolekül identifiziert werden. Dieses bindet dort an eine Vielzahl an Effektorkomponenten und kontrolliert so diverse Ziele wie die Transkription, die Aktivitäten von Enzymen und größeren zellulären Strukturen (Hengge, 2009). Während in Bakterien solche second messenger bereits gut beschrieben und untersucht sind, ist in Archaeen nur sehr wenig darüber bekannt. Erst kürzlich wurde von der Anwesenheit von c-di-AMP in H. volcanii berichtet (Braun et al., 2019), welches ebenfalls in Bakterien gut untersucht ist, aber keinen direkten Bezug zur Motilität oder der Adhäsion und Biofilmbildung besitzt. Möglicherweise existiert auch in Archaeen c-di-GMP als second messenger und erfüllt hier ähnliche Zwecke wie in Bakterien. HVO_2753 könnte hier in durch Bindung von c-di-GMP eine seiner regulatorischen Rollen erhalten und so vielleicht die Transkription des Archaellums steuern. In Bakterien existieren sogenannte Umo(uppregulator of the master opperon flhDC)-Proteine, welche dort mit der Zellhülle assoziiert sind. Von diesen wird vermutet, dass sie an der Erkennung von Oberflächen beteiligt sind (Partridge $\&$ Harshey, 2013). Auch eine Beteiligung von HVO_2753 an der Regulation oder der Funktion von archaealen Proteinen, die Funktionen solcher Umo-Proteine übernehmen, ist vorstellbar. Sie regulieren mit FlhDC einen Hauptregulator, der die 
fundamentale Entscheidung zur Produktion von Flagellen reguliert, wie für Salmonella typhimurium gezeigt werden konnte (Chevance \& Hughes, 2008). In E. coli wiederum reguliert FlhDC zusätzlich die Zellteilung. Es wird vermutet, dass um FlhDC ein breiteres regulatorisches Netzwerk exisitert, indem auch die UmoProteine ihre Rolle spielen. Dieses Netzwerk ist potenziell mit der Chemotaxis und weiteren Bereichen wie der Synthese von extrazellulären Polysacchariden und der Virulenz verknüpft (Fraser \& Hughes, 1999).

In nachfolgenden Versuchen wurden verschiedene Varianten von HVO_2753 plasmidisch exprimiert und dabei überprüft, ob auf diese Weise eine Komplementation der dokumentierten Phänotypen erreicht werden kann. Damit einhergehend wurden zur besseren Vergleichbarkeit Kontrollstämme erstellt, für die der Wildtyp und die Deletionsmutante mit dem Leervektor transformiert wurden. Während die alleinige Anwesenheit des Leervektors im Biofilm-Assay zu keinen Unterschieden führte, konnten in den Schwärmversuchen Unterschiede festgestellt werden. So wies der Wildtyp mit Leervektor ( $\mathrm{H} 26 \mathrm{evc}$ ) eine geringfügig erhöhte Schwärmgeschwindigkeit im Vergleich zum Wildtyp ohne Leervektor auf (Daten nicht gezeigt). In der Deletionsmutante führte die Anwesenheit des Leervektors zu einem Totalverlust der Schwärmfähigkeit, während ohne Leervektor das Schwärmen vermindert vorlag. Befand sich anstelle des Leervektors der Vektor mit einer Genvariante von HVO_2753 in der Zelle, konnte der Verlust der Schwärmfähigkeit durch plasmidische Expression teilweise kompensiert werden. So konnte eine verzögerte Form des Schwärmens der Komplementationsmutanten in halbfestem Medium dokumentiert werden. Beim Biofilm-Assay konnte für keine der Genvarianten eine Komplementation festgestellt werden. Die Unterschiede in der Komplementierbarkeit mittels der verwendeten Methode kann der Stärke des verwendeten plasmidischen Promotors geschuldet sein. So wird HVO_2753 auf diese Weise nicht in nativer Menge und nicht in der nativen chromosomalen Umgebung exprimiert. Die Transkriptmenge bzw. die daraus resultierende Menge des Genprodukts kann also beispielsweise für die regulatorische Funktion bezüglich des Schwärmens teilweise ausreichen, während für die Regulation der Adhäsion bzw. Biofilmbildung eine größere oder aber geringere Menge an HVO_2753 benötigt wird. Da jedoch innerhalb der Schwärmversuche durch Variation der Induktionsstärke des Promotors mittels unterschiedlicher Konzent- 
rationen des Induktors keine Veränderungen in der Komplementierbarkeit erreicht werden konnte, ist die wahrscheinlichere Erklärung für die Unterschiede in den beiden Regulationen die Existenz verschiedener Interaktionspartner von HVO_2753. Für die Komplementation des Schwärmdefizits reichte bereits die basale Promotoraktivität ohne Induktion. Im Gegenzug dazu konnte auch bei hoher Induktionsstärke mittels 4 mM Tryptophan (Large et al., 2007; Allers et al., 2010) im Biofilm-Assay keine Komplementation des Biofilmdefizits erreicht werden (Daten nicht gezeigt).

Einen tieferen Einblick in die Hintergründe der Auswirkungen der Deletion von HVO_2753 auf transkriptionaler Ebene konnte im Rahmen der vorliegenden Arbeit eine RNA-Sequenzierung des Wildtyps, der Deletions- und Komplementationsmutante bieten. Dafür kamen Zellen der exponentiellen Wachstumsphase aus synthetischem Medium mit Glukose als Kohlenstoffquelle zum Einsatz. Nach dem mappen der bei der RNA-Sequenzierung erhaltenen reads auf das Genom von $H$. volcanii konnten, unter Zuhilfenahme der Annotationen, die counts aller Protein-codierenden Gene ermittelt werden. Die counts stellen ein Maß für die Menge an Transkripten für jedes Gen dar. Die Mittelwerte der counts der biologischen Duplikate wurden berechnet und die Ergebnisse der verschiedenen Stämme wurden nach einer Normierung miteinander verglichen. Dabei war besonders auffällig und in Übereinstimmung mit den bereits identifizierten Funktionsverlusten, dass eine Vielzahl an Genen mit Genprodukten, die in Chemotaxis oder Motilität involviert sind, herunterreguliert vorlagen. Hierbei war ein Lokus besonders betroffen, bei dem sich auf dem forward und reverse Strang mehrere Operons befinden. Diese enthalten die Gene codierend für Archaellin A1 und A2, die Archaellin-Cluster-Proteine ArID, ArICE, ArIF, ArIG und ArlH, die ArchaellumMotorproteine Arll und ArlJ, darüber hinaus mehrere Taxis-Cluster-Proteine wie CheC, CheD, CheF1 und CheF2, Sensor-Histidinkinase CheA und weitere Chemotaxis-assoziierte Proteine sowie auch hypothetische und konservierte hypothetische Proteine. Von diesen waren teilweise keine Transkripte in der Deletionsmutante vorhanden oder signifikant weniger als im Wildtyp. Die hier gezeigte umfangreiche Regulation solcher Chemotaxis- und Motilitätsgene spricht erneut für eine Beteiligung von HVO_2753 an einem hauptregulatorischen Prozess, wie von FlhDC in Bakterien. Wie zuvor beschrieben, reguliert dieser die fundamentale Entscheidung zur Produktion von Flagellen. Darüber hinaus konnten fünf weitere 
signifikant herunterregulierte Gene außerhalb dieses Lokus identifiziert werden, die für den Häm-basierten Aerotaxis-Transducer HemAT und die Transducer-Proteine Htr7, Htr38 und zwei Paraloge von Htr15 codieren. Halobakterielle Transducer-Proteine (Htps) wurden in $\mathrm{H}$. salinarum genauer untersucht und stellen Homologe zu bakteriellen Methyl-akzeptierenden Chemotaxis-Proteinen (MCPs) dar (Rudolph et al., 1996; Zhang et al., 1996). Einige von ihnen konnten Signaltransduktionsketten zugeordnet werden (Kokoeva \& Oesterhelt, 2000; Koch \& Oesterhelt, 2005). Dabei wurden einige Transducer-Proteine untersucht und identifiziert, die in die Phototaxis involviert sind und dementsprechend benannt wurden (Kokoeva et al., 2002). In H. salinarum dienen Sensor-Rhodopsin I und II als Photorezeptoren und die involvierten Transducer-Proteine, die für die Weiterleitung des Signals verantwortlich sind wurden halobakterielle Transducer für Sensor-Rhodopsin (Htrs) genannt (Kokoeva \& Oesterhelt, 2000). Homologe dieser in $H$. salinarum identifizierten Htrs wurden auch im Genom von $H$. volcanii annotiert. Da H. volcanii keine Retinalproteine enthält ist von seinen Htrs jedoch keine genaue Funktion bekannt. Eine Beteiligung an der Taxis ist dennoch naheliegend.

Neben einer Vielzahl an weiteren Genen, die differenziell reguliert vorlagen und denen keine gemeinsame übergeordnete Rolle zugeschrieben werden kann, lag noch ein zweites entgegengesetzt reguliertes Cluster vor. Dieses umfasste die Gene verschiedener Transportproteine und einer Vielzahl an Untereinheiten von ABC-Transportern. Darüber hinaus die Gene von zwei SNF-Transportproteinen und von fünf Enzymen der Eisen(III)-Siderophor-Biosynthese. Abgesehen von den beiden SNF-Transportproteinen, wessen Gene herunterreguliert vorlagen, lagen die anderen Gene mit der 2-fachen bis hin zur über 28-fachen Transkriptmenge signifikant hochreguliert vor. ABC-Transporter stellen eine wichtige Klasse von Transportproteinen dar und kommen in allen Domänen des Lebens vor. Sie besitzen eine ATP-bindende Kassete (ABC, $\underline{\text { ATP }}$ binding cassette) und stellen somit eine Klasse aktiver Transporter dar. Dabei sind sie in vielen verschiedenen Prozessen, wie dem Substratimport oder -export, dem Osmosensing oder der Osmoregulation beteiligt (Holland \& A. Blight, 1999). Viele Transporter sind in H. volcanii noch nicht charakterisiert. Bisherige Untersuchungen haben jedoch gezeigt, dass in H. volcanii ein ABC-Transporter spezifisch für Glukose unter anaeroben Bedingungen existiert (Wanner \& Soppa, 1999), während eine generelle Glukose-Auf- 
nahme vermutlich mittels Symporter stattfindet und über ein $\mathrm{Na}^{+}$-elektrochemisches Potenzial angetrieben wird (Tawara \& Kamo, 1991). Auch die Aufnahme von D-Xylose und L-Arabinose involviert einen ABC-Transporter (Johnsen et al., 2019). Außerdem sind Phosphat-spezifische ABC-Transporter (Kliemt et al., 2019) und ATP-getriebene Efflux-Transporter beschrieben (Kaidoh et al., 1996; Miyauchi et al., 1997). Bakterielle und archaeale ABC-Aufnahmesysteme besitzen interessanterweise mit dem extrazellulären Substratbindeprotein eine fünfte Komponente, welche das jeweilige Substrat bindet und der Permeasedomäne übergibt (Albers et al., 2004). Die Gene von elf solchen putativen Substratbindeproteinen befinden sich interessanterweise unter denjenigen, die in Abwesenheit von HVO_2753 stark hochreguliert wurden. Außerdem konnten dabei Gene identifiziert werden, die für Proteine codieren, von denen Homologe mit annotierter Funktion existieren oder die Domänen enthalten, welche in anderen Organismen einer Funktion zugeordnet werden konnten. Zum Beispiel ein Ferrichrom-Bindeprotein (HVO_1464), das im Transport von Metallionen beteiligt ist. Des Weiteren lag HVO_1705 zusammen mit dem zugehörigen putativen Permease-Protein (HVO_1706) und dem putativen ATP-Bindeprotein (HVO_1707) hochreguliert vor. HVO_ 1705 weist Homologien zum Gen des Eisen(III)-Substrat-Bindeproteins PBP2_Fbp auf. Mit HVO_1759, HVO_1760, HVO_1991, HVO_2038, HVO_A0541, HVO_A0558, HVO_B0047, HVO_B0144, HVO_B0150, HVO_B0197 und HVO_B0198 sind elf weitere Gene hochreguliert, von denen homologe Gene in anderen Organismen für Eisenionen-Transporter oder Metallionen-Transporter codieren. Der Eisentransport ist in Bakterien, z.B. in E. coli (Braun \& Braun, 2002) und in Eukaryoten, von Phytoplankton (Sutak et al., 2020) bis hin zum Menschen (Carver, 2017), sehr gut untersucht. In Archaea hingegen ist weniger über den Eisentransport bekannt, jedoch wurden in $\mathrm{H}$. salinarum bereits Untersuchungen durchgeführt. Hier konnten Hinweise auf einen energieabhängigen Eisenaufnahmeprozess gefunden werden (Hubmacher et al., 2007). Eisen stellt dabei ein essenzielles Spurenelement für alle Lebewesen dar und wird in Form von Eisen(III) in einer Vielzahl von essenziellen Enzymen benötigt. Aufgrund der sehr geringen Löslichkeit von Eisen(III) steht freies Eisen(III) nur in sehr geringen Konzentrationen zur Verfügung, was die Notwendigkeit eines effizienten Eisen-Aufnahmesystems unterstreicht. Daher existiert in einer Vielzahl von Mikroorganismen ein Biosyntheseapparat für Eisen-komplexierende Biomoleküle, die sogenannten Siderophore (Barry \& 
Challis, 2009). Diese werden nach der Synthese von der Zelle sekretiert und fangen extrazelluläres Eisen(III) ab, das anschließend von der Zelle aufgenommen werden kann. In H. volcanii konnte kürzlich gezeigt werden, dass hier ein Operon existiert, dessen 6 Gene für die Enzyme zur Herstellung des einzigen Eisen(III)Siderophors von $H$. volcanii codieren (Niessen \& Soppa, 2020). Überraschenderweise befanden sich diese 6 Gene (HVO_B0041 bis HVO_B0046) ebenfalls unter den in Abwesenheit von HVO_2753 signifikant hochregulierten Genen (siehe Tabelle A4).

Durch die Deletion von HVO_2753 entstanden demnach erhöhte Transkriptlevel vieler Gene, die für putative Metallionen-, insbesondere Eisenionen-Transporter und Enzymen der Eisen-Siderophor-Biosynthese codieren. Dies ist generell bei sehr geringen extrazellulären Konzentrationen der lonen zu erwarten, was man hier ausschließen kann. Darüber hinaus wird Eisen(III) für viele Redox-Enzyme benötigt und ist hierbei wichtig für die Eisenkatalyse (Camprubi et al., 2017). In Eisen-Schwefel-Proteinen, einer sehr häufigen Proteinklasse, die viele verschiedene Funktionen, wie z.B. Elektronentransfer, übernehmen können, stellt Eisen einen essenziellen Bestandteil dar (Beinert, 2000). Ist Eisen jedoch in großem Übermaß vorhanden, entstehen durch ungewollte Redoxvorgänge toxische reaktive Sauerstoffspezies, weshalb die Eisen-Homöostase in der Zelle streng reguliert wird. Untersuchungen zur Regulation der Eisen-Homöostase in $\mathrm{H}$. salinarum führten zur Identifikation eines entsprechenden Transkriptionsnetzwerks (Martinez-Pastor et al., 2017). Hierbei konnte gezeigt werden, dass in einem feedback loop-Netzwerk die intrazelluläre Eisenkonzentration reguliert wird, bei dem Bakterien-ähnliche Transkriptionsfaktoren gekoppelt in einer Topologie, wie sie aus Eukaryoten bekannt ist, für die strenge Kontrolle verantwortlich sind. Sollte $H$. volcanii ein ähnlich komplexes Regulationsnetzwerk zur Eisenhomöostase besitzen, könnte HVO_2753 eine direkte Rolle darin spielen oder durch einen indirekten Effekt entsprechende Auswirkungen auf ein ganzes Netzwerk haben. Die starke Verknüpfung von Transportern für viele verschiedene Metallionen auf regulatorischer Ebene können die identifizierten weitreichenden Auswirkungen auch auf andere Transporter erklären.

Während bei den Genen von Motilitäts- und Chemotaxisproteinen keine Komplementation der Regulation durch plasmidische Expression von HVO_2753 erreicht werden konnte, sind bei dem Großteil der Gene von Transportproteinen nahezu 
wildtypische Expressionslevel in der Komplementationsmutante zu finden (siehe Tabelle A4 im Anhang). Der enorme Umfang der Auswirkungen auf das Transkriptom, die die Deletion von HVO_2753 bewirkt, sprechen dafür, dass HVO_2753 in mindestens einem übergeordneten Regulationsprozess involviert ist. Es konnte durch die Transkriptomanalyse gezeigt werden, dass durch die Deletion von HVO_2753 die Expression von 30 Genen signifikant herunterreguliert vorlag. Diese codieren für Proteine des Bewegungsapparates oder der Chemotaxis-Signaltransduktion. Des Weiteren wurden durch die Deletion des Gens des kleinen Zinkfinger-Proteins zahlreiche Gene hochreguliert. Deren Genprodukte wiederum sind in der Metallionen- insbesondere der Eisen(III)-Aufnahme beteiligt. Diese Erkenntnisse sprechen dafür, dass HVO_2753 einen positiven Regulator für das Schwärmen und die Zelladhäsion bzw. Biofilmbildung darstellt, der dafür besonders unter mikroaeroben Bedingungen eine wichtige Rolle spielt. Diese Funktion konnte sowohl mittels RNA-Sequenzierung als auch mittels Schwärmversuchen bzw. Biofilm-Assays gezeigt werden. Gleichzeitig übt HVO_2753 einen negativen regulatorischen Effekt auf die Eisen(III)-Siderophor-Biosynthese und den Eisen(III)-Transport aus, der besonders unter aeroben Bedingungen eine Rolle spielt. Eine Übersicht über die regulatorischen Funktionen gibt Abbildung 25.

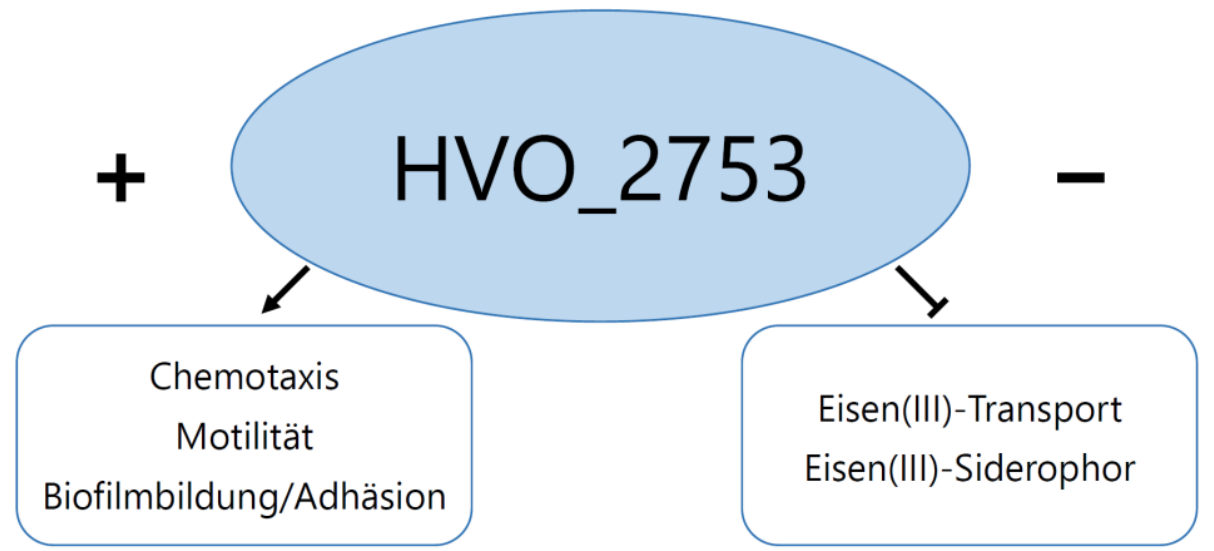

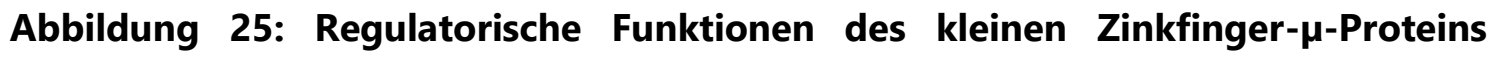
HVO_2753. HVO_2753 übt sowohl positive regulatorische Funktionen (linke Seite) als auch negative regulatorische Funktionen (rechte Seite) aus.

Die Durchführung von in vivo Studien auf Proteinebene könnte in Zukunft interessant sein. Mittels Antikörper gegen HVO_2753 und HVO_2752 könnten die Proteinlevel im Wildtyp und in Mutanten überprüft werden. Der Versuch hochspezifische, polyklonale Antikörper gegen HVO_2753 in der vorliegenden Arbeit 
herzustellen, brachte jedoch Antikörper ohne die benötigte hohe Spezifität hervor. Ein Grund hierfür kann eine Verunreinigung in der Antigen-Lösung sein. Der erhaltene QHVO_2753 wies Kreuzreaktionen mit anderen Proteinen von $H$. volcanii auf und wurde deshalb für keine weiteren Untersuchungen verwendet. Aus zeitlichen Gründen wurde in dieser Arbeit keine erneute Antikörper-Produktion durchgeführt. Durch die neuen Kenntnisse bezüglich der Struktur von HVO_2753 könnte jedoch für eine künftige Antikörper-Produktion ein Teil des Proteins, der exponiert vorliegt, chemisch synthetisiert und gekoppelt an ein Trägermolekül als Antigen verwendet werden.

In dieser Arbeit konnte hingegen gezeigt werden, dass mit HVO_2753 ein Zinkfinger- $\mu$-Protein essenziell für die Bildung von Biofilm bzw. die Adhäsion an eine Oberfläche und für das Schwärmen in einem halbfesten Medium ist. Die Deletion des Gens des kleinen Zinkfinger-Proteins hatte weitreichende Auswirkungen auf das Transkriptom der Zelle. Um die regulatorische Rolle von HVO_2753 weiter aufzuklären, werden jedoch weitere Untersuchungen benötigt. Es müssen Zusammenhänge verschiedener regulatorischer Netzwerke identifiziert werden, die durch die Deletion des Gens eines einzigen kleinen Zinkfinger-Proteins umfangreich beeinflusst wurden. 


\section{Literaturverzeichnis}

Adam, P. S., Borrel, G., Brochier-Armanet, C. \& Gribaldo, S. (2017) 'The growing tree of Archaea: New perspectives on their diversity, evolution and ecology', ISME J., 11(11), pp. 2407-2425.

Albers, S. V., Koning, S. M., Konings, W. N. \& Driessen, A. J. M. (2004) 'Insights into ABC Transport in Archaea', J. Bioenerg. Biomembr., 36(1), pp. 5-15.

Allers, T., Barak, S., Liddell, S., Wardell, K. \& Mevarech, M. (2010) 'Improved strains and plasmid vectors for conditional overexpression of His-tagged proteins in Haloferax volcanii.', Appl. Environ. Microbiol., 76(6), pp. 1759-69.

Allers, T. \& Mevarech, M. (2005) 'Archaeal genetics - the third way', Nat. Rev. Genet., 6(1), pp. 58-73.

Allers, T., Ngo, H. P., Mevarech, M. \& Lloyd, R. G. (2004) 'Development of Additional Selectable Markers for the Halophilic Archaeon Haloferax volcanii Based on the leuB and trpA Genes', Applied and Environmental Microbiology, 70(2), pp. 943-953.

Altschul, S. F., Gish, W., Miller, W., Myers, E. W. \& Lipman, D. J. (1990) 'Basic local alignment search tool', J. Mol. Biol., 215(3), pp. 403-410.

Andrews, S. J. \& Rothnagel, J. A. (2014) 'Emerging evidence for functional peptides encoded by short open reading frames', Nat. Rev. Genet., 15(3), pp. 193204.

Argos, P., Garavito, R. M., Eventoff, W., Rossmann, M. G. \& Brändén, C. I. (1978) 'Similarities in active center geometries of zinc-containing enzymes, proteases and dehydrogenases', J. Mol. Biol., 126(2), pp. 141-158.

Babski, J., Haas, K. A., Näther-Schindler, D., Pfeiffer, F., Förstner, K. U., Hammelmann, M., Hilker, R., Becker, A., et al. (2016) 'Genome-wide identification of transcriptional start sites in the haloarchaeon Haloferax volcanii based on differential RNA-Seq (dRNA-Seq).', BMC Genom., 17(629).

Baglivo, I., Palmieri, M., Rivellino, A., Netti, F., Russo, L., Esposito, S., lacovino, R., Farina, B., et al. (2014) 'Molecular strategies to replace the structural metal site in the prokaryotic zinc finger domain', BBA-Proteins Proteom., 1844(3), pp. 497-504.

Baker, B. J., De Anda, V., Seitz, K. W., Dombrowski, N., Santoro, A. E. \& Lloyd, K. G. (2020) 'Diversity, ecology and evolution of Archaea', Nat. Microbiol., 5(7), pp. 887-900.

Barry, S. M. \& Challis, G. L. (2009) 'Recent advances in siderophore biosynthesis', Curr. Opin. Chem. Biol., 13(2), pp. 205-215.

Baumgartner, D., Kopf, M., Klähn, S., Steglich, C. \& Hess, W. R. (2016) 'Small proteins in cyanobacteria provide a paradigm for the functional analysis of the bacterial micro-proteome', BMC Microbiol., 16(1), pp. 1-15. 
Beinert, H. (2000) 'Iron-sulfur proteins: Ancient structures, still full of surprises', J. Biol. Inorg. Chem., 5(1), pp. 2-15.

Bitan-banin, G., Ortenberg, R. \& Mevarech, M. (2003) 'Development of a Gene Knockout System for the Halophilic Archaeon Haloferax volcanii by Use of the pyrE Gene', J. Bacteriol., 185(3), pp. 772-778.

Boles, B. R. \& McCarter, L. L. (2002) 'Vibrio parahaemolyticus scrABC, a novel operon affecting swarming and capsular polysaccharide regulation', J. Bacteriol., 184(21), pp. 5946-5954.

Born, J. \& Pfeifer, F. (2019) 'Improved GFP variants to study gene expression in Haloarchaea', Front. Microbiol., 10(1200).

Borrel, G., Brugère, J. F., Gribaldo, S., Schmitz, R. A. \& Moissl-Eichinger, C. (2020) 'The host-associated archaeome', Nat. Rev. Microbiol., 18(11), pp. 622-636.

Bouhouche, N., Syvanen, M. \& Kado, C. I. (2000) 'The origin of prokaryotic C2H2 zinc finger regulators', Trends Microbiol., 8(2), pp. 77-81.

Braun, F., Thomalla, L., van der Does, C., Quax, T. E. F., Allers, T., Kaever, V. \& Albers, S. V. (2019) 'Cyclic nucleotides in archaea: Cyclic di-AMP in the archaeon Haloferax volcanii and its putative role', MicrobiologyOpen, 8(9), p. e00829.

Braun, V. \& Braun, M. (2002) 'Iron transport and signaling in Escherichia coli', FEBS Lett., 529(1), pp. 78-85.

Brown, R. S., Sander, C. \& Argos, P. (1985) 'The primary structure of transcription factor TFIIIA has 12 consecutive repeats', FEBS Lett., 186(2), pp. 271274.

Cabrera-Quio, L. E., Herberg, S. \& Pauli, A. (2016) 'Decoding sORF translation - from small proteins to gene regulation', RNA Biol., 13(11), pp. 1051-1059.

Camprubi, E., Jordan, S. F., Vasiliadou, R. \& Lane, N. (2017) 'Iron catalysis at the origin of life', IUBMB Life, 69(6), pp. 373-381.

Caro, F., Bercovich, N., Atorrasagasti, C., Levin, M. J. \& Vázquez, M. P. (2005) 'Protein interactions within the TcZFP zinc finger family members of Trypanosoma cruzi: Implications for their functions', Biochemical and Biophysical Research Communications, 333(3), pp. 1017-1025.

Carver, P. L. (2017) 'The Battle for Iron between Humans and Microbes', Curr. Med. Chem., 25(1), pp. 85-96.

Cassandri, M., Smirnov, A., Novelli, F., Pitolli, C., Agostini, M., Malewicz, M., Melino, G. \& Raschellà, G. (2017) 'Zinc-finger proteins in health and disease', Cell Death Differ., 3(17071).

Chen, X., Chu, M. \& Giedroc, D. P. (1999) 'MRE-binding transcription factor-1: Weak zinc-binding finger domains 5 and 6 modulate the structure, affinity, and specificity of the metal-response element complex', Biochemistry, 38(39), pp. 
$12915-12925$.

Chevance, F. F. V. \& Hughes, K. T. (2008) 'Coordinating assembly of a bacterial macromolecular machine', Nat. Rev. Microbiol., 6(6), pp. 455-465.

Chou, A. Y., Archdeacon, J. \& Kado, C. I. (1998) 'Agrobacterium transcriptional regulator Ros is a prokaryotic zinc finger protein that regulates the plant oncogene ipt.', Proc. Natl. Acad. Sci. U.S.A., 95(9), pp. 5293-5298.

Chroňáková, A., Ascher, J., Jirout, J., Ceccherini, M. T., Elhottová, D., Pietramellara, G. \& Šimek, M. (2012) 'Cattle impact on composition of archaeal, bacterial, and fungal communities by comparative fingerprinting of total and extracellular DNA', Biol. Fert. Soils, 49(3), pp. 351-361.

Conway de Macario, E. \& Macario, A. J. L. (2009) 'Methanogenic archaea in health and disease: A novel paradigm of microbial pathogenesis', Int. J. Med. Microbiol., 299(2), pp. 99-108.

Cox, C. J., Foster, P. G., Hirt, R. P., Harris, S. R. \& Embley, T. M. (2008) 'The archaebacterial origin of eukaryotes', Proc. Natl. Acad. Sci. U.S.A., 105(51), pp. 20356-20361.

D'Lima, N. G., Ma, J., Winkler, L., Chu, Q., Loh, K. H., Corpuz, E. O., Budnik, B. A., Lykke-Andersen, J., et al. (2017) 'A human microprotein that interacts with the mRNA decapping complex', Nat. Chem. Biol., 13(2), pp. 174-180.

Danner, S. \& Soppa, J. (1996) 'Characterization of the distal promoter element of halobacteria in vivo using saturation mutagenesis and selection', Mol. Microbiol., 19(6), pp. 1265-1276.

Delcourt, V., Staskevicius, A., Salzet, M., Fournier, I. \& Roucou, X. (2018) 'Small Proteins Encoded by Unannotated ORFs are Rising Stars of the Proteome, Confirming Shortcomings in Genome Annotations and Current Vision of an mRNA', Proteomics, 18(10).

DeLong, E. F. \& Pace, N. R. (2001) 'Environmental Diversity of Bacteria and Archaea', Systematic Biol. Edited by M. Kane, 50(4), pp. 470-478.

Doolittle, W. F. \& Logsdon, J. M. (1998) 'Archaeal genomics: Do archaea have a mixed heritage?', Curr. Biol., 8(6).

Duval, M. \& Cossart, P. (2017) 'Small bacterial and phagic proteins: an updated view on a rapidly moving field', Curr. Opin. Microbiol., 39, pp. 81-88.

Eisenberg, H., Mevarech, M. \& Zaccai, G. (1992) 'Biochemical, structural, and molecular genetic aspects of halophilism', Adv. Protein Chem., 43, pp. 1-62.

Elrod-Erickson, M., Rould, M. A., Nekludova, L. \& Pabo, C. O. (1996) 'Zif268 protein-DNA complex refined at $1.6 \AA$ : A model system for understanding zinc finger-DNA interactions', Structure, 4(10), pp. 1171-1180.

Eme, L., Spang, A., Lombard, J., Stairs, C. W. \& Ettema, T. J. G. (2017) 'Archaea and the origin of eukaryotes', Nat. Rev. Microbiol., 15(12), pp. 711-723. 
Eom, K. S., Cheong, J. S. \& Lee, S. J. (2016) 'Structural analyses of zinc finger domains for specific interactions with DNA', J. Microbiol. Biotechnol., 26(12), pp. 2019-2029.

Esquivel, R. N. \& Pohlschroder, M. (2014) 'A conserved type IV pilin signal peptide $\mathrm{H}$-domain is critical for the post-translational regulation of flagelladependent motility', Mol. Microbiol., 93(3), pp. 494-504.

Falconi, M., Giangrossi, M., Zabaleta, M. E., Wang, J., Gambini, V., Tilio, M., Bencardino, D., Occhipinti, S., et al. (2019) 'A novel 3'-tRNAGlu-derived fragment acts as a tumor suppressor in breast cancer by targeting nucleolin', FASEB J., 33(12), pp. 13228-13240.

Fernandez-Pol, J. A., Klos, D. J. \& Hamilton, P. D. (1993) 'A growth factorinducible gene encodes a novel nuclear protein with zinc finger structure', J. Biol. Chem., 268(28), pp. 21198-21204.

Ferreira, R. B. R., Antunes, L. C. M., Greenberg, E. P. \& McCarter, L. L. (2008) 'Vibrio parahaemolyticus ScrC modulates cyclic dimeric GMP regulation of gene expression relevant to growth on surfaces', J. Bacteriol., 190(3), pp. 851-860.

Finoulst, I., Pinkse, M., Van Dongen, W. \& Verhaert, P. (2011) 'Sample preparation techniques for the untargeted LC-MS-based discovery of peptides in complex biological matrices', J. Biomed. Biotechnol., 2011(245291).

Fischer, S., Benz, J., Späth, B., Maier, L. K., Straub, J., Granzow, M., Raabe, M., Urlaub, H., et al. (2010) 'The archaeal Ism protein binds to small RNAs', J. Biol. Chem., 285(45), pp. 34429-34438.

Frankel, A. D., Berg, J. M. \& Pabo, C. O. (1987) 'Metal-dependent folding of a single zinc finger from transcription factor IIIA.', Proc. Natl. Acad. Sci. U.S.A., 84(14), pp. 4841-4845.

Fraser, G. M. \& Hughes, C. (1999) 'Swarming motility', Curr. Opin. Microbiol., 2(6), pp. 630-635.

Freese, N. H., Norris, D. C. \& Loraine, A. E. (2016) 'Integrated genome browser: Visual analytics platform for genomics', Bioinformatics, 32(14), pp. 2089-2095.

Frey, J. C., Pell, A. N., Berthiaume, R., Lapierre, H., Lee, S., Ha, J. K., Mendell, J. E. \& Angert, E. R. (2010) 'Comparative studies of microbial populations in the rumen, duodenum, ileum and faeces of lactating dairy cows', J. Appl. Microbiol., 108(6), pp. 1982-1993.

Fumeaux, C., Radhakrishnan, S. K., Ardissone, S., Théraulaz, L., Frandi, A., Martins, D., Nesper, J., Abel, S., et al. (2014) 'Cell cycle transition from S-phase to $\mathrm{G} 1$ in Caulobacter is mediated by ancestral virulence regulators', Nat. Commun., 5(4081).

Gebetsberger, J., Wyss, L., Mleczko, A. M., Reuther, J. \& Polacek, N. (2017) 'A tRNA-derived fragment competes with mRNA for ribosome binding and regulates translation during stress', RNA Biol., 14(10), pp. 1364-1373. 
Gebetsberger, J., Zywicki, M., Künzi, A. \& Polacek, N. (2012) 'TRNA-derived fragments target the ribosome and function as regulatory non-coding RNA in Haloferax volcanii', Archaea, 2012(260909).

Gill, G. N. (1995) 'The enigma of LIM domains', Structure, 3(12), pp. 1285-1289.

Granok, H., Leibovitch, B. A., Shaffer, C. D. \& Elgin, S. C. R. (1995) 'Chromatin: Ga-ga over GAGA factor', Curr. Biol., 5(3), pp. 238-241.

Guo, B., Zhai, D., Cabezas, E., Welsh, K., Nouraini, S., Satterthwait, A. C. \& Reed, J. C. (2003) 'Humanin peptide suppresses apoptosis by interfering with Bax activation', Nature, 423(6938), pp. 456-461.

Hammelmann, M. \& Soppa, J. (2008) 'Optimized generation of vectors for the construction of Haloferax volcanii deletion mutants.', J. Microbiol. Methods, 75(2), pp. 201-204.

Hanahan, D. (1983) 'Studies on Transformation of Escherichia coli with Plasmids', J. Mol. Biol., 166(4), pp. 557-580.

Hanas, J. S., Hazuda, D. J., Bogenhagen, D. F., Wu, F. Y. \& Wu, C. W. (1983) 'Xenopus transcription factor A requires zinc for binding to the 5 S RNA gene.', J. Biol. Chem., 258(23), pp. 14120-14125.

Hartford, C. C. R. \& Lal, A. (2020) 'When Long Noncoding Becomes Protein Coding', Mol. Cell. Biol., 40(6), pp. e00528-19.

Hartman, A. L., Norais, C., Badger, J. H., Delmas, S., Haldenby, S., Madupu, R., Robinson, J., Khouri, H., et al. (2010) 'The complete genome sequence of Haloferax volcanii DS2, a model archaeon', PLOS ONE, 5(3), p. e9605.

Hawkins, M., Malla, S., Blythe, M. J., Nieduszynski, C. A. \& Allers, T. (2013) 'Accelerated growth in the absence of DNA replication origins', Nature, 503(7477), pp. 544-547.

He, C., Hus, J. C., Li, J. S., Zhou, P., Norman, D. P. G., Dötsch, V., Wei, H., Gross, J. D., et al. (2005) 'A methylation-dependent electrostatic switch controls DNA repair and transcriptional activation by E. coli Ada', Mol. Cell, 20(1), pp. 117129.

Heidrich, N., Dugar, G., Vogel, J. \& Sharma, C. M. (2015) 'Investigating CRISPR RNA biogenesis and function using RNA-seq', Methods Mol. Biol., 1311, pp. 1-21.

Hengge, R. (2009) 'Principles of c-di-GMP signalling in bacteria', Nat. Rev. Microbiol., 7(4), pp. 263-273.

Henneman, B., van Emmerik, C., van Ingen, H. \& Dame, R. T. (2018) 'Structure and function of archaeal histones', PLOS Genet., 14(9).

Heyer, R., Dörr, M., Jellen-Ritter, A., Späth, B., Babski, J., Jaschinski, K., Soppa, J. \& Marchfelder, A. (2012) 'High throughput sequencing reveals a plethora of small RNAs including tRNA derived fragments in Haloferax volcanii', RNA Biol., 9(7), pp. 1011-1018. 
Hirano, T., Kikuchi, K., Urano, Y. \& Nagano, T. (2002) 'Improvement and biological applications of fluorescent probes for zinc, ZnAFs', J. Am. Chem. Soc., 124(23), pp. 6555-6562.

Hobbs, E. C., Fontaine, F., Yin, X. \& Storz, G. (2011) 'An expanding universe of small proteins', Curr. Opin. Microbiol., 14(2), pp. 167-173.

Hochstein, L. I., Dalton, B. P. \& Pollock, G. (1976) 'The metabolism of carbohydrates by extremely halophilic bacteria: identification of galactonic acid as a product of galactose metabolism', Can. J. Microbiol., 22(8), pp. 1191-1196.

Holden, H. M., Rayment, I. \& Thoden, J. B. (2003) 'Structure and Function of Enzymes of the Leloir Pathway for Galactose Metabolism', J. Biol. Chem., 278(45), pp. 43885-43888.

Holland, I. B. \& A. Blight, M. (1999) 'ABC-ATPases, adaptable energy generators fuelling transmembrane movement of a variety of molecules in organisms from bacteria to humans', J. Mol. Biol., 293(2), pp. 381-399.

Hölzle, A., Fischer, S., Heyer, R., Schütz, S., Zacharias, M., Walther, P., Allers, T. \& Marchfelder, A. (2008) 'Maturation of the 5S rRNA 5' end is catalyzed in vitro by the endonuclease tRNase $Z$ in the archaeon $\mathrm{H}$. volcanii', $R N A, 14(5)$, pp. 928-937.

Hua, S. S. \& Markovitz, A. (1972) 'Multiple regulator gene control of the galactose operon in Escherichia coli K-12.', J. Bacteriol., 110(3), pp. 1089-1099.

Hubmacher, D., Matzanke, B. F. \& Anemüller, S. (2007) 'Iron-uptake in the Euryarchaeon Halobacterium salinarum', BioMetals, 20(3-4), pp. 539-547.

Huet, J., Schnabel, R., Sentenac, A. \& Zillig, W. (1983) 'Archaebacteria and eukaryotes possess DNA-dependent RNA polymerases of a common type.', EMBO J., 2(8), pp. 1291-1294.

Ingolia, N. T., Hussmann, J. A. \& Weissman, J. S. (2019) 'Ribosome profiling: Global views of translation', CSH Perspect. Biol., 11(5).

Inoue, H., Nojima, H. \& Okayama, H. (1990) 'High efficiency transformation of Escherichia coli with plasmids', Gene, 96(1), pp. 23-28.

Issaq, H. J., Chan, K. C., Blonder, J., Ye, X. \& Veenstra, T. D. (2009) 'Separation, detection and quantitation of peptides by liquid chromatography and capillary electrochromatography', J. Chromatogr. A, 1216(10), pp. 1825-1837.

Jantzer, K., Zerulla, K. \& Soppa, J. (2011) 'Phenotyping in the archaea: optimization of growth parameters and analysis of mutants of Haloferax volcanii', FEMS Microbiol. Lett., 322(2), pp. 123-130.

Jaschinski, K., Babski, J., Lehr, M., Burmester, A., Benz, J., Heyer, R., Dörr, M., Marchfelder, A., et al. (2014) 'Generation and Phenotyping of a Collection of sRNA Gene Deletion Mutants of the Haloarchaeon Haloferax volcanii', PLOS ONE. Edited by D. Zhou, 9(3), p. e90763. 
Jevtić, Ž., Stoll, B., Pfeiffer, F., Sharma, K., Urlaub, H., Marchfelder, A. \& Lenz, C. (2019) 'The Response of Haloferax volcanii to Salt and Temperature Stress: A Proteome Study by Label-Free Mass Spectrometry', Proteomics, 19(20), p. 1800491.

Johnsen, U., Ortjohann, M., Sutter, J. M., Geweke, S. \& Schönheit, P. (2019) 'Uptake of D-xylose and L-arabinose in Haloferax volcanii involves an $A B C$ transporter of the CUT1 subfamily', FEMS Microbiol. Lett., 366(8).

Kaidoh, K., Miyauchi, S., Abe, A., Tanabu, S., Nara, T. \& Kamo, N. (1996) 'Rhodamine 123 efflux transporter in Haloferax volcanii is induced when cultured under "metabolic stress" by amino acids: The efflux system resembles that in a doxorubicin-resistant mutant', Biochem. J., 314(1), pp. 355-359.

Karner, M. B., Delong, E. F. \& Karl, D. M. (2001) 'Archaeal dominance in the mesopelagic zone of the Pacific Ocean', Nature, 409(6819), pp. 507-510.

Karunratanakul, K., Tang, H. Y., Speicher, D. W., Chuangsuwanich, E. \& Sriswasdi, S. (2019) 'Uncovering thousands of new peptides with sequencemask-search hybrid de novo peptide sequencing framework', Mol. Cell. Proteomics, 18(12), pp. 2478-2491.

Klein, C., Aivaliotis, M., Olsen, J. V., Falb, M., Besir, H., Scheffer, B., Bisle, B., Tebbe, A., et al. (2007) 'The low molecular weight proteome of Halobacterium salinarum', J. Proteome Res., 6, pp. 1510-1518.

Kliemt, J., Jaschinski, K. \& Soppa, J. (2019) 'A haloarchaeal small regulatory RNA (sRNA) is essential for rapid adaptation to phosphate starvation conditions', Front. Microbiol., 10(1219).

Kluska, K., Adamczyk, J. \& Krężel, A. (2018) 'Metal binding properties, stability and reactivity of zinc fingers', Coordin. Chem. Rev., 367, pp. 18-64.

Koch, M. K. \& Oesterhelt, D. (2005) 'MpcT is the transducer for membrane potential changes in Halobacterium salinarum', Mol. Microbiol., 55(6), pp. 16811694.

Kokoeva, M. V. \& Oesterhelt, D. (2000) 'BasT, a membrane-bound transducer protein for amino acid detection in Halobacterium salinarum', Mol. Microbiol., 35(3), pp. 647-656.

Kokoeva, M. V., Storch, K. F., Klein, C. \& Oesterhelt, D. (2002) 'A novel mode of sensory transduction in archaea: Binding protein-mediated chemotaxis towards osmoprotectants and amino acids', EMBO J., 21(10), pp. 2312-2322.

Kostic, M., Matt, T., Martinez-Yamout, M. A., Dyson, H. J. \& Wright, P. E. (2006) 'Solution Structure of the Hdm2 C2H2C4 RING, a Domain Critical for Ubiquitination of p53', J. Mol. Biol., 363(2), pp. 433-450.

Krishna, S. S., Majumdar, I. \& Grishin, N. V. (2003) 'Structural classification of zinc fingers', Nucleic Acids Res., 31(2), pp. 532-550. 
Kubatova, N., Jonker, H. R. A., Saxena, K., Richter, C., Vogel, V., Schreiber, S., Marchfelder, A. \& Schwalbe, H. (2020) 'Solution Structure and Dynamics of the Small Protein HVO_2922 from Haloferax volcanii', ChemBioChem, 21(1-2), pp. 149-156.

Kubatova, N., Pyper, D. J., Jonker, H. R. A., Saxena, K., Remmel, L., Richter, C., Brantl, S., Evguenieva-Hackenberg, E., et al. (2020) 'Rapid Biophysical Characterization and NMR Spectroscopy Structural Analysis of Small Proteins from Bacteria and Archaea', ChemBioChem, 21(8), pp. 1178-1187.

Kumar, S., Stecher, G., Li, M., Knyaz, C. \& Tamura, K. (2018) 'MEGA X: Molecular Evolutionary Genetics Analysis across Computing Platforms.', Mol. Biol. Evol., 35(6), pp. 1547-1549.

Laass, S., Monzon, V. A., Kliemt, J., Hammelmann, M., Pfeiffer, F., Förstner, K. U. \& Soppa, J. (2019) 'Characterization of the transcriptome of Haloferax volcanii, grown under four different conditions, with mixed RNA-Seq', PLOS ONE. Edited by A. Kanai, 14(4), p. e0215986.

Lai, Z., Freedman, D. A., Levine, A. J. \& McLendon, G. L. (1998) 'Metal and RNA Binding Properties of the hdm2 RING Finger Domain', Biochemistry, 37(48), pp. 17005-17015.

Large, A., Stamme, C., Lange, C., Duan, Z., Allers, T., Soppa, J. \& Lund, P. A. (2007) 'Characterization of a tightly controlled promoter of the halophilic archaeon Haloferax volcanii and its use in the analysis of the essential cct1 gene', Mol. Microbiol., 66(5), pp. 1092-1106.

Legerme, G., Yang, E., Esquivel, R., Kiljunen, S., Savilahti, H. \& Pohlschroder, M. (2016) 'Screening of a Haloferax volcanii Transposon Library Reveals Novel Motility and Adhesion Mutants', Life, 6(4), p. 41.

De Ley, J. \& Doudoroff, M. (1957) 'The metabolism of D-galactose in Pseudomonas saccharophila', J. Biol. Chem., 227(2), pp. 745-757.

Lipp, J. S., Morono, Y., Inagaki, F. \& Hinrichs, K. U. (2008) 'Significant contribution of Archaea to extant biomass in marine subsurface sediments', Nature, 454(7207), pp. 991-994.

Liu, W. T., Yang, Y. L., Xu, Y., Lamsa, A., Haste, N. M., Yang, J. Y., Ng, J., Gonzalez, D., et al. (2010) 'Imaging mass spectrometry of intraspecies metabolic exchange revealed the cannibalistic factors of Bacillus subtilis', Proc. Natl. Acad. Sci. U.S.A., 107(37), pp. 16286-16290.

Lu, Y., Hall, D. A. \& Last, R. L. (2011) 'A small zinc finger thylakoid protein plays a role in maintenance of photosystem II in Arabidopsis thaliana.', Plant Cell, 23(5), pp. 1861-1875.

Madern, D., Ebel, C. \& Zaccai, G. (2000) 'Halophilic adaptation of enzymes', Extremophiles, 4(2), pp. 91-98.

Makarewich, C. A. (2020) 'The hidden world of membrane microproteins', Exp. 
Cell. Res., 388(2).

Malgieri, G., Palmieri, M., Russo, L., Fattorusso, R., Pedone, P. V. \& Isernia, C. (2015) 'The prokaryotic zinc-finger: structure, function and comparison with the eukaryotic counterpart', FEBS J., 282(23), pp. 4480-4496.

Malgieri, G., Russo, L., Esposito, S., Baglivo, I., Zaccaro, L., Pedone, E. M., Di Blasio, B., Isernia, C., et al. (2007) 'The prokaryotic Cys2His2 zinc-finger adopts a novel fold as revealed by the NMR structure of Agrobacterium tumefaciens Ros DNA-binding domain', Proc. Natl. Acad. Sci. U.S.A., 104(44), pp. 17341-17346.

Marg, B. L., Schweimer, K., Sticht, H. \& Oesterhelt, D. (2005) 'A two- $\alpha$-helix extra domain mediates the halophilic character of a plant-type ferredoxin from Halophilic Archaea', Biochemistry, 44(1), pp. 29-39.

Martinez-Pastor, M., Lancaster, W. A., Tonner, P. D., Adams, M. W. W. \& Schmid, A. K. (2017) 'A transcription network of interlocking positive feedback loops maintains intracellular Iron balance in archaea', Nucleic Acids Res., 45(17), pp. 9990-10001.

Miller, J., McLachlan, A. D. \& Klug, A. (1985) 'Repetitive zinc-binding domains in the protein transcription factor IIIA from Xenopus oocytes.', EMBO J., 4(6), pp. 1609-1614.

Misra, S. \& Hurley, J. H. (1999) 'Crystal structure of a phosphatidylinositol 3phosphate-specific membrane-targeting motif, the FYVE domain of Vps27p', Cell, 97(5), pp. 657-666.

Miyauchi, S., Tanabu, S., Abe, A., Okumura, R. \& Kamo, N. (1997) 'Culture in the presence of sugars increases activity of multi-drug efflux transporter on Haloferax volcanii', Microb. Drug Resist., 3(4), pp. 359-363.

Mojica, F. J. M., Cisneros, E., Ferrer, C., Rodríguez-Valera, F. \& Juez, G. (1997) 'Osmotically induced response in representatives of halophilic prokaryotes: The bacterium Halomonas elongata and the archaeon Haloferax volcanii', J. Bacteriol., 179(17), pp. 5471-5481.

Moreira, D. \& Rodríguez-Valera, F. (2000) 'A mitochondrial origin for eukaryotic $\mathrm{C} 2 \mathrm{H} 2$ zinc finger regulators? (multiple letters) [2]', Trends Microbiol., 8(10), pp. 448-449.

Morgan, B., Sun, L., Avitahl, N., Andrikopoulos, K., Ikeda, T., Gonzales, E., Wu, P., Neben, S., et al. (1997) 'Aiolos, a lymphoid restricted transcription factor that interacts with Ikaros to regulate lymphocyte differentiatisn', EMBO J., 16(8), pp. 2004-2013.

Mullakhanbhai, M. F. \& Larsen, H. (1975) 'Halobacterium volcanii spec. nov., a Dead Sea halobacterium with a moderate salt requirement', Arch. Microbiol., 104(1), pp. 207-214.

Mumtaz, M. A. S. \& Couso, J. P. (2015) 'Ribosomal profiling adds new coding sequences to the proteome', Biochem. Soc. Trans., 43(6), pp. 1271-1276. 
Nagel, C., Machulla, A., Zahn, S. \& Soppa, J. (2019) 'Several One-Domain Zinc Finger $\mu$-Proteins of Haloferax Volcanii Are Important for Stress Adaptation, Biofilm Formation, and Swarming', Genes, 10(5), p. 361.

Niessen, N. \& Soppa, J. (2020) 'Regulated iron siderophore production of the halophilic archaeon haloferax volcanii', Biomolecules, 10(7), pp. 1-17.

Nieuwlandt, D. T. \& Daniels, C. J. (1990) 'An expression vector for the archaebacterium Haloferax volcanii', J. Bacteriol., 172(12), pp. 7104-7110.

Noll, M., Petrukhin, K. \& Lutsenko, S. (1998) 'Identification of a novel transcription regulator from Proteus mirabilis, PMTR, revealed a possible role of YJAI protein in balancing zinc in Escherichia coli', J. Biol. Chem., 273(33), pp. 21393-21401.

Nowacka, M., Fernandes, H., Kiliszek, A., Bernat, A., Lach, G. \& Bujnicki, J. M. (2019) 'Specific interaction of zinc finger protein Com with RNA and the crystal structure of a self-complementary RNA duplex recognized by Com', PLOS ONE, 14(4).

Omichinski, J. G., Pedone, P. V., Felsenfeld, G., Gronenborn, A. M. \& Clore, G. M. (1997) 'The solution structure of a specific GAGA factor-DNA complex reveals a modular binding mode', Nat. Struct. Biol., 4(2), pp. 122-132.

Partridge, J. D. \& Harshey, R. M. (2013) 'Swarming: Flexible roaming plans', J. Bacteriol., 195(5), pp. 909-918.

Paul, S., Bag, S. K., Das, S., Harvill, E. T. \& Dutta, C. (2008) 'Molecular signature of hypersaline adaptation: Insights from genome and proteome composition of halophilic prokaryotes', Genome Biol., 9(4).

Pérez-Fillol, M. \& Rodríguez-Valera, F. (1986) 'Potassium ion accumulation in cells of different halobacteria.', Microbiologia SEM, 2(2), pp. 73-80.

Pfeiffer, F., Broicher, A., Gillich, T., Klee, K., Mejía, J., Rampp, M. \& Oesterhelt, D. (2008) 'Genome information management and integrated data analysis with HaloLex', Arch. Microbiol., 190(3), pp. 281-299.

Picard, B. \& Wegnez, M. (1979) 'Isolation of a 7S particle from Xenopus laevis oocytes: A 5S RNA-protein complex', Proc. Natl. Acad. Sci. U.S.A., 76(1), pp. $241-$ 245.

Plaza, S., Menschaert, G. \& Payre, F. (2017) 'In search of lost small peptides', Annu. Rev. Cell Dev. Bi., 33, pp. 391-416.

Reshma, S. V., Sathyanarayanan, N. \& Nagendra, H. G. (2015) 'Characterization of hypothetical protein VNG0128C from Halobacterium NRC-1 reveals GALE like activity and its involvement in Leloir pathway of galactose metabolism', J. Biomol. Struct. Dyn., 33(8), pp. 1743-1755.

Rhodes, D. \& Klug, A. (1993) 'Zinc fingers', Sci. Am., 268(2), pp. 597-604.

Romeo, T. \& Babitzke, P. (2018) 'Global Regulation by CsrA and Its RNA 
Antagonists', Microbiol. Spectr., 6(2), p. RWR-0009-2017.

Rudolph, J., Nordmann, B., Storch, K.-F., Gruenberg, H., Rodewald, K. \& Oesterhelt, D. (1996) 'A family of halobacterial transducer proteins', FEMS Microbiol. Lett., 139(2-3), pp. 161-168.

Schägger, H. (2006) 'Tricine-SDS-PAGE', Nat. Protoc., 1(1), pp. 16-22.

Schrader, M. (2018) 'Origins, technological development, and applications of peptidomics', Methods Mol. Biol., 1719, pp. 3-39.

Soppa, J. (2006) 'From genomes to function: Haloarchaea as model organisms', Microbiology (Reading), 152(3), pp. 585-590.

Soppa, J. (2011) 'Functional genomic and advanced genetic studies reveal novel insights into the metabolism, regulation, and biology of Haloferax volcanii.', Archaea, 2011(602408).

Srinivasa, S., Ding, X. \& Kast, J. (2015) 'Formaldehyde cross-linking and structural proteomics: Bridging the gap', Methods, 89, pp. 91-98.

Stachler, A. E., Schwarz, T. S., Schreiber, S. \& Marchfelder, A. (2020) 'CRISPRi as an efficient tool for gene repression in archaea', Methods, 172, pp. 76-85.

Storz, G., Wolf, Y. I. \& Ramamurthi, K. S. (2014) 'Small proteins can no longer be ignored.', Annu. Rev. Biochem., 83, pp. 753-77.

Su, M., Ling, Y., Yu, J., Wu, J. \& Xiao, J. (2013) 'Small proteins: untapped area of potential biological importance', Front. Genet., 4(286).

Sumper, M., Berg, E., Mengele, R. \& Strobel, I. (1990) 'Primary structure and glycosylation of the S-layer protein of Haloferax volcanii', J. Bacteriol., 172(12), pp. 7111-7118.

Sun, L., Liu, A. \& Georgopoulos, K. (1996) 'Zinc finger-mediated protein interactions modulate Ikaros activity, a molecular control of lymphocyte development', EMBO J., 15(19), pp. 5358-5369.

Sutak, R., Camadro, J. M. \& Lesuisse, E. (2020) 'Iron Uptake Mechanisms in Marine Phytoplankton', Front. Microbiol., 11(566691).

Sutherland, B. W., Toews, J. \& Kast, J. (2008) 'Utility of formaldehyde crosslinking and mass spectrometry in the study of protein-protein interactions', $J$. Mass Spectrom., 43(6), pp. 699-715.

Taffner, J., Erlacher, A., Bragina, A., Berg, C., Moissl-Eichinger, C. \& Berg, G. (2018) 'What Is the Role of Archaea in Plants? New Insights from the Vegetation of Alpine Bogs', mSphere, 3(3), pp. 122-140.

Tarasov, V. Y., Besir, H., Schwaiger, R., Klee, K., Furtwängler, K., Pfeiffer, F. \& Oesterhelt, D. (2008) 'A small protein from the bop-brp intergenic region of Halobacterium salinarum contains a zinc finger motif and regulates bop and crtB1 transcription.', Mol. Microbiol., 67(4), pp. 772-80. 
Tästensen, J. B., Johnsen, U., Reinhardt, A., Orthjohann, M. \& Schönheit, P. (2020) 'D-galactose catabolism in archaea: Operation of the DeLey-Doudoroff pathway in Haloferax volcanii', FEMS Microbiol. Lett., 367(1).

Tawara, E. \& Kamo, N. (1991) 'Glucose transport of Haloferax volcanii requires the $\mathrm{Na}$--electrochemical potential gradient and inhibitors for the mammalian glucose transporter inhibit the transport', BBA-Biomembranes, 1070(2), pp. 293299.

Tokunaga, H., Hara, S., Arakawa, T., Ishibashi, M., Gupta, R. S. \& Tokunaga, M. (1999) 'Identification and partial purification of DnaK homologue from extremely halophilic archaebacteria, Halobacterium cutirubrum', J. Prot. Chem., 18(8), pp. 837-844.

Torreblanca, M., Rodriguez-Valera, F., Juez, G., Ventosa, A., Kamekura, M. \& Kates, M. (1986) 'Classification of Non-alkaliphilic Halobacteria Based on Numerical Taxonomy and Polar Lipid Composition, and Description of Haloarcula gen. nov. and Haloferax gen. nov.', Syst. Appl. Microbiol., 8(1-2), pp. 89-99.

Wanner, C. \& Soppa, J. (1999) 'Genetic identification of three ABC transporters as essential elements for nitrate respiration in Haloferax volcanii', Genetics, 152(4), pp. 1417-1428.

Waterhouse, A. M., Procter, J. B., Martin, D. M. A., Clamp, M. \& Barton, G. J. (2009) 'Jalview Version 2-A multiple sequence alignment editor and analysis workbench', Bioinformatics, 25(9), pp. 1189-1191.

Wendoloski, D., Ferrer, C. \& Dyall-Smith, M. L. (2001) 'A new simvastatin (mevinolin)-resistance marker from Haloarcula hispanica and a new Haloferax volcanii strain cured of plasmid pHV2', Microbiology (Reading), 147(4), pp. 959964.

Whittaker, R. H. (1969) 'New concepts of kingdoms of organisms', Science, 163(3863), pp. 150-160.

Williams, T. A., Foster, P. G., Cox, C. J. \& Embley, T. M. (2013) 'An archaeal origin of eukaryotes supports only two primary domains of life', Nature, 504(7479), pp. 231-236.

Winter, K., Born, J. \& Pfeifer, F. (2018) 'Interaction of haloarchaeal gas vesicle proteins determined by split-GFP', Front. Microbiol., 9(1897).

Woese, C. R. \& Fox, G. E. (1977) 'Phylogenetic structure of the prokaryotic domain: The primary kingdoms', Proc. Natl. Acad. Sci. U.S.A., 74(11), pp. 50885090.

Woese, C. R., Fox, G. E., Zablen, L., Uchida, T., Bonen, L., Pechman, K., Lewis, B. J. \& Stahl, D. (1975) 'Conservation of primary structure in $16 \mathrm{~S}$ ribosomal RNA', Nature, 254(5495), pp. 83-86.

Woese, C. R., Magrum, L. J. \& Fox, G. E. (1978) 'Archaebacteria', J. Mol. Evol., 11(3), pp. 245-252. 
Wolfe, S. A., Nekludova, L. \& Pabo, C. O. (2000) 'DNA Recognition by Cys 2 His 2 Zinc Finger Proteins', Annu. Rev. Biophys., 29(1), pp. 183-212.

Zahn, S., Kubatova, N., Pyper, D. J., Cassidy, L., Saxena, K., Tholey, A., Schwalbe, H. \& Soppa, J. (2020) 'Biological functions, genetic and biochemical characterization, and NMR structure determination of the small zinc finger protein HVO_2753 from Haloferax volcanii', FEBS J., Epub(Ahead of print).

Zhang, W., Brooun, A., Mueller, M. M. \& Alam, M. (1996) 'The primary structures of the Archaeon Halobacterium salinarium blue light receptor sensory rhodopsin II and its transducer, a methyl-accepting protein', Proc. Natl. Acad. Sci. U.S.A., 93(16), pp. 8230-8235.

Zillig, W., Klenk, H. P., Palm, P., Puhler, G. \& Gropp, F. (1989) 'The phylogenetic relations of DNA-dependent RNA polymerases of archaebacteria, eukaryotes, and eubacteria', Can. J. Microbiol., 35(1), pp. 73-80. 


\section{Publikationen}

Publikationen in wissenschaftlichen Fachzeitschriften

Zahn, S., Kubatova, N., Pyper, D. J., Cassidy, L., Saxena, K., Tholey, A., Schwalbe, H. \& Soppa, J. (2020) 'Biological functions, genetic and biochemical characterization, and NMR structure determination of the small zinc finger protein HVO_2753 from Haloferax volcanii', FEBS J., Epub(Ahead of print).

Nagel, C., Machulla, A., Zahn, S. \& Soppa, J. (2019) 'Several One-Domain Zinc Finger $\mu$-Proteins of Haloferax Volcanii Are Important for Stress Adaptation, Biofilm Formation, and Swarming', Genes, 10(5), p. 361.

\section{Vorträge auf wissenschaftlichen Kongressen}

Zahn, S., Nagel, C., Machulla, A. \& Soppa, J. (2019) 'Characterization of zinc finger $\mu$-proteins in Haloferax volcanii', Vortrag auf dem 20th Frankfurt Meeting on ,Genome Function and Gene Regulation in Archaea' in Schmitten.

Zahn, S., Nagel, C., Machulla, A. \& Soppa, J. (2019) 'Single-domain zinc finger $\mu$-proteins in Haloferax volcanii', Vortrag auf dem Progress Report-Meeting des Schwerpunktprogramms SPP2002 auf Sylt.

Zahn, S., Nagel, C., Machulla, A. \& Soppa, J. (2018) 'Characterization of zinc finger $\mu$-proteins in Haloferax volcanii', Vortrag auf dem 19th Frankfurt Meeting on ,Genome Function and Gene Regulation in Archaea' in Schmitten.

Zahn, S., Nagel, C., Machulla, A. \& Soppa, J. (2018) 'Single-domain zinc finger $\mu$-proteins in Haloferax volcanii', Vortrag auf dem Kick-Off-Meeting des Schwerpunktprogramms SPP2002 in Kiel.

Zahn, S., Machulla, A. \& Soppa, J. (2017) 'Characterization of zinc finger $\mu$-proteins in Haloferax volcanii', Vortrag auf dem 18th Frankfurt Meeting on ,Genome Function and Gene Regulation in Archaea' in Schmitten.

\section{Posterpräsentationen auf wissenschaftlichen Kongressen}

Zahn, S., Nagel, C., Machulla, A. \& Soppa, J. (2020) 'Single-domain zinc finger $\mu$-proteins in Haloferax volcanii', Posterpräsentation auf der Jahrestagung der „Vereinigung für Allgemeine und Angewandte Mikrobiologie" (VAAM) in Leipzig. 
Zahn, S., Nagel, C., Machulla, A. \& Soppa, J. (2019) 'Single-domain zinc finger $\mu$-proteins in Haloferax volcanii', Posterpräsentation auf der Gordon Research Conference on Archaea: Ecology, Metabolism and Molecular Biology in Les Diablerets, Schweiz.

Zahn, S., Nagel, C., Machulla, A. \& Soppa, J. (2019) 'Single-domain zinc finger $\mu$-proteins in Haloferax volcanii', Posterpräsentation auf der Jahrestagung der "Vereinigung für Allgemeine und Angewandte Mikrobiologie" (VAAM) in Mainz.

Zahn, S., Nagel, C., Machulla, A. \& Soppa, J. (2018) 'Single-domain zinc finger $\mu$-proteins in Haloferax volcanii', Posterpräsentation auf der Jahrestagung der "Vereinigung für Allgemeine und Angewandte Mikrobiologie" (VAAM) in Wolfsburg. 


\section{Anhang}

FTMS ESI(+) Full ms

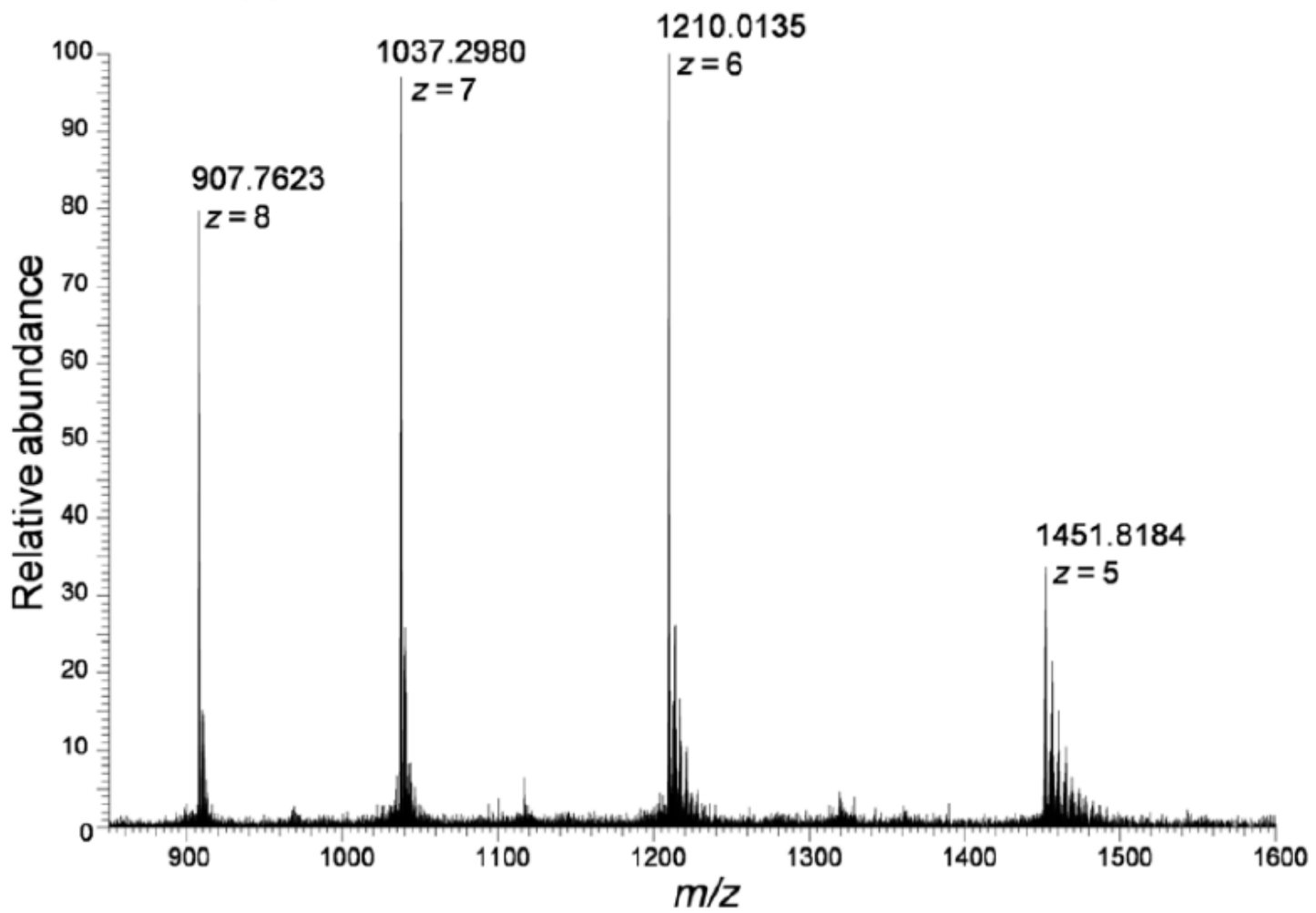

Abbildung A1: Massenspektrometrische Analyse von HVO_2753. Gezeigt ist die Messung des intakten Proteins mittels direct infusion in eine LTQ Orbitrap Velos. Die Masse des häufigsten Peaks und der zugehörigen Ladung sind am jeweiligen Peak vermerkt. Abbildung entnommen und modifiziert aus Zahn et al. (2020). 


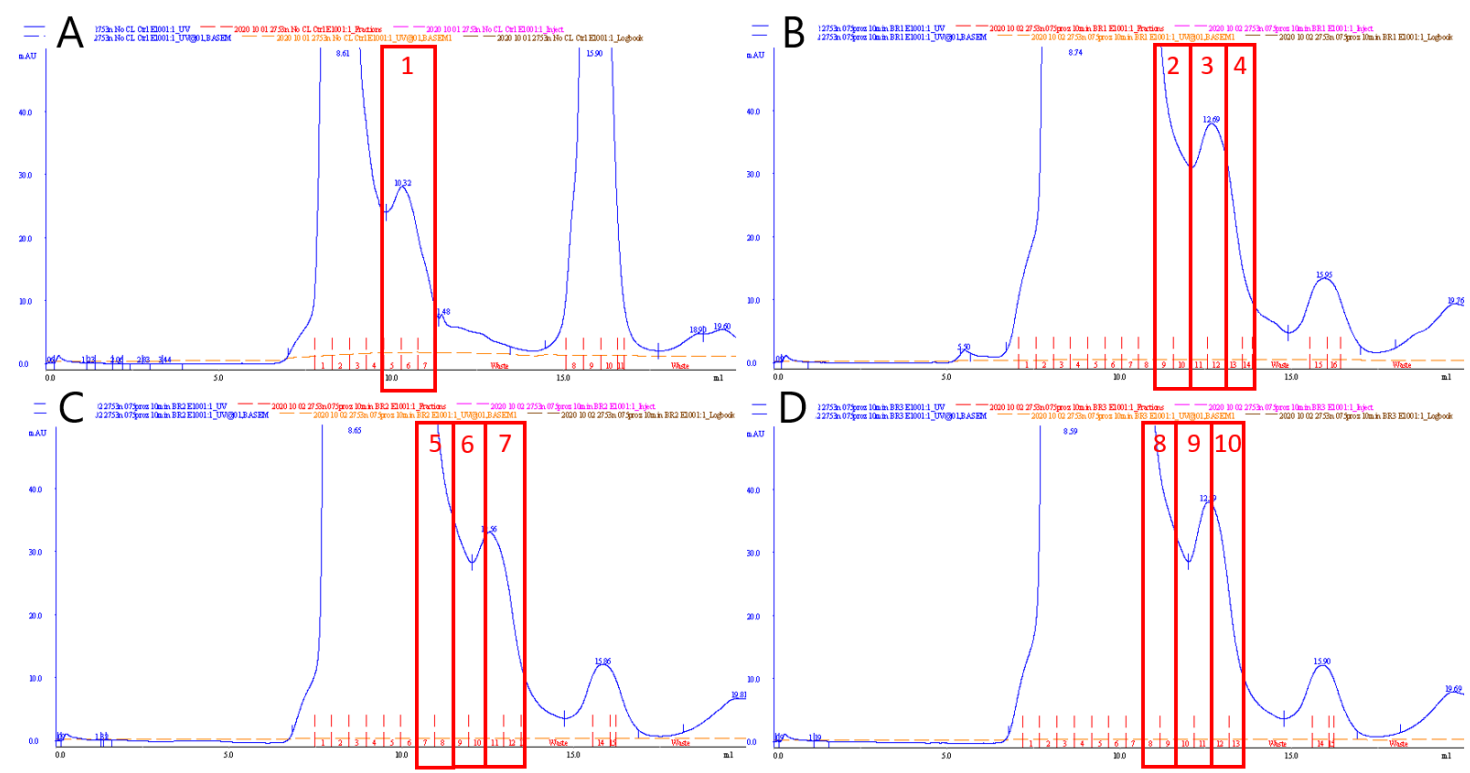

Abbildung A2: Chromatogramme der Größenausschlusschromatographie von HVO_2753n mit und ohne in vivo Crosslink. Eingesetzt wurden hier jeweils Elutionsfraktionen aus vorangegangenen Affinitätsaufreinigungen. Gezeigt sind die Chromatogramme einer Kontrolle ohne Crosslink (A) und von drei unabhängigen biologischen Replikaten BR1-3 (B-D) nach in vivo Crosslink. Als Säule kam hier die Superdex ${ }^{\mathrm{TM}} 75$ Increase 10/300 GL zum Einsatz. Mit roten Kästen sind die Bereiche markiert, die der Fraktion mit der entsprechenden Nummer entspricht. Die Ergebnisse der MS-Analyse der Fraktionen 2, 5 und 8; 3, 6 und 9; 4, 7 und 10 wurden jeweils für die Auswertung vereinigt.

Tabelle A1: Ergebnistabelle der massenspektrometrischen Analyse von Fraktion 1. Gezeigt sind die Gene IDs der identifizierten Proteine mit ihrer Funktionsklasse (FC, siehe Abkürzungsverzeichnis), dem Namen des Proteins, der Coverage von BR1 in Prozent, der Anzahl gefundener Peptide von BR1 (\# Peptides), der Anzahl an PSMs der drei unabhängigen biologischen Replikate (\# PSMs (1-3)), dem Mittelwert der PSMs der biologischen Replikate (PSMs (mean)), der Anzahl an einzigartigen Peptiden (\# Unique Peptides), der Anzahl an Aminosäuren (\# AAs), das entsprechende Molekulargewicht (MW) in Kilodalton und der berechnete pl-Wert (calc. pl). In dunklerem Blauton hinterlegt sind alle Proteine mit einem Molekulargewicht zwischen 23 und 35 kDa.

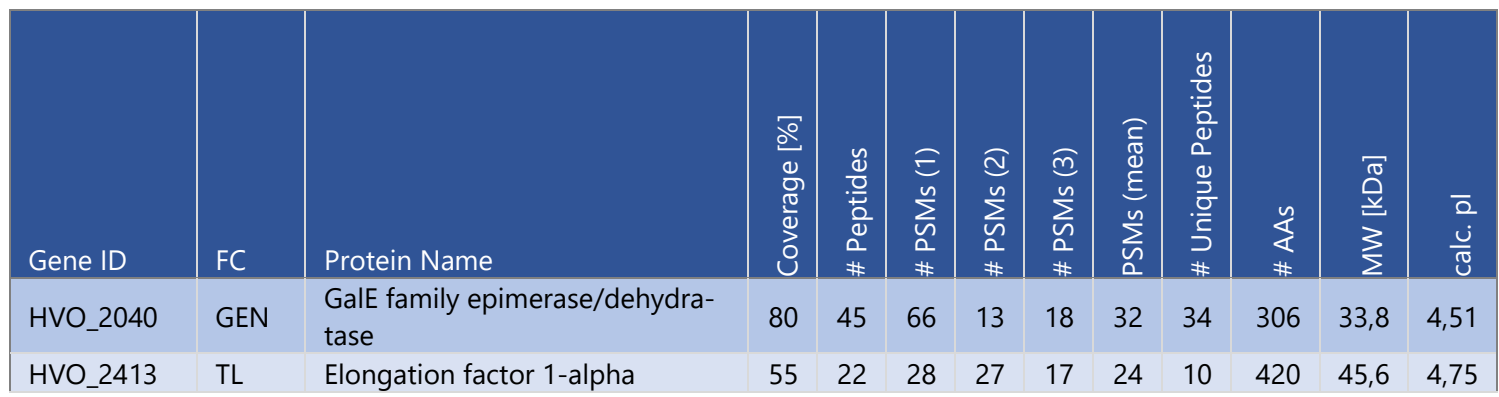




\begin{tabular}{|c|c|c|c|c|c|c|c|c|c|c|c|c|}
\hline HVO_B0049 & COM & $\begin{array}{l}\text { Cobalt-precorrin-8 methyl- } \\
\text { mutase }\end{array}$ & 50 & 9 & 15 & 22 & 15 & 17 & 9 & 226 & 23,8 & 5 \\
\hline HVO_0743 & GEN & Sulfatase & 33 & 10 & 14 & 20 & 16 & 17 & 10 & 449 & 50,5 & 4,56 \\
\hline HVO_1545 & CIM & $\begin{array}{l}\text { Dihydroxyacetone kinase subunit } \\
\text { DhaL }\end{array}$ & 54 & 15 & 20 & 16 & 13 & 16 & 15 & 232 & 24,8 & 4,48 \\
\hline HVO_1727 & TC & TATA-box-binding protein & 62 & 11 & 12 & 17 & 16 & 15 & 10 & 186 & 19,9 & 4,36 \\
\hline HVO_2862 & $A A$ & Serine hydroxymethyltransferase & 39 & 9 & 9 & 21 & 13 & 14 & 9 & 415 & 44,3 & 4,53 \\
\hline HVO_0321 & TL & $\begin{array}{l}\text { Peptide chain release factor sub- } \\
\text { unit } 1\end{array}$ & 23 & 6 & 6 & 21 & 15 & 14 & 6 & 414 & 46,6 & 4,83 \\
\hline HVO_0158 & TC & TATA-box-binding protein 1 & 49 & 7 & 10 & 23 & 8 & 14 & 6 & 189 & 20,3 & 4,22 \\
\hline HVO_0388 & MIS & Ribonuclease R & 16 & 4 & 4 & 23 & 14 & 14 & 4 & 439 & 50,3 & 4,73 \\
\hline HVO_0240 & REG & $\begin{array}{l}\text { Lrp/AsnC family transcription } \\
\text { regulator }\end{array}$ & 65 & 14 & 16 & 12 & 12 & 13 & 12 & 152 & 16,9 & 4,39 \\
\hline HVO_0400 & $\mathrm{CHY}$ & Uncharacterized protein & 79 & 14 & 14 & 14 & 11 & 13 & 14 & 126 & 13,9 & 4,68 \\
\hline HVO_0009 & AA & Tryptophanase & 19 & 6 & 8 & 15 & 14 & 12 & 6 & 448 & 48,5 & 4,83 \\
\hline HVO_0104 & RRR & $\begin{array}{l}\text { DNA repair and recombination } \\
\text { protein RadA }\end{array}$ & 39 & 10 & 12 & 15 & 9 & 12 & 10 & 343 & 37,3 & 4,64 \\
\hline HVO_2204 & MIS & Tubulin-like protein CetZ1 & 21 & 7 & 8 & 16 & 11 & 12 & 7 & 395 & 42 & 4,68 \\
\hline HVO_2029 & REG & $\begin{array}{l}\text { AsnC family transcriptional regu- } \\
\text { lator }\end{array}$ & 63 & 9 & 12 & 10 & 12 & 11 & 7 & 153 & 16,9 & 4,21 \\
\hline HVO_2561 & TL & $50 S$ ribosomal protein $\mathrm{L} 2$ & 42 & 7 & 9 & 11 & 13 & 11 & 7 & 241 & 25,6 & 10,4 \\
\hline HVO_0859 & MIS & $\begin{array}{l}\text { Fe-S cluster assembly ATPase } \\
\text { SufC }\end{array}$ & 38 & 11 & 12 & 8 & 13 & 11 & 11 & 301 & 33,4 & 4,35 \\
\hline HVO_1631 & MIS & $\begin{array}{l}\text { S-adenosyl-L-methionine:L-histi- } \\
\text { dine 3-amino-3-carboxypropyl- } \\
\text { transferase }\end{array}$ & 31 & 8 & 11 & 10 & 12 & 11 & 8 & 344 & 39,1 & 4,73 \\
\hline HVO_0581 & MIS & Cell division protein FtsZ 2 & 27 & 6 & 7 & 17 & 9 & 11 & 6 & 400 & 42,5 & 4,75 \\
\hline HVO_1133 & GEN & HTH domain protein & 67 & 10 & 13 & 7 & 12 & 11 & 10 & 101 & 11,7 & 4,58 \\
\hline HVO_2588 & CIM & $\begin{array}{l}\text { Isocitrate dehydrogenase } \\
\text { [NADP] }\end{array}$ & 15 & 5 & 5 & 17 & 10 & 11 & 5 & 419 & 45,8 & 4,59 \\
\hline HVO_0292 & RRR & Replication factor A & 26 & 6 & 6 & 13 & 12 & 10 & 6 & 311 & 34,6 & 4,31 \\
\hline HVO_A0507 & AA & it $A$ & 33 & 8 & 10 & 10 & 11 & 10 & 8 & 314 & 35,9 & 5,19 \\
\hline HVO_1572 & RRR & se subunit B & 16 & 6 & 6 & 14 & 11 & 10 & 6 & 639 & 71,2 & 4,83 \\
\hline HVO_2564 & TL & $50 \mathrm{~S}$ ribosome & 25 & 8 & 9 & 10 & 10 & 10 & 8 & 338 & 37,2 & 6,68 \\
\hline HVO_1314 & MIS & 5'-nucle & 19 & 4 & 6 & 10 & 12 & 9 & 4 & 263 & 27,8 & 4,48 \\
\hline HVO_0083 & MIS & Nitro & 80 & 8 & 9 & 9 & 8 & 9 & 8 & 123 & 12,9 & 5,01 \\
\hline HVO_1299 & REG & $\begin{array}{l}\text { Cro/C1 family transcription regu- } \\
\text { lator }\end{array}$ & 36 & 6 & 9 & 9 & 8 & 9 & 6 & 173 & 18,9 & 4,84 \\
\hline HVO_0880 & $\mathrm{CHY}$ & Phosphoserine phosphatase & 27 & 4 & 4 & 15 & 7 & 9 & 4 & 307 & 36,3 & 4,74 \\
\hline HVO_0433 & MIS & F42OH2:NADP C & 43 & 7 & 7 & 8 & 10 & 8 & 7 & 222 & 23,3 & 4,72 \\
\hline HVO_2748 & TC & $\begin{array}{l}\text { DNA-directed RNA polymerase } \\
\text { subunit } F\end{array}$ & 44 & 5 & 6 & 8 & 9 & 8 & 5 & 118 & 13,6 & 4,49 \\
\hline HVO_1145 & $\mathrm{TL}$ & $30 \mathrm{~S}$ ribosomal protein $\mathrm{S} 3 \mathrm{Ae}$ & 54 & 10 & 11 & 7 & 5 & 8 & 10 & 220 & 24,8 & 4,86 \\
\hline HVO_2563 & TL & 50 S ribosomal protein $L 4$ & 56 & 11 & 11 & 4 & 8 & 8 & 11 & 248 & 27 & 6,44 \\
\hline HVO_1925 & GEN & GTP-binc & 26 & 5 & 5 & 10 & 8 & 8 & 5 & 325 & 36,5 & 4,72 \\
\hline HVO_2724 & RMT & Ribonuclease J & 23 & 5 & 5 & 11 & 6 & 7 & 5 & 450 & 50,1 & 5,4 \\
\hline HVO_0019 & GEN & $\begin{array}{l}\text { Putative S-adenosylmethionine- } \\
\text { dependent methyltransferase } \\
\text { (Homolog to 24-sterol C-methyl- } \\
\text { transferase) }\end{array}$ & 23 & 5 & 7 & 10 & 4 & 7 & 5 & 226 & 25,6 & 4,64 \\
\hline HVO_B0040 & REG & $\begin{array}{l}\text { ArcR family transcription regula- } \\
\text { tor }\end{array}$ & 35 & 8 & 8 & 7 & 6 & 7 & 8 & 251 & 27,2 & 5,3 \\
\hline & & UCP015877 family protein & & & & 6 & & 6 & 7 & 218 & 23,8 & 4,6 \\
\hline HVO_1454 & NUM & Aspartate carbamoyltransfer & 63 & 10 & 11 & 5 & 3 & 6 & 10 & 304 & 33,7 & 4,92 \\
\hline HVO_0911 & GEN & GTP-binding protein Drg & 25 & 5 & 5 & 8 & 6 & 6 & 5 & 369 & 40,5 & 4,81 \\
\hline HVO_0392 & GEN & Putative SepF protein & 55 & 6 & 6 & 7 & 5 & 6 & 6 & 118 & 12,6 & 4,56 \\
\hline HVO_2542 & $\mathrm{TL}$ & $50 S$ ribosol & 44 & 9 & 9 & 4 & 5 & 6 & 9 & 165 & 17,8 & 4,93 \\
\hline HVO_2419 & LIP & $\begin{array}{l}\text { Hydroxymethylglutaryl-CoA syn- } \\
\text { thase }\end{array}$ & 9 & 3 & 3 & 6 & 9 & 6 & 3 & 445 & 50,1 & 4,64 \\
\hline HVO_1082 & GEN & PyrE-like protein & 27 & 6 & 6 & 6 & 5 & 6 & 6 & 210 & 22,3 & 4,42 \\
\hline HVO_2496 & NUM & Adenylate kinase & 37 & 8 & 9 & 3 & 5 & 6 & 8 & 208 & 23,1 & 4,25 \\
\hline HVO_1004 & $\mathrm{CHY}$ & Uncharacterized protein & 49 & 10 & 11 & 3 & 2 & 5 & 10 & 94 & 10 & 4,03 \\
\hline HVO_1560 & GEN & UPF0212 protein HVO_1560 & 30 & 3 & 4 & 6 & 6 & 5 & 3 & 119 & 12,9 & 4,37 \\
\hline
\end{tabular}




\begin{tabular}{|c|c|c|c|c|c|c|c|c|c|c|c|c|}
\hline HVO_1473 & GEN & UPF0058 family protein & 43 & 2 & 3 & 7 & 5 & 5 & 2 & 92 & 10,3 & 5,26 \\
\hline HVO_1344 & MIS & RNA-associated protein & 27 & 5 & 6 & 5 & 4 & 5 & 5 & 238 & 26,5 & 4,51 \\
\hline HVO_1660 & MIS & Diadenylate cyclase & 11 & 2 & 2 & 8 & 5 & 5 & 2 & 269 & 28,9 & 4,73 \\
\hline HVO_1140 & LIP & Acyl-CoA dehydrogenase & 16 & 5 & 5 & 4 & 6 & 5 & 5 & 380 & 41,2 & 4,55 \\
\hline HVO_2650 & GEN & $\begin{array}{l}\text { 4-hydroxybenzoate } 3 \text {-monooxy- } \\
\text { genase }\end{array}$ & 7 & 2 & 2 & 6 & 7 & 5 & 2 & 461 & 50,7 & 4,73 \\
\hline HVO_0580 & RMT & $\begin{array}{l}\mathrm{N} \text {-type ATP pyrophosphatase } \\
\text { superfamily protein }\end{array}$ & 17 & 4 & 4 & 7 & 3 & 5 & 4 & 321 & 36,1 & 5,01 \\
\hline HVO_2313 & $\mathrm{COM}$ & $\begin{array}{l}\text { Heme biosynthesis protein } \\
\text { NirGH }\end{array}$ & 15 & 2 & 2 & 4 & 8 & 5 & 2 & 353 & 39,6 & 4,64 \\
\hline HVO_A0509 & AA & $\begin{array}{l}\text { 1,2-phenylacetyl-CoA epoxidase } \\
\text { subunit C }\end{array}$ & 21 & 6 & 6 & 3 & 4 & 4 & 6 & 272 & 31,3 & 4,4 \\
\hline HVO_2345 & GEN & NADH oxidase & 11 & 2 & 2 & 5 & 6 & 4 & 2 & 413 & 45,8 & 4,45 \\
\hline HVO_0874 & $\mathrm{TC}$ & Beta-lactamase domain protein & 19 & 10 & 0 & 10 & 3 & 4 & 10 & 640 & 71,9 & 5,14 \\
\hline HVO_1633 & GEN & UPF0342 family protein & 40 & 4 & 4 & 5 & 3 & 4 & 4 & 124 & 13,7 & 4,16 \\
\hline HVO_2559 & $\mathrm{TL}$ & 50 S ribosomal protein $\mathrm{L} 22$ & 44 & 4 & 4 & 4 & 4 & 4 & 4 & 153 & 16,9 & 5,6 \\
\hline HVO_0354 & TL & 30 S ribosomal protein $\mathrm{S7}$ & 47 & 8 & 8 & 2 & 2 & 4 & 8 & 204 & 22,6 & 5,14 \\
\hline HVO_0309 & COM & Membrane protein & 36 & 4 & 4 & 3 & 5 & 4 & 4 & 207 & 23,7 & 4,97 \\
\hline HVO_1507 & AA & $\begin{array}{l}\text { Acetolactate synthase small sub- } \\
\text { unit }\end{array}$ & 19 & 2 & 3 & 7 & 2 & 4 & 2 & 218 & 23,7 & 4,94 \\
\hline HVO_0044 & AA & $\begin{array}{l}\text { Acetylglutamate/acetylamino- } \\
\text { adipate kinase }\end{array}$ & 13 & 3 & 3 & 4 & 5 & 4 & 3 & 327 & 33,2 & 4,49 \\
\hline HVO_1076 & $\mathrm{CHM}$ & Sugar nucleotidyltransferase & 17 & 4 & 4 & 4 & 4 & 4 & 4 & 322 & 35,8 & 4,2 \\
\hline HVO_2932 & GEN & Translation-associated & 16 & 3 & 3 & 6 & 3 & 4 & 3 & 396 & 43,5 & 4,51 \\
\hline HVO_0861 & GEN & SufB domain protein & 36 & 9 & 0 & 9 & 3 & 4 & 9 & 402 & 44,7 & 4,23 \\
\hline HVO_B0382 & $\mathrm{TC}$ & TATA-box-binding protein & 18 & 4 & 5 & 3 & 3 & 4 & 3 & 188 & 20,1 & 4,12 \\
\hline HVO_2242 & TL & $\begin{array}{l}\text { Translation initiation factor IF-2 } \\
\text { subunit beta }\end{array}$ & 28 & 3 & 3 & 2 & 6 & 4 & 3 & 202 & 22,2 & 5,11 \\
\hline HVO_1444 & LIP & $\begin{array}{l}\text { 3-hydroxybutyryl-CoA dehydro- } \\
\text { genase }\end{array}$ & 12 & 3 & 3 & 5 & 3 & 4 & 3 & 286 & 30,8 & 4,46 \\
\hline HVO_0717 & MIS & Cell division protein FtsZ & 10 & 2 & 2 & 6 & 3 & 4 & 2 & 379 & 39,8 & 4,4 \\
\hline HVO_B0062 & $\mathrm{COM}$ & $\begin{array}{l}\text { Probable cobalt-precorrin-6B } \\
\mathrm{C}(15) \text {-methyltransferase (decar- } \\
\text { boxylating) }\end{array}$ & 41 & 5 & 0 & 5 & 5 & 3 & 5 & 184 & 19,8 & 5,3 \\
\hline HVO_1899 & TC & $\begin{array}{l}\text { DNA-directed RNA polymerase } \\
\text { subunit } \mathrm{E}\end{array}$ & 18 & 3 & 5 & 2 & 3 & 3 & 3 & 190 & 21 & 4,74 \\
\hline HVO_0180 & RMT & $\begin{array}{l}\text { osomal RNA large subunit } \\
\text { thyltransferase E }\end{array}$ & 25 & 4 & 5 & 2 & 3 & 3 & 4 & 259 & 28,3 & 4,7 \\
\hline HVO_B0114 & REG & $\begin{array}{l}\text { ICIR family transcription regula- } \\
\text { tor }\end{array}$ & 15 & 3 & 3 & 3 & 4 & 3 & 3 & 252 & 28,4 & 5,44 \\
\hline HVO_B0059 & $\mathrm{COM}$ & Cobalt-precorrin-5A hydrolase & 21 & 6 & 0 & 7 & 3 & 3 & 6 & 326 & 34,5 & 4,51 \\
\hline HVO_1478 & $\mathrm{TC}$ & itiation factor IIB & 11 & 2 & 2 & 3 & 5 & 3 & 2 & 317 & 35,7 & 5,47 \\
\hline HVO_0478 & $\mathrm{CIM}$ & $\begin{array}{l}\text { Glyceraldehyde-3-phosphate de- } \\
\text { hydrogenase }\end{array}$ & 8 & 2 & 2 & 4 & 4 & 3 & 2 & 355 & 38,2 & 4,68 \\
\hline HVO_0860 & GEN & FeS assembly protein SufB & 24 & 7 & 0 & 7 & & 3 & 7 & 476 & 53,2 & 4,69 \\
\hline HVO_1946 & TL & $\begin{array}{l}\text { Protein translation factor SUI1 } \\
\text { homolog }\end{array}$ & 47 & 3 & 3 & 4 & 2 & 3 & 3 & 97 & 10,8 & 4,53 \\
\hline HVO_1857 & GEN & $\begin{array}{l}\text { DNA-binding protein } \\
\text { C498_04555 }\end{array}$ & 32 & 2 & 2 & 5 & 2 & 3 & 2 & 120 & 13,8 & 8,44 \\
\hline HVO_0769 & GEN & Uncharacterized protein & 21 & 3 & & 3 & & J & 3 & 134 & 14,8 & 4,32 \\
\hline HVO_0889 & GEN & FAD-dependent oxidoreductase & 23 & 3 & 4 & 2 & 3 & 3 & 3 & 214 & 21,8 & 3,89 \\
\hline HVO_0867 & GEN & HD family hydrolase & 17 & 3 & 0 & 3 & 6 & 3 & 3 & 230 & 26,2 & 4,78 \\
\hline HVO_B0058 & COM & $\begin{array}{l}\text { Cobalt-factor-III C17-methyl- } \\
\text { transferase }\end{array}$ & 7 & 1 & 2 & 4 & 3 & 3 & 1 & 294 & 31,8 & 4,4 \\
\hline HVO_0665 & $\mathrm{COM}$ & Thiamine thiazole synthase & 14 & 3 & 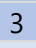 & 4 & 2 & 3 & 3 & 307 & 32,4 & 4,55 \\
\hline HVO_0720 & GEN & $\begin{array}{l}\text { Small CPxCG-related zinc finger } \\
\text { protein }\end{array}$ & 46 & 5 & 0 & 5 & 3 & 3 & 5 & 100 & 11,3 & 5,03 \\
\hline HVO_1303 & REG & $\begin{array}{l}\text { Lrp/AsnC family transcription } \\
\text { regulator }\end{array}$ & 20 & 2 & 3 & 3 & 2 & 3 & 2 & 142 & 15,4 & 4,7 \\
\hline HVO_2784 & TL & 30 S ribosomal protein $\mathrm{S} 13$ & 20 & J & 3 & 0 & & 3 & 3 & 167 & 18,9 & 5,17 \\
\hline HVO_2558 & TL & $30 \mathrm{~S}$ ribosomal protein S3 & 26 & 5 & 0 & 6 & 2 & 3 & 5 & 304 & 33,4 & 4,06 \\
\hline HVO_2256 & GEN & Uncharacterized protein & 16 & 6 & 0 & 6 & 2 & 3 & 6 & 462 & 54,9 & 4,89 \\
\hline HVO_1131 & MIS & UPF0434 family protein & 25 & 1 & 2 & 2 & 3 & 2 & 1 & 61 & 6,9 & 3,99 \\
\hline HVO_B0016 & $\mathrm{CHY}$ & Uncharacterized protein & 47 & 2 & 2 & 3 & 2 & 2 & 2 & 76 & 8,6 & 5,48 \\
\hline
\end{tabular}




\begin{tabular}{|c|c|c|c|c|c|c|c|c|c|c|c|c|}
\hline HVO_1042 & TC & $\begin{array}{l}\text { DNA-directed RNA polymerase } \\
\text { subunit } L\end{array}$ & 21 & 1 & 1 & 4 & 2 & 2 & 1 & 96 & 10,4 & 4,28 \\
\hline HVO_2869 & REG & $\begin{array}{l}\text { PadR family transcription regula- } \\
\text { tor }\end{array}$ & 27 & 3 & 4 & 0 & 3 & 2 & 3 & 95 & 11,4 & 5,16 \\
\hline HVO_0213 & GEN & Ferritin / Dps domain protein & 34 & 2 & 2 & 2 & 3 & 2 & 2 & 150 & 16,9 & 4,28 \\
\hline HVO_2546 & TL & 50 S ribosomal protein $\mathrm{L} 19 \mathrm{e}$ & 23 & 3 & 3 & 2 & 2 & 2 & 3 & 151 & 17,3 & 9,98 \\
\hline HVO_2873 & RRR & Flap endonuclease 1 & 14 & 3 & 3 & 2 & 2 & 2 & 3 & 326 & 36,4 & 4,4 \\
\hline HVO_0317 & EM & V-type ATP synthase beta chain & 5 & 2 & 2 & 3 & 2 & 2 & 2 & 468 & 51,9 & 4,25 \\
\hline HVO_0407 & $\mathrm{CHY}$ & Uncharacterized protein & 37 & 4 & 0 & 4 & 2 & 2 & 4 & 124 & 13,4 & 4,44 \\
\hline HVO_1792 & REG & $\begin{array}{l}\text { Lrp/AsnC family transcription } \\
\text { regulator }\end{array}$ & 20 & 3 & 0 & 3 & 3 & 2 & 3 & 162 & 18,1 & 4,34 \\
\hline HVO_0536 & MIS & Ferritin & 23 & 2 & 2 & 2 & 2 & 2 & 2 & 176 & 19,9 & 4,5 \\
\hline HVO_2552 & $\mathrm{TL}$ & $30 \mathrm{~S}$ ribosomal protein $\mathrm{S4e}$ & 17 & 3 & 3 & 0 & 3 & 2 & 3 & 247 & 26,6 & 4,58 \\
\hline HVO_3007 & $\mathrm{CIM}$ & Malate dehydrogenase & 11 & 2 & 2 & 2 & 2 & 2 & 2 & 304 & 32,6 & 4,4 \\
\hline HVO_0239 & AA & Glutamine synthetase & 18 & 4 & & 4 & 2 & 2 & 4 & 456 & 50,5 & 4,56 \\
\hline HVO_0346 & $\mathrm{TC}$ & $\begin{array}{l}\text { DNA-directed RNA polymerase } \\
\text { subunit } H\end{array}$ & 23 & 1 & 1 & 3 & 1 & 2 & 1 & 75 & 8,5 & 5,03 \\
\hline HVO_1964 & GEN & PRC domain protein & 14 & 1 & 1 & 2 & 2 & 2 & 1 & 81 & 9 & 5,08 \\
\hline HVO_1691 & GEN & PRC domain protein & 13 & 1 & 1 & 1 & rata & & 1 & 97 & 10,8 & 4,28 \\
\hline HVO_1965 & RMT & $\begin{array}{l}\text { rRNA maturation endonuclease } \\
\text { Nob1 }\end{array}$ & 38 & 2 & 0 & 2 & 3 & 2 & 2 & 152 & 16,8 & 4,7 \\
\hline HVO_2981 & NUM & Uracil phosphoribosyltransferase & 11 & 2 & 2 & 0 & 3 & & 2 & 226 & 24,5 & 4,49 \\
\hline HVO_2861 & $\mathrm{CHY}$ & Unch & 18 & 2 & & 3 & ( & & 2 & 275 & 29,1 & 4,27 \\
\hline HVO_2625 & NUM & $\begin{array}{l}\text { GMP synthase [glutamine-hy- } \\
\text { drolyzing] subunit B }\end{array}$ & 21 & 3 & 0 & 3 & 2 & 2 & 3 & 305 & 33,8 & 4,74 \\
\hline HVO_0999 & GEN & DRTGG domain protein & 17 & 3 & & 3 & 2 & & 3 & 378 & 39,8 & 4,44 \\
\hline HVO_0455 & $\mathrm{CHP}$ & Thermo & 6 & 3 & & 3 & 2 & 2 & 3 & 557 & 59,3 & 4,37 \\
\hline HVO_0196 & $\mathrm{CHY}$ & Uncharacterized protein & 31 & 2 & 2 & 1 & 1 & 1 & 2 & 55 & 6,2 & 4,81 \\
\hline HVO_2257 & $\mathrm{CHY}$ & acterized protein & 32 & 1 & & 1 & & 1 & 1 & 56 & 6,6 & 5,03 \\
\hline HVO_2682 & MIS & Dode & 17 & 1 & & 1 & & & 1 & 70 & 7,7 & 4,22 \\
\hline HVO_A0508 & AA & PacF & 49 & 2 & 2 & 2 & c & & 2 & 106 & 11,9 & 4,89 \\
\hline HVO_1090 & $\mathrm{TC}$ & $\begin{array}{l}\text { Putative transcription factor } \\
\text { (Homolog to RNA polymerase III } \\
\text { subunit RPC34) }\end{array}$ & 13 & 2 & 0 & 2 & 2 & 1 & 2 & 117 & 13,1 & 4,41 \\
\hline HVO_2300 & $\mathrm{TL}$ & Translation initiation factor $5 \mathrm{~A}$ & 7 & 2 & & & & & 2 & 124 & 14,2 & 5,22 \\
\hline HVO_0313 & EM & V-type ATP synthase subunit E & 24 & 2 & & 2 & 2 & 1 & 2 & 194 & 22 & 4,31 \\
\hline HVO_2916 & GEN & $\begin{array}{l}\text { Short-chain family oxidoreduc- } \\
\text { tase }\end{array}$ & 15 & 2 & 0 & 2 & 2 & 1 & 2 & 252 & 26 & 4,39 \\
\hline HVO_0511 & $\mathrm{CIM}$ & $\begin{array}{l}\text { NAD-dependent glucose- } 6 \text { - } \\
\text { phosphate dehydrogenase }\end{array}$ & 11 & 2 & 2 & 2 & 0 & 1 & 2 & 262 & 29,3 & 4,78 \\
\hline HVO_2057 & $\mathrm{CHM}$ & $\begin{array}{l}\text { Low-salt glycan biosynthesis nu- } \\
\text { cleotidyltransferase Agl11 }\end{array}$ & 11 & 2 & 0 & 2 & 2 & 1 & 2 & 357 & 37,8 & 4,44 \\
\hline HVO_A0522 & LIP & Acetyl-CoA C-acyltransferase & 7 & 2 & & & 2 & & 2 & 387 & 39,2 & 4,77 \\
\hline HVO_2350 & GEN & YyaL family protein & 10 & 2 & c & 2 & 2 & 1 & 2 & 552 & 58,8 & 4,59 \\
\hline HVO_0758 & GEN & Uncharacterized protein & 29 & 1 & 1 & & 1 & 1 & 1 & 56 & 6,5 & 7,75 \\
\hline HVO_2557 & $\mathrm{TL}$ & 50 S ribosomal protein L29 & 27 & 1 & 1 & 2 & 0 & 1 & 1 & 70 & 7,7 & 4,36 \\
\hline HVO_2752 & TL & Elongation factor 1-beta & 30 & 1 & 1 & 1 & 1 & 1 & 1 & 88 & 9,2 & 4,16 \\
\hline HVO_A0138 & $\mathrm{CHY}$ & Uncharacterized protein & 26 & 1 & & & 0 & 1 & 1 & 61 & 6,9 & 4,96 \\
\hline HVO_2942 & $\mathrm{CHY}$ & Uncharacterized protein & 15 & 1 & 0 & 1 & 1 & 1 & 1 & 65 & 7,4 & 5,4 \\
\hline
\end{tabular}


Tabelle A2: Ergebnistabelle der massenspektrometrischen Analyse von Fraktion 2.

Gezeigt sind die Gene IDs der identifizierten Proteine mit ihrer Funktionsklasse (FC, siehe Abkürzungsverzeichnis), dem Namen des Proteins, der Coverage von BR1 in Prozent, der Anzahl gefundener Peptide von BR1 (\# Peptides), der Anzahl an PSMs der drei unabhängigen biologischen Replikate (\# PSMs (1-3)), dem Mittelwert der PSMs der biologischen Replikate (PSMs (mean)), der Anzahl an einzigartigen Peptiden (\# Unique Peptides), der Anzahl an Aminosäuren (\# AAs), das entsprechende Molekulargewicht (MW) in Kilodalton und der berechnete pl-Wert (calc. pl). In dunklerem Blauton hinterlegt sind alle Proteine mit einem Molekulargewicht zwischen 15 und 23 kDa.

\begin{tabular}{|c|c|c|c|c|c|c|c|c|c|c|c|c|}
\hline Gene ID & FC & Protein Name & 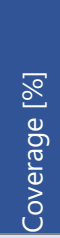 & $\begin{array}{l}\frac{y}{0} \\
\frac{0}{0} \\
\frac{0}{0} \\
\frac{0}{0} \\
\#\end{array}$ & $\underset{\substack{n \\
\sum_{\#}^{n}}}{E}$ & 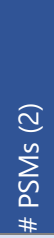 & 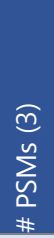 & 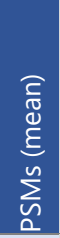 & 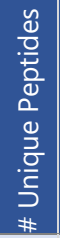 & $\sum_{\#}^{y}$ & 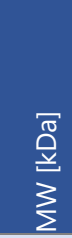 & $\begin{array}{l}\bar{a} \\
\frac{\dot{u}}{\sqrt{J}}\end{array}$ \\
\hline HVO_2040 & GEN & $\begin{array}{l}\text { GalE family epimerase/dehydra- } \\
\text { tase }\end{array}$ & 58 & 25 & 42 & 34 & 37 & 38 & 18 & 306 & 33,8 & 4,51 \\
\hline HVO_1133 & GEN & HTH domain protein & 73 & 15 & 23 & 29 & 24 & 25 & 15 & 101 & 11,7 & 4,58 \\
\hline HVO_1004 & $\mathrm{CHY}$ & Uncharacterized protein & 49 & 20 & 35 & 14 & 18 & 22 & 20 & 94 & 10 & 4,03 \\
\hline HVO_1545 & CIM & $\begin{array}{l}\text { Dihydroxyacetone kinase subunit } \\
\text { DhaL }\end{array}$ & 47 & 7 & 12 & 25 & 22 & 20 & 7 & 232 & 24,8 & 4,48 \\
\hline HVO_0354 & TL & $30 \mathrm{~S}$ ribosomal protein $\mathrm{S} 7$ & 35 & 7 & 8 & 11 & 11 & 10 & 7 & 204 & 22,6 & 5,14 \\
\hline HVO_1454 & NUM & Aspartate carbamoyltransferase & 22 & 5 & 6 & 11 & 13 & 10 & 5 & 304 & 33,7 & 4,92 \\
\hline HVO_0476 & GEN & UCP015877 family protein & 45 & 8 & 10 & 8 & 9 & 9 & 8 & 218 & 23,8 & 4,6 \\
\hline HVO_2542 & $\mathrm{TL}$ & 50 S ribosomal protein $\mathrm{L} 15$ & 47 & 10 & 11 & 7 & 8 & 9 & 10 & 165 & 17,8 & 4,93 \\
\hline HVO_0400 & $\mathrm{CHY}$ & Uncharacterized protein & 52 & 10 & 10 & 10 & 5 & 8 & 10 & 126 & 13,9 & 4,68 \\
\hline HVO_1576 & GEN & UDP-glucose 4-epimerase & 19 & 8 & 9 & 7 & 9 & 8 & 1 & 306 & 33,9 & 4,51 \\
\hline HVO_2748 & TC & $\begin{array}{l}\text { DNA-directed RNA polymerase } \\
\text { subunit } F\end{array}$ & 55 & 5 & 7 & 8 & 8 & 8 & 5 & 118 & 13,6 & 4,49 \\
\hline HVO_1727 & TC & TATA-box-binding protein & 39 & 5 & 7 & 6 & 10 & 8 & 5 & 186 & 19,9 & 4,36 \\
\hline HVO_2496 & NUM & Adenylate kinase & 25 & 4 & 6 & 9 & 8 & 8 & 4 & 208 & 23,1 & 4,25 \\
\hline HVO_2561 & TL & $50 S$ ribosomal protein $\mathrm{L} 2$ & 19 & 3 & 3 & 11 & 8 & 7 & 3 & 241 & 25,6 & 10,4 \\
\hline HVO_1857 & GEN & $\begin{array}{l}\text { DNA-binding protein } \\
\text { C498_04555 }\end{array}$ & 54 & 6 & 9 & 5 & 6 & 7 & 6 & 120 & 13,8 & 8,44 \\
\hline HVO_0889 & GEN & FAD-dependent oxidoreductase & 20 & 3 & 6 & 8 & 6 & 7 & 3 & 214 & 21,8 & 3,89 \\
\hline HVO_0240 & REG & $\begin{array}{l}\text { Lrp/AsnC family transcription } \\
\text { regulator }\end{array}$ & 21 & 3 & 3 & 8 & 8 & 6 & 3 & 152 & 16,9 & 4,39 \\
\hline HVO_1473 & GEN & UPF0058 family protein & 58 & 3 & 3 & 9 & 6 & 6 & 3 & 92 & 10,3 & 5,26 \\
\hline HVO_2242 & TL & $\begin{array}{l}\text { Translation initiation factor IF-2 } \\
\text { subunit beta }\end{array}$ & 35 & 6 & 7 & 3 & 8 & 6 & 6 & 202 & 22,2 & 5,11 \\
\hline HVO_1560 & GEN & UPF0212 protein HVO_1560 & 38 & 3 & 3 & 7 & 7 & 6 & 3 & 119 & 12,9 & 4,37 \\
\hline HVO_0291 & RRR & Rpa-associated protein & 44 & 6 & 6 & 5 & 6 & 6 & 6 & 196 & 22 & 4,42 \\
\hline HVO_1145 & TL & $30 \mathrm{~S}$ ribosomal protein $\mathrm{S} 3 \mathrm{Ae}$ & 29 & 5 & 5 & 5 & 7 & 6 & 5 & 220 & 24,8 & 4,86 \\
\hline HVO_0158 & TC & TATA-box-binding protein 1 & 22 & 3 & 4 & 5 & 7 & 5 & 3 & 189 & 20,3 & 4,22 \\
\hline HVO_2563 & TL & 50 S ribosomal protein $L 4$ & 30 & 4 & 4 & 6 & 6 & 5 & 4 & 248 & 27 & 6,44 \\
\hline HVO_2029 & REG & $\begin{array}{l}\text { AsnC family transcriptional regu- } \\
\text { lator }\end{array}$ & 21 & 2 & 2 & 5 & 8 & 5 & 2 & 153 & 16,9 & 4,21 \\
\hline HVO_1148 & TL & 30 S ribosomal protein $\mathrm{S} 15$ & 32 & 4 & 7 & 3 & 5 & 5 & 4 & 155 & 17,5 & 4,91 \\
\hline HVO_0180 & RMT & $\begin{array}{l}\text { Ribosomal RNA large subunit } \\
\text { methyltransferase } E\end{array}$ & 11 & 2 & 3 & 7 & 5 & 5 & 2 & 259 & 28,3 & 4,7 \\
\hline HVO_2564 & $\mathrm{TL}$ & $50 S$ ribosomal protein $\mathrm{L} 3$ & 11 & 2 & 3 & 6 & 6 & 5 & 2 & 338 & 37,2 & 6,68 \\
\hline HVO_2992 & AA & $\begin{array}{l}\text { Phosphoribosyl-AMP cyclohy- } \\
\text { drolase }\end{array}$ & 25 & 6 & 6 & 3 & 5 & 5 & 6 & 122 & 13,6 & 4,5 \\
\hline HVO_2546 & $\mathrm{TL}$ & $50 S$ ribosomal protein $\mathrm{L} 19 \mathrm{e}$ & 26 & 5 & 6 & 3 & 5 & 5 & 5 & 151 & 17,3 & 9,98 \\
\hline HVO_0392 & GEN & Putative SepF protein & 53 & 5 & 5 & 5 & 3 & 4 & 5 & 118 & 12,6 & 4,56 \\
\hline HVO_2553 & TL & 50 S ribosomal protein $\mathrm{L} 24$ & 47 & 7 & 7 & 0 & 6 & 4 & 7 & 118 & 13,4 & 4,73 \\
\hline
\end{tabular}




\begin{tabular}{|c|c|c|c|c|c|c|c|c|c|c|c|c|}
\hline HVO_1827 & TL & $30 \mathrm{~S}$ ribosomal protein S6e & 36 & 4 & 7 & 2 & 4 & 4 & 4 & 133 & 13,9 & 4,32 \\
\hline HVO_0719 & TC & $\begin{array}{l}\text { Transcription elongation factor } \\
\text { Spt5 }\end{array}$ & 24 & 3 & 4 & 4 & 5 & 4 & 3 & 150 & 16,3 & 4,5 \\
\hline HVO_0491 & GEN & FMN-binding domain protein & 29 & 4 & 4 & 4 & 5 & 4 & 4 & 153 & 17,3 & 4,67 \\
\hline HVO_0536 & MIS & Ferritin & 44 & 3 & 5 & 4 & 4 & 4 & 3 & 176 & 19,9 & 4,5 \\
\hline HVO_0309 & COM & Membrane protein & 10 & 2 & 2 & 5 & 6 & 4 & 2 & 207 & 23,7 & 4,97 \\
\hline HVO_0859 & MIS & $\begin{array}{l}\text { Fe-S cluster assembly ATPase } \\
\text { SufC }\end{array}$ & 8 & 2 & 2 & 8 & 3 & 4 & 2 & 301 & 33,4 & 4,35 \\
\hline HVO_0196 & $\mathrm{CHY}$ & Uncharacterized protein & 31 & 4 & 5 & 3 & 4 & 4 & 4 & 55 & 6,2 & 4,81 \\
\hline HVO_1946 & TL & $\begin{array}{l}\text { Protein translation factor SUI1 } \\
\text { homolog }\end{array}$ & 35 & 3 & 3 & 5 & 4 & 4 & 3 & 97 & 10,8 & 4,53 \\
\hline HVO_2559 & TL & 50 S ribosomal protein L22 & 37 & 3 & 3 & 5 & 4 & 4 & 3 & 153 & 16,9 & 5,6 \\
\hline HVO_2784 & TL & 30 S ribosomal protein $\mathrm{S} 13$ & 17 & 2 & 2 & 6 & 4 & 4 & 2 & 167 & 18,9 & 5,17 \\
\hline HVO_1082 & GEN & PyrE-like protein & 20 & 3 & 3 & 4 & 5 & 4 & 3 & 210 & 22,3 & 4,42 \\
\hline HVO_2551 & TL & 50 S ribosomal protein $\mathrm{L} 5$ & 18 & 2 & 3 & 3 & 5 & 4 & 2 & 172 & 19,1 & 4,78 \\
\hline HVO_1344 & MIS & RNA-associated protein & 12 & 3 & 3 & 3 & 5 & 4 & 3 & 238 & 26,5 & 4,51 \\
\hline HVO_B0114 & REG & $\begin{array}{l}\text { IcIR family transcription regula- } \\
\text { tor }\end{array}$ & 9 & 2 & 2 & 3 & 6 & 4 & 2 & 252 & 28,4 & 5,44 \\
\hline HVO_2783 & TL & 30 S ribosomal protein $\mathrm{S} 4$ & 21 & 3 & 4 & 3 & 3 & 3 & 3 & 175 & 20,1 & 5,24 \\
\hline HVO_1572 & RRR & DNA gyrase subunit B & 4 & 2 & 2 & 3 & 5 & 3 & 2 & 639 & 71,2 & 4,83 \\
\hline HVO_A0206 & MIS & $\begin{array}{l}\text { CRISPR-associated protein } \\
\text { Cas8b }\end{array}$ & 5 & 3 & 3 & 2 & 5 & 3 & 3 & 717 & 79,3 & 4,6 \\
\hline HVO_0651 & $\mathrm{CP}$ & Prefoldin subunit beta & 22 & 2 & 3 & 3 & 3 & 3 & 2 & 127 & 14 & 4,07 \\
\hline HVO_2548 & TL & 50 S ribosomal protein $\mathrm{L} 6$ & 66 & 7 & 7 & 0 & 2 & 3 & 7 & 178 & 19,6 & 4,68 \\
\hline HVO_0579 & $\mathrm{CHY}$ & Uncharacterized protein & 20 & 3 & 3 & 2 & 4 & 3 & 3 & 214 & 23,4 & 4,63 \\
\hline HVO_1303 & REG & $\begin{array}{l}\text { Lrp/AsnC family transcription } \\
\text { regulator }\end{array}$ & 20 & 2 & 2 & 3 & 3 & 3 & 2 & 142 & 15,4 & 4,7 \\
\hline HVO_2758 & TL & 50 S ribosomal protein $\mathrm{L} 11$ & 23 & 3 & 3 & 2 & 3 & 3 & 3 & 159 & 16,8 & 4,04 \\
\hline HVO_2413 & TL & Elongation factor 1-alpha & 11 & 5 & 5 & 0 & 3 & 3 & 1 & 420 & 45,6 & 4,75 \\
\hline HVO_2922 & GEN & Uncharacterized protein & 50 & 2 & 2 & 2 & 3 & 2 & 2 & 60 & 6,7 & 6,54 \\
\hline HVO_1964 & GEN & PRC domain protein & 47 & 3 & 3 & 2 & 2 & 2 & 3 & 81 & 9 & 5,08 \\
\hline HVO_0213 & GEN & / Dps domain protein & 25 & 2 & 2 & 3 & 2 & 2 & 2 & 150 & 16,9 & 4,28 \\
\hline HVO_0484 & TL & $50 \mathrm{~S}$ ribosomal protein $\mathrm{L} 10 \mathrm{e}$ & 22 & 3 & 3 & 2 & 2 & 2 & 3 & 176 & 19,8 & 8,72 \\
\hline HVO_0027 & GEN & $\begin{array}{l}\text { Transcription anti-termination } \\
\text { factor }\end{array}$ & 22 & 2 & 3 & 2 & 2 & 2 & 2 & 199 & 21 & 4,16 \\
\hline HVO_B0016 & $\mathrm{CHY}$ & Uncharacterized protein & 39 & 2 & 2 & 2 & 2 & 2 & 2 & 76 & 8,6 & 5,48 \\
\hline HVO_1691 & GEN & & 28 & 3 & 3 & 1 & 2 & 2 & 3 & 97 & 10,8 & 4,28 \\
\hline HVO_0360 & TL & $30 \mathrm{~S}$ ribosomal protein $\mathrm{S} 10$ & 24 & 2 & 2 & 2 & 2 & 2 & 2 & 102 & 11,5 & 4,88 \\
\hline HVO_2373 & TL & & 30 & 4 & 4 & 0 & 2 & 2 & 4 & 125 & 13,6 & $\begin{array}{r}10,4 \\
8\end{array}$ \\
\hline HVO_1444 & LIP & $\begin{array}{l}\text { 3-hydroxybutyryl-CoA dehydro- } \\
\text { genase }\end{array}$ & 7 & 2 & 2 & 2 & 2 & 2 & 2 & 286 & 30,8 & 4,46 \\
\hline HVO_0758 & GEN & Uncharacterized protein & 29 & 1 & 1 & 2 & 2 & 2 & 1 & 56 & 6,5 & 7,75 \\
\hline HVO_2869 & REG & $\begin{array}{l}\text { PadR family transcription regula- } \\
\text { tor }\end{array}$ & 36 & 3 & 3 & 0 & 2 & 2 & 3 & 95 & 11,4 & 5,16 \\
\hline HVO_0070 & GEN & $\begin{array}{l}\text { NifU-like domain-containing } \\
\text { protein }\end{array}$ & 19 & 3 & 3 & 0 & 2 & 2 & 3 & 125 & 13,2 & 4,45 \\
\hline HVO_2557 & $\mathrm{TL}$ & 50 S ribosomal protein L29 & 29 & 1 & 1 & 2 & 1 & 1 & 1 & 70 & 7,7 & 4,36 \\
\hline HVO_0387 & $\mathrm{CHY}$ & Uncharacterized protein & 13 & 1 & 1 & 1 & 2 & 1 & 1 & 79 & 8,9 & 4,06 \\
\hline HVO_1087 & GEN & UspA domain protein & 13 & 2 & 2 & 0 & 2 & 1 & 2 & 141 & 15,2 & 4,98 \\
\hline HVO_2475 & $\mathrm{TL}$ & 30 s ribosomal protein $\mathrm{S} 17 \mathrm{e}$ & 19 & 1 & 1 & 1 & 1 & 1 & 1 & 62 & 7 & 9,63 \\
\hline HVO_2942 & $\mathrm{CHY}$ & Uncharacterized protein & 15 & 1 & 1 & 1 & 1 & 1 & 1 & 65 & 7,4 & 5,4 \\
\hline HVO_1611 & $\mathrm{CHY}$ & Uncharacterized protein & 18 & 1 & 1 & 1 & 1 & 1 & 1 & 67 & 7,5 & 4,59 \\
\hline HVO_1515 & GEN & CopG domain protein & 14 & 1 & 1 & 1 & 1 & 1 & 1 & 70 & 7,8 & 4,49 \\
\hline HVO_2752 & $\mathrm{TL}$ & Elongation factor 1 -beta & 11 & 1 & 1 & 2 & 0 & 1 & 1 & 88 & 9,2 & 4,16 \\
\hline HVO_2749 & TL & $50 S$ ribosomal protein $\mathrm{L} 21 \mathrm{e}$ & 22 & 2 & 2 & 0 & 1 & 1 & 2 & 96 & 10,6 & $\begin{array}{r}10,9 \\
5\end{array}$ \\
\hline HVO_1075 & GEN & $\begin{array}{l}\text { Putative transcriptional regulator } \\
\text { containing an HTH domain fused } \\
\text { to a Zn-ribbon }\end{array}$ & 10 & 1 & 1 & 1 & 0 & 1 & 1 & 99 & 10,7 & 4,91 \\
\hline
\end{tabular}


Tabelle A3: Ergebnistabelle der massenspektrometrischen Analyse von Fraktion 3.

Gezeigt sind die Gene IDs der identifizierten Proteine mit ihrer Funktionsklasse (FC, siehe Abkürzungsverzeichnis), dem Namen des Proteins, der Coverage von BR1 in Prozent, der Anzahl gefundener Peptide von BR1 (\# Peptides), der Anzahl an PSMs der drei unabhängigen biologischen Replikate (\# PSMs (1-3)), dem Mittelwert der PSMs der biologischen Replikate (PSMs (mean)), der Anzahl an einzigartigen Peptiden (\# Unique Peptides), der Anzahl an Aminosäuren (\# AAs), das entsprechende Molekulargewicht (MW) in Kilodalton und der berechnete pl-Wert (calc. pl). In dunklerem Blauton hinterlegt sind alle Proteine mit einem Molekulargewicht zwischen 9 und 15 kDa.

\begin{tabular}{|c|c|c|c|c|c|c|c|c|c|c|c|c|}
\hline Gene ID & FC & Protein Name & $\begin{array}{l}\bar{d} \\
\frac{0}{0} \\
\frac{0}{0} \\
0 \\
0 \\
0\end{array}$ & $\begin{array}{l}\frac{\tilde{d}}{0} \\
\frac{0}{0} \\
\frac{0}{0} \\
\frac{0}{0} \\
\#\end{array}$ & $\underset{\substack{E \\
\sum_{n}^{n} \\
E}}{E}$ & $\begin{array}{l}\underset{\Xi}{\Xi} \\
\sum_{n}^{n} \\
\# \\
\#\end{array}$ & 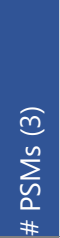 & $\begin{array}{l}\text { ह్ } \\
\text { है } \\
\text { है } \\
\sum_{n}^{n}\end{array}$ & 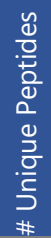 & $\sum_{\#}^{n}$ & 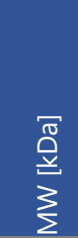 & $\frac{\bar{a}}{\frac{\dot{U}}{\mathbb{J}}}$ \\
\hline HVO_1004 & $\mathrm{CHY}$ & Uncharacterized protein & 51 & 39 & 74 & 21 & 40 & 45 & 39 & 94 & 10 & 4,03 \\
\hline HVO_1858 & TL & 30 S ribosomal protein $\mathrm{S} 19 \mathrm{e}$ & 96 & 39 & 52 & 7 & 50 & 36 & 39 & 151 & 16,7 & 4,84 \\
\hline HVO_1473 & GEN & UPF0058 family protein & 93 & 26 & 48 & 9 & 36 & 31 & 26 & 92 & 10,3 & 5,26 \\
\hline HVO_2560 & TL & 30 S ribosomal protein S19P & 76 & 45 & 52 & 0 & 22 & 25 & 45 & 140 & 16 & 5,57 \\
\hline HVO_2559 & TL & 50 S ribosomal protein L22 & 68 & 22 & 31 & 6 & 21 & 19 & 22 & 153 & 16,9 & 5,6 \\
\hline HVO_0400 & $\mathrm{CHY}$ & Uncharacterized protein & 85 & 25 & 28 & 5 & 22 & 18 & 25 & 126 & 13,9 & 4,68 \\
\hline HVO_1133 & GEN & HTH domain protein & 67 & 13 & 16 & 9 & 22 & 16 & 13 & 101 & 11,7 & 4,58 \\
\hline HVO_1965 & RMT & $\begin{array}{l}\text { rRNA maturation endonuclease } \\
\text { Nob1 }\end{array}$ & 79 & 18 & 25 & 5 & 10 & 13 & 18 & 152 & 16,8 & 4,7 \\
\hline HVO_1827 & TL & $30 \mathrm{~S}$ ribosomal protein $\mathrm{S} 6 \mathrm{e}$ & 76 & 12 & 21 & 6 & 11 & 13 & 12 & 133 & 13,9 & 4,32 \\
\hline HVO_2553 & TL & 50 S ribosomal protein L24 & 49 & 12 & 14 & 11 & 11 & 12 & 12 & 118 & 13,4 & 4,73 \\
\hline HVO_2737 & TL & $50 S$ ribosomal protein $\mathrm{L} 7 \mathrm{Ae}$ & 88 & 25 & 28 & 0 & 7 & 12 & 25 & 120 & 12,6 & 4,16 \\
\hline HVO_2548 & TL & $50 S$ ribosomal protein $\mathrm{L} 6$ & 86 & 16 & 22 & 0 & 12 & 11 & 16 & 178 & 19,6 & 4,68 \\
\hline HVO_2040 & GEN & $\begin{array}{l}\text { GalE family epimerase/dehydra- } \\
\text { tase }\end{array}$ & 52 & 16 & 18 & 4 & 12 & 11 & 16 & 306 & 33,8 & 4,51 \\
\hline HVO_2869 & REG & $\begin{array}{l}\text { PadR family transcription regula- } \\
\text { tor }\end{array}$ & 81 & 12 & 13 & 4 & 11 & 9 & 12 & 95 & 11,4 & 5,16 \\
\hline HVO_1857 & GEN & $\begin{array}{l}\text { DNA-binding protein } \\
\text { C498_04555 }\end{array}$ & 62 & 9 & 11 & 6 & 11 & 9 & 9 & 120 & 13,8 & 8,44 \\
\hline HVO_2749 & TL & $50 \mathrm{~S} r$ & 65 & 11 & 14 & 2 & 10 & 9 & 11 & 96 & 10,6 & $\begin{array}{r}10,9 \\
5\end{array}$ \\
\hline HVO_0438 & EM & Thioredoxin & 96 & 12 & 16 & 0 & 9 & 8 & 12 & 89 & 10 & 4,01 \\
\hline HVO_2992 & AA & $\begin{array}{l}\text { Phosphoribosyl-AMP cyclohy- } \\
\text { drolase }\end{array}$ & 39 & 10 & 15 & 2 & 8 & 8 & 10 & 122 & 13,6 & 4,5 \\
\hline HVO_0476 & GEN & UCP015877 family protein & 40 & 6 & 9 & 5 & 10 & 8 & 6 & 218 & 23,8 & 4,6 \\
\hline HVO_2300 & $\mathrm{TL}$ & Translation initiation factor $5 \mathrm{~A}$ & 60 & 12 & 15 & 0 & 8 & 8 & 12 & 124 & 14,2 & 5,22 \\
\hline HVO_0353 & TL & 30 S ribosomal protein S12 & 58 & 12 & 14 & 0 & 9 & 8 & 12 & 142 & 15,5 & 9,91 \\
\hline HVO_2758 & $\mathrm{TL}$ & $50 S$ ribosomal protein $\mathrm{L} 11$ & 58 & 11 & 11 & 3 & 9 & 8 & 11 & 159 & 16,8 & 4,04 \\
\hline HVO_0491 & GEN & FMN-binding domain protein & 67 & 8 & 9 & 5 & 9 & 8 & 8 & 153 & 17,3 & 4,67 \\
\hline HVO_0720 & GEN & $\begin{array}{l}\text { Small CPxCG-related zinc finger } \\
\text { protein }\end{array}$ & 92 & 12 & 15 & 0 & 7 & 7 & 12 & 100 & 11,3 & 5,03 \\
\hline HVO_2373 & TL & $30 \mathrm{~S}$ ribosomal protein $\mathrm{S} 8 \mathrm{e}$ & 54 & 10 & 14 & 3 & 5 & 7 & 10 & 125 & 13,6 & $\begin{array}{r}10,4 \\
8\end{array}$ \\
\hline HVO_2543 & TL & 50 S ribosomal protein $\mathrm{L} 30$ & 42 & 10 & 15 & 0 & 7 & 7 & 10 & 154 & 17,1 & 4,77 \\
\hline HVO_1545 & CIM & $\begin{array}{l}\text { Dihydroxyacetone kinase subunit } \\
\text { DhaL }\end{array}$ & 35 & 6 & 6 & 5 & 11 & 7 & 6 & 232 & 24,8 & 4,48 \\
\hline HVO_1896 & $\mathrm{TL}$ & 30 S ribosomal protein $524 \mathrm{e}$ & 89 & 11 & 13 & 0 & 8 & 7 & 11 & 101 & 11,6 & 4,68 \\
\hline HVO_2545 & TL & 50 S ribosomal protein L18 & 48 & 12 & 13 & 0 & 8 & 7 & 12 & 184 & 20,2 & 5,6 \\
\hline HVO_2542 & TL & 50 S ribosomal protein $\mathrm{L} 15$ & 41 & 6 & 7 & 5 & 7 & 6 & 6 & 165 & 17,8 & 4,93 \\
\hline HVO_2752 & TL & Elongation factor 1-beta & 60 & 10 & 10 & 2 & 6 & 6 & 10 & 88 & 9,2 & 4,16 \\
\hline
\end{tabular}




\begin{tabular}{|c|c|c|c|c|c|c|c|c|c|c|c|c|}
\hline HVO_2899 & GEN & Uncharacterized protein & $\begin{array}{l}\# \\
\#\end{array}$ & 10 & 16 & 0 & 2 & 6 & 10 & 87 & 9,8 & 4,45 \\
\hline HVO_1691 & GEN & PRC domain protein & 71 & 8 & 10 & 2 & 6 & 6 & 8 & 97 & 10,8 & 4,28 \\
\hline HVO_1946 & TL & $\begin{array}{l}\text { Protein translation factor SUI1 } \\
\text { homolog }\end{array}$ & 61 & 5 & 9 & 2 & 7 & 6 & 5 & 97 & 10,8 & 4,53 \\
\hline HVO_1148 & TL & $30 \mathrm{~S}$ ribosomal protein $\mathrm{S} 15$ & 32 & 6 & 7 & 0 & 10 & 6 & 6 & 155 & 17,5 & 4,91 \\
\hline HVO_1087 & GEN & UspA domain protein & 37 & 6 & 6 & 2 & 8 & 5 & 6 & 141 & 15,2 & 4,98 \\
\hline HVO_2778 & $\mathrm{TL}$ & 50 S ribosomal protein L13 & 43 & 6 & 7 & 3 & 6 & 5 & 6 & 145 & 16 & 5,43 \\
\hline HVO_0027 & GEN & $\begin{array}{l}\text { Transcription anti-termination } \\
\text { factor }\end{array}$ & 69 & 7 & 8 & 0 & 8 & 5 & 7 & 199 & 21 & 4,16 \\
\hline HVO_1377 & GEN & UPF0145 protein C498_11858 & 64 & 6 & 7 & 0 & 8 & 5 & 6 & 124 & 12,8 & 4,37 \\
\hline HVO_0070 & GEN & $\begin{array}{l}\text { NifU-like domain-containing } \\
\text { protein }\end{array}$ & 42 & 5 & 6 & 4 & 5 & 5 & 5 & 125 & 13,2 & 4,45 \\
\hline HVO_0196 & $\mathrm{CHY}$ & Uncharacterized protein & 31 & 4 & 6 & 1 & 7 & 5 & 4 & 55 & 6,2 & 4,81 \\
\hline HVO_0654 & $\mathrm{TL}$ & $50 S$ ribosomal protein $\mathrm{L} 43 \mathrm{e}$ & 56 & 5 & 7 & 1 & 6 & 5 & 5 & 89 & 9,9 & 9,98 \\
\hline HVO_A0508 & AA & PacF protein & 64 & 6 & 7 & 0 & 7 & 5 & 6 & 106 & 11,9 & 4,89 \\
\hline HVO_2783 & $\mathrm{TL}$ & $30 \mathrm{~S}$ ribosomal protein $\mathrm{S} 4$ & 15 & 4 & 4 & 4 & 6 & 5 & 4 & 175 & 20,1 & 5,24 \\
\hline HVO_0889 & GEN & FAD-dependent oxidoreductase & 32 & 4 & 4 & 5 & 5 & 5 & 4 & 214 & 21,8 & 3,89 \\
\hline HVO_2557 & TL & 50 S ribosomal protein $\mathrm{L} 29$ & 90 & 6 & 7 & 1 & 5 & 4 & 6 & 70 & 7,7 & 4,36 \\
\hline HVO_2748 & TC & $\begin{array}{l}\text { DNA-directed RNA polymerase } \\
\text { subunit } F\end{array}$ & 47 & 4 & 5 & 2 & 6 & 4 & 4 & 118 & 13,6 & 4,49 \\
\hline HVO_0354 & TL & 30 S ribosomal protein $\mathrm{S7}$ & 30 & 4 & 4 & 2 & 7 & 4 & 4 & 204 & 22,6 & 5,14 \\
\hline HVO_0392 & GEN & Putative SepF protein & 53 & 6 & 7 & 0 & 5 & 4 & 6 & 118 & 12,6 & 4,56 \\
\hline HVO_2779 & $\mathrm{TL}$ & $50 \mathrm{~S}$ ribosomal protein $\mathrm{L} 18 \mathrm{e}$ & 59 & 4 & 5 & 0 & 7 & 4 & 4 & 116 & 12,7 & 8,5 \\
\hline HVO_1574 & GEN & MutT/nudix family protein & 72 & 8 & 8 & 0 & 4 & 4 & 8 & 156 & 17,6 & 4,98 \\
\hline HVO_B0066 & REG & $\begin{array}{l}\text { Lrp/AsnC family transcription } \\
\text { regulator }\end{array}$ & 58 & 8 & 8 & 0 & 4 & 4 & 8 & 164 & 18,5 & 4,41 \\
\hline HVO_0653 & TC & $\begin{array}{l}\text { DNA-directed RNA polymerase } \\
\text { subunit } P\end{array}$ & 50 & 3 & 5 & 1 & 5 & 4 & 3 & 44 & 5,1 & 8,19 \\
\hline HVO_0360 & TL & $30 \mathrm{~S}$ ribosomal protein $\mathrm{S} 10$ & 63 & 5 & 5 & 2 & 4 & 4 & 5 & 102 & 11,5 & 4,88 \\
\hline HVO_2941 & MIS & $\begin{array}{l}\text { Nonhistone chromosomal pro- } \\
\text { tein }\end{array}$ & 53 & 7 & 8 & 0 & 3 & 4 & 7 & 104 & 11,6 & 5,6 \\
\hline HVO_2995 & EM & Ferredoxin (2Fe-2S) & 43 & 6 & 8 & 0 & 3 & 4 & 6 & 129 & 14,4 & 3,98 \\
\hline HVO_2029 & REG & $\begin{array}{l}\text { AsnC family transcriptional regu- } \\
\text { lator }\end{array}$ & 46 & 5 & 5 & 0 & 6 & 4 & 3 & 153 & 16,9 & 4,21 \\
\hline HVO_2551 & TL & 50 S ribosomal protein $\mathrm{L} 5$ & 38 & 4 & 4 & 2 & 5 & 4 & 4 & 172 & 19,1 & 4,78 \\
\hline HVO_0536 & MIS & Ferritin & 23 & 2 & 4 & 3 & 4 & 4 & 2 & 176 & 19,9 & 4,5 \\
\hline HVO_B0016 & $\mathrm{CHY}$ & Uncharacterized protein & 67 & 4 & 4 & 2 & 4 & 3 & 4 & 76 & 8,6 & 5,48 \\
\hline HVO_0659 & $\mathrm{TL}$ & Peptidyl-tRNA hydrolase & 48 & 5 & 7 & 0 & 3 & 3 & 5 & 112 & 11,9 & 6,32 \\
\hline HVO_A0631 & $\mathrm{CHY}$ & Uncharacterized protein & 43 & 5 & 6 & 0 & 4 & 3 & 5 & 122 & 13,7 & 6,16 \\
\hline HVO_2546 & $\mathrm{TL}$ & 50 S ribosomal protein L19e & 39 & 5 & 5 & 0 & 5 & 3 & 5 & 151 & 17,3 & 9,98 \\
\hline HVO_2922 & GEN & Uncharacterized protein & 73 & 4 & 4 & 2 & 3 & 3 & 4 & 60 & 6,7 & 6,54 \\
\hline HVO_2010 & GEN & Uncharacterized protein & 34 & 3 & 3 & 0 & 6 & 3 & 3 & 102 & 11,4 & 4,92 \\
\hline HVO_1342 & EM & Thioredoxin & 43 & 4 & 4 & 0 & 5 & 3 & 4 & 111 & 12,1 & 4,27 \\
\hline HVO_1560 & GEN & UPF0212 protein HVO_1560 & 30 & 2 & 3 & 2 & 4 & 3 & 2 & 119 & 12,9 & 4,37 \\
\hline HVO_0719 & TC & $\begin{array}{l}\text { Transcription elongation factor } \\
\text { Spt5 }\end{array}$ & 37 & 3 & 3 & 2 & 4 & 3 & 3 & 150 & 16,3 & 4,5 \\
\hline HVO_2222 & MIS & $\begin{array}{l}\text { Peptidyl-prolyl cis-trans isomer- } \\
\text { ase }\end{array}$ & 37 & 5 & 5 & 0 & 4 & 3 & 5 & 172 & 18,7 & 4,44 \\
\hline HVO_1727 & TC & TATA-box-binding protein & 23 & 3 & 4 & 0 & 5 & 3 & 3 & 186 & 19,9 & 4,36 \\
\hline HVO_0291 & RRR & Rpa-associated protein & 15 & 2 & 2 & 0 & 7 & 3 & 2 & 196 & 22 & 4,42 \\
\hline HVO_0448 & AA & $\begin{array}{l}\text { Imidazole glycerol phosphate } \\
\text { synthase subunit HisH }\end{array}$ & 27 & 4 & 5 & 0 & 4 & 3 & 4 & 219 & 23,4 & 4,23 \\
\hline HVO_2942 & $\mathrm{CHY}$ & Uncharacterized protein & 80 & 4 & 5 & 1 & 2 & 3 & 4 & 65 & 7,4 & 5,4 \\
\hline HVO_1964 & GEN & PRC domain protein & 63 & 4 & 4 & 2 & 2 & 3 & 4 & 81 & 9 & 5,08 \\
\hline HVO_1075 & GEN & $\begin{array}{l}\text { Putative transcriptional regulator } \\
\text { containing an HTH domain fused } \\
\text { to a } \mathrm{Zn} \text {-ribbon }\end{array}$ & 47 & 3 & 3 & 1 & 4 & 3 & 3 & 99 & 10,7 & 4,91 \\
\hline HVO_2782 & TL & 30 S ribosomal protein S11 & 43 & 5 & 6 & 0 & 2 & 3 & 5 & 130 & 13,4 & 8,56 \\
\hline HVO_0651 & $\mathrm{CP}$ & Prefoldin subunit beta & 24 & 2 & 2 & 3 & 3 & 3 & 2 & 127 & 14 & 4,07 \\
\hline HVO_0184 & GEN & Uncharacterized protein & 74 & 3 & 3 & 0 & 4 & 2 & 3 & 58 & 6,7 & 4,67 \\
\hline HVO_1131 & MIS & UPF0434 family protein & 25 & 3 & 3 & 0 & 4 & 2 & 3 & 61 & 6,9 & 3,99 \\
\hline HVO_0435 & AA & $\begin{array}{l}\text { Phosphoribosyl-ATP pyrophos- } \\
\text { phatase }\end{array}$ & 31 & 2 & 2 & 1 & 4 & 2 & 2 & 100 & 11,3 & 4,22 \\
\hline
\end{tabular}




\begin{tabular}{|c|c|c|c|c|c|c|c|c|c|c|c|c|}
\hline HVO_2403 & AA & $\begin{array}{l}\text { Probable glycine cleavage sys- } \\
\text { tem H protein }\end{array}$ & 7 & 2 & 2 & 2 & 3 & 2 & 2 & 126 & 13,9 & 3,75 \\
\hline HVO_0107 & MIS & FeS assembly protein SufA & 31 & 3 & 3 & 0 & 4 & 2 & 3 & 142 & 15,5 & 4,56 \\
\hline HVO_1455 & NUM & $\begin{array}{l}\text { Aspartate carbamoyltransferase } \\
\text { regulatory chain }\end{array}$ & 49 & 5 & 5 & 0 & 2 & 2 & 5 & 155 & 16,7 & 4,88 \\
\hline HVO_A0636 & GEN & YbaK/ebsC protein & 22 & 3 & 3 & 0 & 4 & 2 & 3 & 158 & 16,7 & 4,54 \\
\hline HVO_0158 & $\mathrm{TC}$ & TATA-box-binding protein 1 & 20 & 2 & 2 & 0 & 5 & 2 & 2 & 189 & 20,3 & 4,22 \\
\hline HVO_2242 & TL & $\begin{array}{l}\text { Translation initiation factor IF-2 } \\
\text { subunit beta }\end{array}$ & 20 & 2 & 2 & 2 & 3 & 2 & 2 & 202 & 22,2 & 5,11 \\
\hline HVO_0827 & GEN & MTH865 family protein & 44 & 3 & 3 & 0 & 3 & 2 & 3 & 85 & 9,3 & 4,26 \\
\hline HVO_1042 & $\mathrm{TC}$ & $\begin{array}{l}\text { DNA-directed RNA polymerase } \\
\text { subunit L }\end{array}$ & 36 & 3 & 3 & 0 & 3 & 2 & 3 & 96 & 10,4 & 4,28 \\
\hline HVO_2796 & $\mathrm{CHY}$ & Uncharacterized protein & 23 & 3 & 3 & 0 & 3 & 2 & 3 & 106 & 12 & 4,56 \\
\hline HVO_2632 & TC & $\begin{array}{l}\text { DNA-directed RNA polymerase } \\
\text { subunit M2 }\end{array}$ & 35 & 4 & 4 & 0 & 2 & 2 & 4 & 109 & 12,2 & 4,34 \\
\hline HVO_1081 & MIS & Glutaredoxin & 48 & 3 & 3 & 0 & 3 & 2 & 3 & 114 & 12,8 & 4,23 \\
\hline HVO_0830 & CIM & $\begin{array}{l}\text { Methylmalonyl-CoA mutase sub- } \\
\text { unit } B\end{array}$ & 42 & 4 & 4 & 0 & 2 & 2 & 4 & 139 & 14,9 & 4,65 \\
\hline HVO_0450 & $\mathrm{CHP}$ & $\begin{array}{l}\text { Hsp20-type molecular chaper- } \\
\text { one }\end{array}$ & 25 & 3 & 3 & 0 & 3 & 2 & 3 & 135 & 15,2 & 4,34 \\
\hline HVO_2699 & MIS & Peroxiredoxin & 30 & 4 & 4 & 0 & 2 & 2 & 4 & 152 & 16,7 & 4,09 \\
\hline HVO_0390 & GEN & RNA-binding protein & 35 & 4 & 4 & 0 & 2 & 2 & 4 & 159 & 16,7 & 4,3 \\
\hline HVO_0484 & $\mathrm{TL}$ & 50 S ribosomal protein $\mathrm{L} 10 \mathrm{e}$ & 40 & 4 & 4 & 0 & 2 & 2 & & 176 & 19,8 & 8,72 \\
\hline HVO_0134 & MIS & $\mathrm{KH}$ domain protein & 19 & 3 & 3 & 0 & 3 & 2 & 3 & 180 & 19,9 & 4,94 \\
\hline HVO_3014 & MIS & $\begin{array}{l}\text { Origin-associated GTP-binding } \\
\text { protein OapA }\end{array}$ & 12 & 2 & 2 & 0 & 4 & 2 & 2 & 213 & 24 & 5,01 \\
\hline HVO_0602 & AA & 3-dehydroquinate dehydratase & 11 & 2 & 2 & 0 & 4 & 2 & & 247 & 27,3 & 4,51 \\
\hline HVO_C0032 & HY & & 33 & 4 & 4 & 0 & 1 & 2 & 4 & 57 & 6,5 & 3,93 \\
\hline HVO_0758 & GEN & Uncharacterized protein & 30 & 1 & 1 & 0 & 4 & 2 & 1 & 56 & 6,5 & 7,75 \\
\hline HVO_2562 & $\mathrm{TL}$ & $50 S$ ribosomal protein L23 & 45 & 3 & 3 & 0 & 2 & 2 & & 83 & 9,4 & 5,48 \\
\hline HVO_A0444 & $\mathrm{CHY}$ & Uncharacterized protein & 35 & 3 & 3 & 0 & 2 & 2 & 3 & 119 & 12,9 & 4,45 \\
\hline HVO_0083 & MIS & Nitrogen regulatory protein P-II & 32 & 2 & 2 & 0 & 3 & 2 & 2 & 123 & 12,9 & 5,01 \\
\hline HVO_3013 & MIS & $\begin{array}{l}\text { Origin-associated GTP-binding } \\
\text { protein OapB }\end{array}$ & 21 & 2 & 2 & 0 & 3 & 2 & 2 & 130 & 14,3 & 4,56 \\
\hline HVO_1825 & $\mathrm{CHY}$ & Uncharacterized protein & 47 & 3 & 3 & 0 & 2 & 2 & 3 & 142 & 15,3 & 4,17 \\
\hline HVO_1303 & REG & $\begin{array}{l}\text { Lrp/AsnC family transcription } \\
\text { regulator }\end{array}$ & 20 & 2 & 2 & 0 & 3 & 2 & 2 & 142 & 15,4 & 4,7 \\
\hline HVO_1072 & NUM & HGPRTase-like protein & 12 & 2 & 2 & 0 & 3 & 2 & & 188 & 20,5 & 4,6 \\
\hline HVO_2449 & GEN & DUF1684 family protein & 23 & 2 & 2 & 0 & 3 & 2 & & 186 & 21,3 & 4,22 \\
\hline HVO_0346 & TC & $\begin{array}{l}\text { DNA-directed RNA polymerase } \\
\text { subunit } \mathrm{H}\end{array}$ & 23 & 1 & 1 & 1 & 2 & 1 & 1 & 75 & 8,5 & 5,03 \\
\hline HVO_2866 & $\mathrm{CHY}$ & Uncharacterized protein & 14 & 1 & 1 & 1 & 2 & 1 & 1 & 77 & 8,7 & 5,2 \\
\hline HVO_2677 & $\mathrm{CHY}$ & Uncharacterized prote & 24 & 1 & 1 & 0 & 3 & 1 & & 82 & 9,2 & 4,48 \\
\hline HVO_0136 & $\mathrm{TL}$ & Translation initiation factor $1 \mathrm{~A}$ & 47 & 3 & 3 & 0 & 1 & 1 & 3 & 96 & 11,5 & 5,06 \\
\hline HVO_2366 & GEN & UspA domain-containing protein & 22 & 2 & 2 & 0 & 2 & 1 & 2 & 144 & 15,7 & 4,89 \\
\hline HVO_1391 & GEN & NUDIX family hydrolase & 19 & 2 & 2 & 0 & 2 & 1 & & 151 & 17,4 & 5,01 \\
\hline HVO_0429 & MIS & Archaemetzincin & 10 & 2 & 2 & 0 & 2 & 1 & 2 & 173 & 19,3 & 6,54 \\
\hline HVO_2561 & $\mathrm{TL}$ & $50 S$ ribosomal protein $\mathrm{L} 2$ & 10 & 1 & 2 & 0 & 2 & 1 & 1 & 241 & 25,6 & 10,4 \\
\hline HVO_2475 & $\mathrm{TL}$ & $30 \mathrm{~S}$ ribosomal protein $\mathrm{S} 17 \mathrm{e}$ & 15 & 1 & 1 & 1 & 1 & 1 & & 62 & 7 & 9,63 \\
\hline HVO_1611 & $\mathrm{CHY}$ & Uncharacterized protein & 18 & 1 & 1 & 0 & 2 & 1 & & 67 & 7,5 & 4,59 \\
\hline HVO_1515 & GEN & & 14 & 1 & 1 & 1 & 1 & 1 & & 70 & 7,8 & 4,49 \\
\hline HVO_0387 & $\mathrm{CHY}$ & Uncharacterized protein & 13 & 1 & 1 & 2 & 0 & 1 & 1 & 79 & 8,9 & 4,06 \\
\hline HVO_0090 & $\mathrm{CHY}$ & Uncharacterized protein & 28 & 1 & 1 & 0 & 1 & 1 & & 54 & 6,4 & 6,76 \\
\hline HVO_1753 & GEN & $\begin{array}{l}\text { CopA N-terminal domain-con- } \\
\text { taining protein }\end{array}$ & 32 & 1 & 1 & 0 & 1 & 1 & & 65 & 6,6 & 4,13 \\
\hline HVO_A0138 & $\mathrm{CHY}$ & Uncharacterized protein & 26 & 1 & 1 & 0 & 1 & 1 & 1 & 61 & 6,9 & 4,96 \\
\hline & $\mathrm{TC}$ & $\begin{array}{l}\text { DNA-directed RNA polymerase } \\
\text { subunit } N\end{array}$ & 27 & 1 & 1 & 0 & 1 & 1 & & 64 & 7,3 & 5,08 \\
\hline HVO_2739 & $\mathrm{TL}$ & $50 S$ ribosomal protein $\mathrm{L} 24 \mathrm{e}$ & 30 & 1 & 1 & 0 & 1 & 1 & 1 & 66 & 7,5 & 5,17 \\
\hline HVO_1359 & GEN & $\begin{array}{l}\text { Small CPxCG-related zinc finger } \\
\text { protein }\end{array}$ & 26 & 1 & 1 & 0 & 1 & 1 & 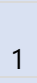 & 68 & 8 & 8,87 \\
\hline HVO_2971 & $\mathrm{CHY}$ & Uncharacterized protein & 27 & 1 & 1 & 0 & 1 & 1 & 1 & 78 & 8,7 & 5,02 \\
\hline
\end{tabular}




\begin{tabular}{|c|c|c|c|c|c|c|c|c|c|c|c|c|}
\hline HVO_2189 & NUM & $\begin{array}{l}\text { Phosphoribosylformyl- } \\
\text { glycinamidine synthase subunit } \\
\text { PurS }\end{array}$ & 11 & 1 & 1 & 0 & 1 & 1 & 1 & 83 & 9,3 & 4,5 \\
\hline HVO_2104 & TP & $\begin{array}{l}\text { Phosphotransferase system } \\
\text { component IIB }\end{array}$ & 15 & 1 & 1 & 0 & 1 & 1 & 1 & 98 & 10,2 & 4,81 \\
\hline HVO_1480 & $\mathrm{CHY}$ & Uncharacterized protein & 12 & 1 & 1 & 0 & 1 & 1 & 1 & 95 & 10,3 & 4,04 \\
\hline HVO_2309 & COM & $\begin{array}{l}\text { Pterin-4-alpha-carbinolamine } \\
\text { dehydratase }\end{array}$ & 13 & 1 & 1 & 0 & 1 & 1 & 1 & 91 & 10,4 & 4,07 \\
\hline HVO_3003 & $\mathrm{CHY}$ & Uncharacterized protein & 25 & 1 & 1 & 0 & 1 & 1 & 1 & 91 & 10,5 & 4,37 \\
\hline HVO_A0637 & $\mathrm{TL}$ & Translation initiation factor $1 \mathrm{~A}$ & 26 & 1 & 1 & 0 & 1 & 1 & 1 & 94 & 11,2 & 6,32 \\
\hline
\end{tabular}

Tabelle A4: Ergebnistabelle 1 der RNA-Sequenzierung. Gezeigt sind Gene mit ihrer Funktionsklasse (FC, siehe Abkürzungsverzeichnis), dem Namen des Genprodukts (Protein Name) und den feature counts in den drei Stämmen Wildtyp H26 evc, Deletionsmutante $\Delta \mathrm{HVO} \_2753$ evc und Komplementationsmutante $\Delta \mathrm{HVO} 2753+2753 \mathrm{c}$. Die letzten beiden Spalten zeigen den Grad der Regulation des jeweiligen Gens in der Deletionsmutante (im Vergleich zum Wildtyp) und in der Komplementationsmutante (im Vergleich zur Deletionsmutante). Gezeigt sind nur Gene mit einer mindestens 2-fachen Herunterbzw. Hochregulation in der Deletionsmutante.

\begin{tabular}{|c|c|c|c|c|c|c|c|}
\hline Gene ID & $\mathrm{FC}$ & Protein Name & 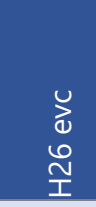 & 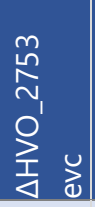 & 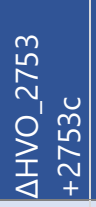 & 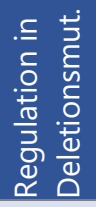 & 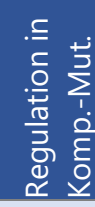 \\
\hline HVO_1207 & SIG & response regulator $\mathrm{CheY}$ & 414 & 0 & 0 & 0,00 & - \\
\hline HVO_1208 & $\mathrm{CHY}$ & conserved hypothetical protein & 433 & 0 & 0 & 0,00 & - \\
\hline HVO_1214 & MIS & arl cluster protein ArlF & 195 & 0 & 0 & 0,00 & - \\
\hline HVO_1220 & $\mathrm{CHY}$ & conserved hypothetical protein & 108 & 0 & 0 & 0,00 & - \\
\hline HVO_1222 & SIG & $\begin{array}{l}\text { protein-glutamate O-methyltransfer- } \\
\text { ase CheR }\end{array}$ & 328 & 0 & 1 & 0,00 & - \\
\hline HVO_1210 & MOT & archaellin A1 & 1929 & 0 & 0 & 0,00 & 0,43 \\
\hline HVO_1211 & МOT & archaellin $\mathrm{A} 2$ & 6840 & 2 & 1 & 0,00 & 0,63 \\
\hline HVO_1213 & MIS & arl cluster protein ArICE & 631 & 0 & 1 & 0,00 & 2,85 \\
\hline HVO_1206 & SIG & taxis cluster protein $\mathrm{CheC}$ & 465 & 0 & 1 & 0,00 & 2,85 \\
\hline HVO_1217 & MOT & $\begin{array}{l}\text { archaellar motor/biogenesis protein } \\
\text { Arll }\end{array}$ & 645 & 0 & 0 & 0,00 & 0,51 \\
\hline HVO_1212 & MIS & KaiC-type circadian clock protein CirA & 224 & 0 & 0 & 0,00 & 1,14 \\
\hline HVO_1215 & MIS & arl cluster protein ArlG & 257 & 0 & 0 & 0,00 & 0,00 \\
\hline HVO_1209 & GEN & HTH domain protein & 296 & 0 & 0 & 0,00 & 1,00 \\
\hline HVO_1219 & SIG & taxis protein CheF2 & 469 & 1 & 0 & 0,00 & 0,62 \\
\hline HVO_1218 & МOT & $\begin{array}{l}\text { archaellar motor/biogenesis protein } \\
\text { ArlJ }\end{array}$ & 565 & 1 & 1 & 0,00 & 1,02 \\
\hline HVO_2753 & GEN & $\begin{array}{l}\text { small CPxCG-related zinc finger pro- } \\
\text { tein }\end{array}$ & 1097 & 5 & 220 & 0,00 & 40,88 \\
\hline HVO_1216 & MIS & arl cluster protein $\mathrm{ArlH}$ & 288 & 2 & 1 & 0,01 & 0,55 \\
\hline HVO_1221 & SIG & taxis protein CheF1 & 317 & 4 & 2 & 0,01 & 0,57 \\
\hline HVO_2649 & $\mathrm{CHY}$ & conserved hypothetical protein & 828 & 27 & 25 & 0,03 & 0,92 \\
\hline HVO_1205 & SIG & taxis cluster protein CheD & 254 & 10 & 7 & 0,04 & 0,69 \\
\hline HVO_0471 & $\mathrm{CHY}$ & conserved hypothetical protein & 327 & 29 & 33 & 0,09 & 1,14 \\
\hline
\end{tabular}




\begin{tabular}{|c|c|c|c|c|c|c|c|}
\hline HVO_2461 & GEN & CBS domain protein & 121 & 13 & 15 & 0,11 & 1,12 \\
\hline HVO_0555 & SIG & transducer protein $\mathrm{Htr} 15$ & 287 & 38 & 31 & 0,13 & 0,81 \\
\hline HVO_1201 & SIG & sensor box histidine kinase & 2801 & 392 & 336 & 0,14 & 0,86 \\
\hline HVO_1225 & SIG & purine-binding taxis protein $\mathrm{CheW}$ & 1271 & 180 & 143 & 0,14 & 0,79 \\
\hline HVO_1126 & SIG & transducer protein HemAT & 272 & 41 & 41 & 0,15 & 1,00 \\
\hline HVO_A0590 & $\mathrm{CHY}$ & conserved hypothetical protein & 101 & 17 & 15 & 0,17 & 0,89 \\
\hline HVO_3004 & GEN & $\begin{array}{l}\text { DUF125 family protein (nonfunc- } \\
\text { tional) }\end{array}$ & 350 & 61 & 71 & 0,18 & 1,16 \\
\hline HVO_2301 & $\mathrm{CHY}$ & conserved hypothetical protein & 419 & 74 & 62 & 0,18 & 0,84 \\
\hline HVO_1224 & SIG & $\begin{array}{l}\text { protein-glutamate methylesterase / } \\
\text { protein-glutamine glutaminase } \mathrm{CheB}\end{array}$ & 133 & 27 & 24 & 0,20 & 0,89 \\
\hline HVO_1713 & SIG & receiver/sensor box histidine kinase & 684 & 140 & 114 & 0,20 & 0,81 \\
\hline HVO_1202 & $\mathrm{CHY}$ & conserved hypothetical protein & 249 & 54 & 56 & 0,22 & 1,03 \\
\hline HVO_1863 & $\mathrm{CHY}$ & conserved hypothetical protein & 134 & 30 & 27 & 0,22 & 0,89 \\
\hline HVO_1902 & $\mathrm{CHY}$ & conserved hypothetical protein & 292 & 67 & 58 & 0,23 & 0,87 \\
\hline HVO_B0193 & REG & ArsR family transcription regulator & 180 & 43 & 36 & 0,24 & 0,84 \\
\hline HVO_1203 & MIS & arl cluster protein ArID & 1829 & 469 & 403 & 0,26 & 0,86 \\
\hline HVO_3005 & SIG & transducer protein $\mathrm{Htr} 15$ & 387 & 99 & 103 & 0,26 & 1,04 \\
\hline HVO_1204 & $\mathrm{HY}$ & hypothetical protein & 1681 & 439 & 343 & 0,26 & 0,78 \\
\hline HVO_1223 & SIG & taxis sensor histidine kinase $\mathrm{CheA}$ & 411 & 111 & 98 & 0,27 & 0,88 \\
\hline HVO_3003 & $\mathrm{CHY}$ & conserved hypothetical protein & 228 & 64 & 75 & 0,28 & 1,16 \\
\hline HVO_1999 & SIG & transducer protein $\mathrm{Htr} 7$ & 140 & 45 & 54 & 0,33 & 1,18 \\
\hline HVO_2294 & $\mathrm{CHY}$ & conserved hypothetical protein & 38 & 13 & 12 & 0,34 & 0,96 \\
\hline HVO_1125 & $\mathrm{TL}$ & cysteine--tRNA ligase & 847 & 312 & 297 & 0,37 & 0,95 \\
\hline HVO_2469 & TP & SNF family transport protein & 610 & 227 & 413 & 0,37 & 1,82 \\
\hline HVO_2648 & GEN & $\begin{array}{l}\text { probable D-2-hydroxyacid dehydro- } \\
\text { genase }\end{array}$ & 207 & 80 & 96 & 0,39 & 1,20 \\
\hline HVO_2470 & $\mathrm{TP}$ & SNF family transport protein & 152 & 60 & 122 & 0,40 & 2,03 \\
\hline HVO_0470 & AA & threonine synthase & 42 & 17 & 15 & 0,40 & 0,89 \\
\hline HVO_2174 & $\mathrm{CHY}$ & conserved hypothetical protein & 3713 & 1493 & 1390 & 0,40 & 0,93 \\
\hline HVO_0553 & SIG & $\begin{array}{l}\text { chemotactic signal transduction sys- } \\
\text { tem periplasmic substrate-binding } \\
\text { protein BasB }\end{array}$ & 39 & 16 & 14 & 0,41 & 0,89 \\
\hline HVO_2074 & GEN & probable secreted glycoprotein & 432 & 178 & 170 & 0,41 & 0,96 \\
\hline HVO_1556 & $\mathrm{CHY}$ & conserved hypothetical protein & 91 & 39 & 38 & 0,42 & 0,99 \\
\hline HVO_2000 & $\mathrm{CHY}$ & conserved hypothetical protein & 53 & 24 & 20 & 0,45 & 0,85 \\
\hline HVO_2512 & $\mathrm{CHY}$ & conserved hypothetical protein & 54 & 25 & 18 & 0,46 & 0,72 \\
\hline HVO_A0402 & $\mathrm{CHY}$ & conserved hypothetical protein & 49 & 23 & 15 & 0,47 & 0,66 \\
\hline HVO_0227 & $\mathrm{CHY}$ & conserved hypothetical protein & 13731 & 6457 & 6293 & 0,47 & 0,97 \\
\hline HVO_1316 & $\mathrm{CHY}$ & conserved hypothetical protein & 47 & 22 & 23 & 0,47 & 1,05 \\
\hline HVO_2220 & SIG & transducer protein $\mathrm{Htr} 38$ & 61 & 29 & 33 & 0,48 & 1,12 \\
\hline HVO_1756 & GEN & GNAT family acetyltransferase Pat1 & 120 & 240 & 287 & 2,00 & 1,20 \\
\hline HVO_2917 & GEN & beta-lactamase domain protein & 431 & 864 & 1681 & 2,01 & 1,95 \\
\hline HVO_A0542 & $\mathrm{HY}$ & hypothetical protein & 52 & 105 & 107 & 2,02 & 1,02 \\
\hline HVO_1386 & $\mathrm{CHY}$ & conserved hypothetical protein & 40 & 81 & 55 & 2,04 & 0,68 \\
\hline HVO_2020 & GEN & DUF502 family protein & 59 & 120 & 88 & 2,05 & 0,73 \\
\hline HVO_0613 & GEN & beta-lactamase domain protein & 11 & 22 & 30 & 2,07 & 1,39 \\
\hline
\end{tabular}




\begin{tabular}{|c|c|c|c|c|c|c|c|}
\hline HVO_1122 & $\mathrm{CHY}$ & conserved hypothetical protein & 206 & 428 & 538 & 2,08 & 1,26 \\
\hline HVO_1481 & GEN & UspA domain protein & 415 & 866 & 1361 & 2,08 & 1,57 \\
\hline HVO_A0547 & GEN & DUF1028 family protein & 79 & 164 & 236 & 2,09 & 1,44 \\
\hline HVO_0133 & $\mathrm{CHP}$ & thermosome subunit 1 & 363 & 762 & 553 & 2,10 & 0,72 \\
\hline HVO_2057 & $\mathrm{CHM}$ & $\begin{array}{l}\text { glucose-1-phosphate thymi- } \\
\text { dylyltransferase Agl11 }\end{array}$ & 161 & 337 & 279 & 2,10 & 0,83 \\
\hline HVO_1991 & TP & $\begin{array}{l}\text { ABC-type transport system periplas- } \\
\text { mic substrate-binding protein }\end{array}$ & 337 & 715 & 261 & 2,12 & 0,36 \\
\hline HVO_1197 & GEN & $\begin{array}{l}\text { RIO-type protein kinase domain pro- } \\
\text { tein }\end{array}$ & 471 & 1006 & 1385 & 2,13 & 1,38 \\
\hline HVO_2027 & GEN & DoxX domain protein & 31 & 67 & 78 & 2,14 & 1,16 \\
\hline HVO_1707 & TP & $\begin{array}{l}\text { ABC-type transport system ATP-bind- } \\
\text { ing protein }\end{array}$ & 52 & 112 & 66 & 2,14 & 0,59 \\
\hline HVO_0401 & GEN & UspA domain protein & 648 & 1427 & 1773 & 2,20 & 1,24 \\
\hline HVO_A0334 & $\mathrm{CHY}$ & conserved hypothetical protein & 329 & 727 & 855 & 2,21 & 1,18 \\
\hline HVO_2030 & SIG & $\begin{array}{l}\text { receiver/sensor box histidine kinase } \\
\text { (nonfunctional) }\end{array}$ & 503 & 1116 & 1173 & 2,22 & 1,05 \\
\hline HVO_2238 & $\mathrm{CHY}$ & conserved hypothetical protein & 32 & 71 & 119 & 2,25 & 1,66 \\
\hline HVO_0598 & $\mathrm{CHY}$ & conserved hypothetical protein & 50 & 114 & 125 & 2,26 & 1,10 \\
\hline HVO_0932 & GEN & UspA domain protein & 27 & 61 & 46 & 2,27 & 0,77 \\
\hline HVO_1697 & GEN & $\begin{array}{l}\text { FAD-dependent oxidoreductase } \\
\text { (GlcD/DLD_GlcF/GlpC domain fusion } \\
\text { protein) }\end{array}$ & 186 & 426 & 492 & 2,28 & 1,16 \\
\hline HVO_1462 & COM & $\begin{array}{l}\text { 1,4-dihydroxy-2-naphthoate poly- } \\
\text { prenyltransferase }\end{array}$ & 52 & 118 & 50 & 2,29 & 0,43 \\
\hline HVO_2018 & $\mathrm{CHY}$ & conserved hypothetical protein & 180 & 415 & 462 & 2,31 & 1,11 \\
\hline HVO_2384 & GEN & CBS domain protein & 1748 & 4053 & 5232 & 2,32 & 1,29 \\
\hline HVO_2150 & EM & halocyanin & 133 & 315 & 426 & 2,36 & 1,35 \\
\hline HVO_2155 & GEN & $\begin{array}{l}\text { homolog to sodium/calcium anti- } \\
\text { porter }\end{array}$ & 80 & 193 & 313 & 2,41 & 1,62 \\
\hline HVO_2044 & MIS & $\begin{array}{l}\text { intein-related probable LAGLIDADG } \\
\text { endonuclease I-EndH }\end{array}$ & 22 & 54 & 52 & 2,42 & 0,97 \\
\hline HVO_1961 & $\mathrm{CHY}$ & conserved hypothetical protein & 318 & 776 & 945 & 2,44 & 1,22 \\
\hline HVO_2025 & GEN & receiver/sensor box protein & 55 & 134 & 128 & 2,45 & 0,96 \\
\hline HVO_2022 & $\mathrm{CHY}$ & conserved hypothetical protein & 66 & 163 & 166 & 2,46 & 1,02 \\
\hline HVO_2040 & GEN & GalE family epimerase/dehydratase & 110 & 271 & 235 & 2,46 & 0,87 \\
\hline HVO_0450 & $\mathrm{CHP}$ & Hsp20-type molecular chaperone & 249 & 614 & 964 & 2,47 & 1,57 \\
\hline HVO_2059 & $\mathrm{CHM}$ & dTDP-glucose 4,6-dehydratase & 62 & 155 & 130 & 2,51 & 0,84 \\
\hline HVO_2032 & TP & $\begin{array}{l}\text { ABC-type transport system ATP-bind- } \\
\text { ing protein (probable substrate } \\
\text { sugar) }\end{array}$ & 73 & 184 & 177 & 2,52 & 0,96 \\
\hline HVO_1706 & TP & $\begin{array}{l}\text { ABC-type transport system permease } \\
\text { protein }\end{array}$ & 105 & 264 & 122 & 2,52 & 0,46 \\
\hline HVO_1763 & GEN & UPF0104 family protein & 21 & 55 & 27 & 2,56 & 0,50 \\
\hline HVO_2239 & GEN & UspA domain protein & 897 & 2341 & 2696 & 2,61 & 1,15 \\
\hline HVO_2037 & GEN & DUF2078 family protein & 1029 & 2688 & 2886 & 2,61 & 1,07 \\
\hline HVO_B0361 & REG & $\begin{array}{l}\text { HTH-10 family transcription regulator } \\
\text { DmsR }\end{array}$ & 66 & 173 & 218 & 2,61 & 1,26 \\
\hline HVO_1198 & GEN & UspA domain protein & 216 & 569 & 715 & 2,63 & 1,26 \\
\hline HVO_2156 & GEN & UspA domain protein & 116 & 306 & 383 & 2,64 & 1,25 \\
\hline
\end{tabular}




\begin{tabular}{|c|c|c|c|c|c|c|c|}
\hline HVO_1087 & GEN & UspA domain protein & 318 & 848 & 1189 & 2,67 & 1,40 \\
\hline HVO_1764 & $\mathrm{CHY}$ & conserved hypothetical protein & 162 & 431 & 198 & 2,67 & 0,46 \\
\hline HVO_2241 & $\mathrm{CHY}$ & conserved hypothetical protein & 243 & 650 & 772 & 2,68 & 1,19 \\
\hline HVO_2015 & $\mathrm{CHY}$ & conserved hypothetical protein & 175 & 474 & 429 & 2,70 & 0,91 \\
\hline HVO_1587 & $\mathrm{CHY}$ & conserved hypothetical protein & 39 & 109 & 52 & 2,75 & 0,48 \\
\hline HVO_2754 & GEN & DUF112 family protein & 6 & 16 & 35 & 2,84 & 2,13 \\
\hline HVO_2035 & REG & TrmB family transcription regulator & 50 & 144 & 136 & 2,86 & 0,95 \\
\hline HVO_2031 & TP & $\begin{array}{l}\text { ABC-type transport system periplas- } \\
\text { mic substrate-binding protein (prob- } \\
\text { able substrate sugar) }\end{array}$ & 82 & 235 & 234 & 2,87 & 0,99 \\
\hline HVO_2159 & $\mathrm{CHY}$ & conserved hypothetical protein & 147 & 429 & 496 & 2,91 & 1,16 \\
\hline HVO_2060 & MIS & $\begin{array}{l}\text { low-salt glycan biosynthesis protein } \\
\text { Agl8 }\end{array}$ & 87 & 256 & 247 & 2,94 & 0,97 \\
\hline HVO_2058 & $\mathrm{CHM}$ & dTDP-4-dehydrorhamnose reductase & 76 & 226 & 170 & 2,97 & 0,76 \\
\hline HVO_2014 & GEN & $\begin{array}{l}\text { small CPxCG-related zinc finger pro- } \\
\text { tein }\end{array}$ & 17 & 50 & 36 & 3,03 & 0,71 \\
\hline HVO_2019 & GEN & PRC domain protein & 135 & 409 & 418 & 3,03 & 1,02 \\
\hline HVO_2039 & $\mathrm{CHY}$ & conserved hypothetical protein & 66 & 206 & 229 & 3,14 & 1,12 \\
\hline HVO_2036 & $\mathrm{CHY}$ & conserved hypothetical protein & 15 & 46 & 46 & 3,16 & 1,00 \\
\hline HVO_1705 & TP & $\begin{array}{l}\text { ABC-type transport system periplas- } \\
\text { mic substrate-binding protein }\end{array}$ & 94 & 307 & 82 & 3,27 & 0,27 \\
\hline HVO_0763 & GEN & DoxX domain protein & 1361 & 4535 & 5298 & 3,33 & 1,17 \\
\hline HVO_2041 & $\mathrm{CHY}$ & conserved hypothetical protein & 23 & 78 & 70 & 3,33 & 0,90 \\
\hline HVO_B0359 & GEN & YidE family protein & 65 & 218 & 260 & 3,36 & 1,19 \\
\hline HVO_1586 & $\mathrm{TP}$ & $\begin{array}{l}\text { SDF family transport protein (proba- } \\
\text { ble substrate glutamate/aspartate) }\end{array}$ & 30 & 102 & 44 & 3,36 & 0,43 \\
\hline HVO_2026 & $\mathrm{HY}$ & hypothetical protein & 10 & 33 & 31 & 3,39 & 0,94 \\
\hline HVO_2009 & $\mathrm{CHY}$ & conserved hypothetical protein & 69 & 234 & 189 & 3,39 & 0,81 \\
\hline HVO_2160 & GEN & probable secreted glycoprotein & 881 & 2993 & 3144 & 3,40 & 1,05 \\
\hline HVO_1704 & GEN & homolog to arabinopyranose mutase & 41 & 142 & 27 & 3,47 & 0,19 \\
\hline HVO_B0041 & MIS & siderophore biosynthesis protein lucC & 188 & 682 & 180 & 3,63 & 0,26 \\
\hline HVO_2066 & $\mathrm{CHY}$ & conserved hypothetical protein & 339 & 1275 & 390 & 3,76 & 0,31 \\
\hline HVO_2033 & $\mathrm{TP}$ & $\begin{array}{l}\text { ABC-type transport system permease } \\
\text { protein (probable substrate sugar) }\end{array}$ & 18 & 71 & 71 & 3,86 & 1,00 \\
\hline HVO_1757 & GEN & DoxX domain protein & 492 & 1978 & 2016 & 4,02 & 1,02 \\
\hline HVO_2037_A & $\mathrm{CHY}$ & conserved hypothetical protein & 22 & 91 & 28 & 4,09 & 0,31 \\
\hline HVO_1797 & GEN & beta-lactamase domain protein & 60 & 246 & 57 & 4,10 & 0,23 \\
\hline HVO_0597 & GEN & OsmC domain protein & 106 & 437 & 395 & 4,13 & 0,90 \\
\hline HVO_1696 & TP & LctP family transport protein & 90 & 372 & 436 & 4,15 & 1,17 \\
\hline HVO_A0548 & GEN & DoxX domain protein & 932 & 4038 & 4339 & 4,33 & 1,07 \\
\hline HVO_1229 & $\mathrm{CHY}$ & conserved hypothetical protein & 46 & 201 & 42 & 4,36 & 0,21 \\
\hline HVO_B0144 & TP & $\begin{array}{l}\text { ABC-type transport system periplas- } \\
\text { mic substrate-binding protein }\end{array}$ & 90 & 394 & 92 & 4,40 & 0,23 \\
\hline HVO_2016 & $\mathrm{CHY}$ & conserved hypothetical protein & 68 & 307 & 315 & 4,55 & 1,03 \\
\hline HVO_1760 & TP & $\begin{array}{l}\text { ABC-type transport system ATP-bind- } \\
\text { ing protein }\end{array}$ & 89 & 430 & 90 & 4,85 & 0,21 \\
\hline HVO_0105 & GEN & FAD-dependent oxidoreductase & 608 & 2974 & 2980 & 4,89 & 1,00 \\
\hline HVO_0537 & $\mathrm{CHY}$ & conserved hypothetical protein & 246 & 1233 & 199 & 5,01 & 0,16 \\
\hline
\end{tabular}




\begin{tabular}{|c|c|c|c|c|c|c|c|}
\hline HVO_1758 & GEN & $\begin{array}{l}\text { oxidoreductase (homolog to thiore- } \\
\text { doxin-disulfide reductase) }\end{array}$ & 45 & 227 & 51 & 5,10 & 0,22 \\
\hline HVO_2034 & TP & $\begin{array}{l}\text { ABC-type transport system permease } \\
\text { protein (probable substrate sugar) }\end{array}$ & 21 & 110 & 124 & 5,22 & 1,13 \\
\hline HVO_2061 & MIS & $\begin{array}{l}\text { low-salt glycan biosynthesis hexosyl- } \\
\text { transferase Agl6 }\end{array}$ & 119 & 638 & 565 & 5,37 & 0,89 \\
\hline HVO_1463 & GEN & $\begin{array}{l}\text { oxidoreductase (homolog to thiore- } \\
\text { doxin-disulfide reductase) }\end{array}$ & 9 & 48 & 8 & 5,51 & 0,16 \\
\hline HVO_1464 & TP & $\begin{array}{l}\text { ABC-type transport system periplas- } \\
\text { mic substrate-binding protein }\end{array}$ & 20 & 117 & 22 & 5,90 & 0,19 \\
\hline HVO_2093 & TP & $\begin{array}{l}\text { probable NhaC-type sodium/proton } \\
\text { antiporter }\end{array}$ & 26 & 159 & 27 & 6,06 & 0,17 \\
\hline HVO_B0196 & SIG & histidine kinase & 67 & 413 & 52 & 6,19 & 0,13 \\
\hline HVO_1759 & TP & $\begin{array}{l}\text { ABC-type transport system permease } \\
\text { protein }\end{array}$ & 29 & 183 & 32 & 6,20 & 0,17 \\
\hline HVO_2012 & SIG & receiver box response regulator & 149 & 966 & 1005 & 6,49 & 1,04 \\
\hline HVO_A0558 & TP & $\begin{array}{l}\text { ABC-type transport system periplas- } \\
\text { mic substrate-binding protein }\end{array}$ & 30 & 202 & 31 & 6,71 & 0,15 \\
\hline HVO_A0541 & TP & $\begin{array}{l}\text { ABC-type transport system periplas- } \\
\text { mic substrate-binding protein }\end{array}$ & 122 & 852 & 150 & 6,97 & 0,18 \\
\hline HVO_0539 & $\mathrm{CHY}$ & conserved hypothetical protein & 17 & 125 & 29 & 7,25 & 0,23 \\
\hline HVO_2065 & $\mathrm{CHY}$ & conserved hypothetical protein & 25 & 192 & 58 & 7,69 & 0,30 \\
\hline HVO_B0150 & TP & $\begin{array}{l}\text { ABC-type transport system periplas- } \\
\text { mic substrate-binding protein }\end{array}$ & 23 & 176 & 23 & 7,71 & 0,13 \\
\hline HVO_B0043 & MIS & $\begin{array}{l}\text { probable N4-hydroxy-1-aminopro- } \\
\text { pane O-acetyltransferase }\end{array}$ & 7 & 68 & 9 & 9,24 & 0,14 \\
\hline HVO_B0197 & TP & $\begin{array}{l}\text { ABC-type transport system permease } \\
\text { protein }\end{array}$ & 58 & 539 & 53 & 9,24 & 0,10 \\
\hline HVO_1230 & TP & $\begin{array}{l}\text { mechanosensitive channel protein } \\
\text { MscS (nonfunctional) }\end{array}$ & 83 & 838 & 74 & 10,05 & 0,09 \\
\hline HVO_B0198 & TP & $\begin{array}{l}\text { ABC-type transport system periplas- } \\
\text { mic substrate-binding protein }\end{array}$ & 60 & 601 & 60 & 10,06 & 0,10 \\
\hline HVO_A0559 & $A A$ & histidine ammonia-lyase & 9 & 118 & 11 & 13,13 & 0,09 \\
\hline HVO_B0044 & MIS & siderophore biosynthesis protein lucA & 20 & 289 & 17 & 14,11 & 0,06 \\
\hline HVO_0538 & REG & $\begin{array}{l}\text { SirR/DtxR family transcription regula- } \\
\text { tor Idr2 }\end{array}$ & 8 & 119 & 12 & 14,52 & 0,10 \\
\hline HVO_1796 & $\mathrm{CHY}$ & conserved hypothetical protein & 26 & 387 & 35 & 15,02 & 0,09 \\
\hline HVO_B0046 & MIS & $\begin{array}{l}\text { diaminobutyrate--2-oxoglutarate } \\
\text { aminotransferase }\end{array}$ & 25 & 388 & 28 & 15,28 & 0,07 \\
\hline HVO_B0047 & TP & $\begin{array}{l}\text { ABC-type transport system periplas- } \\
\text { mic substrate-binding protein }\end{array}$ & 28 & 438 & 40 & 15,84 & 0,09 \\
\hline HVO_2038 & TP & $\begin{array}{l}\text { ABC-type transport system periplas- } \\
\text { mic substrate-binding protein }\end{array}$ & 14 & 390 & 51 & 28,04 & 0,13 \\
\hline HVO_1228 & GEN & $\begin{array}{l}\text { DUF5059 domain / halocyanin do- } \\
\text { main protein }\end{array}$ & 31 & 1022 & 27 & 32,85 & 0,03 \\
\hline HVO_B0045 & MIS & diaminobutyrate decarboxylase & 4 & 191 & 4 & 44,46 & 0,02 \\
\hline HVO_B0042 & MIS & $\begin{array}{l}\text { probable 1,3-diaminopropane } \mathrm{N}-3 \text { - } \\
\text { monooxygenase }\end{array}$ & 5 & 220 & 4 & 46,83 & 0,02 \\
\hline
\end{tabular}


Tabelle A5: Ergebnistabelle 2 der RNA-Sequenzierung. Gezeigt sind Gene mit ihrer Funktionsklasse (FC, siehe Abkürzungsverzeichnis), dem Namen des Genprodukts (Protein Name) und den feature counts in den drei Stämmen Wildtyp H26 evc, Deletionsmutante $\Delta \mathrm{HVO} 2753$ evc und Komplementationsmutante $\Delta \mathrm{HVO} \_2753+2753 \mathrm{c}$. Die letzten beiden Spalten zeigen den Grad der Regulation des jeweiligen Gens in der Deletionsmutante (im Vergleich zum Wildtyp) und in der Komplementationsmutante (im Vergleich zur Deletionsmutante). Gezeigt sind nur Gene mit einer mindestens 2-fachen Herunterbzw. Hochregulation in der Komplementationsmutante.

\begin{tabular}{|c|c|c|c|c|c|c|c|}
\hline Gene ID & FC & Protein Name & $\begin{array}{l}\cup \\
\mathbb{d} \\
\mathfrak{U} \\
\stackrel{I}{I}\end{array}$ & 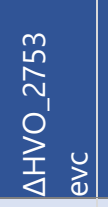 & 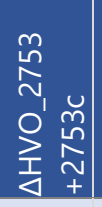 & 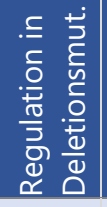 & 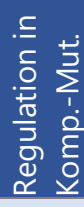 \\
\hline HVO_1215 & MIS & arl cluster protein ArIG & 257 & 0 & 0 & 0,00 & 0,00 \\
\hline HVO_B0042 & MIS & $\begin{array}{l}\text { probable 1,3-diaminopropane } \mathrm{N}-3 \text { - } \\
\text { monooxygenase }\end{array}$ & 5 & 220 & 4 & 46,83 & 0,02 \\
\hline HVO_B0045 & MIS & diaminobutyrate decarboxylase & 4 & 191 & 4 & 44,46 & 0,02 \\
\hline HVO_1228 & GEN & $\begin{array}{l}\text { DUF5059 domain / halocyanin do- } \\
\text { main protein }\end{array}$ & 31 & 1022 & 27 & 32,85 & 0,03 \\
\hline HVO_B0044 & MIS & siderophore biosynthesis protein lucA & 20 & 289 & 17 & 14,11 & 0,06 \\
\hline HVO_B0046 & MIS & $\begin{array}{l}\text { diaminobutyrate--2-oxoglutarate } \\
\text { aminotransferase }\end{array}$ & 25 & 388 & 28 & 15,28 & 0,07 \\
\hline HVO_1230 & TP & $\begin{array}{l}\text { mechanosensitive channel protein } \\
\text { MscS (nonfunctional) }\end{array}$ & 83 & 838 & 74 & 10,05 & 0,09 \\
\hline HVO_1796 & $\mathrm{CHY}$ & conserved hypothetical protein & 26 & 387 & 35 & 15,02 & 0,09 \\
\hline HVO_A0559 & AA & histidine ammonia-lyase & 9 & 118 & 11 & 13,13 & 0,09 \\
\hline HVO_B0047 & TP & $\begin{array}{l}\text { ABC-type transport system periplas- } \\
\text { mic substrate-binding protein }\end{array}$ & 28 & 438 & 40 & 15,84 & 0,09 \\
\hline HVO_B0197 & $\mathrm{TP}$ & $\begin{array}{l}\text { ABC-type transport system permease } \\
\text { protein }\end{array}$ & 58 & 539 & 53 & 9,24 & 0,10 \\
\hline HVO_B0198 & TP & $\begin{array}{l}\text { ABC-type transport system periplas- } \\
\text { mic substrate-binding protein }\end{array}$ & 60 & 601 & 60 & 10,06 & 0,10 \\
\hline HVO_0538 & REG & $\begin{array}{l}\text { SirR/DtxR family transcription regula- } \\
\text { tor Idr2 }\end{array}$ & 8 & 119 & 12 & 14,52 & 0,10 \\
\hline HVO_B0196 & SIG & histidine kinase & 67 & 413 & 52 & 6,19 & 0,13 \\
\hline HVO_2038 & TP & $\begin{array}{l}\text { ABC-type transport system periplas- } \\
\text { mic substrate-binding protein }\end{array}$ & 14 & 390 & 51 & 28,04 & 0,13 \\
\hline HVO_B0150 & TP & $\begin{array}{l}\text { ABC-type transport system periplas- } \\
\text { mic substrate-binding protein }\end{array}$ & 23 & 176 & 23 & 7,71 & 0,13 \\
\hline HVO_B0043 & MIS & $\begin{array}{l}\text { probable N4-hydroxy-1-aminopro- } \\
\text { pane O-acetyltransferase }\end{array}$ & 7 & 68 & 9 & 9,24 & 0,14 \\
\hline HVO_A0558 & TP & $\begin{array}{l}\text { ABC-type transport system periplas- } \\
\text { mic substrate-binding protein }\end{array}$ & 30 & 202 & 31 & 6,71 & 0,15 \\
\hline HVO_1463 & GEN & $\begin{array}{l}\text { oxidoreductase (homolog to thiore- } \\
\text { doxin-disulfide reductase) }\end{array}$ & 9 & 48 & 8 & 5,51 & 0,16 \\
\hline HVO_0537 & $\mathrm{CHY}$ & conserved hypothetical protein & 246 & 1233 & 199 & 5,01 & 0,16 \\
\hline HVO_2093 & TP & $\begin{array}{l}\text { probable NhaC-type sodium/proton } \\
\text { antiporter }\end{array}$ & 26 & 159 & 27 & 6,06 & 0,17 \\
\hline HVO_1759 & TP & $\begin{array}{l}\text { ABC-type transport system permease } \\
\text { protein }\end{array}$ & 29 & 183 & 32 & 6,20 & 0,17 \\
\hline
\end{tabular}




\begin{tabular}{|c|c|c|c|c|c|c|c|}
\hline HVO_A0541 & TP & $\begin{array}{l}\text { ABC-type transport system periplas- } \\
\text { mic substrate-binding protein }\end{array}$ & 122 & 852 & 150 & 6,97 & 0,18 \\
\hline HVO_1464 & TP & $\begin{array}{l}\text { ABC-type transport system periplas- } \\
\text { mic substrate-binding protein }\end{array}$ & 20 & 117 & 22 & 5,90 & 0,19 \\
\hline HVO_1704 & GEN & homolog to arabinopyranose mutase & 41 & 142 & 27 & 3,47 & 0,19 \\
\hline HVO_1760 & TP & $\begin{array}{l}\text { ABC-type transport system ATP-bind- } \\
\text { ing protein }\end{array}$ & 89 & 430 & 90 & 4,85 & 0,21 \\
\hline HVO_1229 & $\mathrm{CHY}$ & conserved hypothetical protein & 46 & 201 & 42 & 4,36 & 0,21 \\
\hline HVO_1758 & GEN & $\begin{array}{l}\text { oxidoreductase (homolog to thiore- } \\
\text { doxin-disulfide reductase) }\end{array}$ & 45 & 227 & 51 & 5,10 & 0,22 \\
\hline HVO_0539 & $\mathrm{CHY}$ & conserved hypothetical protein & 17 & 125 & 29 & 7,25 & 0,23 \\
\hline HVO_B0144 & TP & $\begin{array}{l}\text { ABC-type transport system periplas- } \\
\text { mic substrate-binding protein }\end{array}$ & 90 & 394 & 92 & 4,40 & 0,23 \\
\hline HVO_1797 & GEN & beta-lactamase domain protein & 60 & 246 & 57 & 4,10 & 0,23 \\
\hline HVO_B0041 & MIS & siderophore biosynthesis protein lucC & 188 & 682 & 180 & 3,63 & 0,26 \\
\hline HVO_1705 & TP & $\begin{array}{l}\text { ABC-type transport system peripla } \\
\text { mic substrate-binding protein }\end{array}$ & 94 & 307 & 82 & 3,27 & 0,27 \\
\hline HVO_2065 & $\mathrm{CHY}$ & conserved hypothetical protein & 25 & 192 & 58 & 7,69 & 0,30 \\
\hline HVO_2066 & $\mathrm{CHY}$ & conserved hypothetical protein & 339 & 1275 & 390 & 3,76 & 0,31 \\
\hline HVO_2037_A & $\mathrm{CHY}$ & conserved hypothetical protein & 22 & 91 & 28 & 4,09 & 0,31 \\
\hline HVO_1991 & TP & $\begin{array}{l}\text { ABC-type transport system periplas- } \\
\text { mic substrate-binding protein }\end{array}$ & 337 & 715 & 261 & 2,12 & 0,36 \\
\hline HVO_2392 & $\mathrm{CHY}$ & conserved hypothetical protein & 73 & 58 & 23 & 0,79 & 0,40 \\
\hline HVO_1462 & COM & $\begin{array}{l}\text { 1,4-dihydroxy-2-naphthoate poly- } \\
\text { prenyltransferase }\end{array}$ & 52 & 118 & 50 & 2,29 & 0,43 \\
\hline HVO_1210 & МOT & archaellin A1 & 1929 & 0 & 0 & 0,00 & 0,43 \\
\hline HVO_1586 & TP & $\begin{array}{l}\text { SDF family transf } \\
\text { ble substrate glu }\end{array}$ & 30 & 102 & 44 & 3,36 & 0,43 \\
\hline HVO_1764 & $\mathrm{CHY}$ & conserved hypothetical protein & 162 & 431 & 198 & 2,67 & 0,46 \\
\hline HVO_1706 & TP & $\begin{array}{l}\text { ABC-type transport system perm } \\
\text { protein }\end{array}$ & 105 & 264 & 122 & 2,52 & 0,46 \\
\hline HVO_1587 & $\mathrm{CHY}$ & conserved hypothetical protein & 39 & 109 & 52 & 2,75 & 0,48 \\
\hline HVO_1763 & GEN & UPF0104 family protein & 21 & 55 & 27 & 2,56 & 0,50 \\
\hline HVO_2739 & $\mathrm{TL}$ & $50 \mathrm{~S}$ ribosomal protein $\mathrm{L} 24 \mathrm{e}$ & 141 & 80 & 161 & 0,57 & 2,01 \\
\hline HVO_2470 & TP & SNF family transport protein & 152 & 60 & 122 & 0,40 & 2,03 \\
\hline HVO_0958 & $\mathrm{CHY}$ & conserved hypothetical protein & 51 & 31 & 64 & 0,60 & 2,08 \\
\hline HVO_0917 & GEN & DoxX domain protein & 139 & 180 & 378 & 1,30 & 2,09 \\
\hline HVO_0540 & $\mathrm{CHY}$ & conserved hypothetical protein & 63 & 93 & 196 & 1,46 & 2,11 \\
\hline HVO_2754 & GEN & DUF112 family protein & 6 & 16 & 35 & 2,84 & 2,13 \\
\hline HVO_2918 & NUM & thymidylate synthase & 35 & 56 & 121 & 1,58 & 2,17 \\
\hline HVO_0438 & EM & thioredoxin & 1121 & 809 & 1923 & 0,72 & 2,38 \\
\hline HVO_1213 & MIS & arl clust & 631 & 0 & 1 & 0,00 & 2,85 \\
\hline HVO_1206 & SIG & taxis cluster protein CheC & 465 & 0 & 1 & 0,00 & 2,85 \\
\hline HVO_0177 & MIS & arsenate reductase (glutaredoxin) & 204 & 113 & 370 & 0,56 & 3,27 \\
\hline HVO_2753 & GEN & $\begin{array}{l}\text { small CPxCG-related zinc finger pro- } \\
\text { tein }\end{array}$ & 1097 & ( & 220 & 0,00 & 40,88 \\
\hline
\end{tabular}

